\section{Tropospheric $\mathrm{OH}$ and $\mathrm{HO}_{2}$ radicals: field measurements and model comparisons $\dagger$}

\author{
Daniel Stone, Lisa K. Whalley and Dwayne E. Heard* \\ Received 13th April 2012 \\ DOI: $10.1039 / \mathrm{c} 2 \mathrm{cs} 35140 \mathrm{~d}$
}

The hydroxyl radical, $\mathrm{OH}$, initiates the removal of the majority of trace gases in the atmosphere, and together with the closely coupled species, the hydroperoxy radical, $\mathrm{HO}_{2}$, is intimately involved in the oxidation chemistry of the atmosphere. This critical review discusses field measurements of local concentrations of $\mathrm{OH}$ and $\mathrm{HO}_{2}$ radicals in the troposphere, and in particular the comparisons that have been made with numerical model calculations containing a detailed chemical mechanism. The level of agreement between field measurements of $\mathrm{OH}$ and $\mathrm{HO}_{2}$ concentrations and model calculations for a given location provides an indication of the degree of understanding of the underlying oxidation chemistry. We review the measurement-model comparisons for a range of different environments sampled from the ground and from aircraft, including the marine boundary layer, continental low- $\mathrm{NO}_{x}$ regions influenced by biogenic emissions, the polluted urban boundary layer, and polar regions.

Although good agreement is found for some environments, there are significant discrepancies which remain unexplained, a notable example being unpolluted, forested regions. $\mathrm{OH}$ and $\mathrm{HO}_{2}$ radicals are difficult species to measure in the troposphere, and we also review changes in detection methodology, quality assurance procedures such as instrument intercomparisons, and potential interferences.

\section{Introduction}

The hydroxyl radical, $\mathrm{OH}$, is the dominant daytime oxidant in the troposphere, removing the majority of trace gases emitted

School of Chemistry, University of Leeds, Leeds, LS2 9JT, UK. E-mail: d.e.heard@leeds.ac.uk

$\dagger$ Part of the atmospheric chemistry themed issue. into the atmosphere, including greenhouse gases and substances harmful to health, and initiates the formation of a wide range of secondary species, for example ozone and secondary organic aerosol. The reaction of $\mathrm{HO}_{2}$ and $\mathrm{RO}_{2}$ radicals with $\mathrm{NO}$ initiates the only tropospheric in situ source of ozone. $\mathrm{OH}$ and $\mathrm{HO}_{2}$ are ideal target molecules to test the accuracy of chemical mechanisms in a variety of environments.

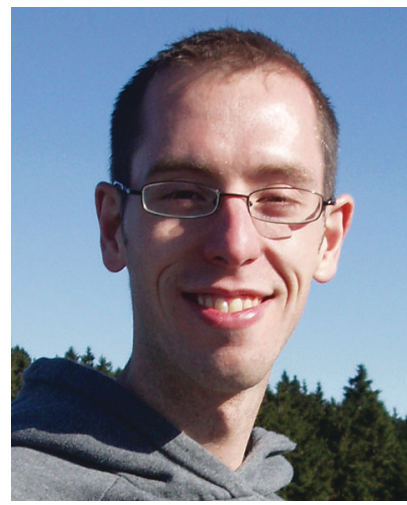

Daniel Stone
Daniel Stone is a post-doctoral researcher in the School of Chemistry, University of Leeds. He obtained his PhD from University College London in 2006 in the field of peroxy radical reaction kinetics, and before joining the atmospheric chemistry group in Leeds he conducted post-doctoral research at the National Centre for Electron Paramagnetic Resonance Spectroscopy at the University of Manchester. His research uses numerical models to simulate atmospheric composition at local and global scales and to interpret field observations of $\mathrm{OH}$ and $\mathrm{HO}_{2}$ radicals, and he has been involved in ground-based and aircraft measurements of $\mathrm{OH}, \mathrm{HO}_{2}$ and $\mathrm{OH}$ reactivity.

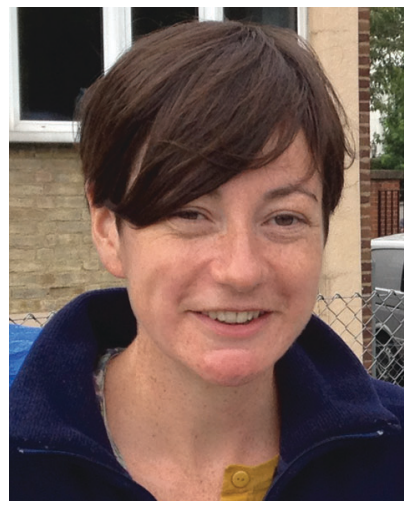

Lisa K. Whalley
Lisa Whalley is a National Centre for Atmospheric Science (NCAS) supported research fellow at the University of Leeds. Having completed her PhD which focused on the development of airborne gas chromatographs for measurements of short-chain alkanes and peroxyacetyl nitrate, she began postdoctoral research using the Master Chemical Mechanism looking at the evolution of North American plumes over the Atlantic and Europe. She joined Professor Heard's group in 2005, with responsibility for the development and operation of the FAGE instrument for ground-based measurements of $\mathrm{OH}, \mathrm{HO}_{2}, \mathrm{OH}$ reactivity and $I O$ radicals and has participated in 11 field campaigns to date. 
The short chemical lifetimes, due to their high reactivity, means that their budgets (and hence concentrations) are only controlled by local in situ chemistry, and not by transport processes. Zero-dimensional models, which consider a box in which the sample is well mixed, can be used to describe the chemistry of $\mathrm{OH}$ and $\mathrm{HO}_{2}$ under specific conditions without having to incorporate transport into or out of the box.

There have now been a considerable number of field campaigns in which measured concentrations of $\mathrm{OH}$ and $\mathrm{HO}_{2}$ radicals have been compared with the results of model simulations which are highly constrained to the co-observed field data for longer-lived species and photolysis rates. In order to adequately describe the photo-oxidative degradation of a wide range of volatile organic compounds, models can be extremely complex, with mechanisms often containing many thousands of reactions and chemical species. An example is the Master Chemical Mechanism (MCM), a near-explicit chemical mechanism describing the detailed gas phase tropospheric degradation of methane and 143 primary emitted nonmethane volatile organic compounds (VOCs), which include the major emitted anthropogenic species as listed in the UK National Atmospheric Emissions Inventory (e.g. Saunders et al. ${ }^{1}$ ). The current version (MCMv3.2) contains $c a .6700$ species and 17000 reactions. ${ }^{2}$ The advantage of a detailed model such as the MCM is that it explicitly treats the oxidation of many VOCs, but a disadvantage is that the kinetics and product branching ratios of most of the reactions in the mechanism have not been adequately studied, and a series of rules and structure activity relationships are needed to provide the data needed to output radical concentrations. In addition, observations of VOCs in the field are almost always not sufficiently comprehensive to exploit the full mechanism. An alternative is the use of lumped mechanisms containing a smaller number of reactions, which have also been used widely to compare with field measurements. An advantage of a lumped mechanism is that it is based on observed results from chamber studies, whereas a disadvantage is that it can only adequately describe the oxidation of a limited range of VOC mixtures.

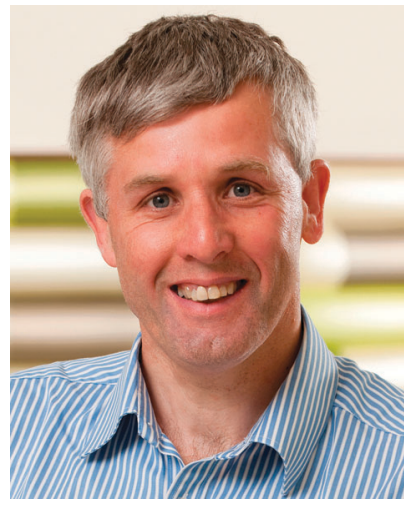

Dwayne E. Heard
Dwayne Heard has worked at the University of Leeds since 1994 where he is Professor of Atmospheric Chemistry. Prior to Leeds he was a lecturer at Macquarie University, Australia, a postdoctoral fellow at SRI International, Menlo Park, and he did both his postgraduate and undergraduate degrees at Oxford University. His research interests include laser-based measurements of short-lived radicals in the atmosphere from surface- and aircraftbased platforms, and comparison with model calculations, and the study of the reaction kinetics and photochemistry of important molecules in the atmosphere. His group has participated in over 25 field campaigns worldwide since 1996.

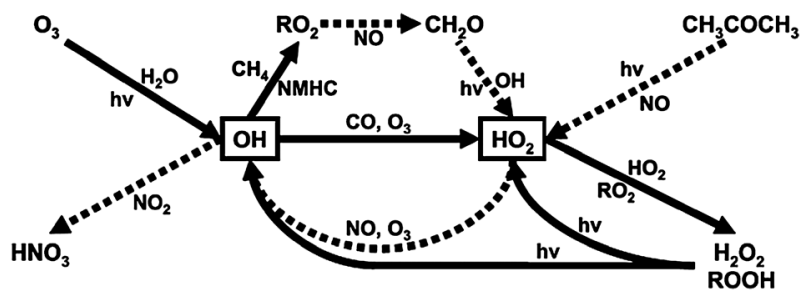

Fig. 1 Simplified $\mathrm{HO}_{x}$ production and loss scheme in the remote troposphere. Pathways amplified by high $\mathrm{NO}_{x}$ concentrations are indicated by dashed lines, solid lines indicate processes which dominate under background conditions. (Reproduced from ref. 48, Copyright (2006) American Geophysical Union. Reproduced by permission of American Geophysical Union. Further reproduction or electronic distribution is not permitted.)

The tropospheric chemistry of $\mathrm{OH}$ and $\mathrm{HO}_{2}$ is summarised in Fig. 1. A major pathway for the formation of $\mathrm{OH}$ is via the reactions:

$$
\begin{aligned}
\mathrm{O}_{3}+h \nu(\lambda<340 \mathrm{~nm}) & \rightarrow \mathrm{O}\left({ }^{1} \mathrm{D}\right)+\mathrm{O}_{2} \\
\mathrm{O}\left({ }^{1} \mathrm{D}\right)+\mathrm{H}_{2} \mathrm{O} & \rightarrow 2 \mathrm{OH}
\end{aligned}
$$

$\mathrm{OH}$ is closely coupled to the hydroperoxy radical, $\mathrm{HO}_{2}$, and collectively they are known as $\mathrm{HO}_{x}\left(=\mathrm{OH}+\mathrm{HO}_{2}\right)$. A key process for the formation of $\mathrm{HO}_{2}$ is:

$$
\mathrm{OH}+\mathrm{CO}\left(+\mathrm{O}_{2}\right) \rightarrow \mathrm{HO}_{2}+\mathrm{CO}_{2}
$$

$\mathrm{OH}$ can then be reformed from $\mathrm{HO}_{2}$ via the reaction:

$$
\mathrm{HO}_{2}+\mathrm{O}_{3} \rightarrow \mathrm{OH}+2 \mathrm{O}_{2}
$$

Another important process for the removal of tropospheric $\mathrm{OH}$ is through its reactions with $\mathrm{CH}_{4}$ and other volatile organic compounds (VOCs) to form peroxy radicals, $\mathrm{RO}_{2}$ :

$$
\mathrm{OH}+\mathrm{RH}+\mathrm{O}_{2} \rightarrow \mathrm{RO}_{2}+\mathrm{H}_{2} \mathrm{O}
$$

$\mathrm{RO}_{2}$ can undergo reactions with other $\mathrm{RO}_{2}$ radicals, in either self-reactions $\left(\mathrm{RO}_{2}+\mathrm{RO}_{2}\right)$ or cross-reactions $\left(\mathrm{RO}_{2}+\mathrm{R}^{\prime} \mathrm{O}_{2}\right)$ and ultimately form $\mathrm{HO}_{2}$. For example, in the case of the methylperoxy radical, $\mathrm{CH}_{3} \mathrm{O}_{2}$ :

$$
\begin{gathered}
\mathrm{CH}_{3} \mathrm{O}_{2}+\mathrm{CH}_{3} \mathrm{O}_{2} \rightarrow 2 \mathrm{CH}_{3} \mathrm{O}+\text { other products } \\
\mathrm{CH}_{3} \mathrm{O}+\mathrm{O}_{2} \rightarrow \mathrm{HO}_{2}+\mathrm{HCHO}
\end{gathered}
$$

In environments where the levels of $\mathrm{NO}$ are very low, the concentration of $\mathrm{HO}_{2}$ is controlled by the loss processes:

$$
\begin{gathered}
\mathrm{HO}_{2}+\mathrm{HO}_{2} \rightarrow \mathrm{H}_{2} \mathrm{O}_{2}+\mathrm{O}_{2} \\
\mathrm{HO}_{2}+\mathrm{CH}_{3} \mathrm{O}_{2} \rightarrow \mathrm{CH}_{3} \mathrm{O}_{2} \mathrm{H}+\mathrm{O}_{2}
\end{gathered}
$$

In environments with higher concentrations of $\mathrm{NO}$, the reactions:

$$
\begin{gathered}
\mathrm{HO}_{2}+\mathrm{NO} \rightarrow \mathrm{OH}+\mathrm{NO}_{2} \\
\mathrm{RO}_{2}+\mathrm{NO} \rightarrow \mathrm{RO}+\mathrm{NO}_{2} \\
\mathrm{RO}+\mathrm{O}_{2} \rightarrow \mathrm{R}^{\prime} \mathrm{CHO}+\mathrm{HO}_{2}
\end{gathered}
$$

are also important, and ozone can be formed from the subsequent photolysis of $\mathrm{NO}_{2}$ :

$$
\begin{array}{r}
\mathrm{NO}_{2}+h \nu(\lambda<420 \mathrm{~nm}) \rightarrow \mathrm{O}\left({ }^{3} \mathrm{P}\right)+\mathrm{NO} \\
\mathrm{O}\left({ }^{3} \mathrm{P}\right)+\mathrm{O}_{2}+\mathrm{M} \rightarrow \mathrm{O}_{3}+\mathrm{M}
\end{array}
$$


$\mathrm{HO}_{2}$ can also be converted to $\mathrm{OH}$ via reaction with halogen oxides, $\mathrm{XO}$ (where $\mathrm{X}=\mathrm{Br}, \mathrm{I}$ ):

$$
\begin{gathered}
\mathrm{HO}_{2}+\mathrm{XO} \rightarrow \mathrm{HOX}+\mathrm{O}_{2} \\
\mathrm{HOX}+h \nu \rightarrow \mathrm{OH}+\mathrm{X}
\end{gathered}
$$

particularly in the marine boundary layer. ${ }^{3-7}$ The HOI and $\mathrm{HOBr}$ produced from reaction (R15) can also be lost via heterogeneous uptake onto aerosol.

The rate of primary production of $\mathrm{OH}$ from reactions (R1) and (R2) is given by:

$$
P(\mathrm{OH})=2 f\left[\mathrm{O}_{3}\right] \times j\left(\mathrm{O}^{1} \mathrm{D}\right)
$$

where $j\left(\mathrm{O}^{1} \mathrm{D}\right)$ is the photolysis rate of ozone and:

$$
f=\frac{k_{\mathrm{O}^{1} \mathrm{D}+\mathrm{H}_{2} \mathrm{O}}\left[\mathrm{H}_{2} \mathrm{O}\right]}{k_{\mathrm{O}^{1} \mathrm{D}+\mathrm{H}_{2} \mathrm{O}}\left[\mathrm{H}_{2} \mathrm{O}\right]+k_{\mathrm{O}^{1} \mathrm{D}+\mathrm{N}_{2}}\left[\mathrm{~N}_{2}\right]+k_{\mathrm{O}^{1} \mathrm{D}+\mathrm{O}_{2}}\left[\mathrm{O}_{2}\right]}
$$

where $k_{\mathrm{O}^{1} \mathrm{D}+\mathrm{H}_{2} \mathrm{O}}, k_{\mathrm{O}^{1} \mathrm{D}+\mathrm{N}_{2}}$ and $k_{\mathrm{O}^{1} \mathrm{D}+\mathrm{O}_{2}}$ are rate coefficients for reactive or quenching removal of $\mathrm{O}\left({ }^{1} \mathrm{D}\right)$ atoms, with removal by other species neglected. The rate of change of $\mathrm{OH}$ is given by:

$$
\begin{aligned}
\frac{\mathrm{d}[\mathrm{OH}]}{\mathrm{d} t}= & P(\mathrm{OH})+k_{4}\left[\mathrm{HO}_{2}\right]\left[\mathrm{O}_{3}\right]+k_{10}\left[\mathrm{HO}_{2}\right][\mathrm{NO}] \\
& +\sum_{\mathrm{i}} \nu_{\mathrm{i}} J_{\mathrm{i}}[\mathrm{i}]+P^{\prime}-\sum_{n} k_{\mathrm{OH}+L_{n}}\left[L_{n}\right][\mathrm{OH}]
\end{aligned}
$$

where $\nu_{\mathrm{i}} J_{\mathrm{i}}$ represents the rate of photolysis from species i $\left(\nu_{\mathrm{i}}\right.$ is the stoichiometric coefficient to form $\mathrm{OH}$ ), for example HONO or HOX ( $\mathrm{X}=$ halogen), that may lead to generation of $\mathrm{OH}, P^{\prime}$ represents the rate of $\mathrm{OH}$ production from any other chemical process, such as alkene ozonolysis reactions, and the last term is the total rate of loss of $\mathrm{OH}$ by reaction with all of its sinks, $L_{n} . k_{\mathrm{OH}+L_{n}}$ is the bimolecular rate coefficient for reaction between $L_{n}$ and $\mathrm{OH}$. A steady-state is established for $\mathrm{OH}$ within seconds in the troposphere and under these conditions, $\mathrm{d}[\mathrm{OH}] / \mathrm{d} t=0$, giving the following expression for the $\mathrm{OH}$ concentration:

$$
[\mathrm{OH}]=\frac{P(\mathrm{OH})+k_{4}\left[\mathrm{HO}_{2}\right]\left[\mathrm{O}_{3}\right]+k_{10}\left[\mathrm{HO}_{2}\right][\mathrm{NO}]+\sum_{\mathrm{i}} v_{\mathrm{i}} J_{\mathrm{i}}[\mathrm{i}]+P^{\prime}}{\sum_{n} k_{\mathrm{OH}+L_{n}}\left[L_{n}\right]}
$$

As long as the steady-state assumption is valid, the concentration of $\mathrm{OH}$ can be calculated equipped with knowledge of

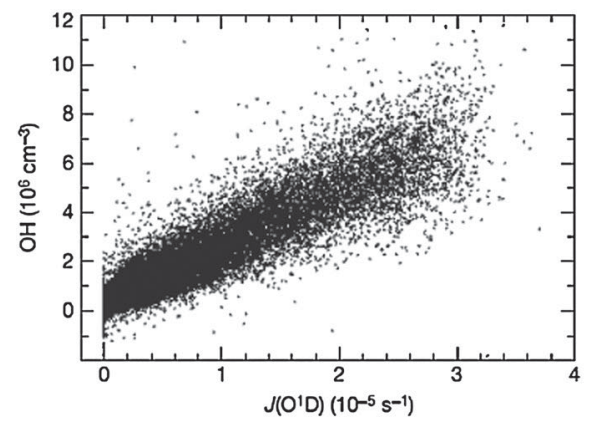

all the terms in the numerator and denominator of the righthand side (RHS) of eqn (E4). The accuracy of the calculated value of $[\mathrm{OH}]$ depends on the comprehensiveness of the measurements of $\mathrm{OH}$ sources and sinks, and of the kinetic parameters (rate coefficients, photolysis frequencies and product branching ratios, and their dependence on temperature and pressure). Often, many of the terms on the RHS are unknown, for example the identity of all of the sinks of $\mathrm{OH}$ (for example intermediates and high molecular weight compounds), or photolysis from species which are not measured. The treatment of unmeasured intermediates, particularly those with relatively long atmospheric lifetimes, in model calculations requires a period of model "spin-up" in which the model is run for several days until the concentrations of such intermediates reach a "diurnal steady state", with calculated concentrations showing little difference from one day to the next. In this way, for some non-measured species, the numerical model can be used to calculate terms on the right-hand side if the relevant chemical steps are contained within the chemical mechanism.

For some remote environments, the reaction of $\mathrm{O}\left({ }^{1} \mathrm{D}\right)$ with water vapour has been shown to dominate the production of $\mathrm{OH}$, giving:

$$
[\mathrm{OH}]=\frac{P(\mathrm{OH})}{\sum_{n} k_{\mathrm{OH}+L_{n}}\left[L_{n}\right]}=\frac{P(\mathrm{OH})}{k_{\mathrm{OH}}^{\prime}}=P(\mathrm{OH}) \times \tau_{\mathrm{OH}}
$$

where $\tau_{\mathrm{OH}}$ is the atmospheric lifetime of $\mathrm{OH}$ with respect to its loss to all sinks, $L_{n}$, and $k_{\mathrm{OH}}^{\prime}$ is the $\mathrm{OH}$ reactivity (inverse of the lifetime), the latter a quantity that is now routinely measured in the field. ${ }^{8-13}$ For a constant lifetime, a plot of $[\mathrm{OH}]$ against $P(\mathrm{OH})$ should be linear with slope $\tau_{\mathrm{OH}}$, an example of which is shown in Fig. 2. More generally, the $\mathrm{OH}$ concentration can be parameterised in terms of $j\left(\mathrm{O}^{1} \mathrm{D}\right)$ (or $P(\mathrm{OH})$ ) using:

$$
[\mathrm{OH}]=\left(a \times j\left(\mathrm{O}^{1} \mathrm{D}\right)^{b}\right)+c
$$

where $a$ represents the influence of all chemical sources and sinks, $b$ accounts for the effect of combining all photolytic processes that produce $\mathrm{OH}$ (either directly or indirectly), and $c$ is the contribution from all light-independent processes. ${ }^{14} \mathrm{OH}$ concentrations are fitted surprisingly well by eqn (E5) or (E6), and the parameters provide a simple, yet useful mechanism to compare $\mathrm{OH}$ concentrations for different environments.

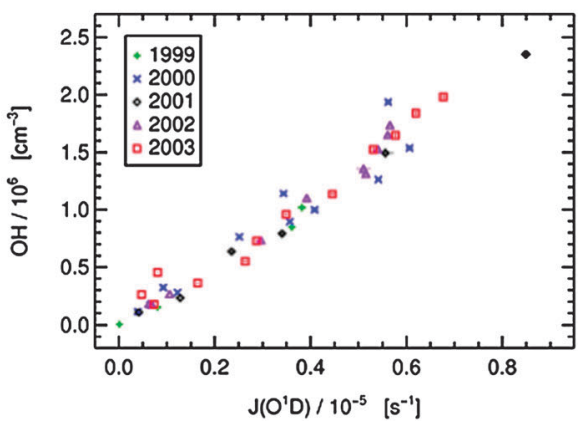

Fig. 2 Correlation of observed $\mathrm{OH}$ concentrations with $j\left(\mathrm{O}^{1} \mathrm{D}\right)$ at the Meteorological Observatory Hohenpeissenberg between April 1999 and December 2003. Left: 5 minute averaged data. Right: Monthly averages (Reproduced from ref. 95, Copyright (2006), with permission from Nature Publishing Group.) 


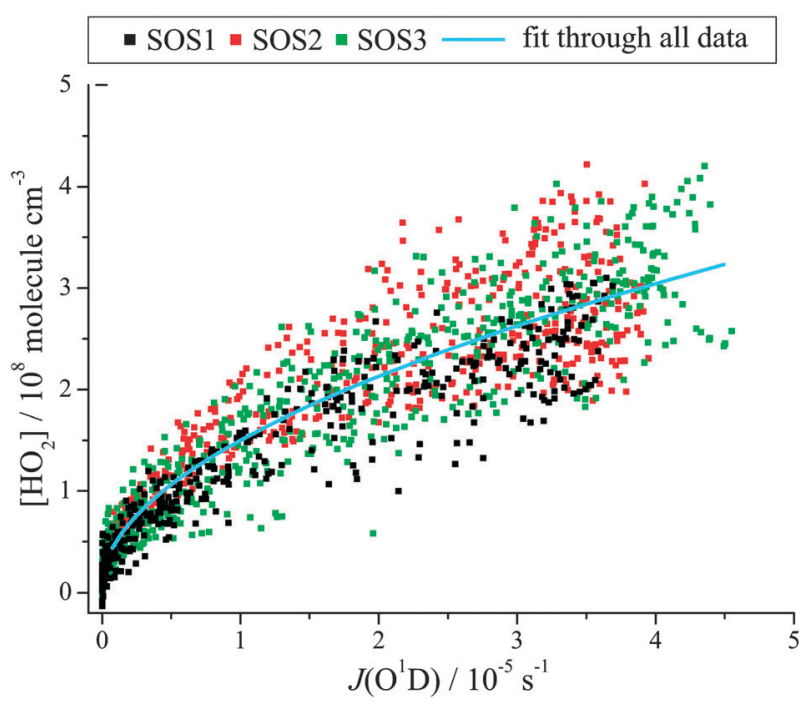

Fig. 3 Correlation of 4 minute averaged $\mathrm{HO}_{2}$ with $j\left(\mathrm{O}^{1} \mathrm{D}\right)$ at the Cape Verde Atmospheric Observatory during three seasons of 2009; SOS1 (Feb.-Mar.), SOS2 (June), SOS3 (Sept.). (Reproduced from ref. 15, Copyright (2012), with permission from Copernicus Publications.)

A similar approach has been used to examine the dependence of $\mathrm{HO}_{2}$ on $j\left(\mathrm{O}^{1} \mathrm{D}\right)$, an example of which is shown in Fig. $3^{15}$. Further examples of this behaviour are given later in the review.

Good agreement between measured and modelled $[\mathrm{OH}]$ may occur fortuitously if the rate of production from missing $\mathrm{OH}$ sources counterbalances the rate of destruction from missing $\mathrm{OH}$ sinks on the RHS of eqn (E4). In such cases, field measurements have not provided an adequate test of the level of understanding of the underlying chemistry. Not surprisingly, the advent of new techniques and updated instrumentation has meant that more and more species are being measured, with halogen oxides and oxygenated volatile organic compounds being two striking examples. Unsurprisingly, there are several examples in the literature where erroneous conclusions were drawn from the level of agreement between measurements and models for $\mathrm{OH}$ because of key missing measurements which were not recognized at the time. These errors often only become evident when measurements are repeated at the same location with a more comprehensive set of model-constraining measurements.

More recently, measurements of the $\mathrm{OH}$ reactivity, $k_{\mathrm{OH}}^{\prime}$, have enabled a deeper understanding of the $\mathrm{OH}$ budget, as comparison with a model calculation allows direct examination of the degree of missing sinks in the model. OH reactivity measurements are now fairly routine, with several instruments worldwide based on three techniques used for the direct measurement of $k_{\mathrm{OH}}^{\prime}$ in both urban ${ }^{8,9}$ and forested environments, ${ }^{10-12,16-18}$ where significant missing sinks for $\mathrm{OH}$ have been reported. For example, in Toyko $\sim 50 \%$ of the $\mathrm{OH}$ sinks were not measured, ${ }^{9}$ whereas in the Amazon rainforest up to $70 \%$ of the measured reactivity could not be accounted for. ${ }^{16}$ A detailed model can be used to calculate the additional $\mathrm{OH}$ reactivity from (unmeasured) secondary products which are generated from the photo-oxidation of the measured primary VOCs. In one study, at Weybourne on the North Norfolk coast, this increased the $\mathrm{OH}$ reactivity by $\sim 10 \%$, with most of the increase coming from unmeasured carbonyls. ${ }^{13}$ Although such an approach provides some clues as to the identity of the missing sinks, and helps to close the $\mathrm{OH}$ reactivity gap, it is only a model result and the identity of missing $\mathrm{OH}$ sinks is not confirmed directly. The atmosphere contains thousands of trace level VOCs, and as carbon number increases, it becomes ever more challenging to measure and identify these. Comprehensive two-dimensional chromatography $(\mathrm{GC} \times \mathrm{GC})$ measurements with flameionisation detection (FID) provided compelling evidence in an urban environment that a significant fraction $(\sim 40 \%)$ of $\mathrm{OH}$ sinks in the form of reactive carbon is not routinely measured by conventional equipment normally deployed during field intensives. ${ }^{19}$ This material is often multifunctional or contains more than 6 carbon atoms. Very recently, Kato et $a l .{ }^{20}$ were able to quantify the $\mathrm{OH}$ reactivity of unidentified VOCs in Tokyo using an $\mathrm{OH}$ reactor connected to a gas chromatograph, and comparing how the peak areas changed for unidentified species in the chromatogram compared to identified species for which the rate coefficient for reaction with $\mathrm{OH}$ was known.

When $\mathrm{OH}$ reactivity and concentrations measurements are combined, eqn (E4) enables "measurement" of the total rate of $\mathrm{OH}$ production, with no assumptions other than that of the steady-state. This is a powerful tool, as comparisons can now be made with model calculations of the production rate of $\mathrm{OH}$ from co-measured species. Often this approach has shown that there are both missing sinks and missing sources, the balance of which controls the agreement of the model with $[\mathrm{OH}]$. Recent examples are the identification of large missing sources of $\mathrm{OH}$ in regions influenced by high levels of biogenic VOCs, where the model, constrained by measurements of $k_{\mathrm{OH}}^{\prime}$ and $\mathrm{OH}$ source terms, underpredicted $[\mathrm{OH}]$ by large factors. ${ }^{21,22}$ The description of instrumentation describing methods to measure $\mathrm{OH}$ reactivity is beyond the scope of this review, but further examples of the use of $k_{\mathrm{OH}}^{\prime}$ measurements will be given later in the review.

In this review, we examine local field measurements of $\mathrm{OH}$ and $\mathrm{HO}_{2}$ radicals, with a focus on comparisons that have been made with model calculations, and the level of agreement found. We concentrate on comparison with box model calculations of $\mathrm{OH}$ and $\mathrm{HO}_{2}$ which are highly constrained with co-measurements, and which contain a detailed chemical mechanism, rather than comparison with multi-dimensional models of $\mathrm{OH}$ which calculate regional and global distributions. Also, globally averaged $\mathrm{OH}$ concentrations, obtained indirectly through measurements of proxies such as methyl chloroform, are not considered. We acknowledge that measurements of concentration ratios of parent/daughter molecules provide an independent measurement of $\mathrm{OH}$ concentrations using a chemical clock-analysis, but in this review we focus on direct in situ measurements of $\mathrm{OH}$ and $\mathrm{HO}_{2}$ and comparisons with models.

Heard and Pilling ${ }^{23}$ comprehensively reviewed measurement techniques used for tropospheric $\mathrm{OH}$ and $\mathrm{HO}_{2}$ radicals, field campaigns using these techniques up until June 2003, and for selected campaigns the interpretation of these field measurements through comparison with model calculations. ${ }^{23}$ 
There has not been a comprehensive review of tropospheric $\mathrm{OH}$ and $\mathrm{HO}_{2}$ measurements since, although overviews of behaviour in certain environments have been made. ${ }^{24-26}$ In 2005 a workshop was held at Leeds under the auspices of ACCENT (Atmospheric Composition Change The European Network of Excellence) to discuss free-radicals in the troposphere, ${ }^{27}$ a significant component of which was concerned with $\mathrm{OH}$ and $\mathrm{HO}_{2}$, and two more recent ACCENT overviews of atmospheric composition change and its measurement have been published. ${ }^{25,26}$ Also, there are significant sections within a more recent book ${ }^{28}$ and review ${ }^{29}$ which have described methods for atmospheric detection of $\mathrm{OH}$ and $\mathrm{HO}_{2}$.

The review is organised as follows. In Section 2 the techniques used to measure $\mathrm{OH}$ and $\mathrm{HO}_{2}$ radicals in the field are briefly summarised. Unlike in Heard and Pilling, ${ }^{23}$ the intention is not to include an up to date description of the instrumentation currently used to measure $\mathrm{OH}$ and $\mathrm{HO}_{2}$. No new methods have emerged, indeed some methods have disappeared. Although closely related to $\mathrm{HO}_{2}$, we do not review methods to measure the sum of peroxy radicals, $\left[\mathrm{HO}_{2}\right]+$ $\left[\Sigma_{\mathrm{i}} \mathrm{RO}_{2, \mathrm{i}}\right]$, nor describe field measurements and model comparisons for this quantity. Section 2 also describes updates on quality assurance procedures, for example calibration and instrument intercomparisons. Section 3 discusses potential interferences for $\mathrm{OH}$ and $\mathrm{HO}_{2}$ measurements which could lead to measurement biases and therefore errors in the interpretation of any differences observed with model calculations. Large discrepancies between measurements and models in low $\mathrm{NO}_{x}$, forested environments has indicated the need to consider possible instrumental artefacts caused by interfering species. ${ }^{30,31}$ Field campaigns and model comparisons are then reviewed for campaigns undertaken in the marine boundary layer (Section 4), low $\mathrm{NO}_{x}$, forested environments (Section 5) polluted environments (Section 6), and polar regions (Section 7), both from ground and airborne platforms. Each of Sections 4-7 contains its own summary, and in Section 8 there is an overall summary, and suggestions for future work.

Although the review is focussed upon comparison with models, no attempt is made to systematically compare the performance of different models. Mechanisms commonly in use for the interpretation and understanding of field measurements of $\mathrm{OH}$ and $\mathrm{HO}_{2}$ range from near-explicit mechanisms, such as the Master Chemical Mechanism (MCM), ${ }^{2,32-35}$ which contains $\sim 6700$ species in approximately 17000 reactions (MCMv3.2), to reduced or lumped mechanisms such as the Regional Atmospheric Chemistry Mechanism (RACM), ${ }^{36}$ which contains 117 species in 375 reactions (v2). A perfectly valid question is: "Using the same input data of constrained measurements, does the calculated output of $\mathrm{OH}$ and $\mathrm{HO}_{2}$ radical concentrations differ in a significant manner from one model to another?" Unfortunately, unlike chemistry-climate models, for which the predictions are compared for the same emissions scenario (for example CCMVAL ${ }^{37}$ ) this question is rarely answered with respect to box models for $\mathrm{OH}$ or $\mathrm{HO}_{2}$, although there have been comparisons between the mechanisms commonly used in modelling studies. ${ }^{38}$ Another, related question is whether the conclusions of a given field study are still valid if new field measurements, or kinetic parameters, not previously available, were included to constrain the model?
It is not easy to get funding for this type of activity, which looks at historical data sets with new, updated models, and which provides a check of the robustness of the previous conclusions. One example serves to illustrate this point. In the marine boundary layer, for example at Mace Head and on some Japanese Islands, earlier field measurements of $\mathrm{HO}_{2}$ were significantly overpredicted by models, which appeared to miss a significant sink. ${ }^{39-41}$ The main suggestion was to include reactive loss onto aerosols in the model with uptake coefficients that were large, approaching unity in some cases, in order to bring the model calculated values down sufficiently. At the time, experimental laboratory measurements of the uptake coefficients of $\mathrm{HO}_{2}$ radicals onto the surface of submicron aerosols, under relevant conditions (for example at low enough $\left[\mathrm{HO}_{2}\right]$ that the self-reaction in the gas phase did not completely dominate), were not well enough defined to support this hypothesis or not. Recent measurements in the marine boundary layer using differential optical absorption spectroscopy (DOAS) ${ }^{42,43}$ and $\mathrm{LIF}^{44,45}$ have revealed the presence of significant concentrations of $\mathrm{BrO}$ and $\mathrm{IO}$ radicals, which if included in the model, bring the calculated $\left[\mathrm{HO}_{2}\right]$ closer to the measurements, without requiring a large uptake coefficient. This finding is consistent with recent measurements of $\mathrm{HO}_{2}$ uptake coefficients which are much smaller. ${ }^{46,47}$ Another question regarding model input is whether the averaging time of a measurement used to constrain the model determines the $\mathrm{OH}$ concentration calculated by a model. Calculations have shown significant differences in calculated $\mathrm{HO}_{x}$ concentrations for aircraft campaigns, ${ }^{48}$ depending on the averaging period of $\left[\mathrm{NO}_{x}\right]$ that was used owing to the nonlinear relationship between $\mathrm{HO}_{x}$ and $\mathrm{NO}_{x}$. At high temporal resolution, $\mathrm{NO}_{x}$ showed considerable variability along the flight track, with spikes at very high concentration.

\section{Measurement of tropospheric $\mathrm{OH}$ and $\mathrm{HO}_{2}$ radicals: instrumentation, calibration, intercomparisons and interferences}

The techniques of laser-induced fluorescence (LIF) spectroscopy at low-pressure, known as FAGE (Fluorescence Assay by Gas Expansion), and CIMS (Chemical Ionisation Mass Spectrometry, sometimes referred to as ion assisted mass spectrometry) remain the workhorses for the measurement of tropospheric $\mathrm{OH}$ radicals. FAGE detects $\mathrm{OH}$ directly, whereas in the CIMS method $\mathrm{OH}$ is first converted to $\mathrm{H}_{2} \mathrm{SO}_{4}$ which is then detected by mass spectrometry. $\mathrm{HO}_{2}$ is not detected directly by either technique, rather it is converted first to $\mathrm{OH}$ through the addition of $\mathrm{NO}$ to the ambient sampling inlet. For CIMS, the conversion chemistry takes place at atmospheric pressure, and so it is more difficult to prevent the simultaneous conversion of $\mathrm{RO}_{2}$ to $\mathrm{OH}$, and typically $\left[\mathrm{HO}_{2}\right]+\left[\Sigma_{\mathrm{i}} \mathrm{RO}_{2, \mathrm{i}}\right]$ is measured, although through judicious control of the reagent gas flows, it is possible to measure $\mathrm{HO}_{2}$ separately. ${ }^{49,50}$ Differential Optical Absorption Spectroscopy (DOAS) has in the past successfully been used for field measurements of $\mathrm{OH}$ radicals, and although four independent instruments had been developed since the first use of DOAS in the $1980 \mathrm{~s},{ }^{51-58}$ only the Forschungszentrum 
Julich instrument remains in service, but is only used within the SAPHIR (Simulation of Atmospheric PHotochemistry In a large Reaction Chamber) chamber, ${ }^{59,60}$ and not in the field. The absence of a DOAS instrument for $\mathrm{OH}$ measurements in the field is lamentable, as the method does not require calibration, only knowledge of fundamental molecular constants and the path length, and DOAS acts as a primary standard. However, as discussed in Section 2.3 below, the DOAS instrument is used within the SAPHIR chamber during intercomparisons, and continues to provide a critical standard to compare with other methods. The Matrix Isolation Electron Spin Resonance (MIESR) technique, ${ }^{61-63}$ which formerly provided the only direct method for the field measurement of $\mathrm{HO}_{2}$ in the troposphere, is no longer operated, and during its last measurements, was also located at the SAPHIR chamber. $^{64}$

\subsection{Instrumentation used to measure tropospheric $\mathrm{OH}$ and $\mathrm{HO}_{2}$ radicals in the field}

Field measurements of tropospheric $\mathrm{OH}$ and $\mathrm{HO}_{2}$ radicals are extremely challenging, owing to their very low concentrations $\left(\mathrm{OH} \sim 10^{6}\right.$ molecule $\mathrm{cm}^{-3} ; \mathrm{HO}_{2} \sim 10^{8}$ molecule $\left.\mathrm{cm}^{-3}\right)$, high reactivity and subsequent short lifetime $(\tau(\mathrm{OH}) \sim 0.01-1 \mathrm{~s}$; $\left.\tau\left(\mathrm{HO}_{2}\right) \sim 5-100 \mathrm{~s}\right)$, and their rapid loss rate onto surfaces of inlets. The FAGE and CIMS techniques, and their historical development, have been described in considerable detail before (for representative references see Heard and Pilling ${ }^{23}$ and Heard ${ }^{65}$ ), and have enjoyed sustained success for field measurement of local $\mathrm{OH}$ and $\mathrm{HO}_{2}$.

In the FAGE technique, $\mathrm{OH}$ radicals are measured by $308 \mathrm{~nm}$ laser-induced fluorescence (LIF) spectroscopy at low pressure and $\mathrm{HO}_{2}$ is first converted to $\mathrm{OH}$ by the addition of NO prior to FAGE detection of the $\mathrm{OH}$ formed. Simultaneous measurements are possible via two independent detection cells, which depending on the design are either in series with a single sampling pinhole and the $\mathrm{OH}$ fluorescence cell closer to the sampling nozzle, or in parallel with two independent sampling pinholes, and allowing a different pressure in each cell. Delayed gated photon counting is used to detect fluorescence from $\mathrm{OH}$ and to discriminate from the more intense scattered light. Two types of high pulse-repetition frequency (prf) laser system are currently used in the field, either a $\mathrm{Nd}: \mathrm{YAG}$ pumped dye-laser, which is frequency doubled to generate $308 \mathrm{~nm}$, or an all solid state $\mathrm{Nd}$ :YAG pumped titanium sapphire laser, which is frequency tripled to generate $308 \mathrm{~nm}$. High prf copper vapour lasers are no longer used in the field as a pump laser, although the EUPHORE chamber in Valencia is still equipped with a copper vapour laser pumped dye laser system. ${ }^{66,67}$ A typical detection limit for the FAGE technique is $(2-5) \times 10^{5}$ and $(5-10) \times 10^{5}$ molecule $\mathrm{cm}^{-3}$ for $\mathrm{OH}$ and $\mathrm{HO}_{2}$, respectively, depending on the individual instrument, averaging period and reported signal-to-noise ratio, with a typical $(1 \sigma)$ accuracy of $\sim 20-30 \% .^{23}$ Field measurements using FAGE of $\mathrm{OH}, \mathrm{HO}_{2}$ and/or $\mathrm{OH}$ reactivity are currently being made by groups at the University of Leeds, ${ }^{12,68-70}$ Pennsylvania State University, ${ }^{71,72}$ Forschungszentrum Julich, ${ }^{73-75}$ the Max Planck Institute for Chemistry at Mainz, ${ }^{76}$ University of Indiana, ${ }^{77,78}$ Frontier Research Centre for Global Change, ${ }^{79-81}$ Tokyo Metropolitan University ${ }^{82,83}$ and Lille, ${ }^{84}$ and other groups have instruments in development. FAGE instruments for measurement of $\mathrm{OH}$ and $\mathrm{HO}_{2}$ radicals close to ambient concentrations are also operated at the EUPHORE, ${ }^{67,85}$ SAPHIR $^{59,60,64}$ and HIRAC ${ }^{86,87}$ chambers.

In a new development, Dlugi et al. ${ }^{88}$ recently reported the first flux measurements of $\mathrm{OH}$ and $\mathrm{HO}_{2}$ using FAGE, above the canopy of a forest. Given the short lifetime for $\mathrm{OH}$, its flux is not directly determined by its transport, rather it is driven by compositional changes induced by small eddy transport of biogenic VOCs. Another recent innovation is the development of the $\mathrm{RO}_{x} \mathrm{LIF}$ method, which is an extension of FAGE enabling $\mathrm{HO}_{2}$ and the sum of organic peroxy radicals to be measured separately, ${ }^{89}$ and with good sensitivity $(\sim 0.1$ pptv detection limit in $\sim 1$ minute). $\mathrm{HO}_{2}$ and the sum of $\mathrm{RO}_{2}$ has also been measured separately using a CIMS detection method to measure $\mathrm{OH}$ via $\mathrm{H}_{2} \mathrm{SO}_{4}$ formation. ${ }^{50,90}$ Although upon addition of $\mathrm{NO}$, conversion of $\mathrm{RO}_{2}$ to $\mathrm{RO}$ is rapid $(\mathrm{OH}$ in the case of $\mathrm{HO}_{2}$ ), in a normal FAGE fluorescence cell, where the pressure is typically between $0.6-4$ Torr, the rate of the reaction:

$$
\mathrm{RO}+\mathrm{O}_{2} \rightarrow \mathrm{R}^{\prime} \mathrm{CHO}+\mathrm{HO}_{2}
$$

is too slow to give significant conversion prior to the laserprobe volume where $\mathrm{OH}$ is detected, and so $\mathrm{RO}_{2}$ does not constitute any of the signal measured as $\mathrm{HO}_{2}$. This assumption, however, has recently been brought into question for larger R, and also when $\mathrm{R}$ contains an unsaturated or oxygenated functional group, ${ }^{91}$ as described in Section 3 below. A disadvantage of the $\mathrm{RO}_{x}$ LIF method, shared by PerCIMS (ROXMAS) is that no distinction can be made between different organic peroxy radicals, so in order to compare with a model calculation, it is necessary first to multiply the modelderived concentration for each $\mathrm{RO}_{2}$ by the relevant sensitivity factor in order to compare with the field measured value. However, the ratio $\left[\Sigma \mathrm{RO}_{2}\right] /\left[\mathrm{HO}_{2}\right]$ from the same instrument still provides important, and novel information about the mechanisms for chemical oxidation.

In the CIMS (or ion assisted mass spectrometry) technique, $\mathrm{OH}$ is converted quantitatively to $\mathrm{H}_{2}{ }^{34} \mathrm{SO}_{4}$ by the following reactions:

$$
\begin{gathered}
\mathrm{OH}+{ }^{34} \mathrm{SO}_{2}+\mathrm{M} \rightarrow \mathrm{H}^{34} \mathrm{SO}_{3}+\mathrm{M} \\
\mathrm{H}^{34} \mathrm{SO}_{3}+\mathrm{O}_{2} \rightarrow{ }^{34} \mathrm{SO}_{3}+\mathrm{HO}_{2} \\
{ }^{34} \mathrm{SO}_{3}+\mathrm{H}_{2} \mathrm{O}+\mathrm{M} \rightarrow \mathrm{H}_{2}{ }^{34} \mathrm{SO}_{4}+\mathrm{M}
\end{gathered}
$$

and $\mathrm{H}_{2}{ }^{34} \mathrm{SO}_{4}$ is chemically ionised by the reaction:

$$
\mathrm{NO}_{3}{ }^{-} \cdot \mathrm{HNO}_{3}+\mathrm{H}_{2}{ }^{34} \mathrm{SO}_{4} \rightarrow \mathrm{H}^{34} \mathrm{SO}_{4}{ }^{-} \cdot \mathrm{HNO}_{3}+\mathrm{HNO}_{3}
$$

with the cluster ion $\mathrm{NO}_{3}{ }^{-} \cdot \mathrm{HNO}_{3}$ produced in a separate sheath containing $\mathrm{HNO}_{3}$. The isotopically labelled ${ }^{34} \mathrm{~S}$ is used to discriminate against naturally occurring $\mathrm{H}_{2}{ }^{32} \mathrm{SO}_{4}$. Finally, following collisional fragmentation of $\mathrm{H}^{34} \mathrm{SO}_{4}{ }^{-} \cdot \mathrm{HNO}_{3}$ the ratio of ions $\mathrm{H}^{34} \mathrm{SO}_{4}{ }^{-} / \mathrm{NO}_{3}{ }^{-}$is measured in a quadrupole mass spectrometer. The CIMS method is the most sensitive of all $\mathrm{OH}$ field instruments, with a detection limit of better than $10^{5}$ molecule $\mathrm{cm}^{-3} \cdot{ }^{23}$ Field measurements of $\mathrm{OH}$, 
$\left[\mathrm{HO}_{2}\right]+\left[\Sigma_{\mathrm{i}} \mathrm{RO}_{2, \mathrm{i}}\right]$ (or sometimes with speciation of $\left[\mathrm{HO}_{2}\right]$ ), and more recently $\mathrm{OH}$ reactivity are currently made by CIMS groups at Georgia Tech, ${ }^{92,93}$ German Weather Service, ${ }^{94,95}$ University of Galway, NCAR/University of Helsinki ${ }^{96-98}$ and LATMOS Paris. $^{99}$

\subsection{Quality assurance: instrument calibration}

There remains only one method used in the field for the calibration of FAGE and CIMS instruments at concentrations close to those found in the troposphere. This method relies on the photolysis of water vapour at $184.9 \mathrm{~nm}$ using a mercury lamp, which in the presence of air generates equal concentrations of $\mathrm{OH}$ and $\mathrm{HO}_{2}$, given by:

$$
[\mathrm{OH}]=\left[\mathrm{HO}_{2}\right]=\left[\mathrm{H}_{2} \mathrm{O}\right] \sigma_{\mathrm{H}_{2} \mathrm{O}, 184.9 \mathrm{~nm}} \phi_{\mathrm{OH}_{1}} F_{184.9 \mathrm{~nm}} t
$$

where $\sigma$ is the water vapour absorption cross-section, $\phi_{\mathrm{OH}}$ is the photodissociation quantum yield of $\mathrm{OH}$ (and hence $\mathrm{HO}_{2}$ in the presence of $\mathrm{O}_{2}$ ) from water vapour (assumed to be 1), $F$ is the photon flux of the lamp, all at $184.9 \mathrm{~nm}$, and $t$ is the photolysis exposure time. Details of this calibration method are given in the review by Heard and Pilling ${ }^{23}$ and references therein and are not repeated here. The first three terms can be determined accurately, and there have been two approaches to measure the product $F_{184.9 \mathrm{~nm}} t$. One approach measures $F_{184.9 \mathrm{~nm}}$ directly using a calibrated phototube, and $t$ is calculated using the known flow properties of the calibration flowtube..$^{97,100}$ The other approach is to use a chemical actinometer to determine the product, rather than each individually, and two actinometers have been developed involving the production and measurement of $\mathrm{O}_{3}$ or $\mathrm{NO}$ initiated from $\mathrm{O}_{2}$ and $\mathrm{N}_{2} \mathrm{O}$ (added to the flow) photolysis, respectively, and which give the same value within errors. ${ }^{72,101}$

One assumption made in this method is that the hydrogen atom co-product of $\mathrm{OH}$ following $184.9 \mathrm{~nm}$ photolysis of water vapour is rapidly relaxed by collisions (it is formed with considerable translational energy) and reacts exclusively with $\mathrm{O}_{2}$ (the calibrations are usually done in air) in the presence of the third body to form $\mathrm{HO}_{2}$ radicals. Alternative, exothermic fates of the initially excited $\mathrm{H}$ atoms are reaction with water vapour or $\mathrm{O}_{2}$ to form $\mathrm{OH}$. If this occurred to any extent, then the concentration of $\mathrm{OH}$ and $\mathrm{HO}_{2}$ would not be equal following photolysis, which is a key assumption in the calibration. In one experiment Fuchs et al. ${ }^{91}$ added sufficient $\mathrm{CO}$ to quickly convert any $\mathrm{OH}$ produced from the photolysis of water vapour ((R3) above), and any $\mathrm{OH}$ produced from subsequent reactions of $\mathrm{H}$ atoms, into $\mathrm{HO}_{2}$ radicals. The measured LIF signal from $\mathrm{HO}_{2}$ represents the sum of $\mathrm{OH}$ and $\mathrm{HO}_{2}$ radicals generated, and this calibration method has an $\mathrm{HO}_{2}$ yield of two, independent of whether $\mathrm{OH}$ is made by any reactions of hot $\mathrm{H}$ atoms or not. In a second experiment $\mathrm{CD}_{4}$ was added as a scavenger to quickly remove any $\mathrm{OH}$ from the calibration gas:

$$
\mathrm{OH}+\mathrm{CD}_{4}+\mathrm{O}_{2} \rightarrow \mathrm{CD}_{3} \mathrm{O}_{2}+\mathrm{HDO}
$$

In this mode, $\mathrm{HO}_{2}$ is only made by reaction of $\mathrm{H}$ atoms with $\mathrm{O}_{2}$ (in the presence of $\mathrm{M}$ ). If reactions of hot $\mathrm{H}$ atoms are occurring with $\mathrm{H}_{2} \mathrm{O}$ or $\mathrm{O}_{2}$ to form $\mathrm{OH}$, because the $\mathrm{OH}$ is scavenged this will result in a lower yield of $\mathrm{HO}_{2}$. In the absence of any reactions of hot $\mathrm{H}$ atoms to form $\mathrm{OH}$, the expected $\mathrm{HO}_{2}$ yield is one. $\mathrm{CD}_{3} \mathrm{O}_{2}$ cannot be converted into any $\mathrm{H}$-containing $\mathrm{HO}_{x}$ species. The ratio of the signals for the two experiments was 0.5 , verifying the assumption of a quantum yield of one for $\mathrm{OH}$ and $\mathrm{HO}_{2}$ from the photolysis of water vapour in air. ${ }^{102}$

All groups active in field measurements of $\mathrm{OH}$ and $\mathrm{HO}_{2}$ continue to rely on the vacuum ultraviolet photolysis of water vapour to calibrate their instruments, and although there is currently no evidence that there is a bias or other problem with this method, it is a concern that reliance for all absolute concentrations is given to a single method. Intercomparisons with the DOAS method, which does not rely on a calibration (only needing knowledge of spectroscopic constants which are well established in the laboratory, and the path length), either in the field ${ }^{103}$ or in chambers, ${ }^{59,60}$ provides confidence in the calibration method (more details of recent work is given in Section 3.2 below). Indirect calibration has been achieved using the decay of a hydrocarbon for which the rate coefficient $k_{\mathrm{OH}+\mathrm{HC}}$ is well established in the literature, with [HC] measured using GC-FID as function of time to give:

$$
[\mathrm{OH}]=\frac{(-\mathrm{d}[\mathrm{HC}] / \mathrm{d} t)}{k_{\mathrm{OH}+\mathrm{HC}}[\mathrm{HC}]}
$$

Such an approach was used in the field in the early days of FAGE by the Portland State group ${ }^{104,105}$ but not by any current $\mathrm{OH}$ measurement groups. This method has given good agreement with $[\mathrm{OH}]$ measured in chambers with instruments calibrated using the water photolysis method. ${ }^{106}$

The calibration of instruments as a function of ambient pressure, which varies during the operation of aircraft measurements, is difficult to achieve. Some groups have developed an in flight calibration system for $\mathrm{OH},{ }^{76,107}$ whereas others rely on a transfer standard in flight (for example Raman scattered light from $\mathrm{N}_{2}{ }^{72}$ ), and an absolute calibration is performed on the ground pre- and post-campaign using the $185 \mathrm{~nm}$ water vapour photolysis technique at atmospheric pressure, but using sampling pinholes of different diameters to reproduce the necessary pressure within the FAGE fluorescence cell. ${ }^{69,72}$ The assumption is made that $\mathrm{OH}$ losses through pinholes of different diameters is the same, and that the sensitivity of the instrument depends only on the pressure within the fluorescence cell and not on the ratio of external to internal pressures. It is difficult to test this assumption using the HC decay method above, as most chambers equipped with $\mathrm{OH}$ instruments are made or Teflon or similar material and hence cannot be evacuated. The Leeds HIRAC (Highly Instrumented Reactor for Atmospheric Chemistry) chamber ${ }^{86}$ is constructed of stainless steel, and has been used to generate $\mathrm{OH}$ radicals close to ambient concentrations at total pressures between 220-760 Torr. In preliminary experiments, $\mathrm{OH}$ concentrations determined using the decay of a hydrocarbon (eqn (E8)) at different total pressures agreed well with concentrations measured by a FAGE instrument previously calibrated by the water vapour photolysis method at atmospheric pressure but using a range of sampling pinholes of different diameters to reproduce the necessary pressure within the fluorescence cell. ${ }^{87}$ Another method of generating $\mathrm{OH}$ at ambient concentrations at atmospheric pressure is via the reaction of ozone with 
alkenes with a known yield of $\mathrm{OH}^{87}$ This method is not currently used in the field but has been compared with FAGE-measured $\mathrm{OH}$ in a chamber. ${ }^{87}$

For $\mathrm{HO}_{2}$, observing the rate of $\mathrm{HO}_{2}$ decay from the second order self-reaction, and knowledge of the rate coefficient and any wall loss, $k_{\text {loss }}$ enables $\left[\mathrm{HO}_{2}\right]$ to be determined from solution of the following differential equation:

$$
\frac{\mathrm{d}\left[\mathrm{HO}_{2}\right]}{\mathrm{d} t}=-\left(k_{\mathrm{loss}}\left[\mathrm{HO}_{2}\right]+2 k_{\mathrm{HO}_{2}+\mathrm{HO}_{2}}\left[\mathrm{HO}_{2}\right]^{2}\right)
$$

in order to calibrate instruments. This method has enjoyed success in chambers, ${ }^{67,87}$ but is not used in the field owing to the difficulty in constructing a suitable apparatus to observe the decay for the required length of time under realistic concentrations of $\mathrm{HO}_{2}$.

\subsection{Quality assurance: intercomparisons}

Confidence in a field measurement is increased if the same result can be obtained with two or more instruments that utilise independent methodologies whilst sampling at the same location. Intercomparisons have been crucial for the development of techniques for the atmospheric detection of the $\mathrm{OH}$ radical, on account of the early problems with its atmospheric detection using LIF spectroscopy, when signals were almost entirely due to laser-generated artefacts. ${ }^{23}$ Intercomparisons between different field instruments measuring $\mathrm{OH}$ and/or $\mathrm{HO}_{2}$ radicals are still uncommon, but represent one of the best quality control mechanisms to probe any differences in instrument behaviour, calibration and susceptibility towards interferences. Intercomparisons up to 2003, for example the ground-based TOHPE (1993) and POPCORN (1994) field campaigns, and the aircraft-based PEM Tropics B (1999) and TRACE-P (2001) campaigns, were reviewed by Heard and Pilling. ${ }^{23}$

The SAPHIR chamber in Julich is a highly-instrumented chamber equipped with the only operating long-path DOAS instrument with the capability of measuring atmospheric levels of $\mathrm{OH}$. As DOAS requires no calibration, merely knowledge of the absorption cross-sections at the relevant temperature and pressure and the path length, it provides an absolute standard for $\mathrm{OH}$. The $\mathrm{HO}_{x}$ Comp campaign, performed in $2005,{ }^{64,108}$ provided both an out of chamber (ambient) and an in chamber formal-blind intercomparison for both $\mathrm{OH}$ and $\mathrm{HO}_{2}$. One DOAS (in SAPHIR chamber only), 3 FAGE and 1 CIMS instruments from Germany and Japan were involved, and followed on from a successful previous $\mathrm{OH}$ intercomparison at SAPHIR involving just the Julich group. ${ }^{59}$ For OH, the agreement is in general very good over a range of different levels of humidity, $\mathrm{O}_{3}, \mathrm{NO}_{2}$, and radiation (including under dark conditions) with gradients of the correlation plots ranging from 1.01-1.13. A CIMS instrument also participated in the ambient phase of the intercomparison, together with 3 FAGE instruments, and correlation gradients of 1.06-1.69 were observed, which were sometimes outside the combined uncertainty limits. Fig. 4 shows examples of ambient and chamber-based correlation plots of $\mathrm{OH}$ recorded during $\mathrm{HO}_{x}$ Comp. A discussion of the agreement with models during $\mathrm{HO}_{x}$ Comp is reviewed in Section 6.2 below.
Three FAGE instruments employing NO induced $\mathrm{HO}_{2} \rightarrow \mathrm{OH}$ conversion participated in an $\mathrm{HO}_{2}$ intercomparison during $\mathrm{HO}_{x}$ Comp, and here the agreement between instruments was more variable, with correlation slopes between 0.69 to 1.26 in the chamber and sometimes higher for ambient. ${ }^{64}$ The agreement in the chamber was a function of the particular experiment, with better correlations when grouped by water vapour. There is an unknown factor related to water vapour which appears to give a bias for some instruments. ${ }^{64}$ Fig. 5 shows examples of ambient and chamber-based correlation plots of $\mathrm{HO}_{2}$ recorded during $\mathrm{HO}_{x}$ Comp. An intercomparison between $\mathrm{RO}_{x} \mathrm{LIF}$ and the matrix isolation electron spin resonance (MIESR) technique for both $\mathrm{HO}_{2}$ and the sum of organic $\mathrm{RO}_{2}$ gave good agreement, with correlation slopes of 0.98 and 1.02, respectively. ${ }^{91}$ An older field intercomparison between a PerCIMS and FAGE instrument for $\mathrm{HO}_{2}$ also gave agreement within $40 \%{ }^{109}$

\section{Potential interferences in $\mathrm{OH}$ and $\mathrm{HO}_{2}$ measurements}

In the early days of LIF detection of tropospheric $\mathrm{OH}$, measurements were performed at atmospheric pressure using an off-resonant scheme, with $\mathrm{OH}$ excited at $282 \mathrm{~nm}$ to the vibrationally excited $\mathrm{A}^{2} \Sigma^{+}, v^{\prime}=1$ level, and fluorescence collected at longer wavelengths $(305-311 \mathrm{~nm})$. Although this excitation scheme offered significant advantages to the on-resonant scheme, it was plagued with a large interference (swamping ambient $\mathrm{OH}$ signals) from the photolysis of ozone at $282 \mathrm{~nm}$ with subsequent production of $\mathrm{OH}$ from the reaction of $\mathrm{O}\left({ }^{1} \mathrm{D}\right)$ atoms with water vapour. ${ }^{23}$ Following several developments, current LIF instruments use low pressures (FAGE) and on-resonant $308 \mathrm{~nm}$ excitation, and are much less subject to this interference. Earlier laboratory work reported in Ren et al., ${ }^{110}$ and confirmed by others, showed no significant interferences for a limited range of species during the detection of both $\mathrm{OH}$ and $\mathrm{HO}_{2}$. In low $\mathrm{NO}_{x}$, forested environments, recent measurements of $\mathrm{OH}$ and $\mathrm{HO}_{2}$, and comparisons with model calculations, as described in Section 5 below, have shown significant model underpredictions and raised questions about our understanding of the chemistry in this environment. There are intense efforts to try to understand the deficiency in our understanding, but a solution that is consistent with all the available data has not been found. An alternative explanation to the reported model underpredictions in these environments is the presence of a systematic bias in the $\mathrm{OH}$ and $\mathrm{HO}_{2}$ measurements, all of which have been taken with FAGE instruments. We describe below some recent work which suggests there may be interferences for both $\mathrm{OH}$ and $\mathrm{HO}_{2}$ for FAGE instruments operating under certain conditions in these types of environments.

\section{1. $\mathrm{HO}_{2}$ interferences using FAGE}

Until recently it was assumed that higher peroxy radicals $\left(\mathrm{RO}_{2}\right)$ did not act as an $\mathrm{HO}_{2}$ interference in FAGE because although these species also react with NO to form an alkoxy radical (RO) at 1 Torr, the subsequent reaction $\mathrm{RO}+\mathrm{O}_{2}$ to give $\mathrm{HO}_{2}$ is too slow. However, recent studies ${ }^{30,111}$ have revealed that alkene-derived $\mathrm{RO}_{2}$ radicals, longer chain 

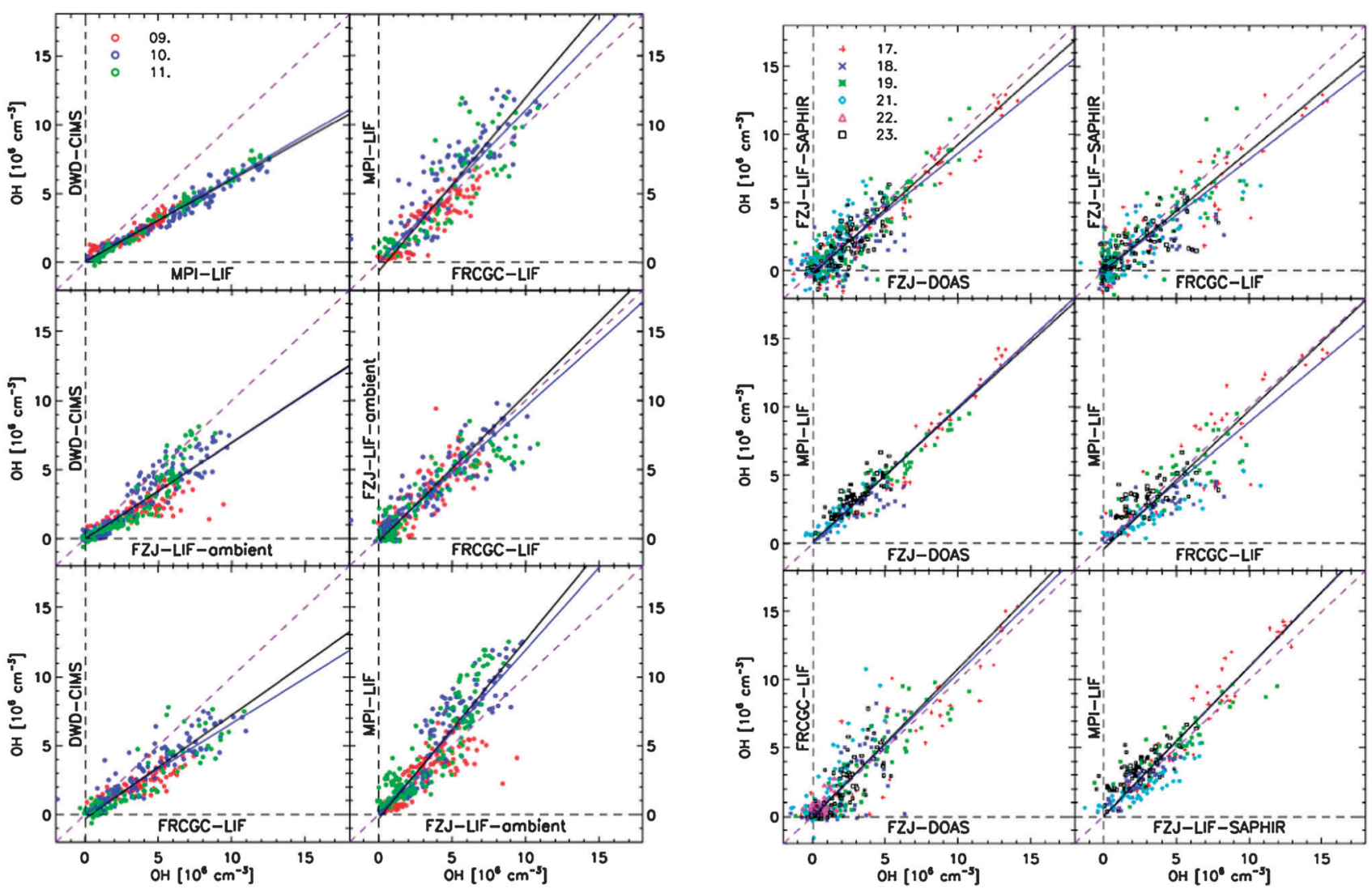

Fig. 4 Linear regressions to ambient (Left) and chamber (Right) OH concentrations (averaged to $300 \mathrm{~s}$ ) with best-fit slopes represented by solid black and blue (forced through the origin) lines. Dashed line represents a slope of one. (Reproduced from ref. 60, Copyright (2009), with permission from Copernicus Publications.)

alkane-derived $\mathrm{RO}_{2}(>\mathrm{C} 3)$ and also $\mathrm{RO}_{2}$ from aromatic species can be converted to $\mathrm{HO}_{2}$ in the presence of $\mathrm{NO}$ in a FAGE detection cell. Actually, this is not a surprise, as the yields of $\mathrm{HO}_{2}$ from these reactions, if permitted to proceed to completion, are well known and included in the MCM. ${ }^{2}$ The interference will only be significant for field reported concentrations of $\mathrm{HO}_{2}$ if the experimental configuration of the FAGE instrument being used is conducive to any conversion of $\mathrm{RO}_{2}$ into $\mathrm{HO}_{2}$ in the presence of NO. The percentage conversion of $\mathrm{RO}_{2}$ to $\mathrm{HO}_{2}$ will be influenced by a number of experimental variables which vary considerably between different field instruments. These include the fluorescence cell pressure, the residence time of the sampled air in the fluorescence cell prior to laser excitation of $\mathrm{OH}$ (related to the pumping speed and geometry of the cell), the concentration of $\mathrm{NO}$ added to convert $\mathrm{HO}_{2}$, details of the supersonic expansion which will determine the degree of mixing of $\mathrm{NO}$ into the ambient jet, the proximity of the walls to the sampled flow, and the volume from which fluorescence is imaged on the detector (factors determining this include whether a single or multi-pass cell is used). Fuchs et al. ${ }^{30}$ demonstrated that by changing the inlet configuration of the FAGE cell (diameter of the sampling pinhole which changed the sample flow rate and hence the conversion reaction time), the interference changed considerably. For example, for $\mathrm{RO}_{2}$ derived from ethene, the relative detection sensitivity compared with $\mathrm{HO}_{2}$ was 0.95 for an inlet orifice diameter of $0.4 \mathrm{~mm}$ (2.7 ms conversion time), changing to 0.17 for a $0.2 \mathrm{~mm}$ sampling orifice $(0.18 \mathrm{~ms}$ conversion time). Similar changes were observed for other alkene-related $\mathrm{RO}_{2}$ species, e.g. for isoprene $\mathrm{RO}_{2}$. Furthermore, the degree of interference could be reduced using a lower concentration of NO in the cell, ${ }^{30}$ as predicted using the MCM. Work-in-progress in other laboratories is giving similar results. ${ }^{111}$ Equipped with knowledge of this interference for $\mathrm{HO}_{2}$ and the controlling parameters, it will be possible for FAGE groups to design the configuration and geometry of their sampling systems and fluorescence cells to minimise interferences from $\mathrm{RO}_{2}$.

It is possible to provide a correction and account for the additional $\mathrm{HO}_{2}$ concentration that derives from $\mathrm{RO}_{2}$ radicals, using the following expression: ${ }^{112}$

$$
\left[\mathrm{HO}_{2} *\right]=\left[\mathrm{HO}_{2}\right]+\Sigma_{\mathrm{i}}\left(\alpha_{\mathrm{RO}_{2}, \mathrm{i}} \times\left[\mathrm{RO}_{2}\right]_{\mathrm{i}}\right)
$$

where $\left[\mathrm{HO}_{2}{ }^{*}\right]$ is the $\mathrm{HO}_{2}$ concentration in ambient air plus contribution from $\mathrm{RO}_{2}$ interferences (the total measured quantity), $\left[\mathrm{HO}_{2}\right]$ is the $\mathrm{HO}_{2}$ concentration in ambient air (the desired quantity), $\alpha_{\mathrm{RO}_{2}, \mathrm{i}}$ is the fraction of a given $\mathrm{RO}_{2}$ species converted to $\mathrm{HO}_{2}$, and subsequently $\mathrm{OH}$ in the detection cell, determined for the FAGE instrument in the laboratory, and $\left[\mathrm{RO}_{2}\right]_{\mathrm{i}}$ is the concentration of a given $\mathrm{RO}_{2}$ in ambient air calculated using a box-model. ${ }^{112}$ A significant disadvantage of this method is that is relies on a model calculation for $\mathrm{RO}_{2}$, as there are no field measurements of 

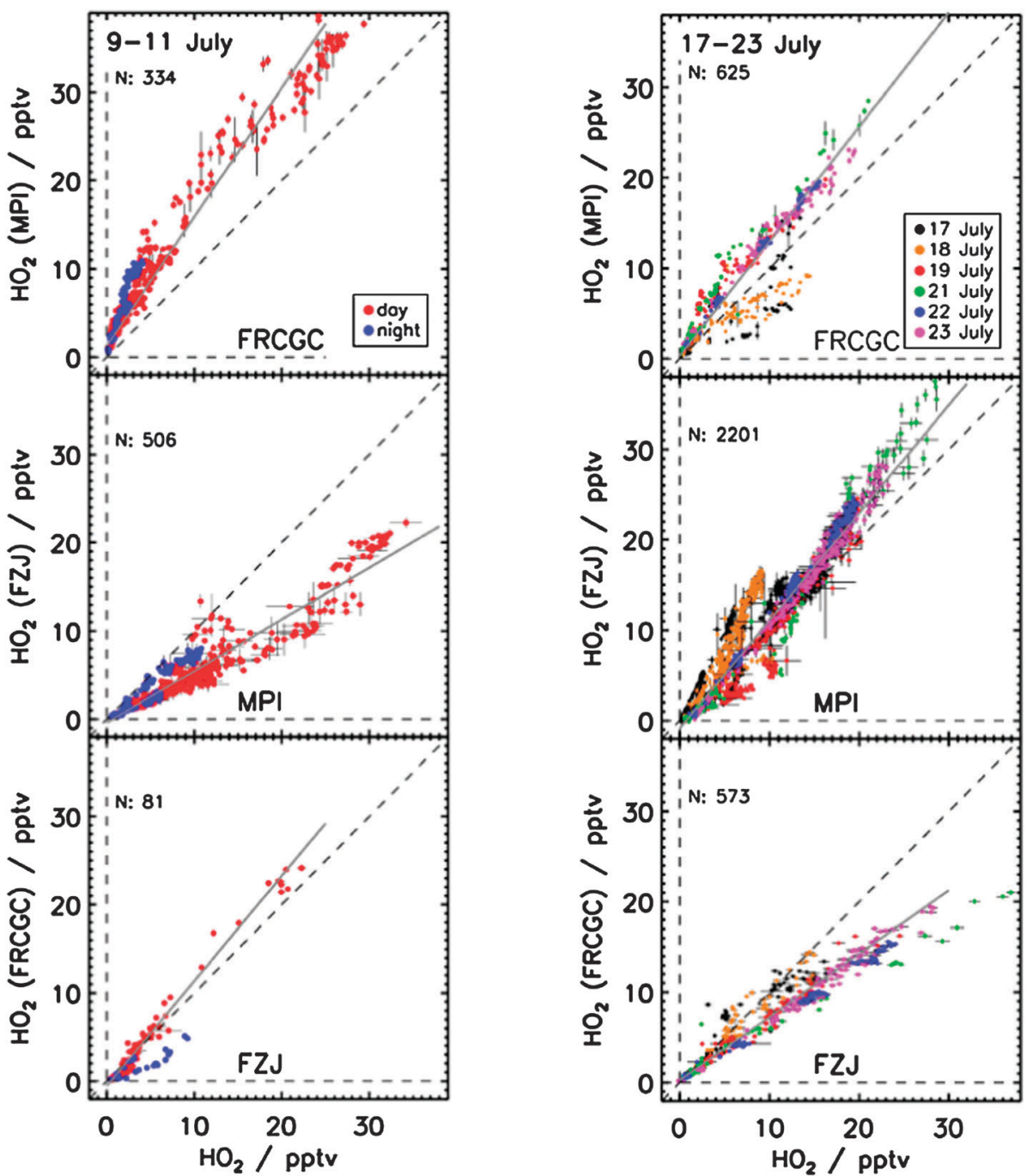

Fig. 5 Correlation of $\mathrm{HO}_{2}$ mixing ratios in ambient (Left) and SAPHIR chamber (Right) experiments (averaged to $1 \mathrm{~min}$ ). The solid lines show the results of the linear fits (daytime only for the ambient data), whilst the dashed line represents a slope of one. (Reproduced from ref. 64, Copyright (2010), with permission from Copernicus Publications.)

individual $\mathrm{RO}_{2}$ species. This method does allow investigation of the difference between $\mathrm{HO}_{2}{ }^{*}$ and $\mathrm{HO}_{2}$, which will depend on the mix of $\mathrm{RO}_{2}$ at a particular location. However, a far better strategy is to make sure that any future measurements of $\mathrm{HO}_{2}$ are not subject to this interference, through judicious design of the instrument.

\subsection{OH interferences using FAGE}

Early experiments performed in the laboratory by Ren et al. ${ }^{110}$ reported negligible interferences for the detection of $\mathrm{OH}$ for a range of species, including $\mathrm{H}_{2} \mathrm{O}_{2}, \mathrm{SO}_{2}, \mathrm{HONO}, \mathrm{HCHO}$ and a range of VOCs with different functional groups (alkanes, alkenes, alcohols, including isoprene). A small $\mathrm{OH}$ interference scaling with ozone and water vapour was observed, as reported by some other groups (possibly heterogeneous in origin) but which can be corrected for. The usual method to determine the background signal in a FAGE instrument is to exploit the narrow spectral profile of a single rotational transition of $\mathrm{OH}$, and move the laser wavelength away from the $\mathrm{OH}$ line and measure the sum of solar, cell-induced and Mie scattered light. However, in the recent BEARPEX (Biosphere Effects on Aerosols and Photochemistry Experiment) study in a California forest using a FAGE instrument ${ }^{31}$ an alternative method to determine the background, which does not involve changing the laser wavelength, was used. $\mathrm{C}_{3} \mathrm{~F}_{6}$ was injected into the sampled ambient air stream to remove ambient $\mathrm{OH}$ before it enters the instrument. Any remaining signal is the background, although a complication was that the addition of $\mathrm{C}_{3} \mathrm{~F}_{6}$ just outside the sampling inlet also removed some of the additional $\mathrm{OH}$ generated inside the cell. The background using this method was considerably higher than using the spectral method, ${ }^{31}$ and showed that the additional background was due to $\mathrm{OH}$ radicals. It was postulated that $\mathrm{OH}$ was generated within the instrument from oxidation of an unidentified biogenic VOC. Evidence was provided to rule out laser-generation of $\mathrm{OH}$ within the cell. Allowing for this increased background gave measured $\mathrm{OH}$ concentrations that were $\sim 40-50 \%$ of those determined using the spectral background method, and which agreed better with the calculations of a constrained box model. ${ }^{31}$ 
The field site was within a Ponderosa pine plantation, and a key question is whether this type of interference has been seen previously by this and other FAGE instruments operating in other forested environments. For $\mathrm{HO}_{2}$, the degree of interference was shown to be dependent upon instrument design, ${ }^{30}$ and the same may be true for any potential $\mathrm{OH}$ interferences. A recent experiment utilising the SAPHIR chamber has compared $\mathrm{OH}$ concentrations measured by DOAS and FAGE under conditions of low $\mathrm{NO}_{x}$ and in which significant concentrations of isoprene, methyl vinyl ketone (MVK), methacrolein (MACR) and aromatic compounds were added and photochemically oxidised. ${ }^{113}$ Conditions were chosen to replicate those in the PRIDE-PRD campaign in China where significantly higher $\mathrm{OH}$ concentrations were measured than model calculations. ${ }^{22}$ Over the entire set of experiments over 20 days, the linear regression of $\mathrm{OH}$ concentrations measured by FAGE compared to DOAS gave a slope of $1.02 \pm 0.01$ and an intercept of $(1.0 \pm 0.3) \times 10^{5}$ molecule $\mathrm{cm}^{-3}$. However, FAGE measurements were approximately $30-40 \%$ larger than those by DOAS after MVK and toluene had been added, although this discrepancy has large associated uncertainties and requires further laboratory investigation. These results support the validity of this FAGE measurement of $\mathrm{OH}$ in the presence of these biogenic VOCs under the specific conditions of these experiments.

\subsection{Interferences for CIMS instruments}

CIMS is a less direct method for the detection of $\mathrm{OH}$ owing to several chemical conversion steps. Reactions competing with the reaction of $\mathrm{SO}_{3}$ with $\mathrm{H}_{2} \mathrm{O}$ vapour (R19), influences of $\mathrm{H}_{2} \mathrm{O}$ vapour on the ion molecule chemistry involving $\mathrm{NO}_{3}{ }^{-} / \mathrm{HNO}_{3} /$ $\mathrm{H}_{2} \mathrm{SO}_{4}$ and potential wall losses of radicals have all been experimentally studied. ${ }^{114}$ Excess propane is periodically added at the inlet (at the same injection point where $\mathrm{SO}_{2}$ is added) in order to rapidly remove ambient $\mathrm{OH}$ (on a timescale that is much shorter than removal by $\mathrm{SO}_{2}$ ) and enables a background signal to be determined. Also, the chemistry which generates $\mathrm{H}_{2} \mathrm{SO}_{4}$ from $\mathrm{OH}$ generates $\mathrm{HO}_{2}$ in reaction (R19), and this together with any $\mathrm{HO}_{2}$ present in the ambient sample (typically $\mathrm{HO}_{2}$ is $10-100$ times more abundant than $\mathrm{OH}$ ), could be recycled to $\mathrm{OH}$, for example by reaction with $\mathrm{NO}$ or $\mathrm{O}_{3}$ and lead to a positive bias for $\mathrm{OH} .{ }^{94,115}$ Any such $\mathrm{OH}$ produced by recycling from $\mathrm{HO}_{2}$ (or indeed from any other mechanism) is prevented from reacting with $\mathrm{SO}_{2}$ (and hence being detected) through removal by the addition of excess propane downstream of the injection position for $\mathrm{SO}_{2}$ (sufficiently downstream so that all ambient $\mathrm{OH}$ reacts with $\mathrm{SO}_{2}$ before it encounters propane). However, any species which can oxidise $\mathrm{SO}_{2}$ to $\mathrm{SO}_{3}$, but which is not removed by reaction with propane, will be detected as $\mathrm{H}_{2} \mathrm{SO}_{4}$, and will cause a positive bias to the $\mathrm{OH}$ measurements. Recently, Welz et al. ${ }^{116}$ showed that the simplest Criegee intermediate, $\mathrm{CH}_{2} \mathrm{OO}$, reacts quickly with $\mathrm{SO}_{2}$, and hence this is one candidate to give such an interference.

A negative bias in the measured $\mathrm{OH}$ concentration could result from species present in ambient air reacting with $\mathrm{OH}$ once the air has been sampled by the CIMS inlet but before the $\mathrm{SO}_{2}$ injection point, as these species will not be present in the calibration gas. As the transit time is short compared with the atmospheric lifetime of $\mathrm{OH}$, only a small fraction of the $\mathrm{OH}$ would be lost in this way, although this assumption may not be true if the $\mathrm{OH}$ reactivity is very high.

\section{Studies in the marine boundary layer}

\subsection{Ground based field campaigns}

The marine boundary layer (MBL) represents a significant proportion of the atmospheric boundary layer, and is largely characterised by clean air with low concentrations of reactive NMHCs and VOCs and little or no influence from anthropogenic activities. Investigation of the marine boundary layer therefore provides an opportunity to examine the chemistry of the 'natural' atmosphere. Field measurements made in the MBL cover those made at coastal sites, which constitute the majority of MBL studies, and those made over the open ocean (ship and aircraft measurements) and on the ground in remote regions relatively isolated from coastal interferences.

We present here an overview of measurements of $\mathrm{OH}$ and $\mathrm{HO}_{2}$ in marine regions, concentrating on those for which model comparisons have been made. A summary of these measurements and model comparisons at ground level is given in Table 1.

Among the earliest measurements of $\mathrm{OH}$ made in the marine boundary layer were those made during the WAOSE95 (Weybourne Atmospheric Observatory Summer Experiment 1995) project in June 1995 at the Weybourne Atmospheric Observatory situated $100 \mathrm{~m}$ from the North Norfolk coast in the UK. ${ }^{117-119}$ The campaign aimed to conduct the first full study of the diurnal oxidising capacity of the troposphere by measuring $\mathrm{OH}, \mathrm{RO}_{2}$ and $\mathrm{NO}_{3}$ radicals, and represented the first field measurements of $\mathrm{OH}$ in the UK, and at the time one of only few in the MBL. ${ }^{117,118}$

Observations of $\mathrm{OH}$ were made using a laser multipass optical absorption spectrometer (MOAS) over an eight day period, with average observed noontime $\mathrm{OH}$ concentrations of 4-7 $\times 10^{6}$ molecule $\mathrm{cm}^{-3}$ with a detection limit of 3-5 $\times$ $10^{5}$ molecule $\mathrm{cm}^{-3}$. However, the maximum $\mathrm{OH}$ concentrations $\left(6 \times 10^{6}\right.$ molecule $\mathrm{cm}^{-3}$ to $1 \times 10^{7}$ molecule $\left.\mathrm{cm}^{-3}\right)$ were observed in the afternoon, indicating the importance of production processes other than ozone photolysis. ${ }^{118}$

Grenfell et al. (1999) ${ }^{119}$ used a photochemical box model and steady state calculations to make comparisons with the $\mathrm{OH}$ measurements made during WAOSE95. The box model, constrained to observations, contained 95 VOCs in 900 thermal reactions and 31 photolysis reactions. Agreement within $50 \%$ of the measured $\mathrm{OH}$ was reported for much of the campaign, with no systematic overestimation by the model, although discrepancies up to a factor of 3 were occasionally apparent and the overall $r^{2}$ value between modelled and observed concentrations was only $0.0002 .^{119}$

Major sources of $\mathrm{OH}$ were found to be $\mathrm{O}\left({ }^{1} \mathrm{D}\right)+\mathrm{H}_{2} \mathrm{O}$, $\mathrm{HO}_{2}+\mathrm{NO}$ and photolysis of HONO, while the major sinks were $\mathrm{NO}_{2}, \mathrm{CO}, \mathrm{CH}_{4}$ and NMHCs, with the NMHCs the largest cumulative sink. Discrepancies between the model and the observations were attributed to a lack of information regarding $\mathrm{CO}$ and fast-reacting $\mathrm{NMHCs}$ on two days, resulting 


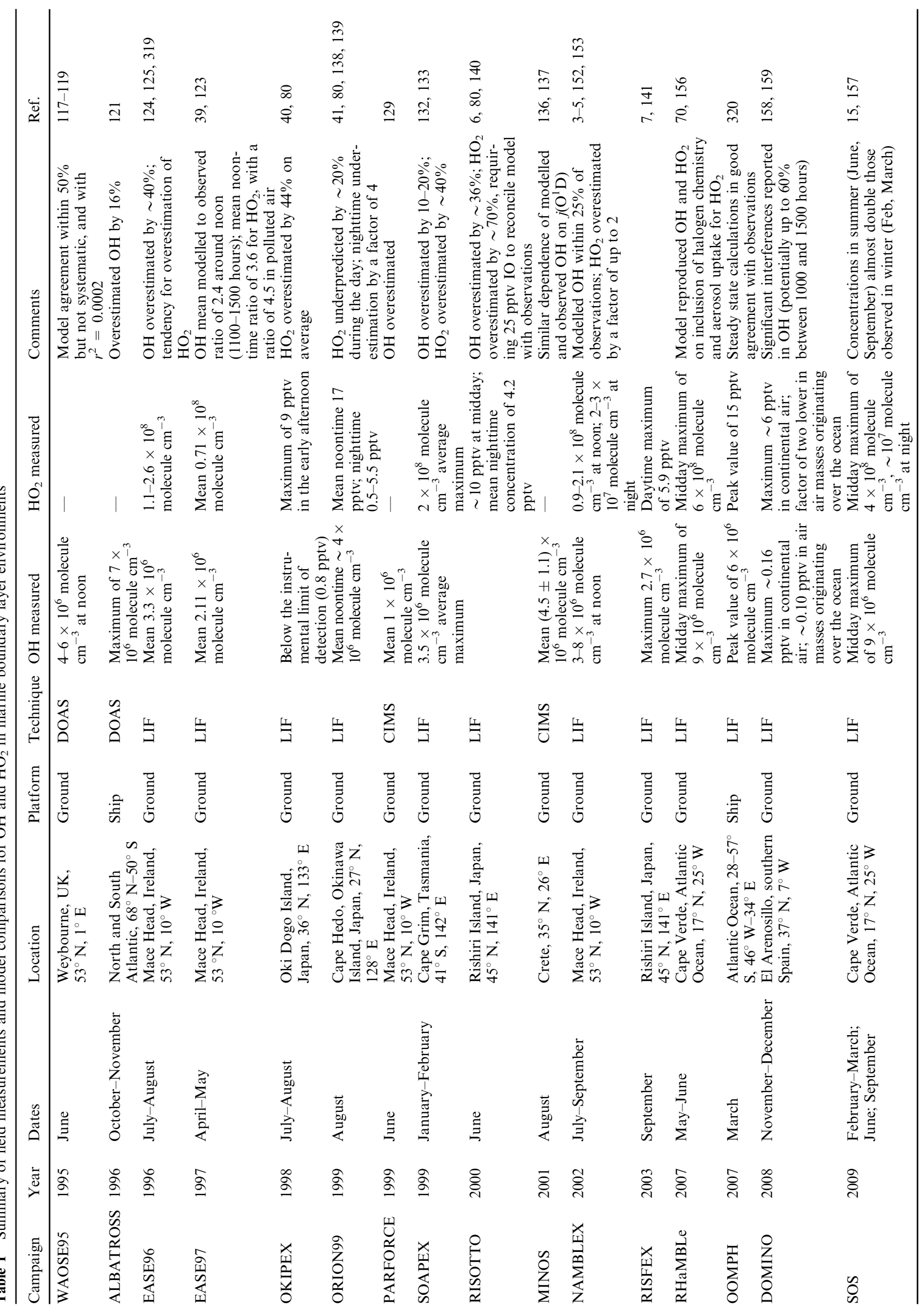


in the use of typical campaign values in the model, and on high molecular mass NMHCs throughout the campaign. ${ }^{118,119}$ In addition, the model overestimated HONO during the day, and underestimated it at night, which may have impacted the simulations for $\mathrm{OH}{ }^{119}$ Unstable meteorological conditions on three days of the campaign, causing rapid changes in cloud cover and windfield, may have had the result that photochemical equilibrium was not truly achieved. ${ }^{119}$

While PERCA (PERoxy radical Chemical Amplifier) measurements of $\mathrm{RO}_{2}$ were made during the campaign, ${ }^{119,120}$ no separate measurement of $\mathrm{HO}_{2}$ was made, precluding a more complete model comparison. Grenfell et al. (1999) ${ }^{119}$ concluded that more information was required regarding high mass NMHCs and that a diurnal $\mathrm{HO}_{2}$ measurement would prove instructive.

Measurements of $\mathrm{OH}$ were also made during the ALBATROSS (air chemistry and lidar studies of tropospheric and stratospheric species) ship campaign in the Atlantic Ocean during October and November 1996 using the DOAS technique, with a linear fit of $\mathrm{OH}$ measurements to $j\left(\mathrm{O}^{1} \mathrm{D}\right)$ displaying a correlation coefficient of $r=0.75 .^{121}$ A box model containing a simple chemistry scheme containing only 27 reactions and using measured concentrations of $\mathrm{NO}, \mathrm{HCHO}, \mathrm{H}_{2} \mathrm{O}_{2}$, $\mathrm{CH}_{3} \mathrm{OOH}, \mathrm{CO}, \mathrm{O}_{3}$ and $\mathrm{CH}_{4}$ to initialise the model, with no other NMHCs or VOCs, was able to reproduce the $\mathrm{OH}$ observations in this clean environment with only a $16 \%$ overestimation $(r=0.72){ }^{121}$

The use of LIF-FAGE to measure $\mathrm{OH}$ and $\mathrm{HO}_{2}$ radicals enabled the observation of the diurnal profiles of $\mathrm{OH}$ and $\mathrm{HO}_{2}$ in the marine boundary layer during the Eastern Atlantic Summer Experiments (EASE96, July-August 1996, and EASE97, April-May 1997) in Mace Head, Ireland. ${ }^{68,122,123}$ Modelling of $\mathrm{OH}$ and $\mathrm{HO}_{2}$ during both EASE96 ${ }^{124,125}$ and EASE97 ${ }^{126}$ was conducted using an observationally constrained box model based on the MCM with an additional description of DMS chemistry. ${ }^{127,128}$

For EASE96, model calculations for $\mathrm{OH}$ tended to overestimate the observations by approximately $40 \%$, although it was noted that this was within the combined uncertainties of the measurements $( \pm 75 \%, 2 \sigma)$ and model $( \pm 31 \%, 2 \sigma)$. For $\mathrm{HO}_{2}$, the model reproduced the observations well on one day, but not on another, with a general tendency towards overestimation. Increased loss of $\mathrm{HO}_{2}$ to aerosol, investigated in a sensitivity study in which the aerosol uptake coefficient for $\mathrm{HO}_{2}\left(\gamma_{\mathrm{HO}_{2}}\right)$ was set to its maximum theoretical value $\left(\gamma_{\mathrm{HO}_{2}}=1\right)$, could not explain the difference between the observed and modelled $\mathrm{HO}_{2} \cdot{ }^{124}$ It should be noted that no halogen chemistry was included in the model owing to the lack of measurements of $\mathrm{IO}, \mathrm{BrO}$ or $\mathrm{I}_{2}$, whereas subsequent studies at Mace Head demonstrated a significant perturbation to $\mathrm{HO}_{2}$ concentrations. ${ }^{4}$

Greater overlap between $\mathrm{HO}_{x}$ observations and supporting measurements during EASE97 permitted a more detailed modelling study than that possible for EASE96. ${ }^{124,126}$ The modelled concentrations for $\mathrm{OH}$ during EASE97 exceeded the observations for almost all data points, with a mean modelled to observed $\mathrm{OH}$ ratio of 2.4 between 1100 and 1500 hours. Similarly, model overpredictions were also found for $\mathrm{OH}$ observations made by a CIMS instrument at Mace Head during the PARFORCE campaign in June 1999, and were most significant at noon and at low tide and during new particle formation events. ${ }^{129}$

For $\mathrm{HO}_{2}$ during EASE97, the agreement was generally worse than for $\mathrm{OH}$, with a mean modelled to observed ratio of 3.6 between 1100 and 1500 hours, and reaching a ratio of 4.5 for polluted air masses originating from the mainland UK. An increase in the $\mathrm{HO}_{2}$ aerosol uptake coefficient to its maximum value gave a decrease of only $37 \%$ in the modelled $\mathrm{HO}_{2}$. Agreement for the sum of peroxy radicals $\left(\mathrm{HO}_{2}+\Sigma \mathrm{RO}_{2}\right)$, measured by the PERCA technique, ${ }^{130,131}$ was much better than for $\mathrm{OH}$ or $\mathrm{HO}_{2}$, with a mean modelled to observed ratio of $0.9 .^{126}$

Based on back trajectory calculations, the air masses encountered at Mace Head during EASE97 could be split into three categories - European continental air, polar air and UK air. For air masses of European origin it was found that a greater fraction of $\mathrm{OH}$ production resulted from ozone photolysis compared to polar or UK air, with photolysis of $\mathrm{HCHO}$ more important for UK air than for the other air masses, and represented over a third of the total radical production rate for UK air masses. Loss of $\mathrm{HO}_{x}$ in polar air masses was dominated by radical-radical reactions, the reaction between $\mathrm{OH}$ and $\mathrm{NO}_{2}$ was the major radical sink in air of UK origin. European continental air masses showed significant radical losses resulting from both radical-radical reactions and $\mathrm{OH}+\mathrm{NO}_{2} \cdot{ }^{126}$

Conditions more indicative of the open ocean, and therefore free from anthropogenic emissions, were observed during the second Southern Ocean Photochemistry Experiment (SOAPEX-2) in 1999 at the Cape Grim Baseline Air Pollution Station in northwest Tasmania. ${ }^{132,133}$ Measurements of $\mathrm{OH}$ and $\mathrm{HO}_{2}$ were made using LIF-FAGE ${ }^{132}$ over a 4 week period during the austral summer, in conjunction with a number of supporting measurements. Air masses at the measurement site originated from the Australian continent, Tasmania and Southern Ocean/Antarctic regions, with the Southern Ocean/ Antarctic air characterised by NO mixing ratios less than 3 pptv and considered to be 'baseline' air. ${ }^{132,133}$

High correlations $(r=0.95)$ between the $\mathrm{OH}$ concentration and rate of $\mathrm{OH}$ production from ozone photolysis were found for baseline air, with a simple steady state expression for $\mathrm{OH}$, based on production from ozone and loss through reaction with $\mathrm{CO}$ and methane, giving an overestimation of $\mathrm{OH}$ of only $20 \%{ }^{132} \mathrm{OH}$ concentrations were also calculated for baseline conditions in a more detailed modelling study using a chemistry scheme based on the MCM and constrained to VOC measurements. ${ }^{133}$ This study gave a 10 to $20 \%$ overestimate for $\mathrm{OH}$, and indicated that $95 \%$ of the $\mathrm{OH}$ loss could be attributed to $\mathrm{CO}$ and methane. A simpler model using only MCM chemistry for $\mathrm{CO}$ and methane degradation differed from that using MCM chemistry for the 17 other VOCs by only 5 to $10 \%{ }^{133}$

While the major source of $\mathrm{OH}$ was found to be ozone photolysis, photolysis of formaldehyde represented a significant source of $\mathrm{HO}_{2}$, contributing $30 \%$ of the total rate of $\mathrm{HO}_{2}$ production. ${ }^{133}$ However, measured formaldehyde concentrations could not be accounted for by methane oxidation chemistry, and modelled concentrations of $\mathrm{HO}_{2}$ tended to overestimate the observations by approximately $40 \%$ using 
the full chemistry scheme, although at dawn and dusk $\mathrm{HO}_{2}$ observations were a factor of two higher than the model. ${ }^{133}$ Once again, reaction with $\mathrm{BrO}$ and $\mathrm{IO}$ was not considered in the model, although upto $\sim 1$ pptv of IO was measured by DOAS close to the site. ${ }^{134}$

Radical loss reactions were almost exclusively $\mathrm{HO}_{2}+\mathrm{HO}_{2}$ and $\mathrm{HO}_{2}+\mathrm{CH}_{3} \mathrm{O}_{2}$, although the modelled $\mathrm{HO}_{2}$ was found to be highly sensitive to aerosol uptake and significant improvements could be made to the daytime overestimate by increasing the aerosol uptake coefficient or the aerosol surface area ${ }^{133}$ and by improved treatment of aerosol uptake processes. ${ }^{135}$ Since the NO concentrations were so low, increasing the $\mathrm{HO}_{2}$ loss to aerosol had a negligible effect on the modelled $\mathrm{OH}^{133}$

The dominance of $\mathrm{CO}$ and $\mathrm{CH}_{4}$ in controlling $\mathrm{OH}$ concentrations in the MBL was also observed during the MINOS (Mediterranean INtensive Oxidant Study) campaign on the northeastern coast of Crete in August 2001. ${ }^{136,137}$ During the campaign, $\mathrm{OH}$ concentrations were measured by a CIMS instrument, and reached a maximum of $2 \times 10^{7}$ molecule $\mathrm{cm}^{-3}$ (some of the highest concentrations ever reported in the troposphere), with a campaign mean of $(4.5 \pm 1.1) \times 10^{6}$ molecule $\mathrm{cm}^{-3}$. ${ }^{136}$ A box model based on $\mathrm{CO}$ and $\mathrm{CH}_{4}$ chemistry was used to interpret the measurements by comparing the dependence of the observed and modelled $\mathrm{OH}$ on $j\left(\mathrm{O}^{1} \mathrm{D}\right)$, with similar results found for the measurements and the model. ${ }^{136}$

A series of experiments have also been conducted at remote coastal sites around Japan, with measurements made on Oki Dogo Island in July/August $1998,{ }^{40,80}$ Okinawa Island in July/August 1999, ${ }^{41,80,138,139}$ and Rishiri Island in June $2000^{6,140}$ and September 2003. ${ }^{7,141}$ Although the experiments were conducted at similar times of year, the latitudinal range of the measurements resulted in variations in photolysis rates and VOC emissions, enabling investigation of $\mathrm{HO}_{x}$ chemistry under different conditions.

Measurements of $\mathrm{OH}$ and $\mathrm{HO}_{2}$ were made by LIF-FAGE. ${ }^{40,79}$ Mixing ratios of $\mathrm{OH}$ at Oki Island in summer 1998, during the OKIPEX campaign, were below the instrumental limit of detection of $\sim 4 \times 10^{6}$ molecule $\mathrm{cm}^{-3}$ for a 1 min integration time. ${ }^{40,79}$ On average, $\mathrm{HO}_{2}$ reached a maximum mixing ratio of 9 pptv in the early afternoon throughout the campaign. ${ }^{40}$ The measurement site was situated $65 \mathrm{~km}$ from mainland Japan, with limited influence of anthropogenic activities apart from local fishing, although pine and low deciduous forests were within $50 \mathrm{~m}$ of the site, resulting in high midday isoprene concentrations. $\mathrm{NO}_{2}$ mixing ratios during the campaign typically peaked at $0800 \mathrm{~h}$ at $\sim 2.5 \mathrm{ppbv}$, decreasing to below 500 pptv at midday, while NO mixing ratios typically peaked at around $700 \mathrm{pptv}$ at 0900 hours and were less than $100 \mathrm{pptv}$ at midday. Compared to the Weybourne and Mace Head measurement campaigns, water vapour concentrations were on average a factor of 2 higher at Oki Island owing to higher temperatures. ${ }^{40}$

Model calculations of $\mathrm{HO}_{2}$ were made using a box model based on the Regional Atmospheric Chemistry Mechanism (RACM), comprising 77 species and 237 reactions. ${ }^{36,40,80}$ For the majority of the campaign, the model overestimated the $\mathrm{HO}_{2}$ observations by an average of $44 \%$, with a slight underprediction on one afternoon and good agreement between the model and observations on one day. The underprediction could be rectified by an additional $\mathrm{HO}_{2}$ source from ozonolysis of monoterpenes, but no monoterpene measurements were available for the campaign and it is unclear how this would impact the overestimation of $\mathrm{HO}_{2}$ observed at other times.

The model overestimate for $\mathrm{HO}_{2}$ displayed some diurnal variation, with the greatest discrepancies observed around midday. A reduction in the rate of primary $\mathrm{HO}_{x}$ production following ozone photolysis was considered as a possible source of the overestimate, but a reduction in $j\left(\mathrm{O}^{1} \mathrm{D}\right)$ by a factor of 1.5 led to a reduction in the modelled concentration of $\mathrm{HO}_{2}$ at midday by only $20 \%$. Missing loss processes for both $\mathrm{OH}$ and $\mathrm{HO}_{2}$ were considered by Kanaya et al. ${ }^{40}$ but additional loss processes acting on $\mathrm{OH}$ required more than $10 \mathrm{ppbv}$ of an unknown hydrocarbon in order to reproduce the observed $\mathrm{HO}_{2}$ concentrations and the authors concluded that additional loss processes acting directly on $\mathrm{HO}_{2}$ would be the more likely cause of the model discrepancy. Later studies demonstrated the importance of $\mathrm{IO}$ as a sink for $\mathrm{HO}_{2}$ at a similar site. ${ }^{6}$

The extent of the discrepancy was observed to show some correlation with water vapour and glyoxal, with correlation coefficients of $r=0.46$ and $r=0.73$ respectively. ${ }^{40}$ The authors ${ }^{40}$ postulated a possible acceleration of $\mathrm{HO}_{2}$ reaction rates as a result of $\mathrm{HO}_{2}$ complexation with water vapour, as is known to occur for the $\mathrm{HO}_{2}$ self-reaction (e.g. ref. 142-144), and questioned the role of water vapour in the loss of $\mathrm{HO}_{2}$ to aerosols. Reactions between $\mathrm{HO}_{2}$ and carbonyl compounds, such as glyoxal and formaldehyde, were also considered as possible sources of the model overestimation. The authors ${ }^{40}$ recommended further laboratory investigation into $\mathrm{HO}_{2}+$ carbonyl kinetics, $\mathrm{HO}_{2}$ uptake coefficients on tropospheric aerosols and the role of water vapour in $\mathrm{HO}_{2}$ chemistry. Measurements of aerosols and carbonyl compounds were also recommended in future field campaigns.

In contrast to the work in Oki Island, observations of $\mathrm{HO}_{2}$ at Cape Hedo on Okinawa Island in 1999 as part of the ORION99 (Observations at a Remote Island of Okinawa 1999) campaign were typically underpredicted by approximately $20 \%$ using steady state and RACM models without including any heterogeneous chemistry. ${ }^{41,138}$ The model underestimations were generally more apparent in the morning, potentially resulting from a model underestimation of HONO, and hence its photolysis to produce $\mathrm{HO}_{x}{ }^{138}$ Differences between the steady state and RACM models for ORION99 were attributed to the effects of oxygenated species on $\mathrm{HO}_{2}$ which were included in the RACM model but not in the steady state calculations. ${ }^{41}$

Similarly to the Oki Island experiments, rapid variations in OH during ORION99 could not be investigated owing to high detection limits, but hourly averaged measurements showed a mean daytime maximum of around $4 \times 10^{6}$ molecule $\mathrm{cm}^{-3}$. ${ }^{138}$ Model calculations for $\mathrm{OH}$ were typically lower than observations, but were within the range of the observational uncertainty. ${ }^{41}$

Production of $\mathrm{OH}$ in the RACM model during the day was dominated by $\mathrm{O}\left({ }^{1} \mathrm{D}\right)+\mathrm{H}_{2} \mathrm{O}$ and $\mathrm{HO}_{2}+\mathrm{NO}$ in approximately equal amounts, with $\mathrm{HO}_{2}+\mathrm{NO}$ being more dominant in the early morning and late afternoon. The major loss process for $\mathrm{OH}$ was its reaction with isoprene, followed by reactions with isoprene oxidation products and $\mathrm{CO}$. 
$\mathrm{HO}_{2}$ production followed the reaction of peroxy radicals with NO, with additional contributions from formaldehyde photolysis and reactions of $\mathrm{OH}$ with $\mathrm{CO}$ and formaldehyde. Loss of $\mathrm{HO}_{2}$ was dominated by its reaction with $\mathrm{NO}$, with reactions of $\mathrm{HO}_{2}$ with $\mathrm{RO}_{2}, \mathrm{HO}_{2}$ and $\mathrm{O}_{3}$ also playing a role. ${ }^{41}$

Significant concentrations of $\mathrm{HO}_{2}$ were also observed at night during ORION99, ranging between 0.5 and 5.5 pptv, with a trend for decreasing concentrations as the night progressed. ${ }^{41}$ Although concentrations of alkenes were below detection limits, and so could not be responsible for $\mathrm{HO}_{2}$ production following their ozonolysis, significant concentrations of monoterpenes were observed. Model calculations of $\mathrm{HO}_{2}$ were slightly lower than observations on one night, but were lower by a factor of up to 4 on another night. DMS chemistry considered to contribute to the missing radical source in the model, but could not explain the full extent of the discrepancy. ${ }^{41}$

Kanaya et $a l .{ }^{41}$ discussed the difference in model results between Oki Island in $1998^{40}$ to those on Okinawa Island in 1999. ${ }^{41,138}$ Similar mixing ratios of water vapour and isoprene were observed during the two campaigns, and so the differences could not be attributed to chemistry involving $\mathrm{HO}_{2} \cdot \mathrm{H}_{2} \mathrm{O}$ complexes or chemistry of isoprene and its oxidation products (including glyoxal). The possibility of relatively high monoterpene emissions from the pine forests on Oki Island compared to Okinawa Island was cited as a potential source of the differences between the two sites, but no monoterpene measurements were made on Oki Island and no definitive conclusions could be made. ${ }^{41}$

Mixing ratios of $\mathrm{NO}_{x}$ during ORION99 were typically 200-400 pptv in the morning and 100-200 pptv in the afternoon, but did reach 3000 pptv at times. Peak NO mixing ratios on Oki Island were typically $700 \mathrm{pptv}$, and observed at around 0900 hours, and the differences in $\mathrm{NO}_{x}$ levels may offer some explanation as to the different model results. Moreover, there were significant differences in the concentrations of halogen species measured during the two campaigns. At Oki Island high concentrations of $\mathrm{Cl}_{2}{ }^{*}\left(=\mathrm{Cl}_{2}+\mathrm{HOCl}\right)$ and $\mathrm{Br}_{2}{ }^{*}$ $\left(=\mathrm{Br}_{2}+\mathrm{HOBr}\right)$ were observed by a tandem diffusion scrubber/ion chromatography system, whereas concentrations during ORION99 remained below the instrument's limit of detection. ${ }^{79}$ As stated by Kanaya et al.,${ }^{41}$ measurements of IO radicals at Mace Head in Ireland ${ }^{145,146}$ were predicted to influence $\mathrm{HO}_{2}$ concentrations through reactions (R15), (R16) and (R23), and it may be that the model discrepancies found for the experiments on Oki Island result from neglect of halogen chemistry in the model. ${ }^{41}$

$$
\begin{gathered}
\mathrm{HO}_{2}+\mathrm{XO} \rightarrow \mathrm{HOX}+\mathrm{O}_{2} \\
\mathrm{HOX}+h \nu \rightarrow \mathrm{OH}+\mathrm{X} \\
\mathrm{X}+\mathrm{O}_{3} \rightarrow \mathrm{XO}+\mathrm{O}_{2}
\end{gathered}
$$

Similarly to the Oki Island campaign, model calculations were not able to explain measurements of $\mathrm{HO}_{2}$ made on Rishiri Island, Japan, in June 2000 during the RISOTTO-2000 (Rishiri Island Study of Oxidants and Transport for Tropospheric Ozone 2000) campaign. ${ }^{6}$ Observed $\mathrm{HO}_{2}$ mixing ratios were approximately $10 \mathrm{pptv}$ at midday, but the model overestimated the observations by an average of $70 \%{ }^{6}$ Although no direct measurements of iodine species were made during the campaign, the site is host to a significant amount of brown seaweed (Laminaria japonica var. ochotensis), and organoiodides have been measured at several locations on Rishiri Island at other times. ${ }^{6}$

The effects of iodine chemistry on $\mathrm{HO}_{2}$ were investigated using a modified RACM chemistry scheme. ${ }^{6}$ In order to reproduce the midday observations of $\mathrm{HO}_{2}$ the model required $25 \mathrm{pptv}$ of $\mathrm{IO}$, although this was reduced to $12 \mathrm{pptv}$ of IO if the aerosol uptake coefficient for HOI $\left(\gamma_{\mathrm{HOI}}\right)$ was increased from $\gamma_{\mathrm{HOI}}=0$ to $\gamma_{\mathrm{HOI}}=0.5$. The model success was also observed to display some dependence on the total $\mathrm{NO}_{x}$ concentration, with greater model success at higher $\mathrm{NO}_{x}$ concentrations. ${ }^{6}$

In contrast to the daytime measurements during RISOTTO, the nighttime measurements of $\mathrm{HO}_{2}$ were underpredicted by the model. ${ }^{140}$ Mean mixing ratios of 4.2 pptv $\mathrm{HO}_{2}$ were observed at night, with temporal variations exhibiting a positive correlation with the sum of the concentrations of $\alpha$-pinene, $\beta$-pinene, camphene and limonene monoterpenes. ${ }^{140}$ Model calculations indicated that ozonolysis of monoterpenes represented the main nighttime radical source, but could still only reproduce the $\mathrm{HO}_{2}$ observations to within $58 \%$. Several explanations were put forward to explain the difference between the modelled and observed concentrations. The first was centred on possible misrepresentation of $\mathrm{RO}_{2}$ chemistry in the model, and recommendations were made for further laboratory work regarding the kinetics of $\mathrm{RO}_{2}+\mathrm{NO}$ reactions, particularly for large $\mathrm{RO}_{2}$ radicals such as those derived from monoterpenes. The second explanation discussed the potential for a systematic interference in the measured $\mathrm{HO}_{2}$ signal from $\mathrm{RO}_{2}$ radicals, and sensitivity calculations in which $5 \%$ of the modelled total $\mathrm{RO}_{2}$ concentration was added to the modelled $\mathrm{HO}_{2}$ concentration could rectify the model discrepancy for two out of the three nights on which measurements were made. In light of the more recent work by Fuchs et al., ${ }^{30}$ in which interferences in FAGE $\mathrm{HO}_{2}$ measurements from several alkene-derived $\mathrm{RO}_{2}$ radicals are reported, the potential for interferences from monoterpene-derived $\mathrm{RO}_{2}$ radicals should most certainly not be ruled out.

The third possible explanation related to the decreased model success at high $\mathrm{NO}_{2}$ concentrations, and it was suggested on the basis of work by Harrison et al. ${ }^{147}$ that reactions of $\mathrm{NO}_{2}$ with conjugated dienes might lead to radical production, or that the chemistry of $\mathrm{HO}_{2} \mathrm{NO}_{2}$ was not well represented in the model. The final possible explanation considered the contributions of ozonolysis of unmeasured species containing double bonds to $\mathrm{HO}_{2}$ production.

Further experiments on Rishiri Island in September 2003 also revealed positive correlations of $\mathrm{HO}_{x}$ with monoterpenes at night, and even stronger correlations between $\mathrm{HO}_{2}$ and the product of $\left[\mathrm{O}_{3}\right]$, [monoterpene] and $\phi_{\text {radical }}$, the total radical $\left(\mathrm{OH}, \mathrm{HO}_{2}\right.$ and $\left.\mathrm{RO}_{2}\right)$ yield from monoterpene ozonolysis. ${ }^{7}$ Model calculations were conducted for three nights during the campaign, with an overestimate of $\mathrm{HO}_{2}$ on two nights and an underestimate on another. The median modelled to observed ratio for $\mathrm{HO}_{2}$ for all three nights was 1.29 , dropping to 0.49 on the one night on which observations were underestimated. 
$\mathrm{OH}$ concentrations were typically underestimated, with a median modelled to observed ratio of 0.56 .

The model calculations indicated that monoterpene ozonolysis was the dominant nighttime radical source, and that $\mathrm{OH}$ loss was dominated by reactions with $\mathrm{CO}, \mathrm{CH}_{4}$ and monoterpenes. Loss of $\mathrm{HO}_{2}$ was found to be controlled by $\mathrm{O}_{3}, \mathrm{NO}$, $\mathrm{HO}_{2}$ and $\mathrm{RO}_{2}$, with $\mathrm{NO}$ thought to be present as a result of local soil emissions. Radical losses were controlled by peroxy radical cross-reactions.

Daytime measurements of $\mathrm{OH}$ and $\mathrm{HO}_{2}$ during the 2003 campaign on Rishiri Island, with daytime maxima of $2.7 \times$ $10^{6}$ molecule $\mathrm{cm}^{-3}$ for $\mathrm{OH}$ and $5.9 \mathrm{pptv}$ for $\mathrm{HO}_{2}$, were significantly overestimated by modelling using the RACM. For the 2003 campaign the model overestimated $\mathrm{OH}$ by an average of $35 \%$ and $\mathrm{HO}_{2}$ by an average of $89 \%,{ }^{7}$ compared to an underestimation of $\mathrm{OH}$ by $36 \%$ and an overestimation of $\mathrm{HO}_{2}$ by $70 \%$ during the 2000 campaign, although the $\mathrm{OH}$ measurements made in 2000 were subject to significantly larger uncertainties owing to a higher detection limit. ${ }^{6}$

The overestimation of $\mathrm{HO}_{2}$ was shown to be worse at low NO concentrations for both the 2000 and 2003 datasets, with a similar diurnal variation in the rate of the additional loss process required to rectify the modelled $\mathrm{HO}_{2}$ concentrations. ${ }^{7}$ Halogen chemistry, heterogeneous loss of $\mathrm{HO}_{2}$ to aerosol surfaces and the possibility of increased rates of $\mathrm{HO}_{2}+\mathrm{RO}_{2}$ reactions were considered as potential sources of the model discrepancy.

Reactions of $\mathrm{HO}_{2}$ with $\mathrm{RO}_{2}$ were found to be the dominant radical loss mechanism, but $\mathrm{HO}_{2}$ loss was dominated by reaction with $\mathrm{NO}$. An increase in the rates of $\mathrm{HO}_{2}+\mathrm{RO}_{2}$ reactions by a factor of 5 was required to replicate the observations during the day, but led to a significant underestimation of the measurements of $\mathrm{HO}_{2}$ at night. ${ }^{7}$ Uptake of $\mathrm{HO}_{2}$ onto aerosol particles could not fully explain the model discrepancies, with an uptake coefficient of unity required to reproduce the observations - a value much greater than reported by recent laboratory studies on atmospheric particles (e.g. Taketani et al., ${ }^{46,47}$ Thornton and Abbatt, ${ }^{148}$ Thornton et al., ${ }^{149}$ Macintyre and Evans ${ }^{150}$ ). In order to replicate the observed $\mathrm{HO}_{2}$ concentrations model calculations required 25 pptv of IO radicals, but measurements of organoiodides were unable to support such high IO mixing ratios, with similar results found for $\mathrm{BrO}^{7}$ Therefore, unless significant inorganic sources of $\mathrm{IO}$ and $\mathrm{BrO}$ were present, the inclusion of halogen chemistry in the model could not fully explain the $\mathrm{HO}_{2}$ observations. No single hypothesis was found which could fully explain the observed concentrations. ${ }^{7}$ It should be noted that IO concentrations at the levels required have been observed using the in situ LIF technique at other coastal locations with significant seaweed beds that are exposed at low tide, ${ }^{44,45}$ and by cavity ringdown spectroscopy. ${ }^{151}$

Identifying the role of halogen chemistry in the marine boundary layer, and its impact on $\mathrm{HO}_{x}$, was one of the main aims of the NAMBLEX (North Atlantic Marine Boundary Layer Experiment) campaign which took place from 23rd July to 4th September 2002 in Mace Head, Ireland. ${ }^{3-5,152,153}$ A comprehensive suite of chemical species and meteorological parameters were measured during NAMBLEX, with measurements of those species required to constrain zero-dimensional box models used to investigate $\mathrm{HO}_{x}$ chemistry co-located at the shore site so that differences in air mass composition could not be a valid reason to explain poor agreement between observed and modelled radical concentrations. ${ }^{152}$

Measurements of $\mathrm{BrO}, \mathrm{IO}, \mathrm{OIO}$ and $\mathrm{I}_{2}$ were made by DOAS $^{154}$ and OIO and $I_{2}$ by broadband cavity ringdown spectroscopy (BBCRDS), ${ }^{155}$ and NAMBLEX represents the first real-time in situ measurements of $\mathrm{I}_{2}$ in the atmosphere, and $\mathrm{BrO}$ in the marine boundary layer. Maximum IO mixing ratios of 4 pptv were recorded over a week from the 15 th to the 21st of August, and $\mathrm{BrO}$ was measured over six days with a maximum mixing ratio of 6.5 pptv and a mean of 2.3 pptv. ${ }^{154}$

$\mathrm{OH}$ and $\mathrm{HO}_{2}$ were measured by the Leeds FAGE group, with local solar noon concentrations of (3-8) $\times 10^{6}$ molecule $\mathrm{cm}^{-3}$ for $\mathrm{OH}$ and $(0.9-2.1) \times 10^{8}$ molecule $\mathrm{cm}^{-3}$ (3.5-8.2 pptv) for $\mathrm{HO}_{2} \cdot{ }^{4}$ Significant concentrations of $\mathrm{HO}_{2}$ were also observed at night, in the range $(2-3) \times 10^{7}$ molecule $\mathrm{cm}^{-3}$. $\mathrm{OH}$ concentrations at night remained below the instrumental limit of detection $\left(6 \times 10^{4}\right.$ molecule $\left.\mathrm{cm}^{-3}\right)$.

Steady state calculations for $\mathrm{OH}$ gave a diurnally averaged calculated to observed ratio of $1.04 \pm 0.36$, and the ratio displayed a distinct diurnal variation, being less than 1 in the early morning and late afternoon and greater than 1 around noon. ${ }^{4}$ Equivalent steady state calculations for $\mathrm{HO}_{2}$ gave a mean calculated to observed ratio of $3.22 \pm 0.69$, which could be reduced to $1.87 \pm 0.61$ by including loss of $\mathrm{HO}_{2}$ to $\mathrm{IO}$ and aerosol surfaces, and reduced further still by increasing the IO concentration to account for possible non-uniform distribution of iodine species in the DOAS light path. ${ }^{4}$

Bloss et al. ${ }^{3}$ used measurements made during NAMBLEX to investigate the impact of $\mathrm{IO}$ on $\mathrm{HO}_{x}$ by calculating the rate of loss of $\mathrm{HO}_{2}$ to $\mathrm{HO}_{2}, \mathrm{CH}_{3} \mathrm{O}_{2}, \mathrm{NO}, \mathrm{O}_{3}$, IO and aerosol (using $\gamma_{\mathrm{HO}_{2}}=0.2$ ), and the rate of $\mathrm{OH}$ production from photolysis of ozone and $\mathrm{HOI}$, and reactions of $\mathrm{HO}_{2}$ with $\mathrm{O}_{3}$ and NO. Fig. 6 shows the results from these calculations, indicating that the reaction between $\mathrm{HO}_{2}$ and the spatially averaged DOAS IO measurements could represent $40 \%$ of the total $\mathrm{HO}_{2}$ removal rate, and that HOI photolysis could comprise up to $15 \%$ of the total $\mathrm{OH}$ production at midday. ${ }^{3}$

A full modelling analysis using the MCM (v3.1) in a box model framework was conducted by Sommariva et al., ${ }^{5,153}$ concentrating on periods characterised by 'clean' conditions

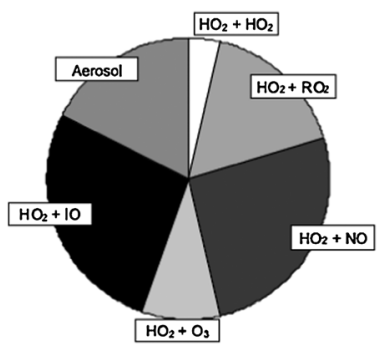

(a) Loss of $\mathrm{HO}_{2}$

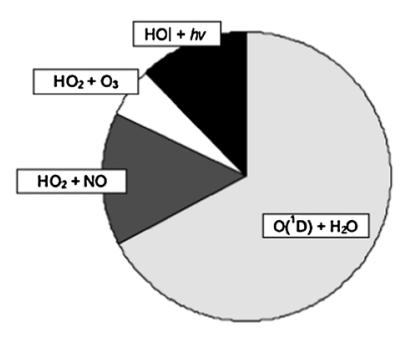

(b) Formation of $\mathrm{OH}$
Fig. 6 Processes contributing to (a) removal of $\mathrm{HO}_{2}$ and (b) production of $\mathrm{OH}$ during the NAMBLEX campaign in Mace Head, showing the impact of iodine species. (Reproduced from ref. 3, Copyright (2005) American Geophysical Union. Reproduced by permission of American Geophysical Union. Further reproduction or electronic distribution is not permitted.) 
( $<30$ pptv NO and 60-80 pptv $\mathrm{NO}_{2}$ ). Model calculations were conducted with varying levels of chemical complexity, to investigate the impacts of a range of VOCs, oxygenated VOCs (oVOCs), peroxides, halogen chemistry and heterogeneous uptake on the simulated concentrations of $\mathrm{OH}$ and $\mathrm{HO}_{2}{ }^{5}$

Fig. 7 shows the observed and modelled $\mathrm{OH}$ concentrations during NAMBLEX. ${ }^{5}$ Modelled concentrations of $\mathrm{OH}$ were generally within $25 \%$ of the measured concentrations. Similarities between the 'clean' base model run, constrained to a limited number of VOCs, and the 'full' base model run, constrained to a wider range of VOCs, were attributed to the dominance of $\mathrm{CO}, \mathrm{CH}_{4}$ and $\mathrm{H}_{2}$ in the $\mathrm{OH}$ loss processes. The largest discrepancy between the 'clean' and 'full' base models was observed during a period characterised by high isoprene concentrations. Inclusion of oxygenated species represented a net sink for $\mathrm{OH}$, despite their photolysis leading to $\mathrm{OH}$ production. In general, inclusion of oVOCs led to improvements in the model simulations for $\mathrm{OH}$, indicating the importance of these species in understanding the radical budgets.

While modelled concentrations of $\mathrm{HO}_{2}$ were also similar for the 'clean' and 'full' base model runs, the modelled concentrations were significantly higher than the observations, with an overestimation on some days by at least a factor of 2 . As noted by Sommariva et al., ${ }^{5}$ model overestimation of $\mathrm{HO}_{2}$ observations is a common feature of studies in the marine boundary layer, suggesting that an important part of the chemistry in these regions is either missing or poorly implemented. The simultaneous measurement of halogen oxides and $\mathrm{HO}_{2}$ during NAMBLEX was a significant advance and enabled investigation of the impacts of $\mathrm{IO}$ and $\mathrm{BrO}$ on the modelled $\mathrm{HO}_{2}$ concentrations. Observations of $\mathrm{IO}$ and $\mathrm{BrO}$ were made by the DOAS technique, and, owing to the different spectral windows required to observe the two species, only one of the two could be measured at any one time. Inclusion of halogen oxide chemistry and heterogeneous chemistry generally had little
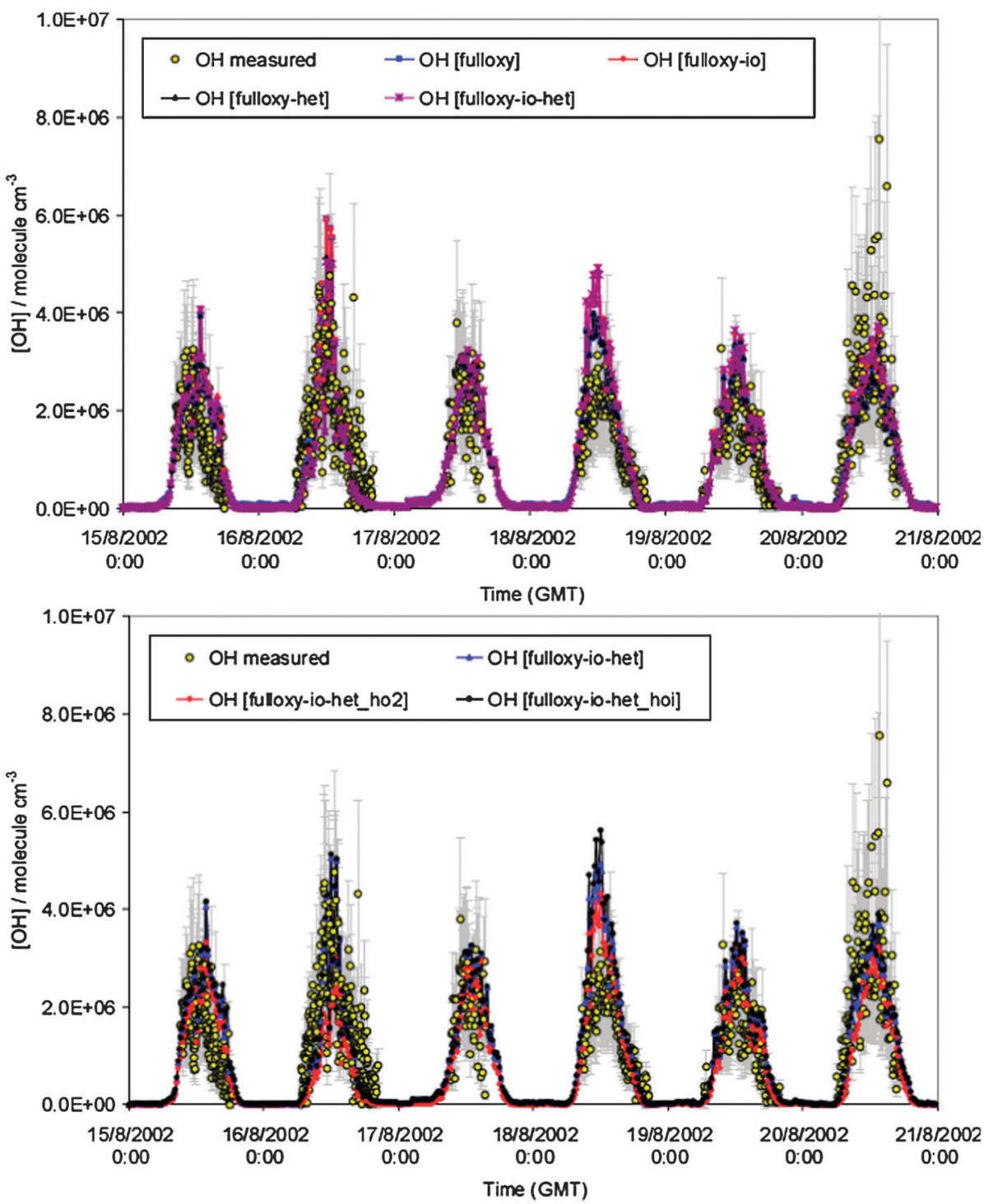

Fig. 7 Observed and modelled $\mathrm{OH}$ concentrations during the NAMBLEX campaign in Mace Head in 2002 using varying levels of model complexity (fulloxy $=$ inclusion of oxygenate measurement constraints; io $=$ inclusion of halogen measurement constraints; het $=$ inclusion of heterogeneous aerosol loss process). (Reproduced from ref. 5, Copyright (2006), with permission from Copernicus Publications.) 
impact on the modelled $\mathrm{OH}$ concentrations, with a maximum increase of $15 \%$ in $\mathrm{OH}$ owing to photolysis of HOI if DOAS measured IO levels ${ }^{154}$ were used. Modelled $\mathrm{HO}_{2}$ concentrations were decreased by up to $30 \%$, insufficient to fully explain the model discrepancy, and were highly dependent on aerosol uptake coefficients for $\mathrm{HO}_{2}, \mathrm{HOI}$ and $\mathrm{HOBr}$. Using the theoretical maximum value of $\gamma_{\mathrm{HO}_{2}}=1$ generally gave good agreement with the measured $\mathrm{HO}_{2}$ concentrations, and led to a model underestimate of up to $50 \%$ on one day. However, such high values of $\gamma_{\mathrm{HO}_{2}}$ are not consistent with laboratory data, and are highly unlikely.

While the observed mixing ratios of $\mathrm{IO}$ and $\mathrm{BrO}$ were insufficient to explain the model discrepancy for $\mathrm{HO}_{2}$ during NAMBLEX, and were much lower than the 25 pptv of IO required by Kanaya et al. ${ }^{6}$ to improve their model simulations for the Rishiri Island campaign, it should be noted that the DOAS technique measures an average concentration over the long path length of the light beam. More recent work at Mace Head, comparing IO measurements made by DOAS with in situ point measurements using LIF, has shown that significant inhomogeneities exist in IO concentrations in intertidal regions. ${ }^{45}$ Commane et al. ${ }^{45}$ showed similarities in the temporal trends of IO measurements by DOAS and LIF, but reported point measurements of up to $50 \mathrm{pptv}$, and generally 6-10 times greater than the spatially averaged observations made by the DOAS instrument. Consideration of such factors may make a significant difference in the assessment of in situ point measurements of $\mathrm{OH}$ and $\mathrm{HO}_{2}$, particularly if the halogen source region is heterogeneous in nature.

Sommariva et al. ${ }^{153}$ also investigated the nighttime radical chemistry during NAMBLEX, attempting to explain the $(2-3) \times 10^{7}$ molecule $\mathrm{cm}^{-3} \mathrm{HO}_{2}$ observed at night during the campaign. The model was able to reproduce the $\mathrm{HO}_{2}$ observations to within the combined uncertainties of the model and measurements $(30-40 \%)$, and showed the dominant radical sources at night to be reactions of ozone with light alkenes. The model calculations indicated that alkene ozonolysis chemistry resulted in a slow but steady source of nighttime radicals, and that cycling between $\mathrm{OH}$ and $\mathrm{HO}_{2}$ was maintained by low concentrations of NO. In addition, loss of radicals was limited by their slow removal through $\mathrm{RO}_{2}+$ $\mathrm{RO}_{2}$ reactions, leading to only small decreases in the total radical concentrations overnight.

The NAMBLEX campaign was followed by a series of field measurements at the Cape Verde Atmospheric Observatory in the tropical North Atlantic in May and June 2007 in the RHaMBLe (Reactive Halogens in the Marine Boundary Layer) campaign and the Seasonal Oxidant Study (SOS) throughout 2009 to investigate the roles of halogen species in the tropical marine boundary layer. ${ }^{156,157}$

Observations of $\mathrm{IO}$ and $\mathrm{BrO}$ were made by the DOAS technique, and measurements made between November 2006 and June 2007 at the observatory displayed diurnal cycles dependent on solar radiation, with mean daytime maxima of $1.4 \pm 0.8$ pptv IO and $2.5 \pm 1.1$ pptv BrO..$^{42,43}$ The presence of the halogen monoxides at such levels was shown to result in extensive destruction of boundary layer ozone in the region. ${ }^{43}$

The impact of halogen monoxides on $\mathrm{OH}$ and $\mathrm{HO}_{2}$ budgets during RHaMBLe was assessed by Whalley et al..$^{70}$ Maximum midday concentrations of $9 \times 10^{6}$ molecule $\mathrm{cm}^{-3} \mathrm{OH}$ and $6 \times$ $10^{8}$ molecule $\mathrm{cm}^{-3}$ ( $\left.\sim 25 \mathrm{pptv}\right) \mathrm{HO}_{2}$ were observed during the campaign, and a box model with MCM chemistry extended to include halogen chemistry and heterogeneous loss processes was used to interpret the observations. ${ }^{70}$ Towards the start of the campaign, when $\mathrm{HCHO}$ mixing ratios were significantly higher than the mean value used to constrain the model (2 ppbv compared to the mean of $328 \mathrm{pptv}$ ), the model underpredicted $\mathrm{HO}_{2}$ by $39 \%$. For the remainder of the campaign, the model was able to reproduce the daytime $\mathrm{OH}$ and $\mathrm{HO}_{2}$ observations to within the measurement uncertainty of $20 \%$ when halogen chemistry and heterogeneous losses for $\mathrm{HO}_{2}$ were considered. ${ }^{70}$ Nighttime measurements of $\mathrm{HO}_{2}$, made on two nights during the RHaMBLe campaign, were significantly underpredicted by the model, with nighttime $\mathrm{HO}_{x}$ production from alkene ozonolysis reactions, particularly of propene $(72 \%)$ and isoprene and its oxidation products $(25 \%)$. Radical production following reactions of $\mathrm{NO}_{3}$ with alkenes was not thought to be important during the campaign. ${ }^{70}$

Production of $\mathrm{OH}$ during the day occurred primarily as a result of $\mathrm{O}_{3}$ photolysis $(76 \%$ of the total at noon), with photolysis of $\mathrm{HOBr}$ and $\mathrm{HOI}$ combined contributing an additional $13 \%$ to the instantaneous $\mathrm{OH}$ production. Loss of $\mathrm{OH}$ was dominated by its reactions with $\mathrm{CO}(28 \%)$ and acetaldehyde $(25 \%)$, with $\mathrm{HO}_{2}$ production principally achieved through $\mathrm{OH}+\mathrm{CO}(41 \%)$ and $\mathrm{CH}_{3} \mathrm{O}+\mathrm{O}_{2}(16 \%)$. At the concentrations of $\mathrm{BrO}$ and $\mathrm{IO}$ observed during $2007,{ }^{42,43}$ the reactions of $\mathrm{BrO}$ and $\mathrm{IO}$ were found to constitute approximately $19 \%$ of the instantaneous sink for $\mathrm{HO}_{2}$, while aerosol uptake (using $\gamma_{\mathrm{HO}_{2}}=0.1$ ) and surface deposition comprised a further $23 \%$ of the noontime $\mathrm{HO}_{2}$ loss. ${ }^{70}$ It was estimated that the $\mathrm{OH}$ concentrations were $9 \%$ higher overall owing to the presence of halogens, leading to a $9 \%$ decrease in the local methane lifetime. ${ }^{70}$

In 2009, seasonal measurements of $\mathrm{OH}$ and $\mathrm{HO}_{2}$ were made at the Cape Verde Atmospheric Observatory during the Seasonal Oxidant Study. ${ }^{15,157}$ The observed concentrations were found to be higher in the summer months (June and September), with maximum daytime concentrations of $9 \times$ $10^{6}$ molecule $\mathrm{cm}^{-3} \mathrm{OH}$ and $4 \times 10^{8}$ molecule $\mathrm{cm}^{-3} \mathrm{HO}_{2}$, similar to those observed at the site in $2007,,^{70}$ and almost double the concentrations observed in winter (late February, early March). ${ }^{15}$

Analysis of the $\mathrm{OH}$ and $\mathrm{HO}_{2}$ variance throughout the 2009 campaign indicated that approximately $70 \%$ of the total variance could be explained by diurnal behaviour, with the remaining $30 \%$ being due to changes in air mass. ${ }^{15}$

In contrast to the predominant marine influence at the Cape Verde site, the DOMINO (Diel Oxidant Mechanisms in relation to Nitrogen Oxides) campaign on the Atlantic coast of southern Spain in 2008 was characterised by air masses from urban and industrial regions as well as those with marine origins. ${ }^{158}$ Although significant interferences in $\mathrm{OH}$, and potentially $\mathrm{HO}_{2}$, were reported, observations of $\mathrm{OH}, \mathrm{HO}_{2}$ and $\mathrm{OH}$ reactivity were greater in air masses originating from continental regions than marine regions, with observations of $\mathrm{HO}_{2}$ in air masses originating from continental regions typically twice those in air masses originating from the ocean. ${ }^{158}$ Modelling of the boundary layer dynamics during DOMINO, 
coupled to chemical reaction schemes including MOZART (Model for Ozone And Related chemical Tracers) and a reduced chemical scheme, underpredicted $\mathrm{OH}$ using the MOZART scheme and gave a reasonable $\mathrm{OH}$ simulation with the reduced scheme, although the potential intereferences in $\mathrm{OH}$ were not accounted for. ${ }^{159}$

\subsection{Aircraft campaigns}

Our understanding of atmospheric chemistry has been greatly enhanced by aircraft measurements of composition. The ability to investigate regional scale composition, and to study differences in composition as a function of altitude and age of airmass, and between marine and continental regions is a significant advantage of aircraft studies. In this section we concentrate on aircraft campaigns in marine regions (Table 2), but also discuss briefly some measurements over continental regions, as both are often sampled within the same flight or campaign. Continental aircraft studies are also discussed in the appropriate sections below.

Several studies using the NASA P3B and DC8 aircraft have been directed towards investigation of $\mathrm{HO}_{x}$ chemistry over the USA, and of the impact of pollution from Asia on composition over the USA. The SUCCESS (Subsonic aircraft: Contrails and Clouds Effect Special Study) mission in 1996 made aircraft measurements of $\mathrm{OH}$ and $\mathrm{HO}_{2}$ throughout the troposphere and lower stratosphere over the USA onboard the NASA DC8 aircraft with the ATHOS-FAGE instrument. ${ }^{160}$ The campaign was largely concerned with the effects of clouds and contrails on $\mathrm{HO}_{x}$ radicals, and reported midday values of $\mathrm{OH}$ in the range $0.1-0.5$ pptv and $\mathrm{HO}_{2}$ in the range $3-15$ pptv. ${ }^{160}$ Steady state box model calculations were able to reproduce the observations at times, but at other times the observations were more than a factor of 4 greater than the modelled concentrations, possibly as a result of unmeasured $\mathrm{HO}_{x}$ sources transported from Asia. ${ }^{160}$

Results from box model calculations investigating $\mathrm{HO}_{x}$ chemistry between 8 and $12.5 \mathrm{~km}$ in altitude indicated that the most significant discrepancies between the model and the observations were found to occur in the outflow of a convective storm, and could be explained by the convective injection of peroxides and formaldehyde from the boundary layer into the upper troposphere. ${ }^{161}$ The results from SUCCESS indicate that local convection was a major source of $\mathrm{HO}_{x}$ (and $\mathrm{NO}_{x}$ ) to the upper troposphere over the central USA, and that high $\mathrm{HO}_{x}$ concentrations in the upper troposphere stimulate ozone production and increase the sensitivity of ozone to $\mathrm{NO}_{x}$ emissions. ${ }^{161}$

Impacts of aircraft $\mathrm{NO}_{x}$ emissions on chemistry in the free troposphere and lower stratosphere were investigated in the SONEX (Subsonic assessment, Ozone and Nitrogen oxide Experiment) campaign in 1997, during which measurements were made onboard the NASA DC8 aircraft in and out of the North Atlantic aircraft corridor. ${ }^{160}$ Diurnal steady state box model calculations were generally able to reproduce the observed $\mathrm{HO}_{x}$ concentrations, but did display a tendency for underestimation at low NO concentrations and sunrise and overestimation at higher NO and inside cirrus clouds. ${ }^{160-162}$ Heterogeneous conversion of $\mathrm{NO}_{2}$ to $\mathrm{HONO}$ on aerosols during the night, followed by photolysis of HONO, could partially explain the discrepancy at sunrise, as could uncertainties in the kinetics of $\mathrm{HO}_{2} \mathrm{NO}_{2}$ production and loss, while heterogeneous loss of $\mathrm{HO}_{2}$ to aerosols and ice crystals improved the simulations inside cirrus clouds. ${ }^{160-162}$ Model discrepancies at high $\mathrm{NO}_{x}$ concentrations were attributed to the possibility of unmeasured $\mathrm{HO}_{x}$ precursors, potentially resulting from recent convective events. ${ }^{160-162}$

Jaegle et al. ${ }^{163}$ used the SUCCESS and SONEX data, together with data from the STRAT (Stratospheric TRacers of Atmospheric Transport) campaign (not discussed here owing to its focus on stratospheric chemistry) to provide a framework for understanding $\mathrm{HO}_{x}$ chemistry in the upper troposphere. This analysis showed that primary production of $\mathrm{HO}_{x}$ in the upper troposphere is dominated by $\mathrm{O}\left({ }^{1} \mathrm{D}\right)+\mathrm{H}_{2} \mathrm{O}$ at mixing ratios of $\mathrm{H}_{2} \mathrm{O}$ above 100 ppmv, with photolysis of acetone and possibly other convected $\mathrm{HO}_{x}$ precursors dominating under drier conditions. Methane oxidation was shown to amplify the primary $\mathrm{HO}_{x}$ sources in the upper troposphere by a factor of 1.1 to $1.9 .{ }^{163}$

Results from the NASA Pacific Exploratory Missions (PEM) over the South Pacific in spring 1996 (PEM-Tropics A) and autumn 1999 (PEM-Tropics B) also indicated that species such as $\mathrm{H}_{2} \mathrm{O}_{2}, \mathrm{CH}_{3} \mathrm{OOH}, \mathrm{CH}_{3} \mathrm{O}_{2}$ and $\mathrm{HCHO}$ represent important sources of $\mathrm{HO}_{x}$ in the upper troposphere, and that inclusion of constraints on these species in model simulations leads to increased $\mathrm{HO}_{x}$ concentrations. ${ }^{164}$ Below altitudes of $11 \mathrm{~km}$, inclusion of acetone and $\mathrm{CH}_{3} \mathrm{OOH}$ led to the greatest increase in modelled $\mathrm{HO}_{x}$ concentrations, while $\mathrm{H}_{2} \mathrm{O}_{2}$ was found to be more important at altitudes between 11 and $12 \mathrm{~km} .{ }^{164}$

Model calculations for altitudes between 8 and $12 \mathrm{~km}$ during the PEM-Tropics B campaign were able to capture $80 \%$ of the variance in the observed $\mathrm{HO}_{2}$ concentrations, with a median simulated to observed ratio of 1.1 , but only $38 \%$ of the variance in the observed $\mathrm{OH}$, with a median simulated to observed ratio of $0.86 .{ }^{165}$ This work showed that the primary sources of $\mathrm{HO}_{x}$ were $\mathrm{O}\left({ }^{1} \mathrm{D}\right)+\mathrm{H}_{2} \mathrm{O}$ and photolysis of acetone, with the contribution from acetone becoming more significant under drier conditions. However, it should be noted that subsequent measurements of the temperature dependence of acetone photolysis quantum yields ${ }^{166}$ indicate that the contribution of acetone photolysis to $\mathrm{HO}_{x}$ production in the upper troposphere is lower than suggested by model calculations based on room temperature measurements of acetone photolysis quantum yields. ${ }^{167,168}$

Photolysis of convected $\mathrm{CH}_{3} \mathrm{OOH}$ has been shown to be important over the Southern Pacific Convergence Zone (SPCZ), representing between 22 and $64 \%$ of the total primary source in this region. ${ }^{165}$ In addition, analysis of data from a single flight during the PEM-Tropics B campaign has also highlighted the importance of convected $\mathrm{CH}_{3} \mathrm{OOH}$ in the upper troposphere. ${ }^{169}$ The flight in question followed a backand-forth pattern at a constant altitude of $10 \mathrm{~km}$ for 4 hours, sampling both the background atmosphere and an aged convective outflow. Compared to the background concentrations, $\mathrm{HO}_{2}$ and $\mathrm{CH}_{3} \mathrm{OOH}$ were $50 \%$ and $350 \%$ higher in the convective outflow. Box model calculations indicated that $\mathrm{CH}_{3} \mathrm{OOH}$ photolysis was responsible for the elevated $\mathrm{HO}_{2}$ concentrations, and the model was able to reproduce the $\mathrm{HO}_{2}$ 


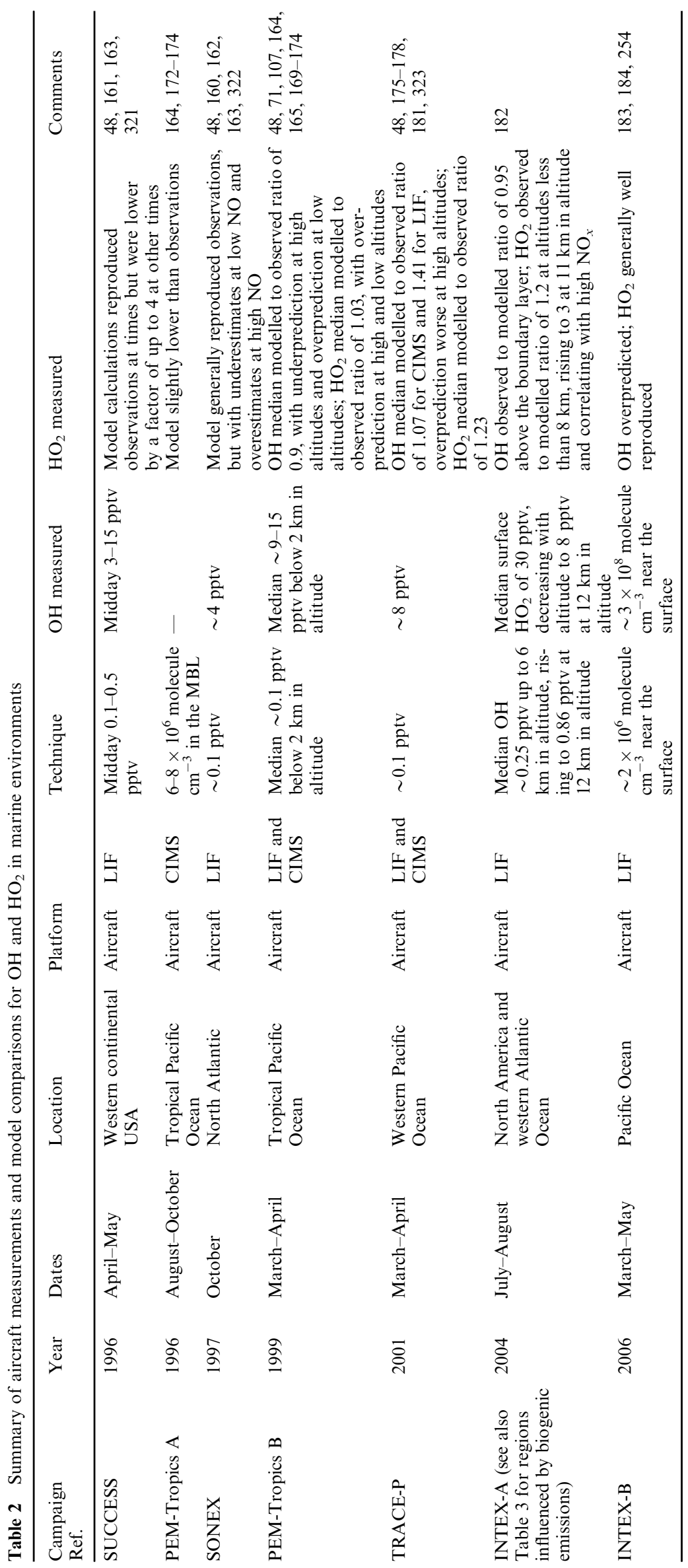


observations when constrained to $\mathrm{CH}_{3} \mathrm{OOH}$. No increase in $\mathrm{OH}$ concentration was observed in the convective outflow, attributed to the reaction between $\mathrm{OH}$ and $\mathrm{CH}_{3} \mathrm{OOH} .{ }^{169}$ Sensitivity analysis of the model indicated that the rate coefficient used in the model for reaction between $\mathrm{HO}_{2}$ and $\mathrm{CH}_{3} \mathrm{O}_{2}$ may be a factor of 3 too low at the low temperatures of the upper troposphere, and that this reaction may represent the single most important loss pathway for $\mathrm{HO}_{x}$ in the upper troposphere. ${ }^{169}$

Investigation of the full dataset for the PEM-Tropics B campaign for the DC8 aircraft, on which $\mathrm{OH}$ and $\mathrm{HO}_{2}$ were measured by the ATHOS-FAGE instrument, revealed that box model calculations were generally able to reproduce the observations, with mean modelled to observed ratios of 0.86 for $\mathrm{OH}$ and 1.03 for $\mathrm{HO}_{2}{ }^{71}$ However, the model calculations had a tendency to underpredict $\mathrm{OH}$ at higher altitudes and overpredict at lower altitudes, ${ }^{71,170}$ and to overpredict $\mathrm{HO}_{2}$ at the extremes of altitude, with no obvious geographical bias. ${ }^{71}$

Production of $\mathrm{OH}$ at altitudes below $7 \mathrm{~km}$ was dominated by $\mathrm{O}\left({ }^{1} \mathrm{D}\right)+\mathrm{H}_{2} \mathrm{O} .{ }^{71}$ As discussed above, $\mathrm{OH}$ production from photolysis peroxides became more important at higher altitudes, with peroxides contributing as much as $20 \%$ of the total production even at low altitudes and reaching $80 \%$ in some regions at high altitudes. ${ }^{71}$ Such large contributions from peroxides result from the partitioning of $\mathrm{HO}_{x}$ towards $\mathrm{HO}_{2}$ at the low $\mathrm{NO}_{x}$ concentrations encountered during the campaign. ${ }^{71} \mathrm{NO}$ concentrations typically increased with altitude and loss of $\mathrm{HO}_{2}$ was dominated by peroxide formation and conversion to $\mathrm{OH}$ by $\mathrm{NO}$, while loss of $\mathrm{OH}$ was dominated by reaction with $\mathrm{CO}, \mathrm{CH}_{4}, \mathrm{HCHO}$, acetone, ethane, propane and peroxides. $^{71}$

$\mathrm{OH}$ measurements were also made onboard the NASA P3B aircraft by CIMS during PEM-Tropics B. ${ }^{171}$ An intercomparison between the two datasets involving normalisation of the measurements with box models run for each aircraft's flighttrack reported agreement within approximately $10 \%$ and did not find any clear measurement discrepancies, although the P3B data was generally higher at lower altitudes and the DC8 was generally higher at higher altitudes. ${ }^{107,172}$ The largest discrepancy between the model and the $\mathrm{OH}$ P3B observations was found at the highest altitude, and although the model displayed a tendency to overestimate the observed concentrations the modelled concentrations were well within the uncertainties of the measurements or model inputs. ${ }^{171}$

The P3B flights provided measurements of $\mathrm{OH}$ in the vicinity of Tahiti $\left(17^{\circ}-22^{\circ} \mathrm{S}\right)$ and Christmas Island $\left(0^{\circ}-3^{\circ} \mathrm{N}\right)$, where average midday boundary layer concentrations of $7-8 \times 10^{6}$ molecule $\mathrm{cm}^{-3}$ and 6-7 $610^{6}$ molecule $\mathrm{cm}^{-3}$ were observed respectively. ${ }^{171}$ Measurements of $\mathrm{OH}$ were also made near Christmas Island by the CIMS instrument onboard the P3B aircraft during the PEM-Tropics A campaign. ${ }^{173}$

In the PEM-Tropics A work, an air mass was sampled in a Lagrangian mode over the course of a day and model calculations were conducted using both a time dependent box model, used to simulate the large scale diurnal variations of $\mathrm{O}_{3}, \mathrm{H}_{2} \mathrm{O}_{2}$, $\mathrm{CH}_{3} \mathrm{OOH}, \mathrm{HCHO}$ and $\mathrm{OH}$, and a photostationary state model, constrained to long-lived species at the specific times and sampling locations during the flight. ${ }^{173}$ The two model approaches were in good agreement with each other (regression analysis giving a slope of 1.18 and $r^{2}=0.91$ ), and were only slightly lower than the observations. ${ }^{173}$ The dominant process responsible for $\mathrm{HO}_{x}$ production was $\mathrm{O}\left({ }^{1} \mathrm{D}\right)+$ $\mathrm{H}_{2} \mathrm{O}(80 \%)$, with photolysis of $\mathrm{H}_{2} \mathrm{O}_{2}$ and $\mathrm{CH}_{3} \mathrm{OOH}$ each contributing an additional $10 \%$. Removal of $\mathrm{HO}_{x}$ radicals was dominated by $\mathrm{CH}_{4}$ chemistry ( $53 \%$ ), followed by production of $\mathrm{H}_{2} \mathrm{O}_{2}$ from $\mathrm{HO}_{2}+\mathrm{HO}_{2}(39 \%)$ and $\mathrm{OH}+\mathrm{HO}_{2}(8 \%){ }^{173}$

Seasonal differences in $\mathrm{HO}_{x}$ chemistry between the PEMTropics A (spring 1996) and PEM-Tropics B (autumn 1999) campaigns were investigated by Olson et al. ${ }^{174}$ using the DC8 data to constrain a photochemical box model. Although $\mathrm{OH}$ and $\mathrm{HO}_{2}$ were not measured during PEM-Tropics A, comparison between modelled and observed concentrations for the PEM-Tropics B data revealed similar results to those described above, with median modelled to observed ratios of 0.91 for $\mathrm{OH}$ and 1.03 for $\mathrm{HO}_{2}$, displaying a tendency for overprediction of $\mathrm{HO}_{2}$ at low and high altitudes. ${ }^{174}$

The predicted concentrations of $\mathrm{OH}$ and $\mathrm{HO}_{2}$ for each campaign showed that the $\mathrm{HO}_{x}$ concentrations were expected to be higher during spring 1996 (PEM-Tropics A) than autumn 1999 (PEM-Tropics B). ${ }^{174}$ While much of these differences reflect seasonal dependence of the primary production of $\mathrm{OH}$ from $\mathrm{O}\left({ }^{1} \mathrm{D}\right)+\mathrm{H}_{2} \mathrm{O}$, in regions such as the middle troposphere in the tropics where high $\mathrm{NO}_{x}$ concentrations were observed during PEM-Tropics A, there is an additional contribution to $\mathrm{OH}$ production from $\mathrm{HO}_{x}$ recycling involving NO. ${ }^{174}$

The combined dataset for the PEM-Tropics campaigns also enabled construction of a geographical grid describing $\mathrm{OH}$ distributions as a function of latitude and altitude. ${ }^{172} \mathrm{~A}$ scaling algorithm was used to convert the $\mathrm{OH}$ observations to an equivalent high-noon value, enabling more robust comparisons to be made between different locations. ${ }^{172}$ On average the box model calculations agreed with the observed $\mathrm{OH}$ concentrations to within a factor of 1.5 , but model results were systematically lower than the observations at higher altitudes with similar results obtained to those described previously. ${ }^{172}$ A three-dimensional model analysis was also conducted, with good agreement reported between the 3D model and the box model, and hence between the 3D model and the observations. ${ }^{172}$

Aircraft experiments involving both the NASA DC8 and P3B aircraft were also conducted over the Pacific Ocean during the TRACE-P (TRansport and Chemical Evolution over the Pacific) campaign in spring 2001. ${ }^{175-177}$ Measurements of $\mathrm{OH}$ and $\mathrm{HO}_{2}$ were made using the ATHOS-FAGE instrument onboard the DC8 aircraft, with measurements on the P3B aircraft made by CIMS for OH and a PerCIMS for the sum of peroxy radicals $\left(\mathrm{HO}_{2}+\Sigma \mathrm{RO}_{2}\right) .{ }^{175-177}$ Comparisons between the two $\mathrm{OH}$ measurements during periods when the two aircraft were within $1 \mathrm{~km}$ or less of each other revealed a correlation between the measurements with a slope of 1.58 (P3B-CIMS vs. DC8-FAGE) and $r^{2}=0.88$, and owing to the short lifetime of $\mathrm{OH}$ and strong dependence on local conditions the differences between the measurements could well reflect real differences in composition. ${ }^{175}$ Similarly, comparisons between the $\mathrm{HO}_{2}$ and $\mathrm{HO}_{2}+\Sigma \mathrm{RO}_{2}$ measurements showed good agreement during some periods but not at others, but do not necessarily indicate instrumental problems. $^{177}$ 
A box model focused on the P3B OH data gave a slope of 0.85 in a regression analysis of the measured $\mathrm{OH}$ against the modelled $\mathrm{OH}$, indicating a trend towards overprediction by the model. ${ }^{176}$ However, at sea level the model had a tendency to underestimate $\mathrm{OH}$, with an average measured to modelled ratio of $\sim 1.5$. At an altitude of approximately $0.8 \mathrm{~km}$, a measured to modelled ratio of 1 was observed, with higher altitudes $(>2 \mathrm{~km})$ having a ratio around 0.8 and dominating the overall trend. ${ }^{176}$

A subsequent study presenting an analysis of the P3B and DC8 data within an identical box model framework, thus allowing for more direct comparisons between the two datasets, gave a median modelled to observed ratio of 1.07 for the P3B OH data and 1.41 for the DC8 OH data. ${ }^{178}$ The modelled to measured ratios for $\mathrm{OH}$ displayed a clear trend with altitude, ${ }^{178}$ with similar results for the P3B data to those reported previously. ${ }^{176}$ The model overprediction of the DC8 data was observed to increase from $7 \%$ at altitudes below $1 \mathrm{~km}$ to $60 \%$ in the middle troposphere and reaching $80 \%$ at higher altitudes. ${ }^{178}$

During analysis of the TRACE-P dataset it was noted ${ }^{176}$ that the average modelled to measured ratios of $\mathrm{OH}$ for the TRACE-P and PEM-Tropics experiments over the Pacific Ocean were generally lower than the values obtained over more continental regions such as Mace Head, ${ }^{124}$ Greece ${ }^{179}$ and forested regions of the US. ${ }^{180}$ It was proposed that air masses over continental regions would contain a greater number of unmeasured VOCs, contributing to $\mathrm{OH}$ loss but not included in the model studies, which would be oxidised during the time required for the air masses to reach the regions of continental outflow investigated during the Pacific Ocean experiments. ${ }^{176}$

The median modelled to observed ratios for the TRACE-P DC8 $\mathrm{HO}_{2}$ data was 1.23 , and although there was in general no clear trend with altitude, elevated ratios at lower to middle altitudes were found to correlate with in-cloud data, indicating the need for heterogeneous loss processes in the model, and the median ratio for stratospheric $\mathrm{HO}_{2}$ was significantly lower at 0.63 than that for the remainder of the dataset (1.24). ${ }^{178} \mathrm{In}$ addition, a subset of $\mathrm{HO}_{2}$ data coincident with observations of high $\mathrm{NO}$ concentrations ( $>135 \mathrm{pptv}$ ) in the upper troposphere had a median modelled to observed ratio of 0.97 , while the overprediction for $\mathrm{OH}$ was greater for this subset of data, suggesting uncertainties in the rate of $\mathrm{HO}_{x}$ recycling by $\mathrm{NO} .{ }^{178}$

Three-dimensional simulations of $\mathrm{OH}$ and $\mathrm{HO}_{2}$ during TRACE-P were able to capture the main features in the observations, but, similarly to the box model simulations, overpredicted both $\mathrm{OH}$ and $\mathrm{HO}_{2}$ by factors of 1.56 and 1.24, respectively. ${ }^{181}$ The overprediction of $\mathrm{OH}$ was observed to be greatest at low observed $\mathrm{NO}$ as a result of a model overestimation of $\mathrm{NO}$, and it was found that the model was more successful at reproducing the $\mathrm{OH}$ and $\mathrm{HO}_{2}$ observations in polluted environments than in the clean marine boundary layer. $^{181}$

Olson et al.$^{48}$ reported a box model re-evaluation of $\mathrm{HO}_{x}$ data from the SUCCESS, SONEX, PEM-Tropics B and TRACE-P campaigns, focusing on the previously described discrepancies between models and observations. In this work, Olson et $a l .{ }^{48}$ showed that much of the model discrepancies for $\mathrm{HO}_{2}$ found at high $\mathrm{NO}_{x}$ concentrations in the SUCCESS

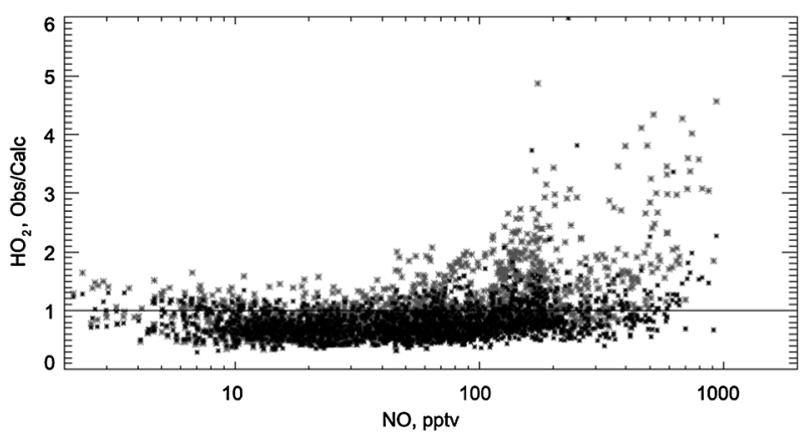

Fig. 8 Observed/calculated $\mathrm{HO}_{2}$ as a function of $\mathrm{NO}$ during the SONEX campaign (reproduced from ref. 48, Copyright (2006) American Geophysical Union. Reproduced by permission of American Geophysical Union. Further reproduction or electronic distribution is not permitted.). The grey symbols show the initial model results reported by Faloona et al. (2000). ${ }^{162}$ The black symbols show the reanalysis by Olson et al. $(2006)^{48}$ using a more comprehensive set of model constraints and updated descriptions of kinetic and photochemical parameters.

campaign could be attributed to the use of data averaged over timescales too long to truly reflect the response of $\mathrm{HO}_{x}$ to highly variable conditions of $\mathrm{NO}_{x}$.

Model discrepancies for the SONEX campaign at high $\mathrm{NO}_{x}$ were also rectified to an extent by Olson et al. ${ }^{48}$ as shown in Fig. 8, but were found to be largely a result of incomplete descriptions of $\mathrm{HO}_{x}$ sources and sinks and uncertainties in kinetic and photochemical parameters rather than the timescale for averaging of constraints. The initial modelling studies for SONEX ${ }^{162}$ were constrained to a limited set of nonmethane hydrocarbons (ethane, propane, $\mathrm{C}_{4}$ alkanes and acetone), while Olson et $a .^{48}$ included observations of $\mathrm{C}_{5}$ and higher alkanes, $\mathrm{C}_{2} \mathrm{H}_{4}$, higher alkenes, aromatics, peroxides $\left(\mathrm{H}_{2} \mathrm{O}_{2}\right.$ and $\left.\mathrm{CH}_{3} \mathrm{OOH}\right), \mathrm{CH}_{3} \mathrm{OH}$, PAN and $\mathrm{HNO}_{3}$ and used updated descriptions for the kinetics and photochemistry. The changes in modelled $\mathrm{HO}_{2}$ were greatest for the points with the highest $\mathrm{NO}_{x}$ concentrations, owing to a combination of improvements in measurements of the rate coefficient for the reaction between $\mathrm{OH}$ and $\mathrm{NO}_{2}$ and photolysis data for $\mathrm{HO}_{2} \mathrm{NO}_{2}$ and acetone, particularly of the temperature dependent acetone photolysis quantum yields which suggest a reduced role for acetone photolysis in the upper troposphere than indicated by earlier modelling studies. Inclusion of alkene and aromatic chemistry in the model calculations also led to improvements in modelled $\mathrm{HO}_{x}$ concentrations at high $\mathrm{NO}_{x}$ since enhanced concentrations of alkenes and aromatics were in general coincident with high $\mathrm{NO}_{x}{ }^{48}$

Olson et al. ${ }^{48}$ noted that increasing $\mathrm{NO}_{x}$ concentrations affect $\mathrm{HO}_{x}$ chemistry by three mechanisms. First, increased $\mathrm{NO}_{x}$ leads to increased importance of $\mathrm{RO}_{2}+\mathrm{NO}$ and thus of recycling of $\mathrm{HO}_{x}$ through VOC chemistry; secondly through partitioning of $\mathrm{HO}_{x}$ towards $\mathrm{OH}$; and thirdly through increased significance of $\mathrm{HO}_{x}$ loss through $\mathrm{OH}+\mathrm{NO}_{2}$.

Model discrepancies at high solar zenith angles could not be explained due to incomplete understanding of nighttime $\mathrm{HO}_{x}$ sources, and problems with $\mathrm{HO}_{2}$ simulations in-cloud for TRACE-P could not be resolved, partly owing to the difficulties associated with evaluating the role of cloud liquid water 
volume as well as that of particulate matter. ${ }^{48}$ An aircraft campaign over West Africa in 2006 also reported the impact of clouds on $\mathrm{HO}_{2}$ measurements, with large decreases in $\mathrm{HO}_{2}$ observed as the aircraft flew through clouds, correlating with measurements of liquid water content, indicating heterogeneous chemistry and uptake of $\mathrm{HO}_{2}$ into cloud droplets. ${ }^{69}$

Following the extensive studies over the Pacific Ocean, the INTEX-A (INtercontinental Chemical Transport Experiment A) campaign was conducted over North America and the Western Atlantic Ocean on the NASA DC8 aircraft in summer $2004 .{ }^{182}$ A number of different types of air mass were sampled during this campaign, including those influenced by anthropogenic pollution, biomass burning, convection and the stratosphere, providing a wide range of conditions under which to test our understanding of $\mathrm{HO}_{x}$ chemistry. ${ }^{182}$

Measurements of $\mathrm{OH}$ and $\mathrm{HO}_{2}$ during INTEX-A were made by the ATHOS-FAGE instrument at altitudes ranging from several hundred metres to almost $12 \mathrm{~km}$. Median mixing ratios of $\mathrm{OH}$ were found to be relatively constant at $\sim 0.25 \mathrm{pptv}$ up to altitudes of $6 \mathrm{~km}$, and then increasing with altitude to a maximum of 0.86 pptv at $12 \mathrm{~km} .{ }^{182}$ Mixing ratios of $\mathrm{HO}_{2}$ were observed to decrease with increasing altitude, from a maximum median of $\sim 30$ pptv near the surface to a minimum median of $\sim 8 \mathrm{pptv}$ at $12 \mathrm{~km}$. Similar altitude profiles for $\mathrm{OH}$ and $\mathrm{HO}_{2}$ were observed during the PEM-Tropics $\mathrm{B}$ and TRACE-P campaigns. ${ }^{182}$

Observations of $\mathrm{OH}$ above the boundary layer were generally within 0.95 of box model calculations based on a diurnal steady state assumption, with a model underprediction in the boundary layer coinciding with continental measurements influenced by high isoprene concentrations. ${ }^{182}$ The model discrepancy in this region will be discussed in Section 5.

Observations of $\mathrm{HO}_{2}$ were generally within 1.2 of the modelled concentrations at altitudes less than $8 \mathrm{~km}$, but the model displayed a significant underprediction of $\mathrm{HO}_{2}$ at higher altitudes. The observed to modelled ratio increased from $\sim 1.2$ at an altitude of $8 \mathrm{~km}$ to a value of $\sim 3$ at $11 \mathrm{~km}$, correlating with high $\mathrm{NO}_{x}$ concentrations, ${ }^{182}$ as shown in Fig. 9. Both $\mathrm{HO}_{2}$ and $\mathrm{NO}$ concentrations were significantly higher during INTEX-A than either PEM-Tropics B or TRACE-P, with $\mathrm{NO}_{x}$ concentrations during INTEX-A on average four to five times those observed during TRACE-P and over an order of magnitude greater than those observed during the PEM-Tropics B campaign. ${ }^{182}$ Moreover, the differences in $\mathrm{NO}_{x}$ concentrations were greatest at altitudes greater than $8 \mathrm{~km}$, where the largest discrepancy for $\mathrm{HO}_{2}$ was observed. ${ }^{182}$

Budget calculations for $\mathrm{HO}_{x}$ indicated that $\mathrm{O}\left({ }^{1} \mathrm{D}\right)+\mathrm{H}_{2} \mathrm{O}$ was the primary $\mathrm{HO}_{x}$ source at altitudes below $7 \mathrm{~km}$, with $\mathrm{HCHO}$ photolysis the dominant source above $7 \mathrm{~km}$ in altitude. ${ }^{182}$ Losses of $\mathrm{HO}_{x}$ were dominated by $\mathrm{HO}_{2}+\mathrm{RO}_{2}$ reactions below $8 \mathrm{~km}$, with $\mathrm{OH}+\mathrm{NO}_{2}$ increasing in importance at higher altitudes. It was suggested that the model underprediction for $\mathrm{HO}_{2}$ at high altitudes, in what was thought to be convected air owing to the high concentrations of $\mathrm{NO}$, may have resulted from the presence of additional unknown $\mathrm{HO}_{x}$ sources. ${ }^{182}$

The second phase of the INTEX experiments (INTEX-B) was conducted in spring 2006, with a focus on the Pacific Ocean and outflow of pollution from Mexico and Asia. ${ }^{183}$
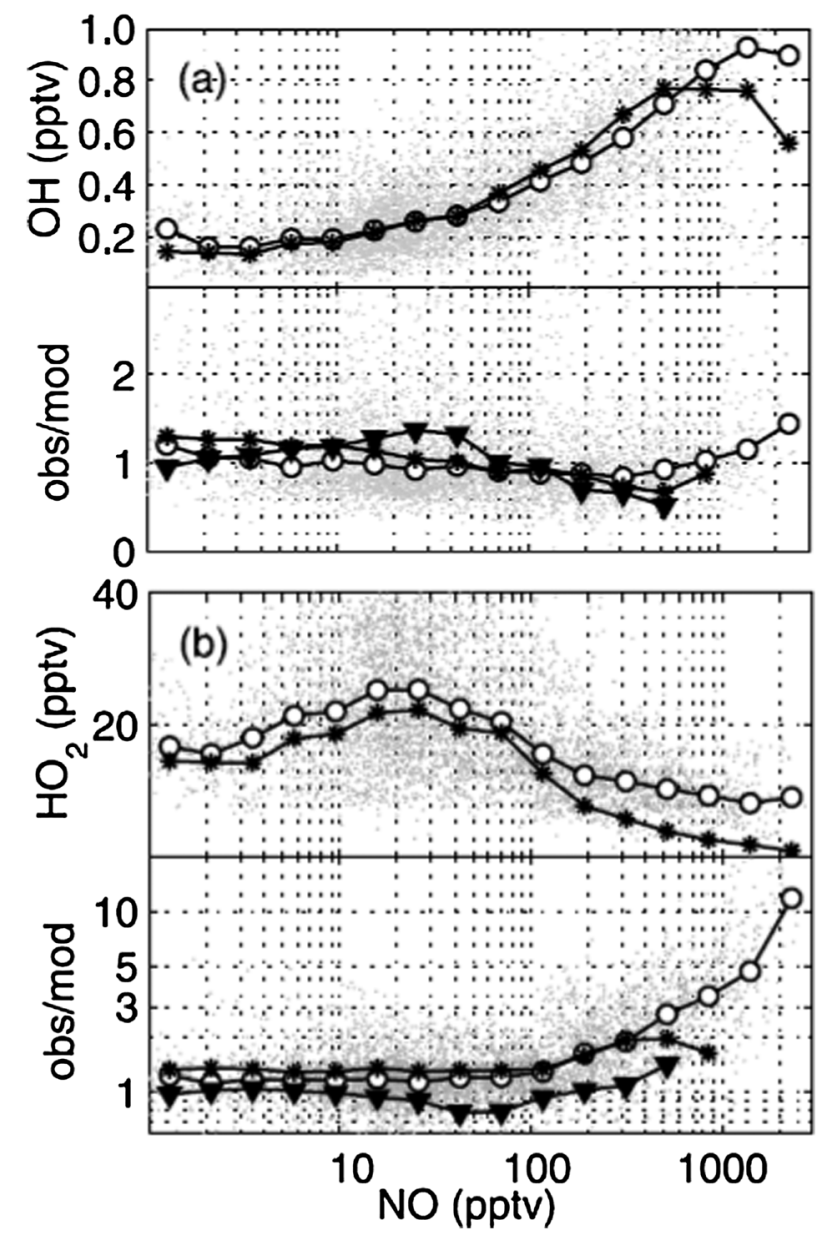

Fig. 9 Dependence of $\mathrm{OH}$ and $\mathrm{HO}_{2}$ mixing ratios and model success (obs/mod) on NO for INTEX-A (circles), TRACE-P (stars) and PEMTropics B (triangles). Lines show the median values. The grey dots indicats the INTEX-A 1-min measurements. (Reproduced from ref. 182, Copyright (2008) American Geophysical Union. Reproduced by permission of American Geophysical Union. Further reproduction or electronic distribution is not permitted.)

The INTEX-B mission reported the first airborne measurements of $\mathrm{OH}$ reactivity, made onboard the NASA DC8 aircraft alongside measurements of $\mathrm{OH}$ and $\mathrm{HO}_{2}$ by ATHOS-FAGE during the second half of the campaign investigating Asian outflow of pollution. ${ }^{184}$ At altitudes below $2 \mathrm{~km}$, a diurnal steady state model for $\mathrm{HO}_{x}$ and $\mathrm{OH}$ reactivity indicates the presence of missing $\mathrm{OH}$ sinks, where the model underpredicted $\mathrm{OH}$ reactivity and overpredicted $\mathrm{OH} .{ }^{184}$ The model discrepancy for $\mathrm{OH}$ and $\mathrm{OH}$ reactivity at low altitudes coincided with a model underestimate of $\mathrm{HCHO}$, leading to the suggestion that the missing $\mathrm{OH}$ sink may produce $\mathrm{HCHO}$ as an oxidation product. ${ }^{184}$ Observations of $\mathrm{HO}_{2}$ were well reproduced by the model, and sensitivity studies showed low sensitivity of $\mathrm{HO}_{2}$ to improvements in the model success for $\mathrm{OH}, \mathrm{HCHO}$ and $\mathrm{OH}$ reactivity. ${ }^{184}$

In a laboratory study, small yields of $\mathrm{HNO}_{3}$ from the reaction of $\mathrm{HO}_{2}$ with $\mathrm{NO}$ have been measured, and found to be pressure and temperature dependent, ${ }^{311-314}$ with an impact on $\mathrm{OH}$ and $\mathrm{HO}_{2}$ concentrations throughout the troposphere, but mostly in the upper troposphere. Spectroscopic measurements 
in a jet of the $\mathrm{OH} \cdot \mathrm{O}_{2}$ complex, which determined an upper limit on the binding energy of $\sim 25 \mathrm{~kJ} \mathrm{~mol}^{-1}$, suggested that a significant fraction of atmospheric $\mathrm{OH}$ may be converted to $\mathrm{HO}_{3}$ in colder parts of the atmosphere, ${ }^{315}$ but more recent kinetics measurements of the reaction of $\mathrm{OH}$ with $\mathrm{O}_{2}$ to form the complex showed that the binding energy was considerably lower. ${ }^{316}$ The complex between $\mathrm{HO}_{2}$ and water vapour is estimated to have a binding energy of $\sim 31 \mathrm{~kJ} \mathrm{~mol}^{-1}$, and measurements of the equilibrium constant of this complex suggests that at sea-level $\sim 10 \%$ of $\mathrm{HO}_{2}$ may be in the form of this complex. ${ }^{317}$

\subsection{Summary of studies in the marine boundary layer}

Some of the earliest studies of atmospheric $\mathrm{HO}_{x}$ chemistry were performed in the MBL, but the early field campaigns were often hindered by a lack of supporting measurements (for example of $\mathrm{OH}$ sinks) and inadequate chemical complexity in the models used, often resulting in model overpredictions of $\mathrm{OH}$ and $\mathrm{HO}_{2}$. More comprehensive measurement suites of VOCs and oVOCs, particularly aldehydes, which even in a remote, clean environment can provide significant $\mathrm{OH}$ reactivity, led to improved model simulations for $\mathrm{OH}$ and $\mathrm{HO}_{2}$, while simultaneous measurements of halogen oxide species enabled recognition of the importance of $\mathrm{IO}$ and $\mathrm{BrO}$ in controlling the interconversion of $\mathrm{OH}$ and $\mathrm{HO}_{2}$, and hence $\mathrm{HO}_{x}$ concentrations in marine regions. However, the majority of halogen oxide measurements have been made by DOAS instruments, and the suitability of the spatially averaged concentrations measured by the DOAS technique for modelling in situ FAGE measurements of $\mathrm{OH}$ and $\mathrm{HO}_{2}$ has been questioned in some coastal environments by the development of in situ methods for IO measurements which show that significant inhomogeneities in emissions and concentrations can exist.

Concentrations of $\mathrm{HO}_{2}$ are often overpredicted in model simulations in the marine boundary layer, particularly at night. The correct treatment of heterogeneous chemistry in models is a significant source of uncertainty, and the use of appropriate uptake coefficients $\left(\gamma_{\mathrm{HO}_{2}}\right)$ to represent $\mathrm{HO}_{2}$ loss to aerosols in atmospheric models is essential to accurate model simulations. Early studies used $\gamma_{\mathrm{HO}_{2}}$ which were unrealistically high compared with more recent measurements, but further laboratory studies of the uptake of $\mathrm{HO}_{2}$ on aerosols are required to provide uptake coefficients for use within models.

Aircraft studies have provided opportunities to investigate the distribution of trace gases throughout the entire troposphere, enhancing our understanding of the chemistry and dynamics of the atmosphere from the boundary layer to high altitudes, and from continental to remote marine locations. In this section we have generally concentrated on aircraft campaigns in marine regions, with aircraft campaigns over continental regions considered in more detail in the relevant sections below. In comparing data from aircraft studies over oceans to those over continental regions, however, it has been found that model calculations are in better agreement with observations over oceans than over continental regions, a result attributed to the more diverse mix of VOCs over continental regions that cannot be fully measured or characterised, and whose oxidation chemistry is not adequately described in models.

With adequate measurement of $\mathrm{OH}$ sinks, as well as halogen species, model simulations in remote marine regions have typically been able to reproduce observations of $\mathrm{OH}$ and $\mathrm{HO}_{2}$ to within the combined uncertainty of the model and the measurement technique, although there is still considerable uncertainty regarding the details of nighttime radical chemistry in this environment. Studies at high altitudes have identified the importance of carbonyl compounds and peroxides as $\mathrm{HO}_{x}$ sources in the upper troposphere, although laboratory measurements of smaller acetone photolysis quantum yields at low temperatures have indicated that acetone photolysis may not be as important for $\mathrm{HO}_{x}$ production in the upper troposphere as expected on the basis of earlier modelling studies which used temperature independent quantum yields. Model discrepancies for $\mathrm{HO}_{2}$ observed at high $\mathrm{NO}_{x}$ concentrations have been partly explained by the use of inappropriate averaging times for rapidly changing concentrations, with shorter and more appropriate time averaging resulting in improved model simulations.

\section{Studies in environments influenced by biogenic emissions}

Isoprene is produced by the biosphere and is the dominant biogenic VOC emitted into the atmosphere $\left(\sim 500 \mathrm{Tg} \mathrm{C}_{\text {year }}{ }^{-1}\right){ }^{185}$ A good representation of the oxidation chemistry of isoprene within a model, which is primarily driven by initial reaction with $\mathrm{OH}$, leading to its chemical processing and ultimate removal is central to our ability to understand the composition of the atmosphere in biogenically influenced regions. A summary of field campaigns in environments influenced by biogenic emissions is given in Table 3 .

The first hydroxyl radical measurements made in a biogenically influenced environment took place at Fritz Peak in Colarado in $1991^{186}$ in a predominantly logdepole pine forest. The campaign involved an informal $\mathrm{OH}$ measurement intercomparison between the National Oceanic and Atmospheric Administration (NOAA) LP-DOAS and the Georgia Tech. CIMS instruments. In general, good agreement was observed between the two measurement techniques, with occasional differences arising most likely associated with differences in the spatial coverage of the LP-DOAS measurements relative to the in situ CIMS measurements. In contrast to this good agreement, model calculations constrained to $\mathrm{CO}$ and $\mathrm{CH}_{4}$ only, consistently overestimated $\mathrm{OH}$ concentrations considerably (by up to a factor of 4). Inclusion of anthropogenic hydrocarbons that were estimated by scaling to observed $\mathrm{NO}_{x}$ levels only led to small reductions in $\mathrm{OH}$. Model calculations determined that $2 \mathrm{ppbv}$ isoprene (acting as an efficient $\mathrm{OH}$ sink) if present (there were no measurements of isoprene) would be sufficient to reconcile the modelled $\mathrm{OH}$ with observations (assuming isoprene does not act as an $\mathrm{OH}$ source).

With the potential impact of biogenic VOCs demonstrated at Fritz Peak, a second campaign, the Tropospheric $\mathrm{OH}$ Photochemistry Experiment, TOHPE, took place at Fritz Peak and a neighbouring site at Idaho Hill from early August to early October of 1993 (Mount and Williams ${ }^{187}$ and papers therein). 


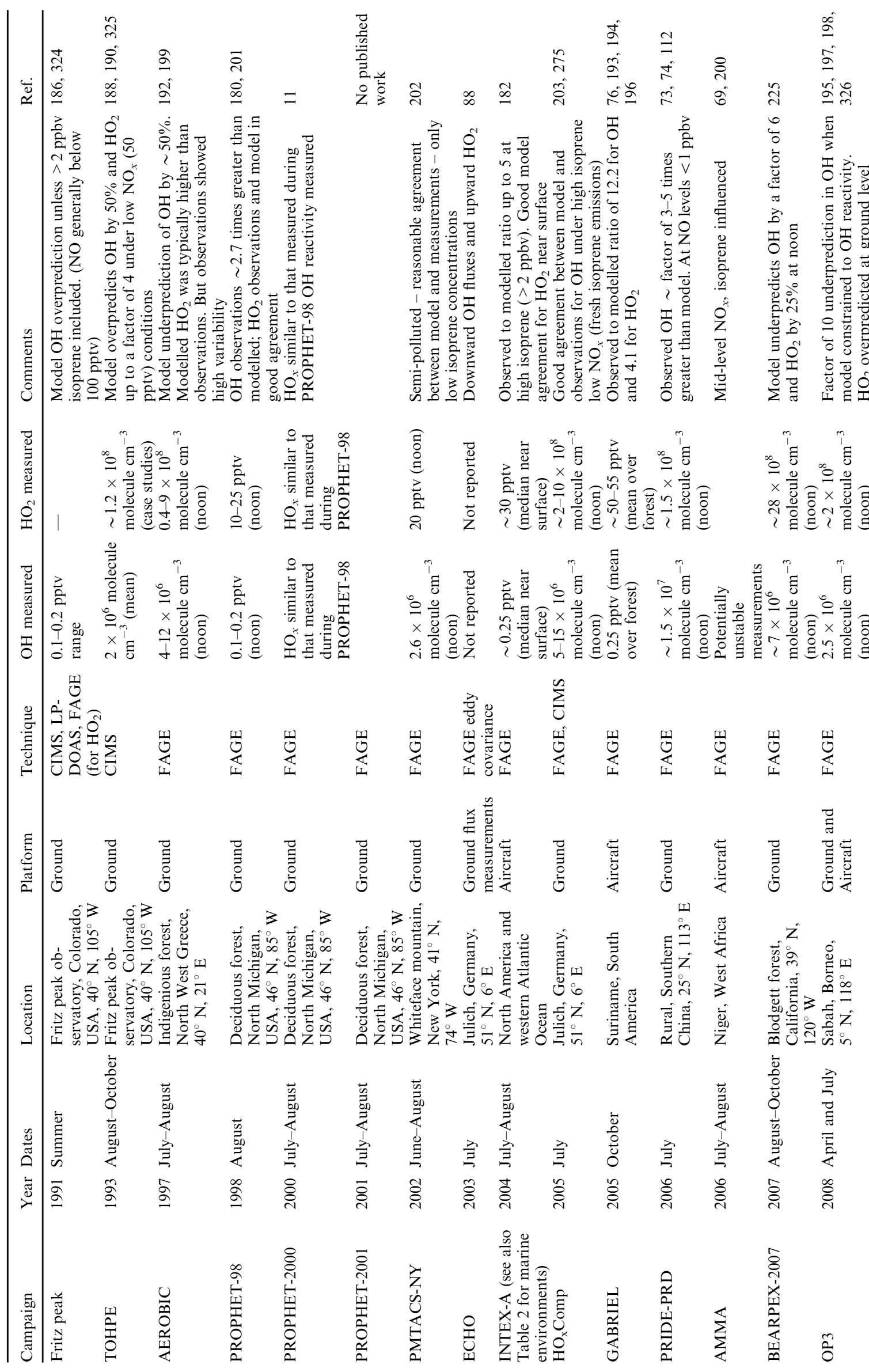


A much more extensive suite of natural hydrocarbon species were made during this project to allow for a meaningful comparison between radical observations and photochemical theory. In addition to the two previous $\mathrm{OH}$ measurements made using a LP-DOAS and CIMS, radical measurements were also performed by a LIF (at low pressure, FAGE) instrument $\left(\mathrm{OH}, \mathrm{HO}_{2}\right.$ ) and PERCA (sum of $\mathrm{HO}_{2}+\mathrm{RO}_{2}$ ). Under clean conditions (NO $<500$ pptv), a zero dimensional photochemical model overpredicted the $\mathrm{OH}$ observations by $51 \%$ on average despite being constrained to the measured biogenic VOCs which included isoprene, $m$-butenol, $\alpha$ - and $\beta$-pinene. ${ }^{188}$ It should be noted that the observed isoprene concentrations were considerably lower (ranging between 100-300 pptv) than levels required to reconcile the modelled $\mathrm{OH}$ with the observations during the 1991 study. A lumped model linking hydrocarbons by functional group and $\mathrm{OH}$ reactivity was employed for the study; degradation mechanisms for the biogenic hydrocarbons were included in model calculations, although a number of assumptions regarding product yields, owing to lack of available data were made. McKeen et al. ${ }^{188}$ suggested that undetected VOCs may have still been contributing as a significant $\mathrm{OH}$ sink or there may have been significant loss of $\mathrm{HO}_{x}$ or $\mathrm{RO}_{2}$ to aerosol surfaces or to the ground. A one-dimensional modelling study, applicable for flat terrain with similar photochemical conditions, suggests that up to $25 \%$ of the $\mathrm{OH}$ loss could be caused by either surface deposition or emission of an efficient $\mathrm{OH}$ scavenger at the ground. ${ }^{189}$ However, the measured aerosol surface areas during the campaign were found to be too low to significantly affect radical concentrations. ${ }^{190}$ Under the low $\mathrm{NO}_{x}$ conditions, $\mathrm{HO}_{2}$ observations were a factor of 6-8 times lower than model expectations and it was suggested that an unknown $\mathrm{RO}_{2}$ radical efficient at reducing $\mathrm{HO}_{2}$ but inefficient at forming $\mathrm{HO}_{2}$ via reaction with $\mathrm{NO}$ could account for this discrepancy. ${ }^{188}$ Any reduction in the modelled $\mathrm{HO}_{2}$ concentration would reduce the modelled to measured $\mathrm{OH}$ discrepancy also. Observations of oxygenated VOCs such as acetaldehyde also suggest that the model mechanisms could be incomplete with modelled acetaldehyde being a factor of 4 lower than observations under clean conditions; a large missing acetaldehyde source could modify the predicted $\mathrm{OH}$ concentrations considerably although the impact of this was not determined explicitly during the study. In contrast, the formaldehyde observations ${ }^{191}$ were represented well by the model, particularly under clean conditions. ${ }^{188}$

In stark contrast to the Fritz Peak and Idaho Hill studies, model comparisons of $\mathrm{OH}$ at many other forested sites significantly underpredict observations. ${ }^{180,192-198}$ Such model failure was first observed during the AEROsols formation from BIogenic organic Carbon AEROBIC97 field project which took place in a forested region in North-western Greece. ${ }^{192,199}$ The project was characterised by high concentrations of isoprene (of the order of several ppbv) and monoterpenes (daytime levels ranging between $0.5-1 \mathrm{ppbv}$ ); this is in contrast to the modest isoprene concentrations observed during TOHPE, and may go some way to explaining the differences between the model results during the two studies. One focus of the AEROBIC study was improved representation of the oxidation mechanisms of isoprene and monoterpenes 
within the MCM model ${ }^{33,34}$ employed. Detailed degradation mechanisms for isoprene and $\alpha$-pinene were integrated into the model, whilst other monoterpenes that were observed were included within the model by initial reaction with $\mathrm{OH}, \mathrm{O}_{3}$ or $\mathrm{NO}_{3}$ according to their specific rate coefficients and the subsequent degradation was modelled using the $\alpha$-pinene mechanism. This more detailed modelling approach, compared to the more lumped model used previously, may also have contributed to the differences reported in modelled to measured ratios of $\mathrm{OH}$ during TOHPE and AEROBIC. One key finding during AEROBIC was that the modelled $\mathrm{OH}$ underprediction worsened as NO concentrations decreased; a feature that has been reported since in a number of other low $\mathrm{NO}_{x}$, biogenically-influenced environments also. ${ }^{74,180,200}$

Similar findings have been reported during the Program for Research on Oxidants: Photochemistry, Emissions and Transport (PROPHET) 1998 field campaign that took place in a hardwood forest in North Michigan that consisted largely of aspen, beech, birch, oak and maple. ${ }^{180}$ Using a zero-dimensional box model based upon the RACM ${ }^{36}$ with the addition of a detailed isoprene oxidation scheme, considerable model underprediction (a factor of 2.66 on average) for $\mathrm{OH}$ was found. For $\mathrm{HO}_{2}$, the model reproduced the observations reasonably well, overpredicting the $\mathrm{HO}_{2}$ measured by less than $15 \%$ on average.

As observed during AEROBIC, the modelled to measured agreement for $\mathrm{OH}$ in PROPHET tended to be worse at the lowest NO concentrations and was particularly poor (underprediction by a factor of 6 or more) at NO $<100$ pptv. In contrast, for $\mathrm{HO}_{2}$, the model displayed the greatest success at low NO. As a result, the predicted $\mathrm{HO}_{2} / \mathrm{OH}$ ratio was much higher than that measured. The disagreement between model and observations for $\mathrm{OH}$ may indicate a missing $\mathrm{OH}$ source in the model. Significant $\mathrm{OH}$ concentrations were observed during the nighttime $\mathrm{e}^{201}$ and may indicate that a non-photolytic source of $\mathrm{OH}$, for example from the ozonolysis of reactive terpenes not measured at the site, were contributing to the $\mathrm{OH}$ budget. In support of this, measurements of total $\mathrm{OH}$ reactivity at the same site during PROPHET2000 indicated that a significant fraction of $\mathrm{OH}$ reactivity was not measured explicitly and displayed a temperature dependence similar to that of a reactive terpene. ${ }^{11}$ Inclusion of a median daytime value of $18 \mathrm{pptv}$ of an undetected terpene with a temporal profile following that of $\Delta^{3}$-carene, reactivity with respect to $\mathrm{O}_{3}$ of $\alpha$-humulene and an $\mathrm{OH}$ yield of one allowed the nighttime $\mathrm{OH}$ profile to be replicated by the model; at these levels the $\mathrm{OH}$ reactivity budget determined during PROPHET 2000 could also be closed. However, the mean of all $\mathrm{OH}$ observations, taking into account the daytime data also, were still greater than modelled by a factor of 1.5, and the previously good model to measured $\mathrm{HO}_{2}$ agreement was reduced, with the model now overpredicting the observations by $\sim 30 \%$. Mechanisms for the degradation of BVOCs are very complex and the kinetic parameters used within the model employed derived largely from smog chamber studies where NO concentrations were typically 3-5 times higher than observed during PROPHET (excepting the initial isoprene oxidation step). The authors suggested that the cycling of $\mathrm{HO}_{2}$ to $\mathrm{OH}$ may not be described correctly within the model under low
NO, high isoprene conditions. Increasing the NO concentrations by a factor of 3 allowed the model to reproduce $\mathrm{OH}$ observed to within $10 \%$ and $\mathrm{HO}_{2}$ to within $25 \%$. Although not discussed by the authors, a factor of 3 increase in NO within the model would undoubtedly perturb $\mathrm{O}_{3}$ production rates. Hofzumahaus et al. ${ }^{74}$ demonstrated that an additional cycling step of $\mathrm{RO}_{2}$ to $\mathrm{HO}_{2}$ and $\mathrm{HO}_{2}$ to $\mathrm{OH}$ under the low $\mathrm{NO}_{x}$ conditions experienced during the Program of Regional Integrated Experiments of Pearl River Delta (PRIDE-PRD) campaign improved the modelled radical concentrations but concluded that the conversion chemistry was unlikely to involve $\mathrm{NO}$ or any other species that produced $\mathrm{O}_{3}$ as this would lead to a net production of $\mathrm{O}_{3}$ of $\sim 60 \mathrm{ppbv} \mathrm{h}^{-1}$ compared to the modest 2 ppbv $\mathrm{h}^{-1}$ that was observed at the site.

The PROPHET and AEROBIC projects demonstrate that under high isoprene, low $\mathrm{NO}_{x}$ conditions ( $\mathrm{NO}<100 \mathrm{pptv}$ ) models fail to reproduce the elevated $\mathrm{OH}$ concentrations observed. Radical measurements performed on board the NASA DC8 aircraft during the Intercontinental Chemical Transport Experiment-A (INTEX-A) ${ }^{182}$ involving flights over North America and the western Atlantic Ocean demonstrated a strong relationship between the extent of model failure and isoprene concentration. As shown in Fig. 10, the observed to modelled ratio increased from $1-1.5$ as isoprene increased from 10-500 pptv and reached 5 as isoprene levels increased to greater than 1 ppbv. A similar trend was observed during flights over tropical forests in Suriname during the Guyanas Atmosphere-Biosphere exchange and Radicals Intensive Experiment with the Learjet (GABRIEL) campaign, ${ }^{196}$ which is also shown in Fig. 10.

There is some evidence that model failure in biogenically influenced regions may be limited to extremely low $\mathrm{NO}_{x}$ conditions. Under moderately polluted regimes (NO $\sim 0.1-1 \mathrm{ppbv}$ ), the modelled to measured $\mathrm{OH}$ discrepancy has been found to be greatly improved. ${ }^{202}$ During the PM2.5 Technology Assessment and Characteristics StudyNew York (PMTACS-NY) Whiteface Mountain campaign that took place within a deciduous forest canopy, observations of $\mathrm{OH}, \mathrm{HO}_{2}$ and $\mathrm{OH}$ reactivity were in reasonable agreement with box model predictions based on $\mathrm{RACM}^{202}$ with median modelled to measured ratios of 0.82 and 1.21 for $\mathrm{OH}$ and $\mathrm{HO}_{2}$ (daytime) respectively. Isoprene was found to contribute to only a small fraction of the total $\mathrm{OH}$ reactivity at Whiteface Mountain (isoprene typically less than $1 \mathrm{ppbv}$ ), in contrast to the PROPHET site, suggesting significant differences in biogenic emissions and may indicate that the missing source of $\mathrm{OH}$ may be directly related to isoprene under low NO conditions. As shown in Fig. 11, Hofzumahaus et al. ${ }^{74}$ noted during PRIDE-PRD that box model calculations based on the RACM and constrained with a total $\mathrm{OH}$ reactivity measurement were able to replicate morning observations of $\mathrm{OH}$, when NO concentrations were greater than 1 ppbv, but when NO concentrations dropped (to below 200 pptv) in the afternoon the measured $\mathrm{OH}$ was significantly larger than predictions. This site, although not forested, was significantly influenced by substantial isoprene emissions. Stone et $a .^{200}$ did not observe any dependence of model success for $\mathrm{HO}_{2}$ on isoprene levels during aircraft measurements over West Africa as part of the African Monsoon Multidisciplinary Analyses (AMMA) 

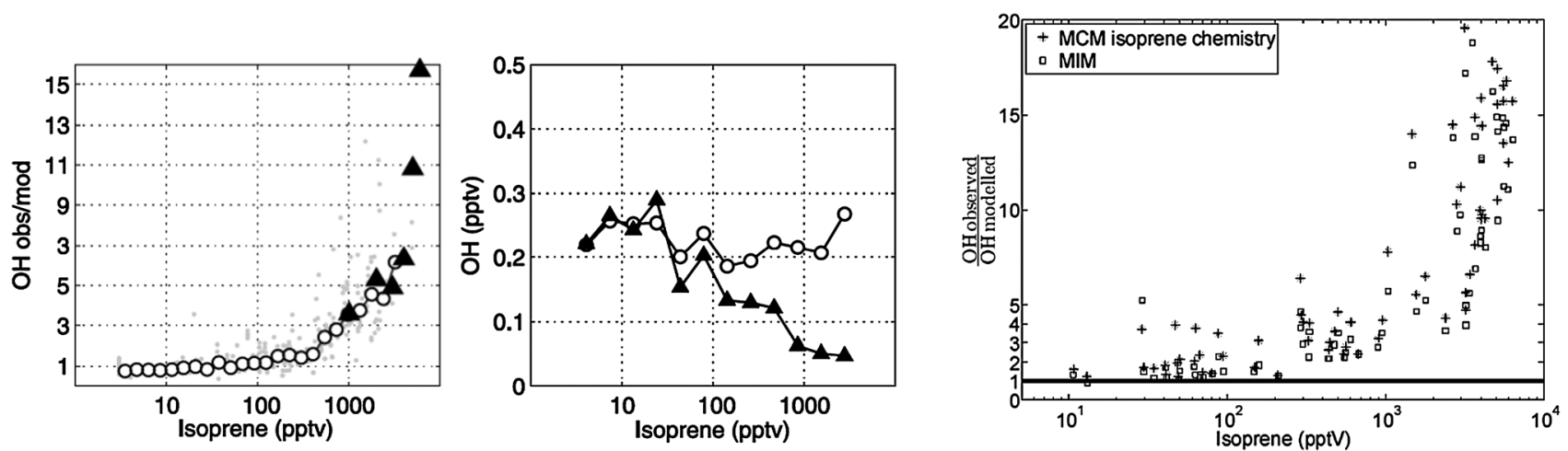

Fig. 10 (Left) The observed-to-modelled $\mathrm{OH}$ ratio as a function of isoprene with open circles showing data taken at $<1 \mathrm{~km}$ altitude and SZA $<$ $60^{\circ}$ during INTEX-A and filled triangles showing data from PROPHET-2000 (ground-based). (Middle) The median observed OH (circles) and modelled $\mathrm{OH}$ (triangles) during INTEX-A as a function of isoprene. (Right) Observed to modelled ratio of [OH] during the GABRIEL campaign over the Suriname rainforest as a function of isoprene concentration, for two different models. (Reproduced from ref. 182, Copyright (2008) American Geophysical Union, reproduced by permission of American Geophysical Union (further reproduction or electronic distribution is not permitted) and ref. 196, Copyright (2010), with permission from Copernicus Publications.)

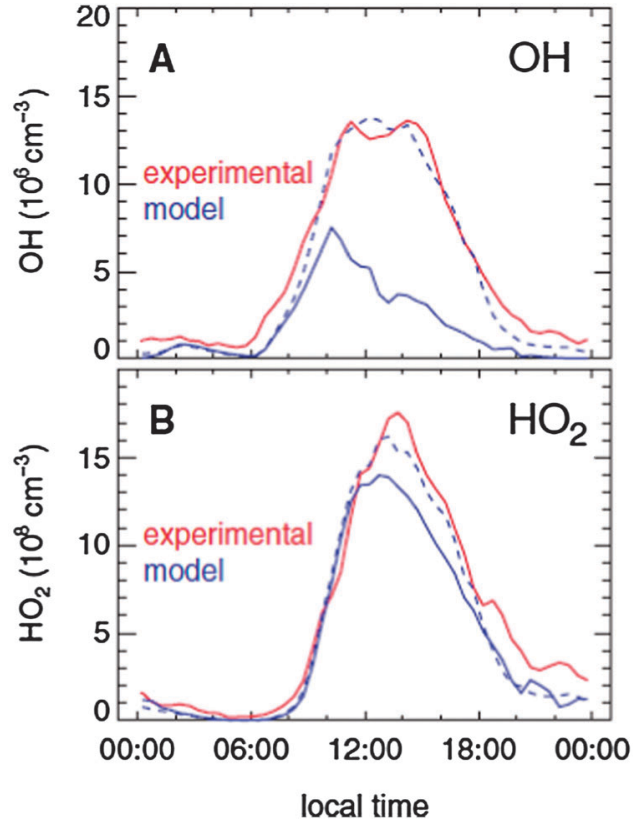

Fig. 11 Comparison of measured (red line) and modelled diurnal profiles of $\mathrm{OH}$ and $\mathrm{HO}_{2}$ during the Pearl River Delta Campaign (PRIDE-PRD), China. The blue solid line represents the base case RACM model results and the dashed line the results from the extended RACM model with enhanced $\mathrm{HO}_{2}$ and $\mathrm{RO}_{2}$ recycling. (Reproduced from ref. 22, Copyright (2009), with permission from American Association for the Advancement of Science.)

project. NO levels ranged from $5-300$ pptv, which was sufficient to efficiently recycle isoprene derived $\mathrm{RO}_{2}$ radicals to $\mathrm{HO}_{x}$ by reaction with $\mathrm{NO}$ within the model. Only modest levels of radical recycling were required to reproduce radical measurements during the ambient observational period of the $\mathrm{HO}_{x}$ Comp field campaign made in a mixed deciduous forest in a rural area close to Jülich in Germany. ${ }^{203}$ During the campaign isoprene levels ranged from $0.3-2 \mathrm{ppbv}$ and $\mathrm{NO}$ concentrations fell as low as 0.1 ppbv. $\mathrm{OH}$ and $\mathrm{HO}_{2}$ were detected by four different instruments ${ }^{204}$ and base model simulations were able to reproduce radical concentrations reasonably well (RACM model to measured ratio of $0.83-1.33$ and $0.72-0.97$ for $\mathrm{OH}$ and $\mathrm{HO}_{2}$ respectively ${ }^{203}$ ). An increasing underestimation of $\mathrm{OH}$ using a zero-dimensional model based on the MCMv3.2 was observed as NO concentrations decreased, reaching $65 \%$ at NO $<0.2$ ppbv. ${ }^{203}$ This missing $\mathrm{OH}$ source is in qualitative agreement with the earlier studies discussed above but is quantitatively much lower. The isoprene and $\mathrm{NO}$ mixing ratios observed during $\mathrm{HO}_{x} \mathrm{Comp}$ are comparable to those encountered during PRIDE-PRD, where modelled $\mathrm{OH}$ underpredicted observations by a factor of 8 . Kanaya et al. ${ }^{203}$ suggest that this apparent discrepancy between $\mathrm{HO}_{x}$ Comp and PRIDE-PRD may result from the Jülich site experiencing fresh isoprene emissions rather than photochemically aged air in which second or third generation products of VOC oxidation would be present. However, the total $\mathrm{OH}$ reactivity (which was well represented in the models) was higher during PRIDE-PRD $\left(\sim 20 \mathrm{~s}^{-1}\right)$ compared to $\mathrm{HO}_{x}$ Comp $\left(\sim 8 \mathrm{~s}^{-1}\right)$, implying that PRIDE-PRD took place under a more $\mathrm{NO}_{x}$-limited regime.

In recent years, measurements of radicals in and above tropical rainforests have become available..$^{76,197,198}$ Within these regions, NO concentrations are extremely low, (mean NO $\sim 20$ pptv), and emissions of highly reactive biogenic VOCs are large. Global modelling studies ${ }^{205,206}$ predict that $\mathrm{OH}$ concentrations will be severely depleted in tropical forested regions owing to the high BVOC emissions and, as a consequence, isoprene levels build up in the modelled boundary layer (to unrealistic values) and the lifetime of methane in these areas is extended considerably. To circumvent this problem, and to give agreement with measured concentrations of isoprene, isoprene emissions are typically reduced by factors of two or more within global models. ${ }^{207}$ However, such reductions are at odds with the most up to date global emissions inventories ${ }^{208}$ indicating that the oxidative capacity and, hence, the rate of processing and ultimate rate of removal of isoprene, is likely sustained in rainforests, despite high biogenic emissions; similar to findings from mid-latitude forests, as discussed above. 
During the Guyanas Atmosphere-Biosphere exchange and Radicals Intensive Experiment with the Learjet (GABRIEL) campaign, $\mathrm{OH}$ and $\mathrm{HO}_{2}$ observations were made over the Amazonian rainforest. ${ }^{76,193}$ Model simulations were carried out using both the European Centre for Medium-Range Weather Forecasts-Hamburg/Module Earth Submodel System (ECHAM5/MESSy) global chemistry-climate model $^{193,194}$ and the Module Efficiently Calculating the Chemistry of the Atmosphere (MECCA) box model, ${ }^{193,196}$ using chemistry derived from the MCM. ${ }^{33,34}$ Significant underestimates in the observed $\mathrm{HO}_{x}$ concentrations were apparent, with mean observed to modelled ratios of $12.2 \pm$ 3.5 and $4.1 \pm 1.4$ for $\mathrm{OH}$ and $\mathrm{HO}_{2}$ respectively; ${ }^{196}$ similar to the model to measured discrepancies observed during INTEX-A under high isoprene loadings.

Similarly large discrepancies were observed between models constrained by the MCM and observations of $\mathrm{OH}$ during ground $^{198}$ and airborne ${ }^{197}$ measurements made in the Sabah region of the Borneo rainforest during the Oxidant and Particle Photochemical Processes (OP3) project. ${ }^{209}$ With the additional constraint of a measurement of total $\mathrm{OH}$ reactivity, the magnitude of the missing $\mathrm{OH}$ source at the ground $(4 \mathrm{~m})$ was determined to be approximately a factor of 10 greater than the sum of the known $\mathrm{OH}$ sources used to constrain the model, as shown in Fig. 12; whilst flights over isoprene influenced regions above the Borneo rainforest determined a mean observed to modelled ratio of $\sim 5$ for $\mathrm{OH}$. In contrast to the large model underestimates of $\mathrm{HO}_{2}$ reported during the GABRIEL and INTEX-A projects, airborne $\mathrm{HO}_{2}$ was reasonably well represented by models containing standard chemistry with a mean observed to modelled ratio of 1.18; the model was found to slightly overestimate $\mathrm{HO}_{2}$ observations at the ground site. Similar trends were observed during the PRIDE-PRD project ${ }^{74}$ with the standard model reproducing the $\mathrm{HO}_{2}$ observations well for the entire day whilst $\mathrm{OH}$ was significantly underpredicted under low NO conditions. One

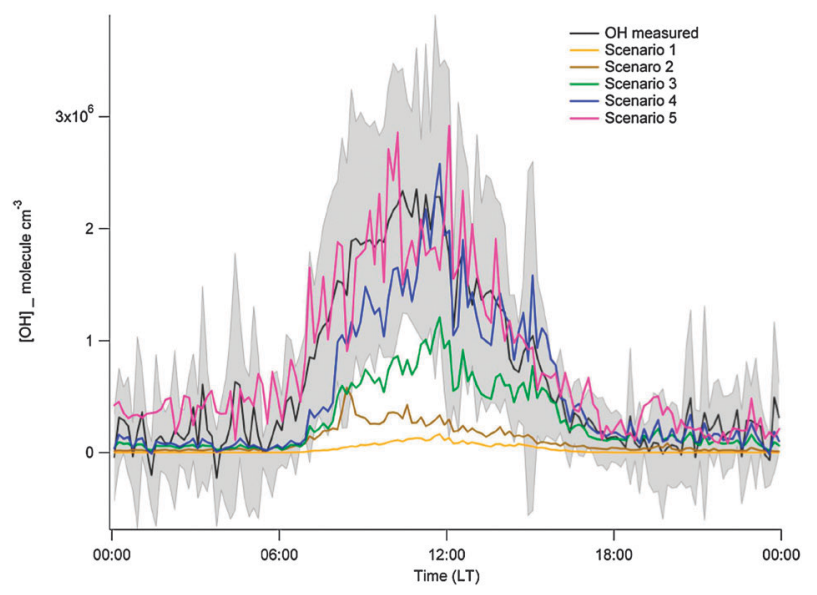

Fig. 12 Diurnal profile of measured $\mathrm{OH}$ concentrations during the OP-3 campaign in Borneo (black line) together with model calculations constrained by the measured $\mathrm{OH}$ reactivity and various source terms (Scenarios 1-5). Unless a significant $\mathrm{OH}$ recycling term during the oxidation of isoprene is included, the measured/modelled ratio of $[\mathrm{OH}]$ is high. (Reproduced from ref. 198, Copyright (2011), with permission from Copernicus Publications.) possible explanation for the differences in the model to observed $\mathrm{HO}_{2}$ ratios reported during GABRIEL and INTEX-A compared to the ratios reported from PRIDE-PRD and OP3 may in part be caused by instrumental differences or interferences that have recently been identified and discussed in Section 3.1. Fuchs et al. ${ }^{30}$ demonstrated that LIF instruments that rely on chemical titration of $\mathrm{HO}_{2}$ to $\mathrm{OH}$ with $\mathrm{NO}$ for $\mathrm{HO}_{2}$ detection can suffer positive bias (to varying degrees) by partial chemical conversion of certain $\mathrm{RO}_{2}$ radicals to $\mathrm{OH}$. Alkene-derived $\mathrm{RO}_{2}$ species, formed by $\mathrm{OH}$ addition rather than $\mathrm{H}$-atom abstraction, have the potential to interfere with the $\mathrm{HO}_{2}$ measurement, owing to fast decomposition of the RO radical that forms in the presence of $\mathrm{NO}$ in the FAGE detection cell, ultimately generating $\mathrm{OH}$. Under the operating conditions employed during the OP3 campaign the groundbased FAGE system was relatively insensitive to this interference. ${ }^{210}$ The high pumping capacity and fast gas throughput of the fluorescence cell, coupled with incomplete mixing of $\mathrm{NO}$ into the ambient air stream for $\mathrm{HO}_{2}$ titration effectively minimised the interference from the ambient $\mathrm{RO}_{2}$ radicals present. Experiments revealed that decomposition of ethene-derived $\mathrm{RO}_{2}$ radicals contributed a $12 \% \mathrm{HO}_{2}$ yield. Model simulations suggest, as an upper limit, $10 \%$ of the $\mathrm{HO}_{2}$ signal observed during OP3 may be attributed to $\mathrm{RO}_{2}$ radicals. For the aircraft measurements during OP3, model simulations show that, on average, $23 \%$ of the measured $\mathrm{HO}_{2}$ may be due to an interference from $\mathrm{RO}_{2}$ radicals. Fuchs et al. ${ }^{30}$ found that $\mathrm{RO}_{2}$ species formed from alkene and aromatic precursors were detected as $\mathrm{OH}$ with relative sensitivities greater than $80 \%$ with respect to that for $\mathrm{HO}_{2}$ in their FAGE system, corresponding to an estimated interference of 30\% during PRIDEPRD, whilst a relative sensitivity of $60 \%$ was determined for the Penn State instrument used during INTEX-A. ${ }^{31}$ These findings highlight that the level of the interference is highly dependent upon cell designs and set-ups. Accounting for this artefact signal would help to reduce the large underprediction of $\mathrm{HO}_{2}$ reported during GABRIEL and INTEX-A; the magnitude of the reduction would ultimately depend upon the $\mathrm{RO}_{2}$ loading in each environment as well as the relative sensitivity of each instrument to these species.

\subsection{Novel $\mathrm{OH}$ sources under BVOC rich, $\mathrm{NO}_{x}$ poor conditions}

The growing dataset supporting a large unknown $\mathrm{OH}$ source in VOC rich $\mathrm{NO}_{x}$ poor environments has, in recent years, sparked considerable interest in the atmospheric community, and has led to a range of novel mechanisms being identified that could provide a significant source of $\mathrm{OH}$ under biogenically influenced conditions and potentially resolve the discrepancies between models and observations that have been discussed above.

Lelieveld et al. ${ }^{193}$ propose that the missing $\mathrm{OH}$ in the model for GABRIEL may derive from potential $\mathrm{OH}$ producing channels in $\mathrm{HO}_{2}+\mathrm{RO}_{2}$ reactions. Production of $\mathrm{OH}$ in certain $\mathrm{HO}_{2}+\mathrm{RO}_{2}$ reactions has been observed directly by Dillon and Crowley, ${ }^{211}$ and has been inferred by product studies. ${ }^{212-216}$ Inclusion of $\mathrm{OH}$ production in reactions of $\mathrm{HO}_{2}$ with peroxy radicals derived from isoprene $\left(\mathrm{ISOPO}_{2}\right)$ in the MECCA box model provided a marked improvement in 


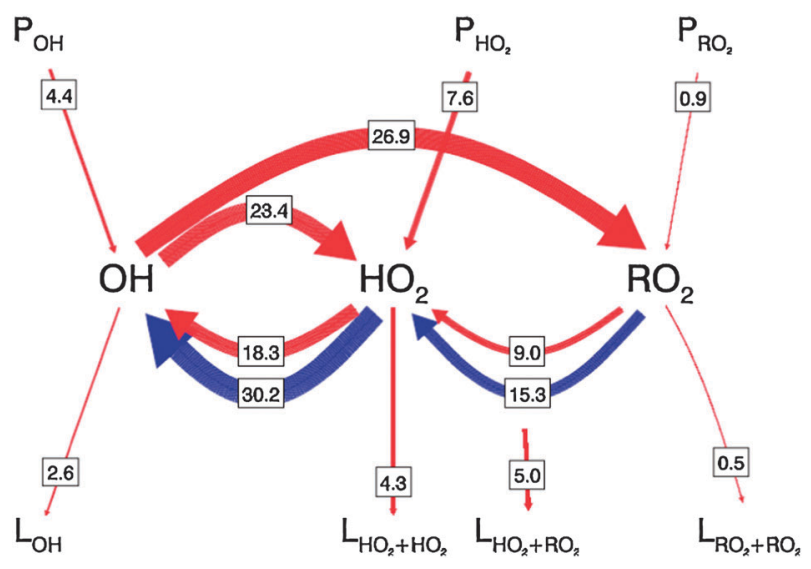

Fig. 13 Schematic of the chemistry of tropospheric $\mathrm{OH}$ radicals during PRIDE-PRD as proposed by Hofzumahaus et al. (2009). ${ }^{22}$ The arrows represent chemical processes which generate $(\mathrm{P})$, remove (L) or interconvert radicals with the width of the arrows scaled to reactions rates $\left(\mathrm{ppbv} \mathrm{h}^{-1}\right)$ at 12:00 $\mathrm{LT}$, given by the numbers in the boxes. The red arrows represent known reaction pathways and the blue arrows the additional recycling processes required to maintain the high levels of $\mathrm{OH}$ observed. (Reproduced from ref. 22, Copyright (2009), with permission from American Association for the Advancement of Science.)

model success for $\mathrm{OH}$ and $\mathrm{HO}_{2} \cdot{ }^{193,196}$ However, high branching ratios for $\mathrm{OH}$ producing channels (200 to 400\%) were required in the model, and generation of $\mathrm{OH}$ in reactions of $\mathrm{HO}_{2}$ with $\mathrm{RO}_{2}$ radicals has thus far only been observed for $\mathrm{RO}_{2}$ radicals containing acyl, -carbonyl, -hydroxy or -alkoxy functionalities. $^{211-216}$ The observed branching ratio for $\mathrm{OH}$ production from $\mathrm{RO}_{2}$ radicals structurally similar to $\mathrm{ISOPO}_{2}$ has been given an upper limit of $6 \% \cdot{ }^{211}$ Hofzumahaus et al. ${ }^{74}$ found that the inclusion of an additional $\mathrm{OH}$ production channel from $\mathrm{HO}_{2}+\mathrm{RO}_{2}$ reactions within the RACM model constrained by total $\mathrm{OH}$ reactivity was not able to reproduce $\mathrm{OH}$ observations during PRIDE-PRD. Instead an unidentified species able to convert $\mathrm{RO}_{2}$ to $\mathrm{HO}_{2}$ and $\mathrm{HO}_{2}$ to $\mathrm{OH}$ independently of $\mathrm{NO}$ and without producing $\mathrm{O}_{3}$ was necessary to replicate diurnal cycles of $\mathrm{OH}$ and $\mathrm{HO}_{2}$ as shown in Fig. 13. Similarly, ground observations of $\mathrm{OH}$ and $\mathrm{HO}_{2}$ made during OP3 could be reproduced if 0.74 ppbv NO equivalent of an unknown species able to convert $\mathrm{HO}_{2}$ to $\mathrm{OH}$ at the same rate of NO was included in model calculations. ${ }^{198}$

In chamber studies Paulot et al. ${ }^{217}$ demonstrated that the reaction of $\mathrm{OH}$ with isoprene-hydroxy-hydroperoxides (ISOPOOH), produced in the reaction of isoprene derived peroxy radicals $\left(\mathrm{ISOPO}_{2}\right)$ with $\mathrm{HO}_{2}$, can lead to the formation of epoxide species with regeneration of $\mathrm{OH}$ under low $\mathrm{NO}_{x}$ conditions. Density functional theory (DFT) calculations have predicted the unimolecular decomposition of $\beta-\mathrm{ISOPO}_{2}$ radicals (the dominant ISOPO$_{2}$ isomers), resulting in production of $\mathrm{OH}$, formaldehyde and (depending on the isomer) MVK or MACR ${ }^{218}$ However, the rates of decomposition are expected to be slow, and may not be sufficient to compete effectively with the bimolecular reactions of ISOPO 2 radicals with $\mathrm{HO}_{2}$ and NO in all but the most remote environments. ${ }^{218}$ Theoretical investigation of the $\mathrm{OH}$-initiated oxidation of isoprene using ab initio quantum calculations by the Leuven group has also led to the proposal of $\mathrm{HO}_{x}$ radical production following unimolecular processes in $\mathrm{ISOPO}_{2}$ radicals. ${ }^{219-221}$ Fig. 14 shows the calculated pathways for the $\mathrm{OH}$-initiated oxidation of isoprene, which is referred to as the "Peeters' mechanism" or "Leuven Isoprene Mechanism" (LIM).

Under low $\mathrm{NO}_{x}$ conditions, the fastest pathways occur through unimolecular 1,6- $\mathrm{H}$ shifts in two of the isomeric $\mathrm{ISOPO}_{2}$ radicals, producing $\mathrm{HO}_{2}$ and unsaturated hydroperoxyaldehydes (HPALDs). The HPALD products have recently

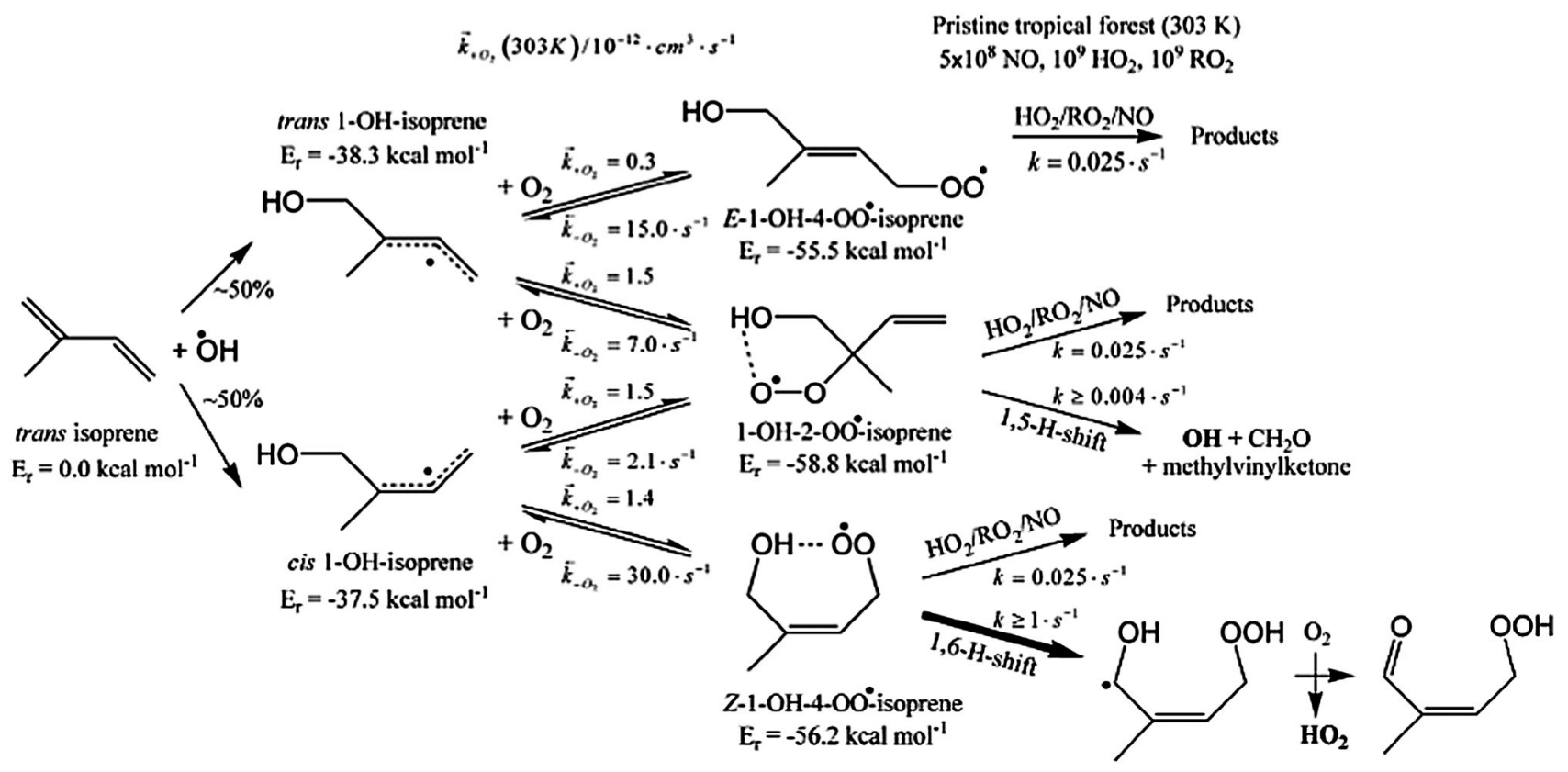

Fig. 14 Outline of the initial steps in the Leuven Isoprene Mechanism, also known as the Peeters' mechanism, with their predicted rates, following 1-OH addition to isoprene. (Reproduced from ref. 219, Copyright (2009), with permission from the PCCP Owner Societies.) 
been demonstrated to photolyse with an $\mathrm{OH}$ yield of $\sim 1$, , $^{31,222}$ owing to the combination of the $-\mathrm{OOH}$ hydroperoxide moiety and an $\mathrm{O}=\mathrm{C}-\mathrm{C}=\mathrm{C}$ chromophore, thereby increasing the yield of both $\mathrm{OH}$ and $\mathrm{HO}_{2} \cdot{ }^{219}$ Subsequent chemistry of the organic fragments of HPALD photolysis, resulting in rapid production of photolabile peroxy-acid-aldehydes (PACALDs), is also expected to increase the $\mathrm{OH}$ and $\mathrm{HO}_{2}$ yields further. $^{219-221}$ A number of modelling studies have assessed the potential impact of these modified isoprene mechanisms. ${ }^{197,223-226}$ A global modelling study by Stavrakou et al. ${ }^{223}$ using the Intermediate Model of Global Evolution of Species - version 2 (IMAGESv2) global chemistry transport model has shown that the Peeters' mechanism is able to reproduce average boundary layer concentrations of $\mathrm{OH}$ and $\mathrm{HO}_{2}$ observed during GABRIEL and INTEX-A aircraft campaigns to within $30 \%$. Implementation of the Peeters' mechanism in this model increased the modelled $\mathrm{OH}$ concentrations by a factor of up to 4 over densely vegetated areas, and increased the $\mathrm{HO}_{2}$ concentrations by a factor between 2.5 and $3 .{ }^{223}$ The epoxide scheme, ${ }^{217}$ however, gave increases in $\mathrm{OH}$ concentration by a factor of only 0.25 in the same model framework ${ }^{223}$ and could not replicate the observations. Hofzumahaus et al. ${ }^{74}$ rejected additional $\mathrm{HO}_{x}$ initiation pathways, as inclusion in model calculations caused an overestimation in previously well replicated $\mathrm{HO}_{2}$ concentrations; a finding also supported by model-measurement comparisons conducted as part of the OP3 project. ${ }^{197,198}$ It is worth noting that the $\mathrm{RO}_{2}$ interference discussed above in Section 3.1 was not known about at that time and was not considered by Stavrakou et al. ${ }^{223}$ The conclusion of an improved modelled to measured agreement for $\mathrm{HO}_{2}$ measured during INTEX-A and GABRIEL when the Peeters' mechanism is incorporated may need to be reevaluated if there were an interference experienced during these campaigns.

Recent chamber studies under low $\mathrm{NO}_{x}$ conditions ${ }^{227}$ provide experimental evidence that HPALDs do form during $\mathrm{OH}$-initiated isoprene oxidation, supporting the Peeters' mechanism, but the observed rate of formation was approximately 50 times slower than calculated by the Leuven group. Similarly, Karl et al. ${ }^{228}$ found that to reconcile the Peeters' mechanism with the observed OVOC ratios (specifically methacrolein (MACR), methyl vinyl ketone (MVK) and hydroxyacetone) during the Amazonian Aerosol Characterization Experiment (AMAZE) campaign would require the 1,6-shift decomposition rate and the reverse reaction rates of the $Z-1-\mathrm{OH}-4-\mathrm{OO}^{*}$ and $Z-4-\mathrm{OH}-1-\mathrm{OO} *$ peroxy radicals to be reduced. Such an adjustment would lead to a corresponding reduction in the overall $\mathrm{HO}_{x}$ yield from the Peeters' mechanism, with an approximate yield of $0.1 \mathrm{HO}_{2}$ and $0.12 \mathrm{OH}$ radicals, thus significantly reducing the overall potential of the mechanism to regenerate $\mathrm{HO}_{x}$.

Pugh et al., ${ }^{195}$ using the Cambridge tropospheric trajectory model of chemistry and transport (CiTTyCAT) to assess the chemistry during OP3, suggest that a $50 \%$ reduction in the rate coefficient for reaction with $\mathrm{OH}$ and isoprene (caused by incomplete mixing of isoprene rich air parcels near the surface) was able to resolve the model underestimation of $\mathrm{OH}$ whilst maintaining agreement with measured isoprene and isoprene oxidation products. Experimental evidence suggests, however, that the degree of segregation is unlikely to be greater than $15 \%{ }^{229}$ A similar explanation of segregation was suggested by Butler et al. ${ }^{194}$ to reconcile the model with both $\mathrm{OH}$ and isoprene measurements during GABRIEL. In a recent innovative study, Dlugi et al. ${ }^{88}$ reported the first flux measurements of $\mathrm{OH}$ and $\mathrm{HO}_{2}$ using FAGE, measured at a height of $37 \mathrm{~m}$, $7 \mathrm{~m}$ above the canopy of a mixed deciduous forest in Julich using the eddy covariance method. Fluxes of isoprene, the sum of MVK and MACR and the sum of monoterpenes were also measured using a proton transfer mass spectrometer (PTR-MS). The measurements, made during the ECHO (Emission and CHemical transformation of biogenic volatile Organic compounds) intensive field study in July 2003, showed an upward flux for $\mathrm{HO}_{2}$ out of the canopy, and a downward flux for $\mathrm{OH}$. This suggests a significant local chemical sink of $\mathrm{OH}$ and conversion to $\mathrm{HO}_{2}$ above the canopy. For $\mathrm{OH}$ the measured flux is balanced by chemical production and loss, with direct transport playing no role, whereas for $\mathrm{HO}_{2}$, with a longer chemical lifetime ( $20 \mathrm{~s}$ in this study), the radical balance is significantly influenced by both chemistry and transport. ${ }^{88}$ The segregation of $\mathrm{OH}$ and BVOCs was also calculated for the measurements, and the effective rate constant for $\mathrm{OH}$ reacting with isoprene was $15 \%$ lower than the normal value due to inhomogeneous mixing of the reactants, close to that reported by Pugh et al. ${ }^{229}$

\subsection{A possible $\mathrm{OH}$ interference in low $\mathrm{NO}_{x}$ regions influenced by biogenic emissions}

It would therefore not seem possible to simultaneously reconcile all field observations of $\mathrm{OH}$ and $\mathrm{HO}_{2}$, isoprene and isoprene oxidation products using suggestions that have been put forward relating to the $\mathrm{OH}$ initiated oxidation chemistry of isoprene. As discussed in Section 3.2, an alternative explanation is that the measurements made in these environments are subject to an artefact giving a positive bias. The $\mathrm{OH}$ observations discussed above have primarily been detected using LIF. Mao et al. $^{31}$ have demonstrated that the measured $\mathrm{OH}$ concentration in a low $\mathrm{NO}_{x}$ high BVOC environment is different depending on the method used to determine the background signal. In the first method, the background signal is determined by shifting the laser wavelength from an $\mathrm{OH}$ absorption line to an offline wavelength and subsequent subtraction of this background gives the $\mathrm{OH}$ concentration (OH-wave). In the second method, the background is determined with the laser wavelength fixed on an $\mathrm{OH}$ absorption line and $\mathrm{C}_{3} \mathrm{~F}_{6}$ is periodically added to the FAGE detection cell to chemically scrub the ambient $\mathrm{OH}$ to determine the background signal for subsequent subtraction to give the $\mathrm{OH}$ concentration (OH-chem). During the Biosphere Effects on Aerosols and Photochemistry Experiment (BEARPEX)-09, the $\mathrm{OH}$-chem signal agreed well with model estimates of $\mathrm{OH}$ derived using a RACM model constrained with standard isoprene chemistry, with no novel $\mathrm{OH}$ recycling mechanism required but $\mathrm{OH}$-wave was significantly higher than $\mathrm{OH}$-chem and the model calculations. Mao et al. $^{31}$ suggest that the difference between $\mathrm{OH}$-wave and $\mathrm{OH}$-chem may be caused by a BVOC oxidation product rapidly forming $\mathrm{OH}$ within the FAGE detection cell. In support of this, the discrepancy 
between $\mathrm{OH}$-wave and $\mathrm{OH}-\mathrm{chem}$ displayed a marked temperature dependence with agreement between the two methods observed at $295 \mathrm{~K}$ whilst $\mathrm{OH}$-wave became more than twice that of $\mathrm{OH}$-chem at temperatures over $300 \mathrm{~K}$. During BEARPEX-2007, modelled to measured agreement for key BVOC oxidation products such as glyoxyal ${ }^{230}$ and acyl peroxy nitrates $^{231}$ improved considerably when the model was constrained to a scaled $\mathrm{OH}$-wave (determined from the ratio of OH-wave to OH-chem measured during BEARPEX-09) providing indirect evidence of an $\mathrm{OH}$ interference using this FAGE instrument under high BVOC loadings. Owing to differences in instrumental design, for example flow geometry, pumping capacity, cell pressure, laser frequency and optical paths it is unlikely that other FAGE instruments will suffer the same level of interference. A similar FAGE instrument was compared with a CIMS instrument during the HUMPPACOPEC (Hyytiala United Measurement of Photochemistry and Particles-Comprehensive Organic Particle and Environmental Chemistry) campaign in a boreal forest in Finland in 2010, with initial reports suggesting the observations of $\mathrm{OH}$ by LIF to be a factor of 10 greater than those observed by CIMS. ${ }^{232}$ Mao et al. ${ }^{31}$ suggested that interferences may also differ among different forested environments. If, for example, the interfering species is a product of ozonolysis, then, owing to the low $\mathrm{O}_{3}$ levels typically found in tropical forests ( $\sim 10 \mathrm{ppbv})$ compared to levels typically observed in Blodgett forest (mean $\mathrm{O}_{3}$ of $54 \mathrm{ppbv}$ during BEARPEX-09), the artefact $\mathrm{OH}$ signal may be expected to be much reduced in the tropical forest. There is support for the elevated levels of $\mathrm{OH}$ observed during $\mathrm{OP} 3^{198}$ from co-observations of formaldehyde and glyoxal made using DOAS during OP3, which could only be reproduced during model simulations if the model was constrained to the $\mathrm{OH}$ that was observed. ${ }^{233}$

\subsection{Summary of model measurement comparisons in regions influenced by high biogenic emissions}

Observations of hydroxyl and hydroperoxy radicals in environments containing high levels of biogenic emissions and comparison with detailed chemical box models have revealed major gaps in our understanding of the oxidation processes occurring in these regions. In fact, some of the largest discrepancies between measured and modelled $\mathrm{OH}$ have occurred in recent studies in these environment. The earliest measurement studies highlighted the importance of constraining models with a complete inventory of $\mathrm{OH}$ sinks and demonstrate that large model overpredictions of $\mathrm{OH}$ can occur if there are major omissions. In regions influenced by a diverse range of VOC such as forests, a measurement of the total $\mathrm{OH}$ reactivity can be extremely useful in testing the completeness of a model.

Isoprene levels were modest during the Fritz Peak/Idaho Hill studies. In the more recent studies in a range of forested environments, a clear trend between models and observations has emerged particularly in isoprene rich, $\mathrm{NO}_{x}$ poor environments with models consistently underpredicting the $\mathrm{OH}$ concentrations observed by a considerable amount, sometimes by a factor of 10. Evidence supporting this finding is limited to studies undertaken under extremely low $\mathrm{NO}_{x}$ conditions, which suggests that the mechanisms for VOC oxidation are less well understood when reactions between peroxy radicals and NO do not dominate.

The ability of models to reproduce $\mathrm{HO}_{2}$ in these regions is more variable with a number of model comparisons underpredicting $\mathrm{HO}_{2}$, whilst others reproduce concentrations and diurnal profiles well despite similar $\mathrm{VOC}$ and $\mathrm{NO}_{x}$ loadings. Some of this discrepancy may be resolved by taking into account the recently discovered $\mathrm{RO}_{2}$ interference that will impact $\mathrm{HO}_{2}$ measurements made using FAGE instruments to varying degrees depending upon the instrumental set-up and ambient $\mathrm{RO}_{2}$ loadings. $\mathrm{HO}_{2}$ sinks may also be poorly represented within models and could vary between the different measurement sites, and better constraints of these may also help to resolve the differences observed.

Very recently, $\mathrm{OH}$ artefact signals have been identified in one FAGE system, and believed to be limited to measurements undertaken under VOC rich conditions at higher temperatures, although the species causing the interference are yet to be identified. The extent of any potential interference suffered by other FAGE systems will likely depend upon individual instrumental design. Indirect evidence from the measurement and modelling of isoprene oxidation products can be used to support or otherwise refute the elevated $\mathrm{OH}$ levels observed during these forested campaigns.

Recent laboratory, chamber and theoretical studies have helped to better constrain the isoprene oxidation mechanism. To date, however, not one mechanism can satisfactorily reconcile all $\mathrm{OH}$ and $\mathrm{HO}_{2}$ observations that have been made in these environments influenced by large emissions of biogenic VOCs.

A process not considered routinely in the models described above is the excitation of weak absorption features, for example vibrational overtone transitions in organic peroxides, ${ }^{307}$ which are hypothesised to promote photolysis to form $\mathrm{HO}_{x}$. However, constraints on the rate of certain key processes that have been suggested, for example the photolysis and $\mathrm{OH}$ reactivity of HPALDs, are beginning to emerge from intense activity both in the laboratory and in instrumented chamber studies.

\section{Studies in polluted environments}

\subsection{Urban conurbations}

While marine and forested regions cover a significant proportion of the globe, atmospheric composition and air quality in urban regions have the greatest direct impact on human health, as more than $50 \%$ of the world's population now reside in urban conurbations. ${ }^{234}$ Despite this, there have been relatively few field experiments to investigate $\mathrm{HO}_{x}$ chemistry in urban areas, largely as a result of problems associated with supporting measurements of the large numbers of VOCs present in such environments. Measurements of $\mathrm{OH}$ reactivity can help in such circumstances, enabling quantification of the total sink for $\mathrm{OH}$, which includes reaction of $\mathrm{OH}$ with species, either directly emitted or secondary oxidation products, that are not measured directly.

Table 4 provides a summary of measurements and model comparisons for $\mathrm{OH}$ and $\mathrm{HO}_{2}$ in polluted urban environments. 


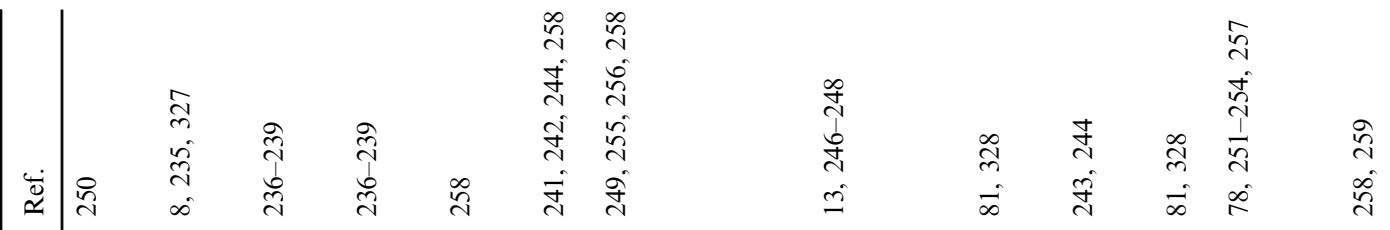

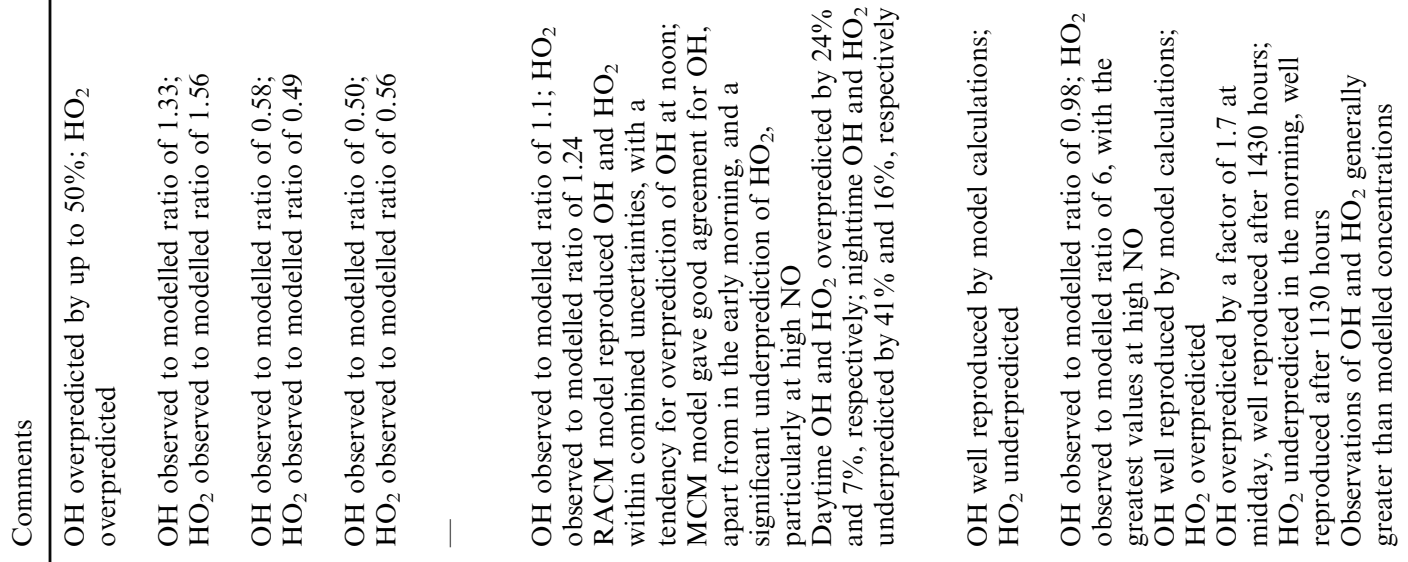

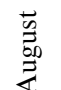

妾棎

完

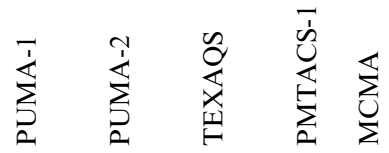

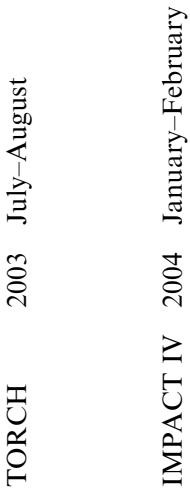

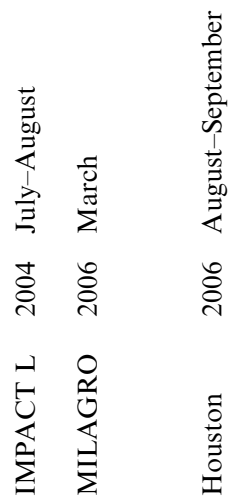


Earlier measurements in urban areas have been reviewed by Heard and Pilling ${ }^{23}$ and by Kanaya et al. ${ }^{81}$

Observations of $\mathrm{OH}$ and $\mathrm{HO}_{2}$ by LIF-FAGE were combined with determination of $\mathrm{OH}$ reactivity during the Southern Oxidant Study (SOS) in the polluted metropolitan environment of Nashville in 1999, representing the first direct measurements of $\mathrm{OH}$ reactivity in the atmosphere. ${ }^{8,235}$ The reactivity measurements indicated that $30 \%$ of the total $\mathrm{OH}$ reactivity in Nashville resulted from VOCs that are not routinely measured during intensive field studies or by the US Environment Protection Agency (EPA) Photochemical Assessment Monitoring Stations, ${ }^{8}$ and enabled analysis of the $\mathrm{HO}_{x}$ data in light of this information. ${ }^{235}$

The diurnal behaviour of $\mathrm{OH}$ and $\mathrm{HO}_{2}$ during $\mathrm{SOS}$ was well described by a box model run to steady state, although the daytime measured mixing ratios of $\mathrm{OH}$ (noontime maximum 0.8 pptv) and $\mathrm{HO}_{2}$ (noontime maximum $80 \mathrm{pptv}$ ) were 1.33 and 1.56 times higher than the modelled values, respectively. ${ }^{235}$ Photolysis of $\mathrm{O}_{3}$ and $\mathrm{HCHO}$ were the main daytime $\mathrm{HO}_{x}$ sources, with strong influences from biogenic emissions and alkene ozonolysis reactions, representing $8 \%$ of the total daytime $\mathrm{HO}_{x}$ production and $95 \%$ of the modelled nighttime production. ${ }^{235}$ Production of $\mathrm{HO}_{2}$ following $\mathrm{NO}_{3}+$ alkene chemistry was not included in the model, but was expected to represent a similar nighttime source strength to that of the ozonolysis chemistry. ${ }^{235}$ While the $\mathrm{NO}_{3}$ chemistry may partly explain the model discrepancies at night, when the modelled $\mathrm{HO}_{2}$ was a factor of 2 to 8 times too low and modelled $\mathrm{OH}$ was a factor of 10 to 100 too low, significant uncertainty remains regarding nighttime $\mathrm{HO}_{x}$ chemistry. ${ }^{235}$ The dominant $\mathrm{HO}_{x}$ sink during the campaign was found to be $\mathrm{OH}+\mathrm{NO}_{2}$, representing $50 \%$ of the total $\mathrm{HO}_{x}$ loss, with other contributions from $\mathrm{HO}_{2}+\mathrm{RO}_{2}$ and net formation of $\mathrm{HONO}$ and $\mathrm{HO}_{2} \mathrm{NO}_{2}{ }^{235}$

In the same year as the SOS study in Nashville, the PUMA (Pollution of the Urban Midlands Atmosphere) campaign investigated urban air pollution and atmospheric chemistry in the UK. ${ }^{236}$ Comparisons of summer (1999) and winter (1999/2000) FAGE measurements of $\mathrm{OH}$ and $\mathrm{HO}_{2}$ in Birmingham during PUMA showed that noontime $\mathrm{OH}$ concentrations in winter $\left(\sim 1.5 \times 10^{6}\right.$ molecule $\left.\mathrm{cm}^{-3}\right)$ were only a factor 2 lower than the equivalent measurements in summer $(\sim 3.0 \times$ $10^{6}$ molecule $\mathrm{cm}^{-3}$ ), despite a factor of 15 reduction in $\mathrm{OH}$ production following photolysis of ozone. ${ }^{237}$ A box model, using the MCM and constrained to $15 \mathrm{~min}$ average measurements of long-lived species, yielded modelled to measured ratios of 0.58 and 0.50 for $\mathrm{OH}$ between the hours of 1100 and 1500 for the summer and winter datasets, respectively. ${ }^{238}$ Concentrations of $\mathrm{HO}_{2}$ were found to be similar between the summer and winter campaigns, ${ }^{237}$ and were also underpredicted by the model. ${ }^{238}$ The modelled to measured ratios of 0.56 and 0.49 were obtained for $\mathrm{HO}_{2}$ between 1100 and 1500 for summer and winter, respectively. ${ }^{238}$ Sensitivity analyses on the model were unable to identify potential sources of the discrepancy, although the modelled concentrations of $\mathrm{OH}$ and $\mathrm{HO}_{2}$ were found to be highly sensitive to changes in $\mathrm{NO}_{x}{ }^{238}$

Alkene ozonolysis reactions were found to dominate $\mathrm{OH}$ production in both summer and winter during PUMA, contributing 46 and $62 \%$ of the total $\mathrm{OH}$ production, respectively,
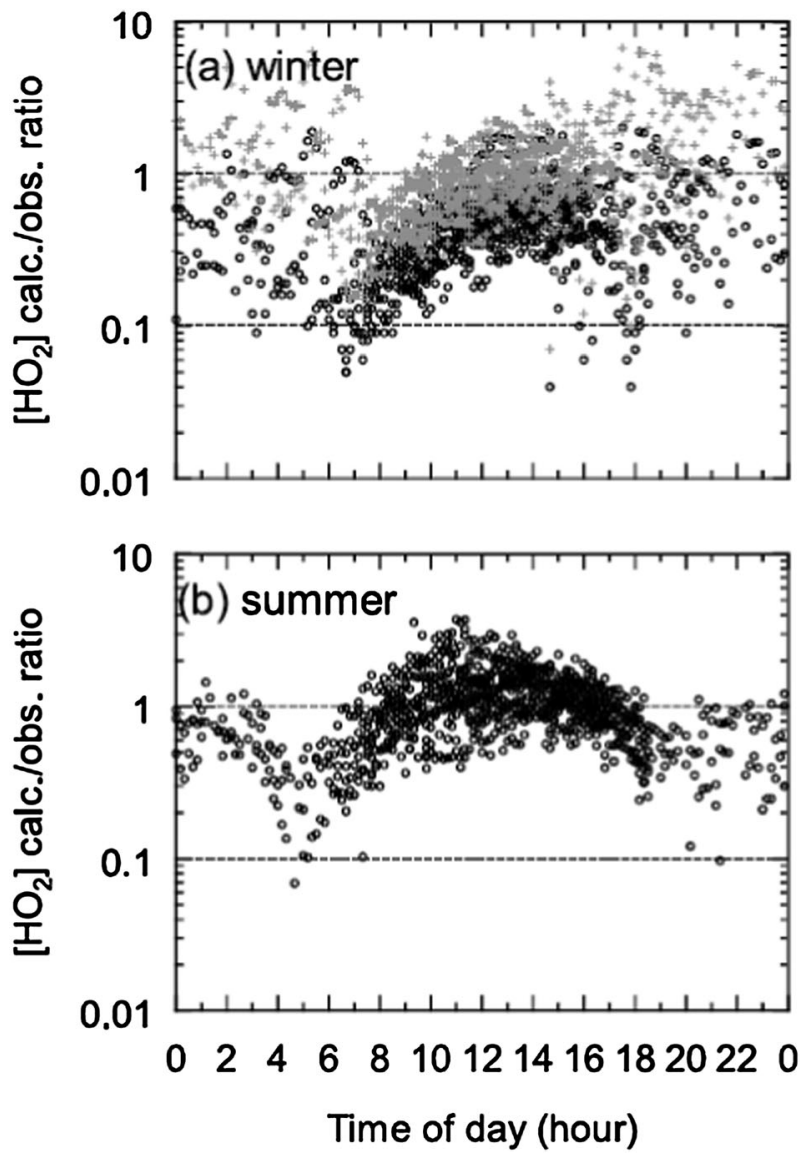

Fig. 15 Diurnal variations in the calculated to observed ratio for $\mathrm{HO}_{2}$ in (a) winter and (b) summer during the IMPACT campaigns in Tokyo in 2004 showing the model underestimate in winter and overestimate in summer. (Reproduced from ref. 81, Copyright (2007) American Geophysical Union, reproduced by permission of American Geophysical Union. Further reproduction or electronic distribution is not permitted.)

and largely responsible for the maintenance of relatively high $\mathrm{OH}$ concentrations during the winter campaign. ${ }^{237,239}$ In summer, production from $\mathrm{O}_{3}$ photolysis comprised $24 \%$ of the total $\mathrm{OH}$ production, but only $0.6 \%$ in winter. ${ }^{237,239}$ Production of $\mathrm{HO}_{2}$ was dominated in summer and winter by the photolysis of $\mathrm{HCHO}$ and other carbonyl compounds. ${ }^{237,239}$

The role of alkene ozonolysis reactions in $\mathrm{HO}_{x}$ production was also investigated in a study in Tokyo, which found that although ozonolysis reactions were important for daytime winter $\mathrm{HO}_{x}$ production and production at night during summer and winter, carbonyl photolysis and HONO photolysis were also important in summer and winter. ${ }^{81}$ During the winter (January-February 2004), median daytime peaks of $1.5 \times 10^{6}$ molecule $\mathrm{cm}^{-3}$ and 1.1 pptv were observed for $\mathrm{OH}$ and $\mathrm{HO}_{2}$, respectively, compared to values of $6.3 \times 10^{6}$ molecule $\mathrm{cm}^{-3}$ and $5.7 \mathrm{pptv}$ for $\mathrm{OH}$ and $\mathrm{HO}_{2}$, respectively, during the summer (July-August 2004). ${ }^{81} \mathrm{~A}$ box model using RACM chemistry was generally able to reproduce the daytime $\mathrm{OH}$ observations in summer and winter, but $\mathrm{HO}_{2}$ was underestimated in winter and overestimated in summer as shown in Fig. $15 .^{81}$

Inhomogeneities in $\mathrm{NO}_{x}$ concentrations were proposed as a source of uncertainty in the model results, since the $\mathrm{NO}_{x}$ 
measurements were made at a distance of $250 \mathrm{~m}$ from the $\mathrm{OH}$ and $\mathrm{HO}_{2}$ measurements. ${ }^{81}$ In addition, concurrent measurements of $\mathrm{OH}$ reactivity during winter provided evidence for missing $\mathrm{OH}$ sinks. ${ }^{82,83,240}$ Inclusion of additional alkanes and alkenes in the model analysis for $\mathrm{OH}$ and $\mathrm{HO}_{2}$ yielded increases in the modelled $\mathrm{HO}_{2}$, owing to $\mathrm{HO}_{x}$ production through ozonolysis of the additional alkenes, but had little impact on the modelled $\mathrm{OH}$ owing to a balance between the increase in $\mathrm{HO}_{x}$ production through ozonolysis and an increase in $\mathrm{OH}$ loss through $\mathrm{OH}+$ alkane and $\mathrm{OH}+$ alkene reactions. $^{81}$

In contrast to the results obtained in Tokyo and in Birmingham during the PUMA campaign, the PMTACS (PM2.5 Technology Assessment and Characteristics Study) study in New York in summer 2001 found that photolysis of HONO was the dominant $\mathrm{HO}_{x}$ source during the day, constituting $\sim 56 \%$ of the total daytime $\mathrm{HO}_{x}$ production as a result of high HONO concentrations $(\sim 1.4 \mathrm{ppbv}$ on average in the morning). ${ }^{241,242}$ Unfortunately, HONO observations were not made during PUMA, ${ }^{236}$ and were only made in the winter campaign in Tokyo. ${ }^{81}$ Alkene ozonolysis reactions were found to represent only $10 \%$ of the total daytime $\mathrm{HO}_{x}$ sources in New York, and were only of significance during the night. ${ }^{242}$ Loss of $\mathrm{HO}_{x}$ was dominated $(99.3 \%)$ by the reaction of $\mathrm{OH}$ with $\mathrm{NO}_{2},{ }^{242}$ with average $\mathrm{NO}_{2}$ levels of $\sim 20-30$ ppbv. ${ }^{241}$ In this study, daytime maximum $\mathrm{OH}$ concentrations of 5-20 $\times$ $10^{6}$ molecule $\mathrm{cm}^{-3}$ were observed, and reproduced by a box model using RACM chemistry with an observed to modelled ratio of 1.10 during the day. ${ }^{241,242}$ Daytime maximum $\mathrm{HO}_{2}$ concentrations of $0.4-6 \times 10^{8}$ molecule $\mathrm{cm}^{-3}$ were observed, and the model was able to reproduce daytime and nighttime $\mathrm{HO}_{2}$ with an average observed to modelled ratio of $1.24 .^{241,242}$ The $\mathrm{OH}$ reactivity measurements were reproduced by model calculations to within $10 \%{ }^{242}$

A subsequent study in the same location in New York in winter 2004 observed maximum $\mathrm{OH}$ mixing ratios of $0.05 \mathrm{pptv}$ $\left(1.4 \times 10^{6}\right.$ molecule $\left.\mathrm{cm}^{-3}\right)$ and maximum $\mathrm{HO}_{2}$ of $0.7 \mathrm{pptv}$ $\left(2.0 \times 10^{7}\right.$ molecule $\left.\mathrm{cm}^{-3}\right)$, approximately one fifth of the concentrations observed in the same location in summer $2001 .^{243}$ The daytime $\mathrm{OH}$ observations were well reproduced by the RACM-based model, with a median measured to modelled ratio of 0.98 , although both day and night $\mathrm{HO}_{2}$ were significantly underpredicted, with a daytime median measured to modelled ratio of 6 and a notably increased discrepancy at high concentrations of NO. ${ }^{243}$

Sources and sinks of $\mathrm{HO}_{x}$ were found to be similar between the summer and winter campaigns. ${ }^{243}$ Average HONO concentrations peaked in the morning at a value of approximately 700 pptv, approximately half that observed in the summer campaign, ${ }^{242}$ decreasing to $\sim 300 \mathrm{pptv}$ at midday and then increasing to $\sim 600$ pptv in the afternoon, and HONO photolysis was responsible for $48 \%$ of the total $\mathrm{HO}_{x}$ production, followed by alkene ozonolysis reactions $(36 \%)$ and $\mathrm{HCHO}$ photolysis $(6 \%){ }^{243}$ Photolysis of $\mathrm{O}_{3}$, followed by reaction of $\mathrm{O}\left({ }^{1} \mathrm{D}\right)$ with water vapour, represented only $1 \%$ of the total $\mathrm{HO}_{x}$ source at the low solar intensities and low $\mathrm{O}_{3}$ mixing ratios ( $\sim 20 \mathrm{ppbv}$ on average) in winter, ${ }^{243}$ compared to $13 \%$ of the total $\mathrm{HO}_{x}$ production in the summer campaign, ${ }^{242}$ with the total rate of $\mathrm{OH}$ production from $\mathrm{O}_{3}$ photolysis decreased by a factor of $\sim 25$ in the winter campaign compared to the summer campaign owing to the differences in $\mathrm{O}_{3}$, solar intensities and water vapour concentrations. Reaction of $\mathrm{OH}$ with $\mathrm{NO}_{2}$ dominated $\mathrm{HO}_{x}$ loss in both summer and winter, and constituted an average of $95 \%$ of the total $\mathrm{HO}_{x}$ sink in winter. ${ }^{243}$

An Air Quality Forecast Modelling System (AQFMS) consisting of a chemical transport model coupled to a mesoscale meteorological forecasting model used to predict air quality and provide warnings regarding air pollution for the Northeastern United States significantly underpredicted HONO, and thus $\mathrm{HO}_{x}$, for both the summer 2001 and winter 2004 campaigns in New York. ${ }^{244}$ The underprediction for $\mathrm{OH}$ was worse for the winter data than for summer, indicating greater uncertainties with the chemical mechanism for winter conditions. ${ }^{244}$

Differences between the radical concentrations observed in New York and those observed in Birmingham during the PUMA campaign were attributed to higher $\mathrm{NO}_{x}$ : VOC ratios in New York, which would drive the $\mathrm{OH}: \mathrm{HO}_{2}$ partitioning towards $\mathrm{OH}$ and increase the efficiency of $\mathrm{OH}+\mathrm{NO}_{2} \cdot{ }^{243}$ The $\mathrm{NO}_{2}$ concentrations in Birmingham were generally between 10 and 30 ppbv, ${ }^{236}$ while those in New York were typically between 20 and 30 ppbv, ${ }^{243}$ with VOC concentrations up to a factor of two higher in Birmingham (e.g. benzene was $\sim 500$ pptv on average) compared to New York. ${ }^{243,245}$ Average temperatures in New York were also approximately $10{ }^{\circ} \mathrm{C}$ lower than those in Birmingham, which may have contributed to decreased radical production rates. ${ }^{243}$

High temperatures and high ozone mixing ratios ( $>110 \mathrm{ppbv})$ were encountered during a heatwave in the TORCH (Tropospheric ORganic CHemistry experiment) campaign near London in summer 2003 and, on average, alkene ozonolysis represented only $29 \%$ of the total $\mathrm{OH}$ source, equivalent to that of HONO photolysis (using modelled HONO concentrations) and less important than $\mathrm{O}\left({ }^{1} \mathrm{D}\right)+\mathrm{H}_{2} \mathrm{O}(42 \%){ }^{246,247}$ Observed daytime maxima in $\mathrm{OH}$ during $\mathrm{TORCH}$ were in the range $1.2-7.5 \times 10^{6}$ molecule $\mathrm{cm}^{-3}$, and were overpredicted by an MCM-based box model by an average of $24 \%{ }^{247}$ On several nights, up to $8.5 \times 10^{6}$ molecule $\mathrm{cm}^{-3}$ were recorded, and were underpredicted by the model. ${ }^{247}$

Noontime maxima of $0.16-3.3 \times 10^{8}$ molecule $\mathrm{cm}^{-3}$ were observed for $\mathrm{HO}_{2}$, and the diurnal profile for $\mathrm{HO}_{2}$ often displayed asymmetry around noon, with secondary peaks occurring in the late afternoon/early evening. ${ }^{247}$ Modelled concentrations of $\mathrm{HO}_{2}$ overpredicted the observations, but only by $7 \%$, and such good model agreement was attributed to the inclusion of a more complete representation of $\mathrm{HO}_{2}$ loss to aerosol surfaces and the inclusion of a greater number of oxygenated VOCs compared to other campaigns. ${ }^{247}$ On average, $\mathrm{HO}_{2}$ production was achieved through photolysis of dicarbonyls (44\%), aldehydes (29\%) and HCHO (24\%). Loss of $\mathrm{HO}_{2}$ was dominated throughout the campaign by loss to aerosol surfaces $(83 \%)$, although a high value for $\mathrm{HO}_{2}$ aerosol uptake was used in this study $\left(\gamma_{\mathrm{HO}_{2}}=0.5\right)$, with an $18 \%$ decrease in modelled $\mathrm{HO}_{2}$ concentrations when $\gamma_{\mathrm{HO}_{2}}$ was changed from 0.02 to 1.0 . Loss of $\mathrm{OH}$ was dominated by reaction with $\mathrm{NO}_{2}(57 \%)$ and $\mathrm{NO}(16 \%){ }^{247}$

The elevated $\mathrm{O}_{3}$ concentrations during the TORCH campaign $\left(>110 \mathrm{ppbv}\right.$ at times $\left.^{246}\right)$ also led to significant radical production at night, primarily through alkene ozonolysis reactions. ${ }^{248}$ Observed mean nighttime concentrations of 
$\mathrm{OH}$ and $\mathrm{HO}_{2}$ were $2.6 \times 10^{5}$ molecule $\mathrm{cm}^{-3}$ and $2.9 \times$ $10^{7}$ molecule $\mathrm{cm}^{-3}$, respectively, but in contrast to the daytime study, the nighttime observations were underpredicted by the model by $41 \%$ for $\mathrm{OH}$ and $16 \%$ for $\mathrm{HO}_{2} \cdot{ }^{248}$ Direct production of $\mathrm{OH}$ and $\mathrm{HO}_{2}$ at night was dominated by alkene ozonolysis reactions $(99.6 \%$ and $92.1 \%$, respectively), with production of $\mathrm{RO}_{2}$ split between ozonolysis reactions $(66 \%)$ and reactions of alkenes with $\mathrm{NO}_{3}(33 \%){ }^{248}$

Although the high $\mathrm{O}_{3}$ concentrations and high temperatures observed during TORCH are somewhat anomalous for the UK, such conditions are not unusual in other locations. High concentrations of ozone are common in locations such as Los Angeles and Mexico City, with a median observed $\mathrm{O}_{3}$ of 115 ppbv in Mexico City in April 2003, ${ }^{249}$ similar to that observed in the UK during the TORCH heatwave. ${ }^{246,248}$ Experiments have been performed to investigate the $\mathrm{HO}_{x}$ chemistry occurring in Los Angeles smog in $1993^{250}$ and in ambient conditions in the Mexico City Metropolitan Area (MCMA) in April $2003^{249}$ and March 2006. ${ }^{78,251-254}$

The Los Angeles experiments were conducted in late September to coincide with the highest ozone levels in the Los Angeles basin. ${ }^{250}$ Midday $\mathrm{OH}$ concentrations were approximately $5.5 \times 10^{6}$ molecule $\mathrm{cm}^{-3}$, and although model calculations were able to reproduce the observations early and late in the day, the modelled $\mathrm{OH}$ at midday was generally $50 \%$ too high. ${ }^{250}$ Similarly, the $\mathrm{HO}_{2}$ observations were well reproduced by the model in the early morning, but the observed midday concentrations of approximately $2 \times 10^{8}$ molecule $\mathrm{cm}^{-3}$ were overpredicted by the model. ${ }^{250}$ Constraining the model to the observed $\mathrm{HO}_{2}$ concentrations improved the simulations for $\mathrm{OH}$, leading to the conclusion that the $\mathrm{HO}_{x}$ sources in the model were too large, the model was missing $\mathrm{HO}_{x}$ loss processes, or the parameterisation of the $\mathrm{RO}_{2} / \mathrm{HO}_{2}$ chemistry used in the model was inadequate to describe the complex behaviour of these radicals.

Mexico City generally suffers more pollution than typical US and European cities, ${ }^{249}$ and in April 2003, GTHOS-FAGE measurements by the Penn State group observed median midday $\mathrm{OH}$ concentrations of $\sim 7 \times 10^{6}$ molecule $\mathrm{cm}^{-3}$ (0.35 pptv) in Mexico City, comparable to those observed in Los Angeles ${ }^{250}$ and other cities in the US. ${ }^{249}$ Observations of $\mathrm{HO}_{2}$ peaked at 1300 hours, an hour later than those for $\mathrm{OH}$, with a median mixing ratio of $40 \mathrm{pptv}$ - higher than recorded in most US cities. ${ }^{249}$ The $\mathrm{HO}_{2}$ observations during the Mexico City Metropolitan Area (MCMA) project were typically 8 times higher than those observed in New York in July $2001,{ }^{241,242,249}$ resulting from large differences in the $\mathrm{HO}_{x}$ sources. $^{249}$ Although photolysis frequencies during the MCMA project were only $40 \%$ higher than those during the New York campaign, mixing ratios of $\mathrm{O}_{3}$ and $\mathrm{HCHO}$ were significantly higher during MCMA, with $\mathrm{HCHO}$ mixing ratios in Mexico City approximately 15 times greater than those in New York at midday and representing approximately $40 \%$ of the total $\mathrm{HO}_{x}$ source. ${ }^{249}$

The similarities in the $\mathrm{OH}$ observations between Mexico City and New York were attributed to the buffering effects of the $\mathrm{OH}$ production and loss processes, while the differences in $\mathrm{HO}_{2}$ observations between the two campaigns, and the day-today variability in the $\mathrm{HO}_{2}$ observations during the MCMA project, were explained by the differences in the $\mathrm{HO}_{x}$ sources. ${ }^{249}$ The sensitivity of $\mathrm{HO}_{2}$, but not $\mathrm{OH}$, to the $\mathrm{HO}_{x}$ sources and sinks was used to demonstrate the need for $\mathrm{HO}_{2}$ measurements alongside $\mathrm{OH}$ to provide a real test of our understanding of fast photochemistry in the atmosphere. ${ }^{249}$ Both $\mathrm{OH}$ and $\mathrm{HO}_{2}$ observations during the MCMA project agreed with RACM-based box model calculations within the combined measurement and modelling uncertainties, although there was a tendency for overestimation of $\mathrm{OH}$ by the model at midday. ${ }^{249}$ A subsequent study using the MCM (v3.1), however, found good agreement for $\mathrm{OH}$ for most of the day, with the exception of an underprediction in the early morning (0600-0700 hours), and a significant underprediction of $\mathrm{HO}_{2}$, particularly at high $\mathrm{NO}_{x}$ levels $(25-130 \mathrm{ppbv}){ }^{255,256}$

Measurements of $\mathrm{OH}$ and $\mathrm{HO}_{2}$ were also made in the Mexico City Metropolitan Area in March 2006 as part of the Megacity Initiative: Local And Global Research Observations (MILAGRO) campaign. ${ }^{78,251}$ The MCMA-2006 measurements were made with the Indiana University FAGE instrument (IU-FAGE), with maximum median observations of $4.6 \times 10^{6}$ molecule $\mathrm{cm}^{-3} \mathrm{OH}$ and $1.9 \times 10^{8}$ molecule $\mathrm{cm}^{-3}$ $\mathrm{HO}_{2}{ }^{78}$ Initial modelling studies, using a box model with chemistry described by the RACM, overpredicted both $\mathrm{OH}$ and $\mathrm{HO}_{2}{ }^{251}$ However, when the model was constrained to dicarbonyl species, using measured concentrations of glyoxal and estimated concentrations of other dicarbonyls such as methylglyoxal, the model underpredicted $\mathrm{HO}_{2}$ in the morning (0800-1130 hours), reaching an underprediction of a factor of 5 at approximately 1000 hours, and overpredicted $\mathrm{OH}$ by a factor of 1.7 around noon. ${ }^{251}$ Observations of $\mathrm{HO}_{2}$ were reasonably well reproduced by the model after 1130 hours, and the modelled $\mathrm{OH}$ was in good agreement with the observations after 1430 hours. ${ }^{251}$

The requirement for additional $\mathrm{HO}_{2}$ sources in the model in the morning was linked to elevated concentrations of benzene and toluene, and it was postulated that there may be missing sources of $\mathrm{HO}_{2}$ related to oxidation of aromatics under high $\mathrm{NO}_{x}$ conditions. ${ }^{251}$ However, as discussed above, the work of Fuchs et al. ${ }^{30}$ indicates the existence of interferences in $\mathrm{HO}_{2}$ measurements by FAGE from $\mathrm{RO}_{2}$ radicals produced following oxidation of unsaturated hydrocarbons. At the current time it is unclear how such interferences may have impacted the $\mathrm{HO}_{2}$ measurements, and hence model agreement, during the MILAGRO campaign.

Analysis of the radical budgets in the model as displayed in Fig. 16 revealed that production of $\mathrm{OH}$ from $\mathrm{O}\left({ }^{1} \mathrm{D}\right)+\mathrm{H}_{2} \mathrm{O}$ represented only $6 \%$ of the total daytime radical production during the MILAGRO campaign. ${ }^{251}$ The main daytime radical sources were found to be photolysis of HONO $(35 \%)$ and $\mathrm{HCHO}(24 \%)$, followed by alkene ozonolysis reactions $(19 \%)$ and photolysis of dicarbonyls $(8 \%)$, with the alkene ozonolysis reactions dominating in the late afternoon and comprising $56 \%$ of the total radical production. In keeping with this work, a study using the WRF-CHEM (Weather Research and Forecast model coupled with chemistry) model found that additional HONO sources were required to reproduce the $\mathrm{HO}_{x}$ concentrations observed during the MILAGRO campaign. ${ }^{257}$ Loss of radicals was dominated by $\mathrm{OH}+\mathrm{NO}_{2}$ $(60 \%)$ and $\mathrm{OH}+\mathrm{NO}(20 \%){ }^{251}$ 


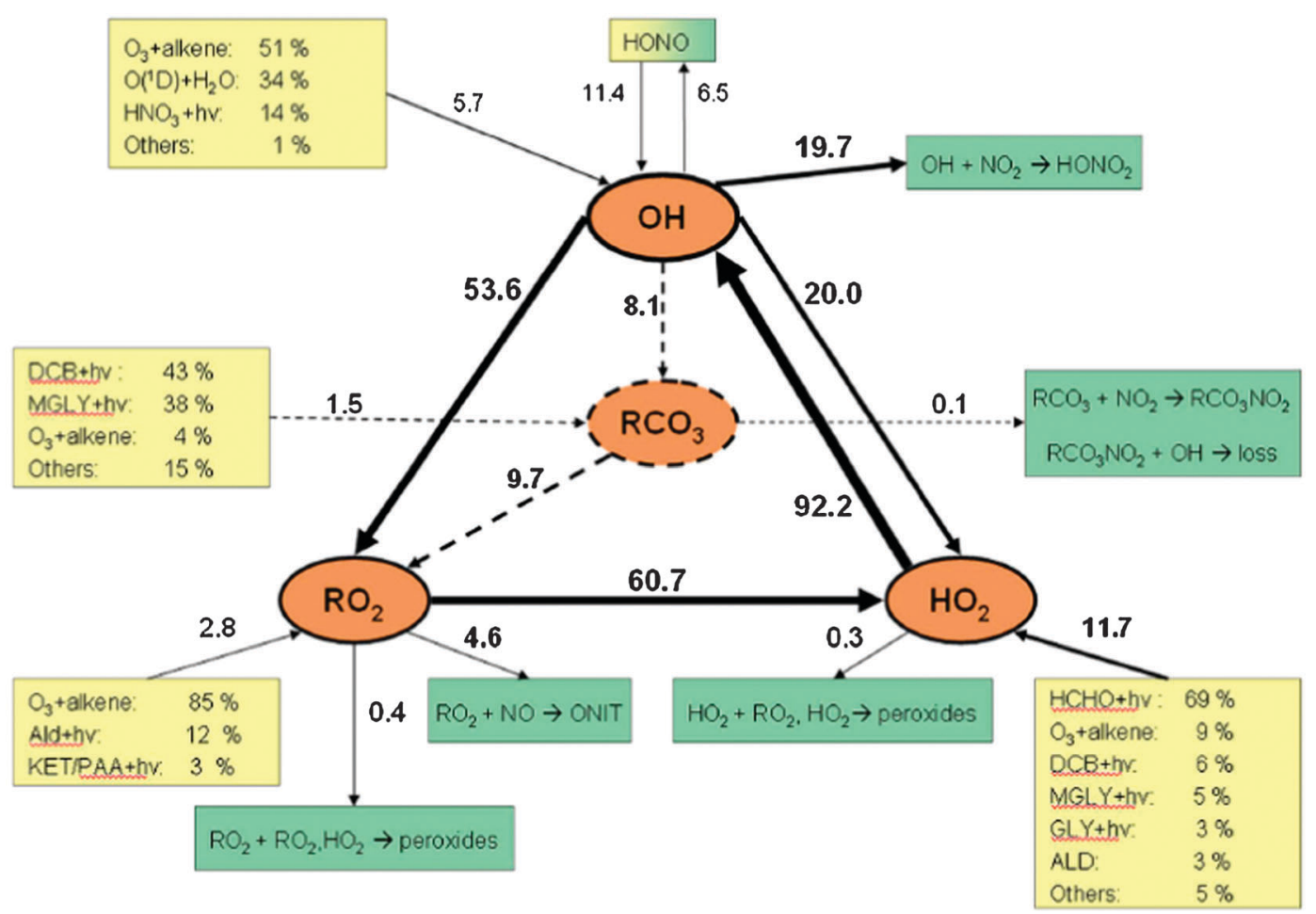

Fig. 16 Median daytime (0840-1840 hours) radical budgets during the MCMA-2006 campaign (reproduced from ref. 251, Copyright (2009), with permission from Copernicus Publications). Rates are in $10^{6}$ molecule $\mathrm{cm}^{-3} \mathrm{~s}^{-1}$.

A comparison between observations made in Mexico City (in 2003), New York in (2001) and Houston (in 2000 and 2006) indicated that the tropospheric photochemistry in Houston was more similar to that observed in Mexico City than New York. ${ }^{258}$ Although production of $\mathrm{HO}_{x}$ was dominated by photolysis of HONO and $\mathrm{HCHO}$ in all three locations, concentrations of $\mathrm{OH}$ and $\mathrm{HO}_{2}$ were found to be higher in Houston than in New York, and the ratio of VOCs to $\mathrm{NO}_{x}$ in Houston was comparable to that in Mexico City, and much lower than in New York. ${ }^{258}$ Such differences arise not only from the differences in climate between the three regions, but also in the extent of air quality regulation, with VOC emissions in New York significantly reduced compared to Houston and Mexico City as a result of regulatory activity. ${ }^{258}$

The 2006 Houston measurements were examined in detail using a box model with a number of different chemical mechanisms (RACM, CB05, LaRC, SAPRC-99, SAPRC-07 and MCMv3.1). ${ }^{259}$ In general, the observed $\mathrm{OH}$ and $\mathrm{HO}_{2}$ concentrations were generally higher than the modelled concentrations. The differences between the various mechanisms were smallest under more polluted conditions, indicating that differences in mechanistic details are less important in polluted conditions as a result of the dominance of reactive nitrogen chemistry, ${ }^{259}$ with similar results reported by Emmerson and Evans. ${ }^{38}$

\subsection{Suburban and semi-polluted continental boundary layer}

Suburban and rural regions display a broad range of $\mathrm{NO}_{x}$ concentrations to test our understanding of $\mathrm{HO}_{x}$ chemistry over a wider variety of conditions. A number of campaigns have been conducted in such regions, summarised in Table 5, with some overlap between regions that could be considered as urban, suburban or rural. The TORCH experiments described above, ${ }^{13,246,247}$ for example, were characterised by air masses from a number of different environments, including air originating from the Atlantic Ocean and passing over mainland UK, air from the Arctic and North Sea, and the more polluted air from UK cities, such as London and Birmingham, and from mainland Europe. ${ }^{13,246,247}$ However, since the TORCH experiments in summer 2003, conducted approximately 25 miles north east of central London, were largely characterised by elevated temperatures and high levels of pollution ${ }^{246,247}$ they are included above in Section 6.1.

Several experiments in suburban and rural regions have been conducted in Germany, including one of the earliest campaigns in such regions (POPCORN, Photochemistry Of Plant-Emitted Compounds and $\mathrm{OH}$ Radicals in Northeastern Germany) ${ }^{103,260-262}$ and long-term measurements of $\mathrm{OH}$ at the Meteorological Observatory Hohenpeissenberg (MOHp) in southern Germany. ${ }^{94,95}$

During the POPCORN campaign in north east Germany in 1994, OH radicals were measured by both FAGE and DOAS, with the two techniques showing good agreement in the concentrations and diurnal variation of $\mathrm{OH}$ (correlation coefficient of $r=0.90$ and slope $=1.09 \pm 0.12$ ) when the two instruments were sampling the same air mass. ${ }^{103}$ Maximum $\mathrm{OH}$ concentrations at the site were on the order of $10^{7}$ molecule $\mathrm{cm}^{-3}$, and the diurnal cycles were closely linked to primary production following photolysis of $\mathrm{O}_{3}{ }^{103,262}$

Although detailed modelling of $\mathrm{OH}$ radicals was not conducted for the POPCORN campaign, the subsequent BERLIOZ (BERLIner OZone experiment) campaign at 


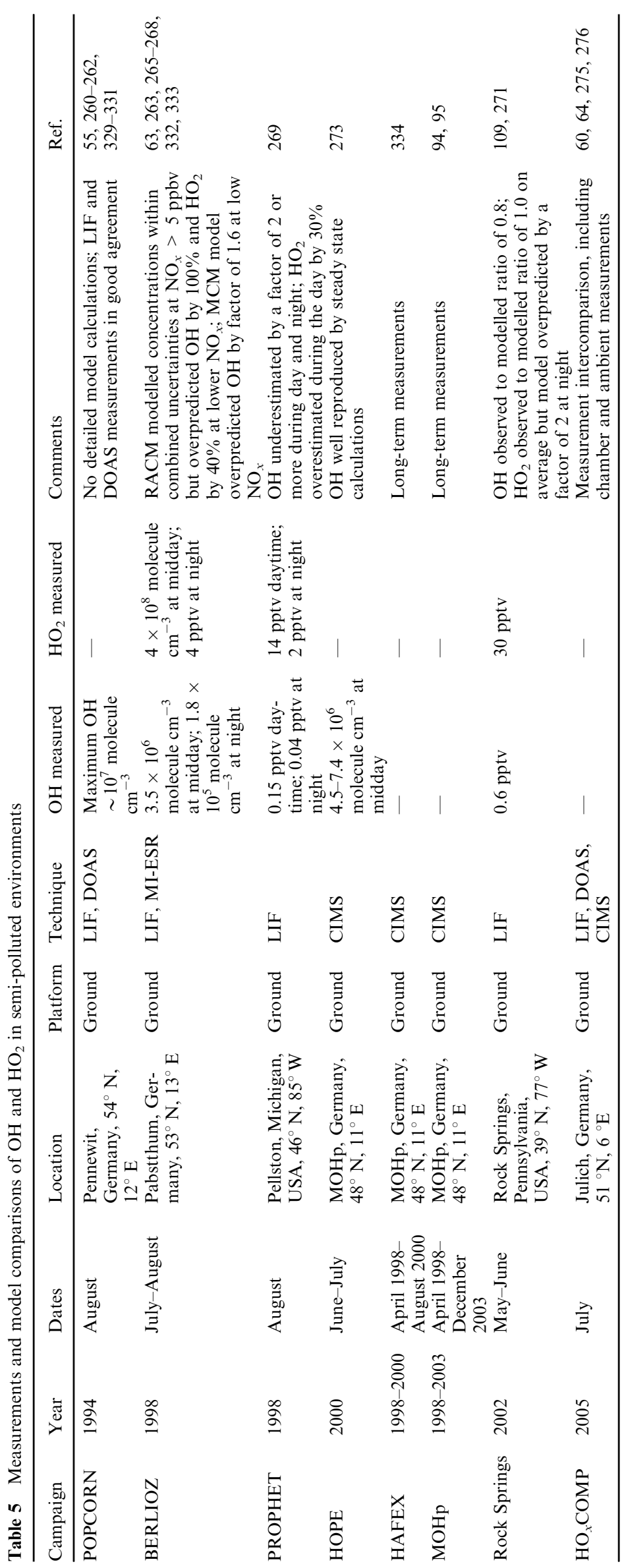


Pabstthum near Berlin in July and August 1998 provided a more comprehensive suite of measurements to enable a more in-depth analysis of the processes controlling $\mathrm{OH}$ and $\mathrm{HO}_{2}$ concentrations. ${ }^{263-266,63}$ During the BERLIOZ campaign, $\mathrm{OH}$ and $\mathrm{HO}_{2}$ were measured by LIF-FAGE, and additional measurements of $\mathrm{HO}_{2}$ and $\mathrm{RO}_{2}$ were made by MIESR and chemical amplification techniques. ${ }^{263,264}$

Measurements of $\mathrm{OH}$ and $\mathrm{HO}_{2}$ by FAGE found maximum concentrations of $8.0 \times 10^{6}$ molecule $\mathrm{cm}^{-3}$ and $8.0 \times$ $10^{8}$ molecule $\mathrm{cm}^{-3}$, respectively, although the average midday concentrations were $3.5 \times 10^{6}$ molecule $\mathrm{cm}^{-3}$ and $4.0 \times$ $10^{8}$ molecule $\mathrm{cm}^{-3}$, respectively. ${ }^{265} \mathrm{~A}$ high linear correlation $(r=0.90)$ was observed between $\mathrm{OH}$ and $j\left(\mathrm{O}^{1} \mathrm{D}\right)$ during the day, with deviation from this general behaviour at dawn and dusk when appreciable concentrations of $\mathrm{OH}$ were observed despite near-zero $j\left(\mathrm{O}^{1} \mathrm{D}\right) .{ }^{265} \mathrm{~A}$ box model using the RACM was constrained to measurements of over 60 non-methane hydrocarbons made during the campaign, and was able to reproduce the observed $\mathrm{OH}, \mathrm{HO}_{2}$ and $\mathrm{RO}_{2}$ concentrations within the experimental errors of the measurements when mixing ratios of $\mathrm{NO}_{x}$ were above 5 ppbv, indicating air masses advected from the direction of Berlin. ${ }^{266}$ At lower $\mathrm{NO}_{x}$ mixing ratios, however, the model overestimated $\mathrm{OH}$ and $\mathrm{HO}_{2}$ by $100 \%$ and $40 \%$, respectively. ${ }^{266}$ The reactivity of the measured VOCs to $\mathrm{OH}$ was dominated by alkenes $(>60 \%)$, with isoprene and $\alpha$-pinene representing the most significant species, and although increasing the VOC concentrations in the model improved the simulations for $\mathrm{OH}$ and $\mathrm{HO}_{2}$ at low $\mathrm{NO}_{x}$ levels, the modelled $\mathrm{RO}_{2}$ concentrations were overestimated by a factor of 2 as a consequence. ${ }^{266}$

An additional modelling study of the radical concentrations during BERLIOZ, using a box model with MCM chemistry, was also able to reproduce the $\mathrm{HO}_{x}$ observations at high $\mathrm{NO}_{x}$, but at low $\mathrm{NO}_{x}$ mixing ratios (defined as $<10 \mathrm{ppbv}$ in this study) the $\mathrm{OH}$ observations were overpredicted by a factor of 1.6, and under conditions characterised by low $\mathrm{NO}_{x}$ and high isoprene the model overestimated $\mathrm{OH}, \mathrm{HO}_{2}$ and $\mathrm{RO}_{2} \cdot{ }^{63}$ The radical budgets from the MCM model show that production of $\mathrm{OH}$ was dominated by recycling of $\mathrm{HO}_{x}$ through the reaction of $\mathrm{HO}_{2}$ with $\mathrm{NO}(\sim 70 \%$ of the total), with the remainder largely resulting from photolysis of $\mathrm{O}_{3},{ }^{63}$ with significant contributions from HONO photolysis in the early morning. ${ }^{267}$ In fact, HONO photolysis was found to contribute up to $20 \%$ of the total $\mathrm{OH}$ production over a 24 hour period. ${ }^{267}$ When $\mathrm{NO}_{x}$ levels were high, the loss of $\mathrm{OH}$ to $\mathrm{NO}_{2}$ was approximately equal to the loss to VOCs, while reactions with VOCs dominated at lower $\mathrm{NO}_{x}$ concentrations. ${ }^{63}$ The production of $\mathrm{HO}_{2}$ was dominated by reactions of $\mathrm{RO}_{2}$ radicals with $\mathrm{NO}$, even during the low $\mathrm{NO}_{x}$ periods when this production route constituted approximately $60 \%$ of the total $\mathrm{HO}_{2}$ production, followed by reactions of $\mathrm{OH}$ with $\mathrm{CO}$ and $\mathrm{HCHO}$ and photolysis of HCHO. ${ }^{63}$ Removal of $\mathrm{HO}_{2}$ was dominated by its reaction with NO $(>80 \%){ }^{63}$

Production of radicals at night was also investigated during the BERLIOZ campaign. ${ }^{268}$ Modelled nighttime concentrations overpredicted $\mathrm{OH}$ and $\mathrm{HO}_{2}$ observations, by a factor of 2.2 and 1.5 , respectively, for the maximum observed $\mathrm{OH}$ and $\mathrm{HO}_{2}$ of $1.85 \times 10^{5}$ molecule $\mathrm{cm}^{-3}$ and $4 \mathrm{pptv}$, respectively, indicating missing nighttime sinks. ${ }^{268}$ Reactions of the nitrate radical $\left(\mathrm{NO}_{3}\right)$ with terpenes was found to be responsible for $36 \%$ of the $\mathrm{OH}$ produced and $53 \%$ of the $\mathrm{HO}_{2}$, while ozonolysis reactions of alkenes were responsible for $64 \%$ of the $\mathrm{OH}$ produced and $47 \%$ of the $\mathrm{HO}_{2}{ }^{268}$

Nighttime $\mathrm{OH}$ chemistry was also the subject of an investigation at a rural site in the United States, in Pellston, Michigan, in summer $1998 .^{269}$ Measurements of $\mathrm{HO}_{x}$ were made by the Penn State GTHOS instrument, and up to 0.04 pptv of $\mathrm{OH}$ and 2 pptv of $\mathrm{HO}_{2}$ were observed at night, compared to 0.15 pptv $\mathrm{OH}$ and 14 pptv $\mathrm{HO}_{2}$ during the day. ${ }^{269}$ Model calculations, using a 1-D Lagrangian model, underestimated the observed $\mathrm{OH}$ concentrations by a factor of 2 or more during both day and night, and overestimated daytime $\mathrm{HO}_{2}$ by $30 \%{ }^{269}$ Model calculations of nighttime $\mathrm{HO}_{x}$ concentrations may have been impacted by uncertainties in nighttime boundary layer heights, and thus of transport and mixing of VOCs at night, and also by model descriptions of nighttime chemistry. Reactions of $\mathrm{NO}_{3}$ with $\mathrm{RO}_{2}$ radicals can act as nighttime sources of $\mathrm{OH},{ }^{270}$ but are often not included in models designed to simulate daytime chemistry, potentially leading to model underpredictions of nighttime $\mathrm{OH}$ concentrations.

Further measurements of $\mathrm{OH}$ and $\mathrm{HO}_{2}$ in 2002 by the Penn State group at Rock Springs, a rural region on an agricultural research farm of the Pennsylvania State University, showed maximum daytime mixing ratios of $0.6 \mathrm{pptv} \mathrm{OH}$ and $30 \mathrm{pptv}$ $\mathrm{HO}_{2}{ }^{109,271}$ A box model using the RACM was able to reproduce the $\mathrm{OH}$ observations during day and night, with an average observed to modelled ratio of 0.80 . The model success for $\mathrm{OH}$ at night was attributed to the continuous soil emissions of $\mathrm{NO}$, with the result that high $\mathrm{OH}$ concentrations at night were maintained by the reaction between $\mathrm{HO}_{2}$ and $\mathrm{NO} .{ }^{271}$ However, although the average observed to modelled ratio for $\mathrm{HO}_{2}$ was 1.0, the model did overpredict $\mathrm{HO}_{2}$ at night by a factor of 2 , and the model success for $\mathrm{OH}$ at night may therefore be somewhat fortuitous. ${ }^{271}$ Differences in the actual VOC speciation at night and the parameterisation used in the RACM model may have contributed to the overprediction of nighttime $\mathrm{HO}_{2},{ }^{271}$ again highlighting the impact of using models designed for daytime conditions to simulate nighttime radical concentrations.

While the majority of $\mathrm{HO}_{x}$ measurements have been made during intensive field campaigns, long-term measurements of $\mathrm{OH}$ have been achieved by the Deutscher Wetterdienst (DWD, the German Weather Service) at the Meteorological Observatory Hohenpeissenberg in rural southern Germany. ${ }^{94,95,272-274}$ The measurements, made by a CIMS instrument were in operation between April 1998 and December 2003, ${ }^{94,95}$ and were incorporated in the HOPE (Hohenpeissenberg Photochemical Experiment) 2000 intensive field campaign in June $2000 .{ }^{273}$ During the HOPE campaign, maximum midday $\mathrm{OH}$ concentrations ranged between $4.5 \times 10^{6}$ molecule $\mathrm{cm}^{-3}$ and $7.4 \times 10^{6}$ molecule $\mathrm{cm}^{-3}$, and were well reproduced by a photostationary steady state model when the calculations assumed the presence of 3 ppbv $\mathrm{HCHO} .^{273}$ Budget analyses indicated that the majority of $\mathrm{OH}$ was produced from $\mathrm{HO}_{2}+$ $\mathrm{NO}$, with primary production occurring equally from $\mathrm{O}_{3}$ and HCHO photolysis. ${ }^{273}$ Subsequent measurements of HONO at the site in 2002 and 2004 indicated that production of $\mathrm{HO}_{x}$ from photolysis of $\mathrm{HONO}$ could be comparable to that following photolysis of $\mathrm{O}_{3}$ or $\mathrm{HCHO} .^{274}$ 
Table 6 Summary of parameters in eqn (E6) used to describe $\mathrm{OH}$ observations in a number of locations

\begin{tabular}{|c|c|c|c|c|c|c|}
\hline Campaign & Location & Year & $a$ & $b$ & $c$ & Ref. \\
\hline POPCORN & Rural Germany & 1994 & 3.9 & 0.95 & $0.04 \pm 0.01$ & 95,329 \\
\hline ALBATROSS & Remote Atlantic Ocean & 1996 & 1.4 & 1.3 & $0.20 \pm 0.21$ & 95,121 \\
\hline BERLIOZ & Rural Germany & 1998 & 2.0 & 0.95 & $0.43 \pm 0.02$ & 95,265 \\
\hline MOHp & Rural Germany & $1998-2003$ & 2.4 & 0.93 & $0.13 \pm 0.01$ & 95 \\
\hline MINOS & Coastal Crete & 2001 & 2.2 & 0.68 & $0.01 \pm 0.05$ & 95,136 \\
\hline NAMBLEX & Coastal Ireland & 2002 & $1.47 \pm 0.08$ & $0.84 \pm 0.05$ & $0.44 \pm 0.06$ & 4,335 \\
\hline TORCH & Urban UK & 2003 & $1.07 \pm 0.04$ & $1.16 \pm 0.05$ & $0.62 \pm 0.03$ & 247,335 \\
\hline CHABLIS & Antarctica & 2005 & $0.25 \pm 0.16$ & $0.74 \pm 0.04$ & $0.11 \pm 0.12$ & 295 \\
\hline RHaMBLe & Coastal Cape Verde & 2007 & $1.73 \pm 0.57$ & $0.90 \pm 0.25$ & $0.95 \pm 0.45$ & 70,336 \\
\hline OP3 & Tropical forest Borneo & 2008 & $0.94 \pm 0.11$ & $0.61 \pm 0.09$ & $0.20 \pm 0.07$ & 21,336 \\
\hline SOS & Coastal Cape Verde & 2009 & 1.19 & $0.98 \pm 0.05$ & 0.50 & 15 \\
\hline
\end{tabular}

Analysis of the $\mathrm{OH}$ measurements made in the period between April 1999 and December 2003 revealed a strong correlation between the observed $\mathrm{OH}$ concentration and $j\left(\mathrm{O}^{1} \mathrm{D}\right)$, as shown in Fig. 2. ${ }^{95}$ The long-term measurements indicate that despite the myriad of species reacting with $\mathrm{OH}$ in the atmosphere, the observed concentrations could be parameterised by a simple relationship (eqn (E6)) with solar UV radiation:

$$
[\mathrm{OH}]=\left(a \times j\left(\mathrm{O}^{1} \mathrm{D}\right)^{b}\right)+c
$$

where $a$ represents the dependence of $\mathrm{OH}$ on reactants such as $\mathrm{NO}_{x}$, hydrocarbons and $\mathrm{O}_{3}$ etc., $b$ reflects the combined effects of all photolytic processes responsible for $\mathrm{OH}$ production, and $c$ represents the combined effects of light-independent processes. ${ }^{95}$

It was found that between $87 \%$ and $100 \%$ of the observed variance in $\mathrm{OH}$ could be explained by the dependence of $\mathrm{OH}$ on $j\left(\mathrm{O}^{1} \mathrm{D}\right)$ and instrument noise. ${ }^{95}$ This led to the proposal that regional or even global distributions of $\mathrm{OH}$ could be characterised by a simple set of coefficients, such as those in eqn (E6), to define an 'OH index' that describes the oxidising capacity of the troposphere in different chemical regimes. ${ }^{95}$ Table 6 summaries the parameters in eqn (E6) reported in the literature for a number of field campaigns.

Several of the instruments described above took part in the $\mathrm{HO}_{x}$ Comp project in Julich, Germany, in 2005 to facilitate a formal comparison between the different instruments and techniques used to measure $\mathrm{OH}$ and $\mathrm{HO}_{2}$ in the atmosphere. ${ }^{60,64}$ The experiments involved chamber measurements under controlled conditions $s^{60,64}$ as well as ambient measurements $^{275,276}$ on the campus of Forschungszentrum Julich (FJZ), situated in a mixed deciduous forest in a rural environment. During the ambient measurements a range of $\mathrm{NO}_{x}$ concentrations were encountered, with one day characterised by high $\mathrm{NO}_{x}$ (NO 1-3 ppbv) in the morning, followed by low $\mathrm{NO}_{x}\left(\mathrm{NO}<1\right.$ ppbv) in the afternoon. ${ }^{276}$ The measured $\mathrm{OH}$ concentrations, taken as the mean of the observations reported by the different instruments involved in the project, reached a maximum of $9.4 \times 10^{6}$ molecule $\mathrm{cm}^{-3}$ around noon, and then decreased sharply during the low $\mathrm{NO}_{x}$ period. ${ }^{276}$ Model calculations for $\mathrm{OH}$, using the MCM (v3.2), gave a slight overestimation during the high $\mathrm{NO}_{x}$ period, with an increasing underestimation during the low $\mathrm{NO}_{x}$ period, reaching an underestimation of $65 \%$ at $<0.2$ ppbv NO. ${ }^{276}$ Concentrations of $\mathrm{HO}_{2}$, corrected for potential interferences from alkene-derived $\mathrm{RO}_{2}$ radicals, were reasonably well reproduced by the model during the high $\mathrm{NO}_{x}$ period, but were overpredicted by a factor of 1.3-1.8 during the low $\mathrm{NO}_{x}$ period. ${ }^{276}$ A comparison of the radical fluxes during the high and low $\mathrm{NO}_{x}$ periods is shown in Fig. 17.

Further investigation of the full ambient measurement period was carried out using a RACM-based model with MCM (v3.1) chemistry and epoxide formation ${ }^{277}$ to describe isoprene oxidation, but with isoprene emissions only added to the modelled air mass for the last 12 min of the five day model run to optimise agreement between observed and modelled MACR and MVK, the oxidation products of isoprene. ${ }^{275}$

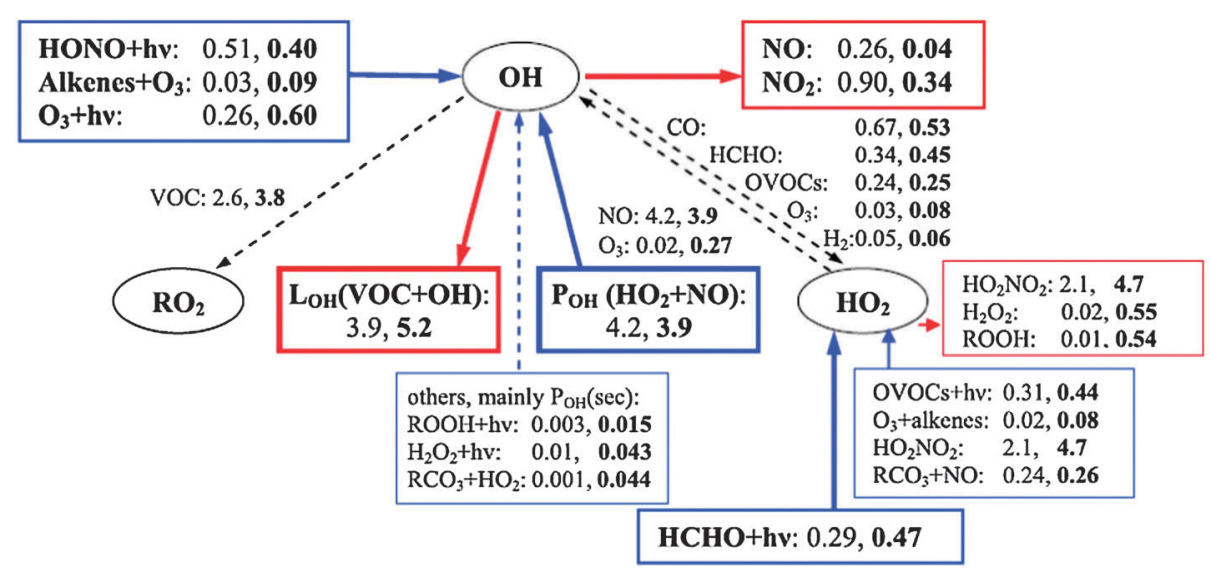

Fig. 17 Average fluxes of the key radical sources and sinks during the high- $\mathrm{NO}_{x}$ period and low- $\mathrm{NO}_{x}$ period (bold) on 10 th July 2005 during $\mathrm{HO}_{x}$ Comp. Units are in ppbv ${ }^{-1}$. (Reproduced from ref. 276, Copyright (2012), American Geophysical Union, reproduced by permission of American Geophysical Union. Further reproduction or electronic distribution is not permitted.) 
Modelled $\mathrm{OH}$ concentrations were reproduced to within $33 \%$ over a range of isoprene (0.3-2 ppbv) and NO (0.1-10 ppbv) mixing ratios, with significant overestimations (up to $60 \%$ ) of $\mathrm{OH}$ found when isomerisation of isoprene peroxy radicals ${ }^{219,220}$ was included in the model. ${ }^{275}$ Observed concentrations of $\mathrm{HO}_{2}$, corrected for potential $\mathrm{RO}_{2}$ interferences, were typically overestimated by factors greater than 1.8, although during the low isoprene and high NO period described by Elshorbany et al., ${ }^{276} \mathrm{HO}_{2}$ was underestimated using the RACM scheme. ${ }^{275}$

\subsection{Summary of measurements in polluted/semi-polluted environments}

Results from field campaigns in urban and polluted regions have demonstrated the significance of HONO photolysis, carbonyl photolysis and alkene ozonolysis in the production of $\mathrm{HO}_{x}$ radicals. In many cases, measurements of HONO have not been made, reducing our ability to truly evaluate model successes for $\mathrm{OH}$ in these environments. Similarly, measurements of carbonyl compounds are generally limited to a small number of species, and improvements in measurement techniques for this class of compounds will aid our understanding of their role in oxidation chemistry in polluted regions.

The oxidation of aromatic compounds has been highlighted as a significant source of uncertainty in models, and an area in need of further attention. The development of new laboratory techniques for the study of complex reaction mechanisms is an important ongoing research area in atmospheric chemistry, and recent advances in the detection of key intermediate species in ozonolysis reactions, with direct measurements of their kinetics, is an exciting new discovery for the development of chemical mechanisms for atmospheric modelling. ${ }^{116}$

Suburban and rural regions encompass a wide range of $\mathrm{NO}_{x}$ and VOC conditions, with such regions often impacted by the transport of species from local forests or urban centres. As a result, many of the uncertainties encountered in urban regions, with regard to HONO measurements for example, or forested regions, such as the impact of isoprene on $\mathrm{HO}_{x}$, are relevant to suburban and rural regions.

The successes of the German Weather Service in making long-term measurements of $\mathrm{OH}$ have provided an impressive dataset for the investigation of seasonal behaviour in $\mathrm{OH}$ chemistry. Results of this study ${ }^{95}$ indicate that $\mathrm{OH}$ concentrations can be described as a simple function of $j\left(\mathrm{O}^{1} \mathrm{D}\right)$, and have been corroborated by other seasonal studies of $\mathrm{HO}_{x}$ observations, ${ }^{15}$ enabling the definition of an $\mathrm{OH}$ index (eqn (E6)) to describe the oxidising capacity of the troposphere in different chemical regimes. However, if we are to use this relationship to its full potential for the assessment and prediction of atmospheric oxidising capacities, further field campaigns in a wide range of locations will be required to parameterise and validate the terms in eqn (E6) for different environments.

Finally, laboratory measurements relevant to polluted environments $^{308}$ suggested that $\mathrm{OH}$ and HONO could be formed from the reaction:

$$
\mathrm{NO}_{2} *+\mathrm{H}_{2} \mathrm{O} \rightarrow \mathrm{HONO}+\mathrm{OH}
$$

where $\mathrm{NO}_{2} *$ represents electronically excited $\mathrm{NO}_{2}$ following absorption of sunlight in the visible region $(420-650 \mathrm{~nm})$, and that under some polluted conditions at high solar zenith angles, this process could provide a significant new source of $\mathrm{OH}$. However, these results are not widely accepted, and are inconsistent with earlier studies ${ }^{309}$ and more recent laboratory measurements. ${ }^{310}$

There are relatively few measurements of $\mathrm{OH}$ and $\mathrm{HO}_{2}$ radicals at night, yet the presence of both species has been confirmed in several campaigns, particularly in urban areas. The ROle of Nighttime chemistry in controlling the Oxidising Capacity of the atmosphere (RONOCO) campaign took place in September 2011 and January 2012, an aircraft based project to measure $\mathrm{HO}_{x}$ and $\mathrm{NO}_{3}$ radicals at night, as well as a large number of supporting species, in the polluted boundary layer and free-troposphere. A strong correlation between $\mathrm{HO}_{2}$ and $\mathrm{NO}_{3}$ was observed, with the $\mathrm{NO}_{3}$ and $\mathrm{O}_{3}$ initiated oxidation of VOCs providing a source of $\mathrm{HO}_{x}$ at night. Another major field campaign sampling in the polluted boundary layer over a range of $\mathrm{NO}_{x}$ in California and the eastern Pacific region, from ground and airborne platforms, was the California Nexus (CalNex) campaign.

\section{Measurements of $\mathrm{OH}$ and $\mathrm{HO}_{2}$ and model comparisons in polar environments}

Studies of $\mathrm{OH}$ and $\mathrm{HO}_{2}$ in polar regions are summarised in Table 7. The interest in the hydroxyl radical at high latitudes was initially sparked by its role in the natural sulfur cycle and the oxidation of marine-released Dimethyl Sulfide (DMS) leading ultimately to the formation of sulfate aerosol. The Antarctic Peninsula provides an environment rich in biogenic sulfur emissions far from anthropogenic sources making it uniquely suited for studying DMS oxidation chemistry. The first measurements of $\mathrm{OH}$ in the polar boundary layer were made at Palmer Station on Anvers Island in Antarctica $\left(64^{\circ} 46^{\prime} \mathrm{S}, 64^{\circ} 03^{\prime} \mathrm{W}\right)$ in the Sulphur chemistry in the Antarctic Troposphere Experiment (SCATE) during the austral summer of 1993/1994 using CIMS. ${ }^{278}$ In agreement with simple model predictions, the steady state hydroxyl radical concentrations were low, ranging between $1-9 \times 10^{5}$ molecule $\mathrm{cm}^{-3}$, reflecting the high solar zenith angle (SZA), extensive cloud cover, lack of snow cover and low NO experienced at the measurement site. The levels of NO were close to the detection limit of the instrument used (2-4 pptv), and the modelled $\mathrm{OH}$ levels were only consistent with very low NO (1-5 pptv). Modelling results suggested that the primary source $(70 \%)$ of $\mathrm{OH}$ resulted from the photolysis of $\mathrm{O}_{3}$ and the subsequent reaction of $\mathrm{O}\left({ }^{1} \mathrm{D}\right)$ with $\mathrm{H}_{2} \mathrm{O}$ vapour ((R1) and (R2)); the reaction of $\mathrm{HO}_{2}$ with $\mathrm{NO}$ or $\mathrm{O}_{3}$ contributed $\sim 25 \%$. The major $\mathrm{OH}$ sink was reaction with $\mathrm{CO}$.

$$
\begin{aligned}
\mathrm{O}_{3}+h \nu(\lambda<340 \mathrm{~nm}) & \rightarrow \mathrm{O}\left({ }^{1} \mathrm{D}\right)+\mathrm{O}_{2} \\
\mathrm{O}\left({ }^{1} \mathrm{D}\right)+\mathrm{H}_{2} \mathrm{O} & \rightarrow 2 \mathrm{OH}
\end{aligned}
$$

It was assumed, due to low oceanic NMHC emissions, that NMHCs contributed $<1 \%$ to $\mathrm{OH}$ removal; DMS was found to contribute $<2 \%$ to the total $\mathrm{OH}$ loss. The major radical sinks, under the low $\mathrm{NO}_{x}$ conditions, involved radical self reactions forming peroxides which readily deposit to the surface (e.g. (R8) and (R9)). The strong correlation of $\mathrm{OH}$ model 


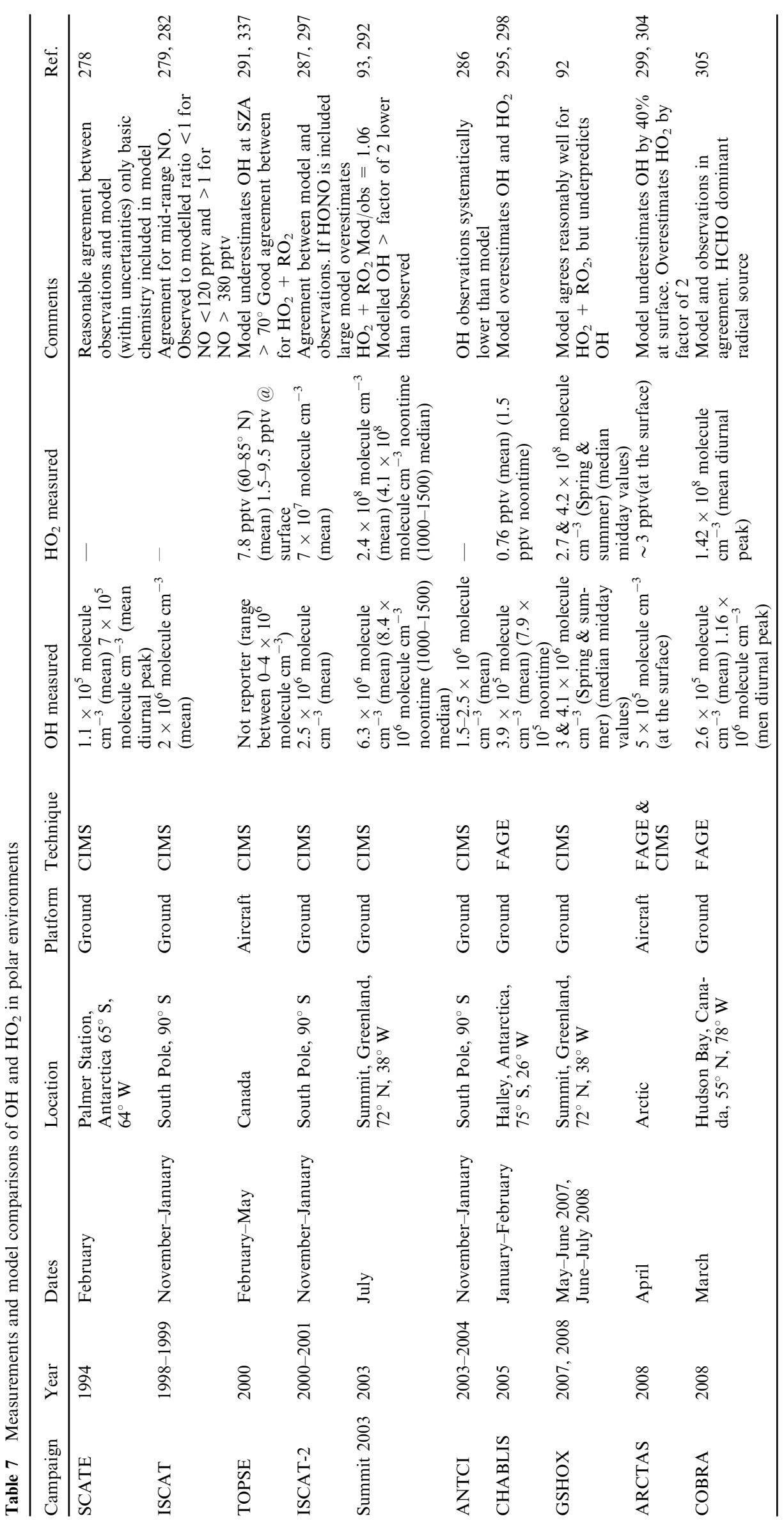


calculations with observations (agreement within model-measured uncertainties of $25 \%$ and \pm 1.5 respectively) suggests a reasonably good understanding of the $\mathrm{OH}$ chemistry in this region.

$$
\begin{gathered}
\mathrm{HO}_{2}+\mathrm{HO}_{2} \rightarrow \mathrm{H}_{2} \mathrm{O}_{2}+\mathrm{O}_{2} \\
\mathrm{HO}_{2}+\mathrm{CH}_{3} \mathrm{O}_{2} \rightarrow \mathrm{CH}_{3} \mathrm{O}_{2} \mathrm{H}+\mathrm{O}_{2}
\end{gathered}
$$

\subsection{Snowpack emissions of $\mathrm{NO}_{x}$ and the impact on radical concentrations}

In the Antarctic summer of 1998-1999, polar OH chemistry was re-investigated during the Investigation of Sulphur Chemistry in the Antarctic Troposphere (ISCAT) field study that took place at the South Pole. In contrast to the earlier $\mathrm{OH}$ measurements, $\mathrm{OH}$ concentrations (also measured using CIMS) were found to be elevated, with an average $\mathrm{OH}$ concentration of $2 \times 10^{6}$ molecule $\mathrm{cm}^{-3}$ observed $(24 \mathrm{~h}$ average), ${ }^{279}$ which is approximately 20 times greater than the $\mathrm{OH}$ observed at a coastal Antarctic station ${ }^{278}$ and exceeds the daily mean $\mathrm{OH}$ levels observed at equatorial marine locations (in part caused by the fact that the South Pole experiences $24 \mathrm{~h}$ of sunlight). This is an unexpected result when first considered, given the dry conditions and the low angle of the sun that should effectively limit the primary production of $\mathrm{OH}$ via reactions (R1) and (R2).

Model simulations revealed that much of the observed $\mathrm{OH}$ resulted from the much higher NO concentrations (up to $600 \mathrm{pptv}$ ) present at the South Pole relative to Antarctic coastal environments $(\sim 5 \mathrm{pptv}){ }^{278}$ These high levels of $\mathrm{NO}$ are a result of emissions of $\mathrm{NO}_{x}$ from the snow pack into a mixed layer with a low boundary layer height, a process initiated by the photolysis of $\mathrm{NO}_{3}{ }^{-}$from within the snow pack. ${ }^{280,281}$ The model and observations were found to be in good agreement at NO levels between 120 and 380 pptv; at lower NO concentrations the basic model overestimated $\mathrm{OH}$ observations and at concentrations greater than $380 \mathrm{pptv}$ the model tended to underpredict $\mathrm{OH}$ levels. ${ }^{282}$ Further investigation highlighted that the low NO data corresponded to foggy conditions suggesting that additional $\mathrm{HO}_{x}$ radical losses due to droplet scavenging could be missing from the model. Indeed, if an irreversible uptake coefficient (or sticking coefficient) $\gamma$ of unity was assumed for $\mathrm{HO}_{2}$, the additional first order loss introduced into the model was sufficient to bring $\mathrm{OH}$ model and observations into a high level of agreement at the low NO range. ${ }^{282}$ However, recent laboratory studies indicate that $\gamma$ is likely to be much less than unity. ${ }^{46,148}$

In contrast to SCATE, the presence of NO alters the major radical sink pathways with the dry deposition of $\mathrm{HNO}_{3}(52 \%)$, formed via (R24), and $\mathrm{HO}_{2} \mathrm{NO}_{2}(22 \%)$, formed via (R25), dominating the loss.

$$
\begin{gathered}
\mathrm{OH}+\mathrm{NO}_{2}+\mathrm{M} \rightarrow \mathrm{HNO}_{3}+\mathrm{M} \\
\mathrm{HO}_{2}+\mathrm{NO}_{2}+\mathrm{M} \rightarrow \mathrm{HO}_{2} \mathrm{NO}_{2}+\mathrm{M}
\end{gathered}
$$

\subsection{Snowpack emissions of $\mathrm{HCHO}, \mathrm{H}_{2} \mathrm{O}_{2}$ and $\mathrm{HONO}$ acting as important radical sources}

Along with missing radical sinks, the basic model employed in this study may also have neglected key radical sources.
Snow emissions of formaldehyde (HCHO), hydrogen peroxide $\left(\mathrm{H}_{2} \mathrm{O}_{2}\right)$, and nitrous acid (HONO) could all increase radical concentrations ((R26)-(R28)) and have been observed in other polar regions/studies. ${ }^{283-285}$ Assuming that these additional $\mathrm{HO}_{x}$ sources parallel the NO trend, the concentration of which was found to be strongly influenced by the atmospheric mixing depth at the South Pole, they could help reconcile the model $\mathrm{OH}$ underprediction under the high NO conditions without adversely affecting the agreement between model and observations under the lower NO conditions.

$$
\begin{gathered}
\mathrm{HCHO}+h \nu\left(+2 \mathrm{O}_{2}\right) \rightarrow \mathrm{CO}+2 \mathrm{HO}_{2} \\
\mathrm{H}_{2} \mathrm{O}_{2}+h \nu \rightarrow 2 \mathrm{OH} \\
\mathrm{HONO}+h \nu \rightarrow \mathrm{OH}+\mathrm{NO}
\end{gathered}
$$

In a more recent paper, the authors report that there remains unresolved $\mathrm{OH}$ calibration issues associated with the ISCAT 1998-1999 dataset ${ }^{286}$ and, as such, any conclusions drawn from direct comparison with model predictions may be in error. The $\mathrm{OH}$ model to observation ratio over the full $\mathrm{NO}$ range encountered may still help reveal missing chemistry in the model under different $\mathrm{NO}_{x}$ regimes.

A second ISCAT campaign took place at the South Pole during 2000 and further radical measurements were made using CIMS at the South Pole during the Antarctic Chemistry Investigation (ANTCI) in 2003. Calibrations for these two campaigns compared well, showing a variation of $19 \%(2 \sigma)$ for $\mathrm{OH}$ providing confidence in the absolute radical levels reported. Similarly elevated $\mathrm{OH}$ concentrations, as were observed during the austral summer of 1998-1999, were seen once again with a mean $\mathrm{OH}$ concentration of $2.5 \times$ $10^{6}$ molecule $\mathrm{cm}^{-3}$ recorded during ISCAT 2000 and typical daily average values ranging from $1.5-2.5 \times 10^{6}$ molecule $\mathrm{cm}^{-3}$ in 2003. On average the $\mathrm{OH}$ observations were higher during the ISCAT 2000 campaign relative to ANTCI. ${ }^{286}$ During the 2000 campaign, the first measurements of $\mathrm{HO}_{2}+\mathrm{RO}_{2}$ were made allowing the influence of primary ((R1) and (R2)) and secondary $\mathrm{OH}$ production $\left(\mathrm{HO}_{2}+\mathrm{NO}\right.$ or $\left.\mathrm{HO}_{2}+\mathrm{O}_{3}\right)$ to be determined directly from measurements and compared with model predictions. In contrast to the 1998 campaign, NO levels were a factor of 3 times lower during the ISCAT 2000 campaign (median NO $=88 \mathrm{pptv}$ ); the median $\mathrm{NO}$ values during ANTCI were 231 pptv. During ISCAT 2000 and ANTCI, key $\mathrm{HO}_{x}$ precursor species ( $\mathrm{HCHO}, \mathrm{H}_{2} \mathrm{O}_{2}, \mathrm{HONO}$ ) which were missing from the earlier ISCAT campaign were measured alongside the radicals. Basic model predictions which exclude additional radical sources from $\mathrm{HCHO}, \mathrm{H}_{2} \mathrm{O}_{2}$ and $\mathrm{HONO}$ were found to underpredict $\mathrm{OH}$ observations during ISCAT 2000 at all NO concentrations except at $\mathrm{NO}<40$ pptv with a median model to observation $(\mathrm{M} / \mathrm{O})$ ratio of 0.68 . For $\mathrm{HO}_{2}$ (which was assumed to make up $75 \%$ of the $\mathrm{HO}_{2}+\mathrm{RO}_{2}$ observations) the same basic model underpredicted $\mathrm{HO}_{2}$ observations also $(\mathrm{M} / \mathrm{O}=0.65),{ }^{287}$ as shown in Fig. 18. Constraining the model to observations of $\mathrm{HCHO}, \mathrm{H}_{2} \mathrm{O}_{2}$ and $\mathrm{HONO}$ led to significant model overestimations of $\mathrm{OH}$ and $\mathrm{HO}_{2}$, with $\mathrm{OH}$ being overpredicted by a factor of 3-5 and $\mathrm{HO}_{2}$ by a factor of 2-3 (see Fig. 18). The model, constrained to HONO observations, was also used to estimate 

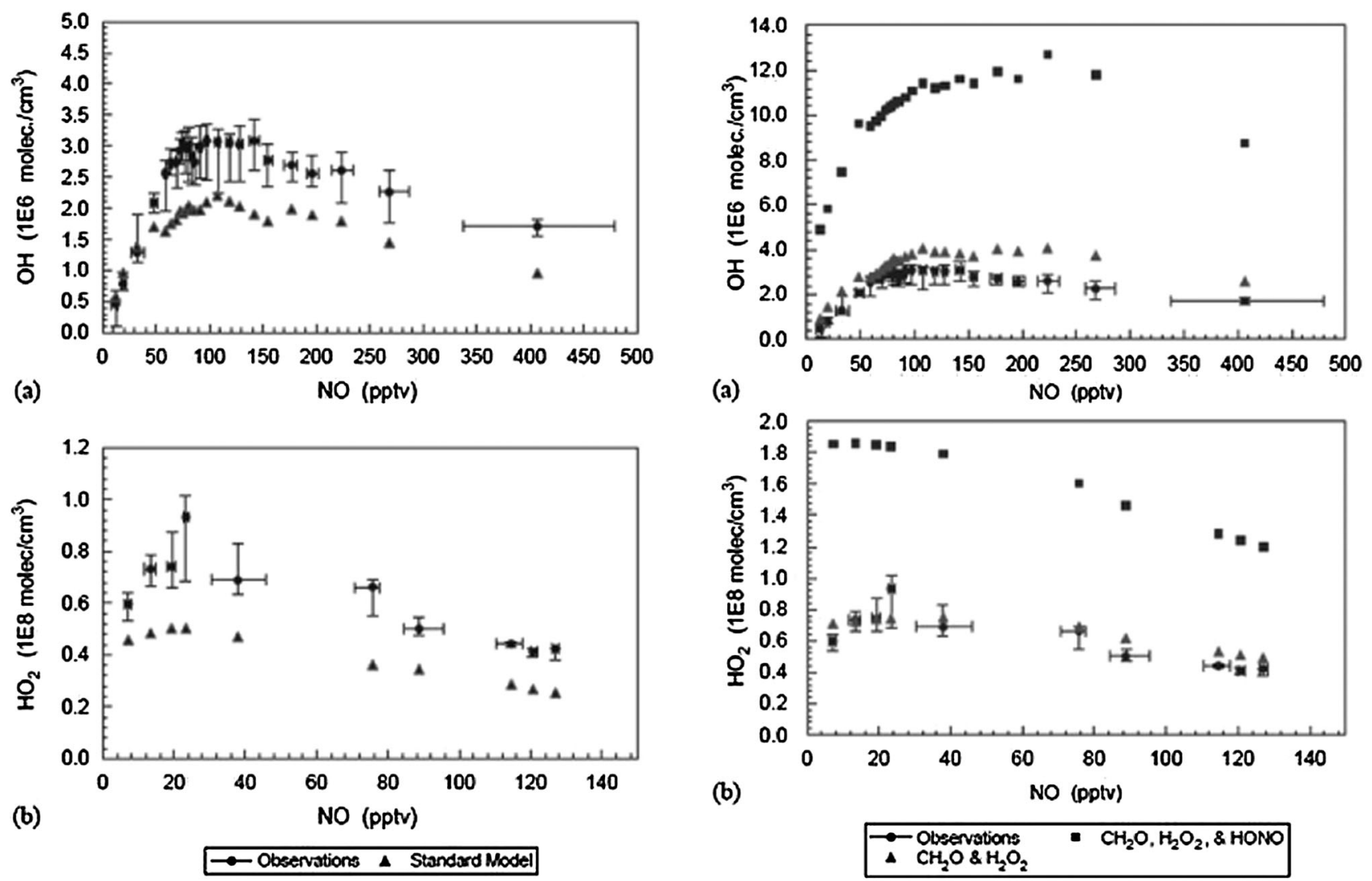

Fig. 18 (Left) Comparison of observations of $\mathrm{OH}$ and $\mathrm{HO}_{2}$ during ISCAT 2000 with standard model predictions (gas phase chemistry only) as a function of NO. (Right) Comparison to models constrained with snow pack emissions of formaldehyde, hydrogen peroxide (and nitrous acid). (Reproduced from ref. 287, Copyright (2004), with permission from Pergamon.)

$\mathrm{NO}_{x}$ levels. Using this approach the median modelled $\mathrm{NO}_{x}$ concentration was approximately 10 times higher than observations leading to the suggestion that the HONO measurements made using mist chamber/ion chromatography $(\mathrm{MC} / \mathrm{IC})^{288}$ may suffer from a systematic interference. ${ }^{287}$ An alternative laser flash photolysis-laser induced fluorescence (LFP-LIF) detection of HONO was employed alongside $\mathrm{MC} / \mathrm{IC}$ during the ANTCI campaign. In support of an interference from MC/IC HONO observations, LFP-LIF HONO observations were found to be $7.2 \pm 2.3$ times lower than those reported by $\mathrm{MC} / \mathrm{IC}$ during this campaign. ${ }^{289}$ Model observations constrained to the basic oxidation chemistry plus $\mathrm{HCHO}$ and $\mathrm{H}_{2} \mathrm{O}_{2}$ improved the median $\mathrm{M} / \mathrm{O}$ ratio for $\mathrm{OH}(1.27)$ and $\mathrm{HO}_{2}$ (1.12), with $\mathrm{HCHO}$ and $\mathrm{H}_{2} \mathrm{O}_{2}$ contributing $32 \%$ and $14 \%$ to the total $\mathrm{HO}_{x}$ budget. Systematic overpredictions of both radicals were still observed over the whole NO range, with the overprediction becoming larger at the highest NO concentrations (>150 pptv) (Fig. 18). During ANTCI, OH observations were also systematically lower than model predictions. $^{286}$ The authors suggest that this trend may indicate a missing $\mathrm{OH}$ sink in the model mechanism, a systematic error in the calibration or systematic losses of $\mathrm{OH}$ during sampling.

A number of measurements of key $\mathrm{HO}_{x}$ precursors $(\mathrm{HCHO}$, $\mathrm{H}_{2} \mathrm{O}_{2}$, HONO) have been made in the Arctic since the late 1990s and have been used to constrain models used to predict radical concentrations. Yang et al. ${ }^{290}$ predicted noontime $\mathrm{OH}$ concentrations of $9 \times 10^{6}$ molecule $\mathrm{cm}^{-3}$ and a diel average of approximately $4 \times 10^{6}$ molecule $\mathrm{cm}^{-3}$ based on direct observations of the $\mathrm{HO}_{x}$ precursors at Summit in Greenland. These hydroxyl radical levels are a factor of 2-3 times greater than $\mathrm{OH}$ observations at the South Pole. This elevated $\mathrm{OH}$ in the polar northern hemisphere relative to the southern hemisphere is in part driven by the lower SZA and higher $\mathrm{O}_{3}$ and humidity experienced in the Arctic. The role of $\mathrm{HCHO}, \mathrm{H}_{2} \mathrm{O}_{2}$ and $\mathrm{HONO}$ as $\mathrm{HO}_{x}$ precursors is also significant at Summit; the authors conclude that $\mathrm{HO}_{x}$ production from these species combined is greater than the $\mathrm{HO}_{x}$ produced by primary production ((R1) and (R2)).

During the Tropospheric Ozone Production about the Spring Equinox (TOPSE) aircraft campaign several flights were performed over the Arctic region providing observations of $\mathrm{OH}$ and $\mathrm{HO}_{2}+\mathrm{RO}_{2}$ by CIMS; measurements were limited, however, to altitudes outside the boundary layer. A modelling study tended to underestimate $\mathrm{OH}$ observations at the highest latitudes and at $\mathrm{SZA}>70^{\circ}$ potentially indicating missing $\mathrm{OH}$ sources; inclusion of new HCHO photolysis quantum yields was suggested as a means to improve the model underestimation at the highest SZA. Generally good agreement between modelled $\mathrm{HO}_{2}+\mathrm{RO}_{2}$ and observations was reported. ${ }^{291}$

The first direct ground-based observations of $\mathrm{OH}$ and $\mathrm{HO}_{2}+$ $\mathrm{RO}_{2}$ in this region were made by CIMS during the summer of 2003 at Summit $\left(72^{\circ} 34^{\prime} \mathrm{N}, 38^{\circ} 30^{\prime}\right) .^{93}$ The median $\mathrm{HO}_{2}+\mathrm{RO}_{2}$ and $\mathrm{OH}$ concentrations were $2.2 \times 10^{8}$ molecule $\mathrm{cm}^{-3}$ and 

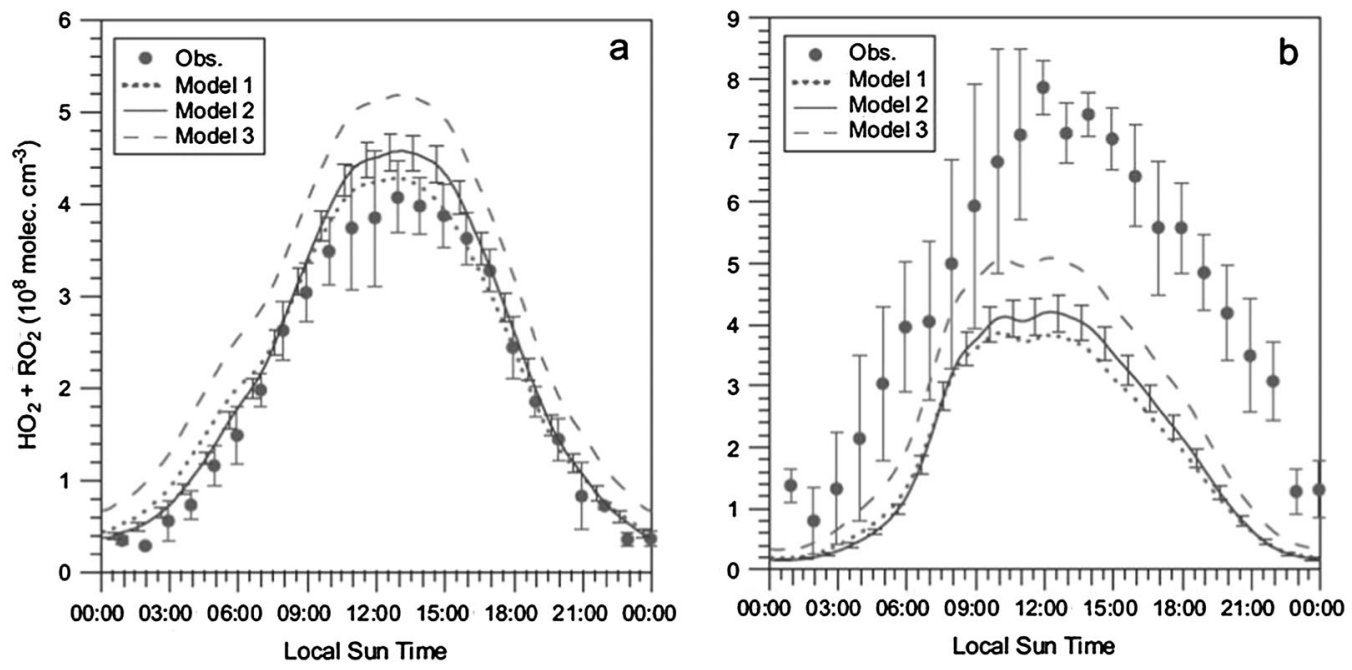

Fig. 19 Comparison of observations with model predictions for (a) $\mathrm{HO}_{2}+\mathrm{RO}_{2}$ and (b) $\mathrm{OH}$. Model 1: calculation without snow influenced precursors, model 2: calculations constrained by $\mathrm{H}_{2} \mathrm{O}_{2}$ and $\mathrm{CH}_{2} \mathrm{O}$, model 3: calculations constrained by $\mathrm{H}_{2} \mathrm{O}_{2}, \mathrm{CH}_{2} \mathrm{O}$ and $\mathrm{HONO}$. $(\mathrm{Reproduced}$ from ref. 292, Copyright (2007), with permission from Pergamon.)

$6.4 \times 10^{6}$ molecule $\mathrm{cm}^{-3}$ respectively. Excellent agreement between peroxy radical observations and highly constrained model predictions was realised when the model was not constrained to HONO observations $(\mathrm{M} / \mathrm{O}=1.06)$; the $\mathrm{M} / \mathrm{O}$ ratio when HONO was included increased by approximately $20 \%$. Modelled $\mathrm{OH}$ concentrations were typically a factor of 2-3 times lower than observations, as shown in Fig. 19, this discrepancy was found to be highly dependent upon the local meteorology. Under relatively calm conditions the model compared most favourably with observations with a median $\mathrm{M} / \mathrm{O}$ for $\mathrm{OH}$ of 0.65 when the modelled was constrained to HONO observations; this dropped to 0.48 when the model was left unconstrained to HONO. Unlike at the South Pole, the impact of the $\mathrm{HONO}$ observations on $\mathrm{HO}_{x}$ concentrations at Summit was relatively small as a result of the lower HONO concentrations measured at Summit (10 pptv) compared to those measured at the South Pole (33 pptv) and also due to the larger percentage impact of primary radical production from $\mathrm{O}_{3}$ and $\mathrm{H}_{2} \mathrm{O}_{2}$ photolysis at Summit ${ }^{93}$ compared to HONO. As found at the South Pole, model predictions of NO, when constrained to HONO observations were greatly overpredicted suggesting that HONO observations at both locations may suffer the same artefact signal. ${ }^{292} \mathrm{HCHO}$ and $\mathrm{H}_{2} \mathrm{O}_{2}$ were found to contribute $3 \%$ and $37 \%$ as $\mathrm{HO}_{x}$ sources.

\subsection{The role of halogen oxides in polar regions}

Sjostedt et al..$^{93}$ using the measured peroxy radical levels at the Summit, calculated an $\mathrm{O}_{3}$ production rate of approximately $0.8 \mathrm{ppbv}^{-1} \mathrm{day}^{-1}$ within the boundary layer, about $2 \%$ of the daily $\mathrm{O}_{3}$ concentration:

$$
\mathrm{PO}_{3}=k_{11}\left[\mathrm{RO}_{2}\right][\mathrm{NO}]+k_{10}\left[\mathrm{HO}_{2}\right][\mathrm{NO}]
$$

However, balloon profiles of $\mathrm{O}_{3}$ at the site suggest that $\mathrm{O}_{3}$ is actually depleted within the boundary layer. The presence of halogen radicals was suggested to explain both the perturbed $\left(\mathrm{HO}_{2}+\mathrm{RO}_{2}\right) / \mathrm{OH}$ ratio from the expected value (via ( $\left.\mathrm{R} 15\right)$, (R16) and (R29)) and the lack of $\mathrm{O}_{3}$ production (R23) at the site. ${ }^{93}$ This hypothesis was, in part, supported by a number of ancillary measurements made during the campaign that detected the presence of halocarbons ${ }^{293}$ and soluble gas phase bromide $^{294}$ although measurements of the halogen oxides themselves were not attempted during the campaign.

$$
\begin{gathered}
\mathrm{HO}_{2}+\mathrm{XO} \rightarrow \mathrm{HOX}+\mathrm{O}_{2} \\
\mathrm{HOX}+h \nu \rightarrow \mathrm{OH}+\mathrm{X} \\
\mathrm{X}+\mathrm{O}_{3} \rightarrow \mathrm{XO}+\mathrm{O}_{2} \\
\mathrm{HOX}+\text { aerosol } \rightarrow \text { loss }
\end{gathered}
$$

During the spring of 2007 and summer of 2008 additional field campaigns (Greenland Summit Halogen-HO $\left.\mathrm{H}_{x}-\mathrm{GSHOX}\right)$ took place at Summit aiming to specifically investigate the impact of halogens on $\mathrm{HO}_{x}$ cycling in this region to test the conclusions drawn from the earlier study. ${ }^{92}$ As found during the 2003 campaign at the Arctic site, box model calculations were able to predict the $\mathrm{HO}_{2}+\mathrm{RO}_{2}$ observations reasonably well $\left(\mathrm{M} / \mathrm{O}_{\text {spring }}=0.87, \mathrm{M} / \mathrm{O}_{\text {summer }}=0.96\right)$ but underpredicted $\mathrm{OH}$ concentrations $\left(\mathrm{M} / \mathrm{O}_{\text {spring }}=0.72, \mathrm{M} / \mathrm{O}_{\text {summer }}=\right.$ 0.54) although it should be noted that $\mathrm{HCHO}$ and $\mathrm{H}_{2} \mathrm{O}_{2}$ concentrations were estimated as no direct measurements were made during this campaign. Constraining the model with observations of $\mathrm{BrO}$ was found to bring the average hourly $\mathrm{OH}$ and $\mathrm{HO}_{2}+\mathrm{RO}_{2}$ predictions much closer to those observed.

In 2005 the first polar measurements of $\mathrm{OH}$ and $\mathrm{HO}_{2}$ radicals using FAGE were made at a coastal site in Antarctica during the Chemistry of the Antarctic Boundary Layer and the Interface with Snow (CHABLIS) project, as shown in Fig. 20. ${ }^{295}$ DOAS measurements of the halogen oxides of IO and $\mathrm{BrO}^{296}$ were also made during the project allowing the impact of these species on the oxidant concentrations to be determined directly. Mean $\mathrm{OH}$ and $\mathrm{HO}_{2}$ concentrations of $3.9 \times 10^{5}$ molecule $\mathrm{cm}^{-3}$ and 0.76 pptv were observed respectively; maximum radical levels, observed at local noon, were of the order of $7.9 \times 10^{5}$ molecule $\mathrm{cm}^{-3}$ and $1.5 \mathrm{pptv}$ for $\mathrm{OH}$ and $\mathrm{HO}_{2}$. These radical concentrations are similar to early $\mathrm{OH}$ 

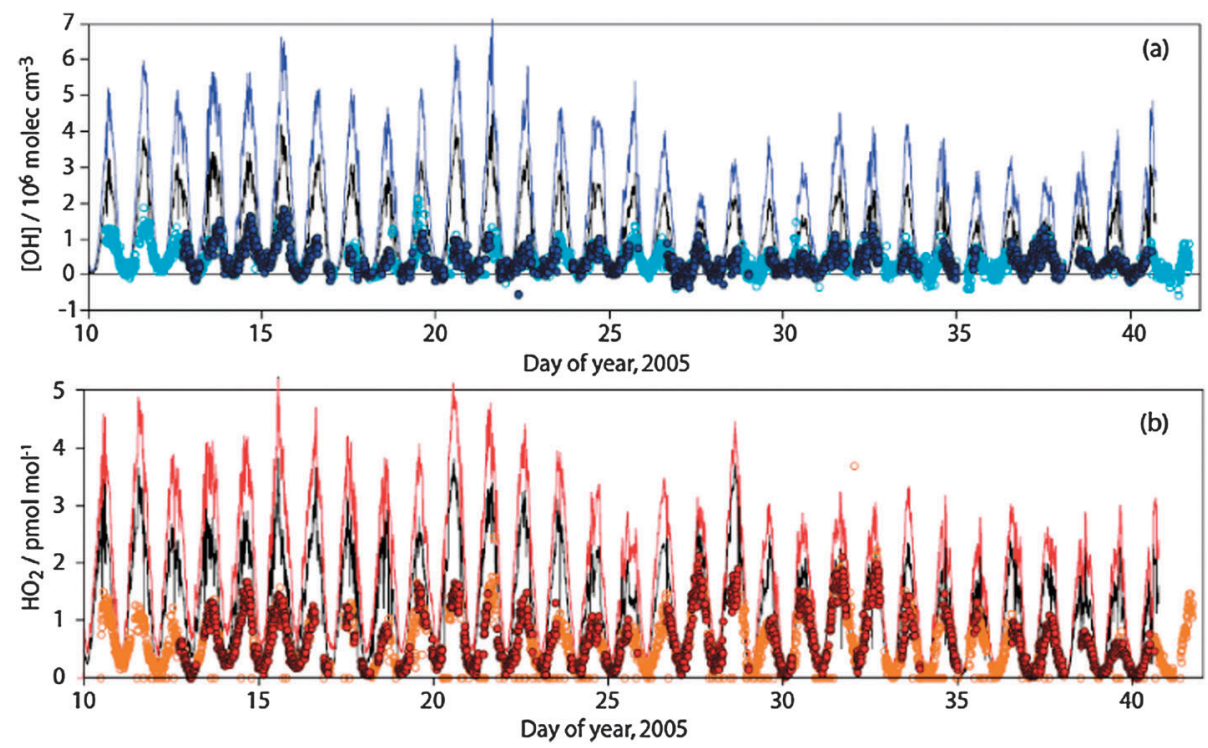

Fig. 20 Observed and simulated time series of (a) $\mathrm{OH}$ concentrations and (b) $\mathrm{HO}_{2}$ mixing ratios. Open circles: all $\mathrm{HO}_{x}$ observations. Filled circles: observations for which all other data present, as used in the model-measurement comparisons. Blue and red lines: model simulations constrained to observations of halogen oxides, $\mathrm{NO}_{x}$ and VOC. Black line: simplified model scheme, containing $\mathrm{C} 1$ chemistry only. (Reproduced from ref. 295 , Copyright (2007), with permission from Copernicus Publications.)

concentrations made on the Antarctic Peninsula 278 but lower than observations made at the South Pole $279,286,297$ likely reflecting the lower mixed layer height at the South Pole which effective amplifies snowpack emissions of $\mathrm{NO}_{x}$ and $\mathrm{HO}_{x}$ precursor species. During CHABLIS a mean NO of 8.1 pptv during $\mathrm{HO}_{x}$ measurement period was observed. A steady-state analysis found that $\mathrm{O}_{3}$ and $\mathrm{HCHO}$ photolysis acted as the main source of $\mathrm{HO}_{x}$; the contributions from HONO photolysis was found to be significant at nominal HONO concentrations of 1 and 5 pptv which were used in the model, however, the observations of HONO that were made were consistent with neither $\mathrm{OH}$ nor $\mathrm{NO}$ observations; large model overpredictions of $\mathrm{OH}$ and $\mathrm{NO}$ were noted when the model was constrained to $\mathrm{HONO}$ observations ${ }^{298}$ similar to findings from the South Pole experiments. ${ }^{287}$ Reactions of $\mathrm{HO}_{2}$ with halogen oxides ((R10)-(R12)) dominated $\mathrm{HO}_{2}$ to $\mathrm{OH}$ interconversion over and above $\mathrm{NO}$ (mean $\mathrm{IO}=3.3$ pptv, $\mathrm{BrO}=$ 2.5 pptv). A photochemical box model, including halogen chemistry was found to significantly overpredict the observed $\mathrm{OH}$ and $\mathrm{HO}_{2}$, as shown in Fig. 20, despite being able to reproduce the observed $\mathrm{IO}, \mathrm{BrO}$ and $\mathrm{NO}_{x}$ concentrations. The authors suggest that uncertainties in key kinetic and photochemical parameters associated with iodine chemistry, coupled with uncertainties arising from the lack of measured physical parameters such as aerosol surface area and boundary layer structure during the project could account for the model overprediction. ${ }^{298}$

\subsection{Impact of aerosols on polar radicals}

The potential impact of aerosols on polar $\mathrm{HO}_{x}$ concentrations was demonstrated during recent aircraft measurements of $\mathrm{OH}$ and $\mathrm{HO}_{2}$ over the Arctic during springtime of 2008 as part of the Arctic Research of the Composition of the Troposphere from Aircraft and Satellites (ARCTAS) campaign.
Comparison of the measurements taken on board the DC8 aircraft with a global 3-D chemical model (GEOS-Chem) demonstrated that the standard gas phase chemical model implemented in the model led to large overpredictions of the observed $\mathrm{HO}_{2}$ concentrations; a large influx of peroxides from northern mid-latitudes in the model accounted for $50 \%$ of the $\mathrm{HO}_{y}$ sources above $6 \mathrm{~km}$ suggesting a large missing sink necessary to compensate for this. ${ }^{299}$ The transport of aerosol pollution from mid-latitudes to Arctic regions is often greatest during the spring. ${ }^{300}$ Low temperatures and reasonably high aerosol loadings experienced under Arctic conditions, particularly during springtime, lead to the uptake of $\mathrm{HO}_{2}$ on aerosol surfaces becoming increasingly important. A standard uptake coefficient, $\gamma=0.02$ at $275 \mathrm{~K}$ increasing to $\gamma=0.5$ at $220 \mathrm{~K}$ was sufficient to reproduce the concentrations and vertical distributions of $\mathrm{OH}$ and $\mathrm{HO}_{2}$ that were observed during the ARCTAS campaign. ${ }^{299}$ The presence of aerosols in the Arctic was estimated to lead a decrease in $\mathrm{OH}$ and $\mathrm{HO}_{2}$ of approximately $30 \%$ throughout the tropospheric column, with heterogeneous loss acting as the dominant radical sink at altitudes above $5 \mathrm{~km}$; below $5 \mathrm{~km}$ radical-radical self reactions became the dominant sink ((R8) and (R9)). Recent laboratory experiments that have studied the uptake of $\mathrm{HO}_{2}$ on different surface types and under different conditions ${ }^{46,148,301}$ indicate that uptake coefficients generally increase with a decreasing temperature, reflecting the negative temperature dependence of the mass accommodation coefficient $(\alpha)$ on the surface and the solubility constant. ${ }^{302}$ Aqueous surfaces tend to have higher uptake coefficients than solid surfaces and the presence of transition metals such as copper increase the reactive uptake considerably. Biomass burning from Siberian wildfires acted as a major aerosol source during ARCTAS and aerosol mass spectrometric observations taken on board the DC8 aircraft demonstrated that a significant portion of the aerosol was made up of organics $(32 \%)$, for which there are limited data 
on the reactive uptake coefficient of $\mathrm{HO}_{2}$ (just one reported $\mathrm{HO}_{2}$ uptake coefficient on levoglucosan ${ }^{303}$ ) leading to large uncertainties in the overall impact of aerosols on the oxidising capacity over this region.

Data from the ARCTAS campaign have also been examined using the NASA Langley Research Center photochemical box model (LaRC-V08). ${ }^{304}$ During spring, the model was generally able to replicate the observations, with an observed to modelled ratio of 0.96 , although the observed $\mathrm{OH}$ concentrations were frequently at the limit of detection. Observed concentrations of $\mathrm{OH}$ during summer were four times larger than those observed during spring, but the model underestimated the observations, with an observed to modelled ratio of 1.25. ${ }^{304}$ Modelled $\mathrm{HO}_{2}$ concentrations overestimated the observations by a factor of up to 2 , and although the use of a temperature dependent $\gamma_{\mathrm{HO}_{2}}$ decreased the modelled $\mathrm{HO}_{2}$ concentrations by $\sim 23 \%,{ }^{304}$ the difference was insufficient to reconcile the model with the observations. The differences between the global model and box model predictions relate to the fact that many of the $\mathrm{HO}_{x}$ precursor fields generated by the global model were lower than those observed, with GEOS-Chem predicting lower values for $\mathrm{H}_{2} \mathrm{O}_{2}, \mathrm{CH}_{2} \mathrm{O}, \mathrm{H}_{2} \mathrm{O}$ and $j\left(\mathrm{O}^{1} \mathrm{D}\right)$. Olson et al. found that when the box model was constrained by GEOS-Chem precursor predictions, the modelled $\mathrm{HO}_{x}$ determined by the two models was equivalent. These discrepencies highlight that a direct comparison of in situ $\mathrm{HO}_{x}$ measurements to a model can only be achieved when the observed precursors and physical parameters are used. Nevertheless, global models provide a useful tool to identify key atmospheric processes.

Model measurement comparisons of $\mathrm{OH}$ and $\mathrm{HO}_{2}$ detected using FAGE have been made during a recent ground-based sub-Arctic study that took place on the Eastern coast of Hudson Bay in Northern Canada during the COmbined iodine and Bromine release on the Arctic atmosphere (COBRA) project. ${ }^{305} \mathrm{An}$ average peak $\mathrm{OH}$ concentration of $1.16 \times$ $10^{6}$ molecule $\mathrm{cm}^{-3}$ was observed and $\mathrm{HO}_{2}$ peaked at $1.34 \times$ $10^{8}$ molecule $\mathrm{cm}^{-3}$. The model was in good general agreement with the observations for both $\mathrm{OH}$ and $\mathrm{HO}_{2}$; this is in contrast to findings from experiments conducted at Summit which underpredicted $\mathrm{OH}$ observations. During COBRA, HCHO was measured alongside the radicals using DOAS and was found to be at higher concentrations (mean $\mathrm{HCHO}=$ 363 pptv) than previously reported during earlier Arctic studies (mean HCHO during the 2003 Summit campaign = 90 pptv) and helped to elevate modelled $\mathrm{HO}_{x}$ concentrations. During COBRA, $74 \%$ of the $\mathrm{HO}_{x}$ came from photolysis of HCHO which was the dominant radical source. Radical concentrations were also lower on average at Hudson Bay than at Summit, potentially reflecting the lower $\mathrm{NO}$ and $\mathrm{O}_{3}$ concentrations at Hudson Bay compared to Summit (mean $\mathrm{NO}=4$ pptv, $\mathrm{O}_{3}=30$ ppbv at Hudson Bay and $\mathrm{NO}=$ 21 pptv, $\mathrm{O}_{3}=50$ ppbv at Summit). During the $\mathrm{HO}_{x}$ measurement period in COBRA, the halogen oxides of $\mathrm{IO}$ and $\mathrm{BrO}$ were generally not detected above the 1 pptv detection limit of DOAS and as such had a limited impact on the radical cycling. The $\mathrm{HO}_{x}$ precursors of $\mathrm{HONO}$ and $\mathrm{H}_{2} \mathrm{O}_{2}$ were not measured during the COBRA project and were omitted from modelling studies. The photolysis of $\mathrm{H}_{2} \mathrm{O}_{2}$ contributed as much as $37 \%$ during the 2003 Summit campaign ${ }^{292}$ and so if present during COBRA may suggest that additional sinks would be required to compensate for this missing radical source to maintain good model to measured agreement. Uncertainties in the reactive uptake coefficient employed in the model could compensate for missing $\mathrm{OH}$ sources. ${ }^{305}$ A relatively low uptake coefficient of $0.025-0.05$ was found to best agree with observations when $\mathrm{H}_{2} \mathrm{O}_{2}$ was not considered. Higher values of the uptake coefficients, particularly considering the low temperatures experienced during the campaign (mean temperature, $-22^{\circ} \mathrm{C}$ ), could still be consistent with theory ${ }^{306}$ and recent laboratory results, ${ }^{301}$ which indicate that the $\mathrm{HO}_{2}$ uptake coefficient increases with decreasing temperature. However, no temperature dependent laboratory data for $\mathrm{HO}_{2}$ uptake have been published. It is noteworthy that heterogeneous loss for $\mathrm{HO}_{2}$ was not considered during earlier modelling studies based on Summit observations ${ }^{92,93,292}$ which may suggest that the models would further underpredict $\mathrm{OH}$ concentrations if this additional sink were included.

\subsection{Summary of model measurement comparisons in polar regions}

Despite the large SZA and low humidity experienced in polar regions, both of which limit the rate of primary production of $\mathrm{OH}$ via the reaction of $\mathrm{O}\left({ }^{1} \mathrm{D}\right)$ atoms with water vapour, the oxidising capacity, embodied by the observed $\mathrm{OH}$ concentration, at many polar sites has been shown to rival that experienced under equatorial marine conditions. The observations of radicals and comparison with model predictions demonstrate that the snowpack acts as an important source of $\mathrm{HO}_{x}$ precursors, namely $\mathrm{HCHO}$ and $\mathrm{H}_{2} \mathrm{O}_{2}$. In many studies $\mathrm{HCHO}$ and $\mathrm{H}_{2} \mathrm{O}_{2}$ have been identified as the dominant radical sources over and above $\mathrm{O}\left({ }^{1} \mathrm{D}\right) / \mathrm{H}_{2} \mathrm{O}$ primary production. HONO emissions have also been observed from the snowpack, although the levels reported are, in many cases, not consistent with the observations of $\mathrm{OH}$ and $\mathrm{NO}$ and have led to the suggestion that the HONO measurements (typically carried out using mist chambers/ion chromatography) suffer an artefact signal. There is a pressing need for accurate, artefact free measurements of the very low concentrations of HONO found in polar regions.

NO emissions from the snowpack have also been demonstrated to increase the oxidising capacity, particularly at the South Pole where the boundary layer is, at times, only a few metres in height, by promoting secondary production of $\mathrm{OH}$ from $\mathrm{HO}_{2}$ and higher peroxy radicals, and leading to ozone production.

Discrepancies between the modelled and observed $\mathrm{OH}$ to $\mathrm{HO}_{2}$ ratio has helped to identify the presence of halogen oxides in polar regions. Direct observations of $\mathrm{IO}$ and $\mathrm{BrO}$ both in the Arctic and Antarctic have demonstrated the importance of halogens in both radical cycling and ozone depletion events. In several studies, inclusion of halogen oxide chemistry in model schemes has helped to improve the agreement between predictions and observations.

A number of studies have suggested that aerosols may act as significant radical sinks in polar regions, for example the uptake coefficients for $\mathrm{HO}_{2}$ are expected to increase at lower 
temperatures, but the absolute impact of aerosols on the oxidising capacity remains highly uncertain. In some cases this uncertainty arises from the lack of direct aerosol observations but, in the most part, is caused by the lack of reported data of reactive uptake coefficient on different aerosol types under appropriate low temperature conditions.

Much of the work to date has focussed on the chemistry of the polar boundary layer, whilst the polar free-troposphere has received less attention with only two aircraft campaigns conducted in which radical measurements were made. Snowpack emissions and halogen radical photochemistry which have been identified as important sources in controlling the radical concentrations in the boundary layer are expected to have a limited impact on the radical chemistry outside of the boundary layer, instead interaction with aerosols has been identified as the dominant radical sink above $5 \mathrm{~km}$ in the Arctic, whilst long-range transport of peroxides from northern mid-latitudes act as important $\mathrm{HO}_{x}$ sources at this altitude.

Good agreement between radical observations and predictions have been reported at a number of the polar sites but discrepancies between radical observations and predictions still exist at others, despite the improved knowledge on the radical sources and sinks and inclusion of these in models. Models have a tendency to overpredict $\mathrm{OH}$ concentrations at the South Pole and Coastal Antarctica implying missing radical sinks or uncertainties in key kinetic parameters employed in models (for example, uncertainties in halogen chemistry kinetics has been suggested as a reason for model overpredictions of $\mathrm{OH}$ during $\mathrm{CHABLIS}$ ). Focussed laboratory studies addressing these issues are necessary to minimise these uncertainties and model discrepancies in the future.

\section{Overall summary and future requirements}

Individual section summaries above highlight the main findings for different environments, for example the level of agreement found between measurements and models. In this section we provide an overall synthesis and make recommendations for future work to help solve some of the remaining uncertainties in our understanding of photochemical oxidation in the troposphere mediated by $\mathrm{OH}$ and $\mathrm{HO}_{2}$ radicals. Such recommendations are of course subjective, but we have tried to highlight some of the major uncertainties which need addressing.

$\mathrm{OH}$ concentrations fit the general expression $[\mathrm{OH}]=a$ $j\left(\mathrm{O}^{1} \mathrm{D}\right)^{b}+c$ expression in most environments, but parameters vary considerably and are heavily influenced by unexpected factors, for example halogens. Given the right conditions, concentrations of $\mathrm{OH}$ have reached as high as $2 \times$ $10^{7}$ molecule $\mathrm{cm}^{-3}$, although $\mathrm{OH}$ is remarkably buffered, varying by a relatively small amount (usually in the $10^{6}$ molecule $\mathrm{cm}^{-3}$ range) for a wide range of environments, latitudes and seasons. There are also a paucity of data at night when $j\left(\mathrm{O}^{1} \mathrm{D}\right)=0$. There is a need to systematically characterise this relationship in different global regions over time scales that are longer than most campaigns in order to establish an index of $a$, $b$ and $c$ that could be useful for parameterisation of $\mathrm{OH}$ in multidimensional models, although there are some examples of seasonal studies of $\mathrm{OH}$ in certain locations. With the advent of smaller, electrically-efficient and more reliable instrumentation, it is recommended that more long-term measurements of $\mathrm{OH}$ and $\mathrm{HO}_{2}$ in a variety of locations are performed.

In the marine boundary layer, $\mathrm{OH}$ measurements and box model calculations are now broadly in good agreement within the combined uncertainties. Earlier campaigns suffered from a lack of supporting measurements, in particular of oxygenated VOCs (a significant sink for $\mathrm{OH}$ ) and halogen species (which convert $\mathrm{HO}_{2}$ to $\mathrm{OH}$ reducing the $\mathrm{HO}_{2}$ to $\mathrm{OH}$ ratio). In environments characteristic of the open ocean, model calculations show significant impacts of bromine and iodine on $\mathrm{HO}_{x}$ chemistry, with subsequent impacts on local methane lifetimes. However, given that $\sim 70 \%$ of the Earth's surface is ocean, further open-ocean measurements are required from ships over a range of latitudes. A major gap in our understanding is the influence of oceanic emissions as you move vertically above the ocean. In order to examine the vertical extent of the influence of halogen chemistry, vertically resolved measurements of $\mathrm{OH}$ and $\mathrm{HO}_{2}$ are needed, particularly in the first kilometre, together with supporting measurements of sources and sinks (e.g. IO and $\mathrm{BrO}$ and aerosols). In coastal regions at low tide where macroalgae are exposed, halogen chemistry can become a dominant factor, and the impact of halogen species may be underestimated if there is heterogeneity in source regions. Although the laboratory database for uptake coefficients onto aerosols is improving, heterogeneous loss of $\mathrm{HO}_{2}$ still remains a significant source of uncertainty in determining its budget in this region, and further direct studies in the laboratory are needed. Measurements to probe the interaction of $\mathrm{HO}_{x}$ with sulfur containing species over the open-ocean, determined as a function of altitude, are also required.

Some of the worst agreement with models, with discrepancies up to an order of magnitude, is in regions characterised by significant emissions of biogenic VOCs. The model-measurement agreement is very dependent upon the level of $\mathrm{NO}_{x}$, with significant model underprediction for $\mathrm{OH}$ observed at low $\mathrm{NO}$ $(<100 \mathrm{pptv})$. Although advances in instrumentation mean that the number and functionality of measured VOCs has increased significantly, $\mathrm{OH}$ reactivity measurements show that significant $\mathrm{OH}$ sinks are still missing in models for forested regions. When the rate of $\mathrm{OH}$ removal is constrained using field measurements of $\mathrm{OH}$ reactivity, model calculations show that significant unknown $\mathrm{OH}$ sources exist at low $\mathrm{NO}_{x}$ in these environments. Although a number of suggestions have been put forward for the new source of $\mathrm{OH}$ in such an environment, based on theoretical and experimental studies, for example the Peeters' mechanism involving the isomerisation and subsequent decomposition of isoprene peroxy radicals, no single mechanism is yet able to close the model-measurement gap. A process not considered routinely in models or in Section 5 above is the excitation of weak absorption features, for example vibrational overtone transitions in organic peroxides, ${ }^{307}$ which are hypothesised to promote photolysis to form $\mathrm{HO}_{x}$. However, constraints on the rate of certain key processes that have been suggested, for example the rate of photolysis and reaction with $\mathrm{OH}$ of HPALDS are beginning to emerge from intense activity both in the laboratory and in instrumented chamber studies. It is strongly recommended that further $\mathrm{OH}$ 
and $\mathrm{HO}_{2}$ measurements are made in low $\mathrm{NO}_{x}$ environments, such as forests, using a variety of instrumentation to ensure a stringent model constraint.

From an experimental point of view, it is important for the community to know whether these unexpectedly high measurements of $\mathrm{OH}$ in low $\mathrm{NO}_{x}$ environments are accurate or not. The implementation of any new chemistry that is developed to explain these findings may lead to erroneous results, for example in the calculation of the lifetime of $\mathrm{CH}_{4}$, if the field data upon which the development of the new chemistry is based, are wrong. The conclusions are based on measurements of $\mathrm{OH}$ using FAGE, and one group, using an alternative method to obtain the background signal, has reported an artefact under certain conditions. It is difficult to know if previous measurements during other campaigns are subject to the same type of interference. It is strongly recommended, as a matter of priority, that all groups should perform agreed laboratory experiments to investigate the presence or not of interferences, which may allow some understanding of whether corrections to previous data are required or not. However, if an interference were revealed, the concentration of the guilty species may not have been measured, but it may be possible to use a model to calculate its concentration. Measurement groups should adopt instrument designs and sampling procedures (for example the addition of $\mathrm{C}_{3} \mathrm{~F}_{6}$ to determine the $\mathrm{OH}$ background) which minimise the possibility of interferences. In addition, there need to be further intercomparisons for $\mathrm{OH}$ and $\mathrm{HO}_{2}$ using different methods, for example FAGE and CIMS, under field conditions in environments that provide a range of potentially interfering species. A recent chamber intercomparison has provided support for the accuracy of FAGE OH measurements in these types of environments, but further studies of this type are urgently needed.

The level of agreement for $\mathrm{HO}_{2}$ in low $\mathrm{NO}_{x}$, high biogenic VOC environments is more variable from campaign to campaign, but clear conclusions cannot be drawn until the level of possible interferences in $\mathrm{HO}_{2}$ measurements, which have largely been measured using FAGE and chemical conversion to $\mathrm{OH}$, have been quantified by the measurement groups involved. Recent work suggests that the level of interference is likely to be influenced by details of the design of an individual FAGE instrument. Some campaigns suggest there is a missing species which is able to convert $\mathrm{HO}_{2}$ to $\mathrm{OH}$, but without any concomitant production of ozone. Measurements at high temporal resolution above the canopy combined with micrometeorological data have enabled the flux of $\mathrm{OH}$ and $\mathrm{HO}_{2}$ to be determined, and the role of turbulent mixing (which controls deposition rates) on the budgets of these radicals to be determined.

In polluted urban regions, characterised by high levels of $\mathrm{NO}_{x}$ and VOCs, there is significant $\mathrm{HO}_{x}$ production from $\mathrm{HONO}, \mathrm{HCHO}$ and other carbonyl/oxygenated species, and from reactions of ozone with alkenes. $\mathrm{OH}$ reactivity measurements demonstrate, once again, that models are missing $\mathrm{OH}$ sinks, and chemical mechanisms are often deficient or completely missing for the oxidative degradation of more complex, multifunctional VOCs. At the ground, the level of modelmeasurement agreement is variable, often displaying a diurnal variation that scales with $\mathrm{NO}_{x}$. Models underpredict $\mathrm{HO}_{x}$ at high levels of $\mathrm{NO}_{x}$, when the rate of $\mathrm{O}_{3}$ production is highest, and therefore underestimate net ozone production. Aircraft measurements over continental regions show a consistent model underprediction for $\mathrm{HO}_{2}$ that becomes worse with increasing NO concentration, suggesting unknown sources of $\mathrm{HO}_{x}$ that may be present downwind of convection. These results imply uncertainties in our understanding of chemical oxidation at high $\mathrm{NO}_{x}$, for example of aromatic species, although potential interferences for $\mathrm{HO}_{2}$ FAGE measurements from alkene- and aromatic-derived $\mathrm{RO}_{2}$ species (which will scale with the level of VOCs, and also $\mathrm{NO}_{x}$ ) need to be taken into account for some studies to confirm these conclusions.

Concentrations of $\mathrm{OH}$ and $\mathrm{HO}_{2}$ in polar regions can be surprisingly high given the high solar zenith angle and low concentrations of water vapour, because of $\mathrm{HO}_{x}$ sources emitted from the snowpack. $\mathrm{H}_{2} \mathrm{O}_{2}, \mathrm{HCHO}$ and $\mathrm{HONO}$ can be dominant sources of $\mathrm{HO}_{x}$, but a lack of high quality measurements of these species to constrain box models have limited the studies. In the case of HONO, there are large overpredictions of $\mathrm{OH}$ if measured $\mathrm{HONO}$ is used to constrain the model, casting doubt on the reliability of some methods to measure HONO. At the South Pole the very low mixed boundary layer leads to high levels of $\mathrm{NO}_{x}$ following emission of precursors, which enhances the concentration of $\mathrm{OH}$ via the reaction of $\mathrm{HO}_{2}$ with NO. Radical budgets calculated using box models constrained by measurements of halogen oxides in coastal Antarctica show that halogen species are a significant source of $\mathrm{HO}_{x}$ and can dominate the conversion of $\mathrm{HO}_{2}$ into $\mathrm{OH}$. However, significant $\mathrm{OH}$ overpredictions remain, suggestive of $\mathrm{OH}$ sinks missing in the model, or that there are errors in the kinetic data involving halogen species at lower temperatures. In the free troposphere above the Arctic, at altitudes above $5 \mathrm{~km}$, and where halogen influences are likely to be small, $\mathrm{HO}_{2}$ overpredictions can be improved via inclusion of uptake onto aerosols, the rate of which is expected to increase at lower temperatures. However, there is an absence of direct laboratory measurements of $\mathrm{HO}_{2}$ uptake coefficients under relevant conditions at low temperature.

For all environments studied, there is an almost complete lack of $\mathrm{OH}$ and $\mathrm{HO}_{2}$ measurements in the altitude range 10-500 m, although limited vertically-resolved measurements exist from elevator-based instruments in the range $2-40 \mathrm{~m}$ within forest canopies. There are likely to be large gradients in the concentration of $\mathrm{HO}_{x}$ source and sink gases as well as aerosols, and extrapolating conclusions of measurementmodel studies at the surface to higher altitudes is risky. There have been pioneering measurements of $\mathrm{OH}, \mathrm{HO}_{2}$ and supporting measurements at very low altitudes in the last 2-3 years in Germany using an instrumented Zeppelin, and the results of these studies will greatly extend our knowledge of a little probed region. It is recommended that vertically resolved measurements are made in the boundary layer over land, the ocean and the snowpack.

Following the ending of MIESR measurements, a fundamental gap in the arsenal of field instruments is a direct field measurement for $\mathrm{HO}_{2}$. Although there have been remote sensing measurements of stratospheric $\mathrm{HO}_{2}$ from space using far-IR emission rotational spectroscopy, and integrated 
column abundances have been measured from the ground using $\mathrm{mm}$ wave absorption spectroscopy (but most sensitive to stratospheric and mesospheric $\mathrm{HO}_{2}$ ), these methods have not been used for local in situ $\mathrm{HO}_{2}$ in the troposphere. Continuous wave cavity ringdown absorption spectroscopy in the near-IR, using the first vibrational overtone of the $\mathrm{OH}$ stretch around $6638 \mathrm{~cm}^{-1}$, has been used to detect $\mathrm{HO}_{2}$ directly in a large photoreactor, ${ }^{318}$ although the detection limit reported of $1.5 \times 10^{10}$ molecule $\mathrm{cm}^{-3}$ (at $<100$ Torr total pressure) is not low enough to enable tropospheric detection. It is strongly recommended that the community strive to develop a technique capable of direct in situ measurements for $\mathrm{HO}_{2}$, and other specific peroxy radicals, with good time resolution.

Clouds play a crucial role in the chemistry of the atmosphere, occupying, on average, $\sim 15 \%$ of the volume of the troposphere. Other than by modifying $j\left(\mathrm{O}^{1} \mathrm{D}\right)$, the role of clouds in determining local $\mathrm{HO}_{x}$ concentrations is not well understood, although aqueous phase chemistry in clouds can influence gas phase radical chemistry. A number of aircraft projects and one recent ground-based 2010 Hill Cap Cloud Thuringia (HCCT) project atop Mt Schmucke in Germany have identified significantly reduced $\mathrm{HO}_{2}$ concentrations in clouds that exceed the depletion expected due to the reduction in radiation alone. ${ }^{338}$ Further work is required to probe the influence of clouds on local $\mathrm{HO}_{x}$ concentrations.

\section{Acknowledgements}

The authors wish to thank the National Centre for Atmospheric Science, which is a distributed institute funded by the Natural Environment Research Council, for funding. We also wish to thank the two reviewers for their comments which have helped to improve the manuscript.

\section{References}

1 S. Saunders, M. Jenkin, R. Derwent and M. Pilling, Atmos. Chem. Phys., 2003, 3, 161-180.

2 MCM, http://mcm.leeds.ac.uk/MCM

3 W. J. Bloss, J. D. Lee, G. P. Johnson, R. Sommariva, D. E. Heard, A. Saiz-Lopez, J. M. C. Plane, G. McFiggans, H. Coe, M. Flynn, P. Williams, A. R. Rickard and Z. L. Fleming, Geophys. Res. Lett., 2005, 32, L06814.

4 S. C. Smith, J. D. Lee, W. J. Bloss, G. P. Johnson, T. Ingham and D. E. Heard, Atmos. Chem. Phys., 2006, 6, 1435.

5 R. Sommariva, W. J. Bloss, N. Brough, N. Carslaw, M. Flynn, A.-L. Haggerstone, D. E. Heard, J. R. Hopkins, J. D. Lee, A. C. Lewis, G. McFiggans, P. S. Monks, S. A. Penkett, M. J. Pilling, J. M. C. Plane, K. A. Read, A. Saiz-Lopez, A. R. Rickard and P. I. Williams, Atmos. Chem. Phys., 2006, 6, 1135 .

6 Y. Kanaya, Y. Yokouchi, J. Matsumoto, K. Nakamura, S. Kato, H. Tanimoto, H. Furutani, K. Toyota and H. Akimoto, Geophys. Res. Lett., 2002, 29, 531.

7 Y. Kanaya, R. Cao, S. Kato, Y. Miyakawa, Y. Kajii, H. Tanimoto, Y. Yokouchi, M. Mochida, K. Kawamura and H. Akimoto, J. Geophys. Res., 2007, 112, D11308.

8 T. A. Kovacs, W. H. Brune, H. Harder, M. Martinez, J. B. Simpas, G. J. Frost, E. Williams, T. Jobson, C. Stroud, V. Young, A. Fried and B. Wert, J. Environ. Monit., 2003, 5, 68.

9 Y. Sadanaga, A. Yoshino, S. Kato and Y. Kajii, Environ. Sci. Technol., 2005, 39, 8847.

10 V. Sinha, J. Williams, J. Lelieveld, T. M. Ruuskanen, M. K. Kajos, J. Patokoski, H. Hellen, H. Hakola,
D. Mogensen, M. Boy, J. Rinne and M. Kulmala, Environ. Sci. Technol., 2010, 44, 6614.

11 P. Di Carlo, W. H. Brune, M. Martinez, H. Harder, R. Lesher, X. R. Ren, T. Thornberry, M. A. Carroll, V. Young, P. B. Shepson, D. Riemer, E. Apel and C. Campbell, Science, 2004, 304, 722.

12 T. Ingham, A. Goddard, L. K. Whalley, K. L. Furneaux, P. M. Edwards, C. P. Seal, D. E. Self, G. P. Johnson, K. A. Read, J. D. Lee and D. E. Heard, Atmos. Meas. Tech., 2009, 2, 465.

13 J. D. Lee, J. C. Young, K. A. Read, J. F. Hamilton, J. R. Hopkins, A. C. Lewis, B. J. Bandy, J. Davey, P. Edwards, T. Ingham, D. E. Self, S. C. Smith, M. J. Pilling and D. E. Heard, J. Atmos. Chem., 2009, 64, 53.

14 D. H. Ehhalt and F. Rohrer, J. Geophys. Res., 2000, 105.

15 S. Vaughan, T. Ingham, L. K. Whalley, D. Stone, M. J. Evans, K. A. Read, J. D. Lee, S. J. Moller, L. J. Carpenter, A. C. Lewis, Z. L. Fleming and D. E. Heard, Atmos. Chem. Phys., 2012, 12, 2149.

16 V. Sinha, J. Williams, J. N. Crowley and J. Lelieveld, Atmos. Chem. Phys., 2008, 8, 2213.

17 S. Kim, A. Guenther, T. Karl and J. Greenberg, Atmos. Chem. Phys., 2011, 11, 8613.

18 D. Mogensen, S. Smolander, A. Sogachev, L. Zhou, V. Sinha, A. Guenther, J. Williams, T. Nieminen, M. K. Kajos, J. Rinne, M. Kumala and M. Boy, Atmos. Chem. Phys., 2011, 11, 9709.

19 A. C. Lewis, N. Carslaw, P. J. Marriott, R. M. Kinghorn, P. Morrison, A. L. Lee, K. D. Bartle and M. J. Pilling, Nature, $2000, \mathbf{4 0 5}, 778$.

20 S. Kato, T. Sato and Y. Kajii, Atmos. Environ., 2011, 45, 5531.

21 L. K. Whalley, P. M. Edwards, K. L. Furneaux, A. Goddard, T. Ingham, M. J. Evans, D. Stone, J. R. Hopkins, C. E. Jones, A. Karunaharan, J. D. Lee, A. C. Lewis, P. S. Monks, S. J. Moller and D. E. Heard, Atmos. Chem. Phys. 2011, 11, 7223.

22 A. Hofzumahaus, F. Rohrer, K. D. Lu, B. Bohn, T. Brauers, C. C. Chang, H. Fuchs, F. Holland, K. Kita, Y. Kondo, X. Li, S. R. Lou, M. Shao, L. M. Zeng, A. Wahner and Y. H. Zhang, Science, 2009, 324, 1702.

23 D. E. Heard and M. J. Pilling, Chem. Rev., 2003, 103, 5163.

24 P. S. Monks, Chem. Soc. Rev., 2005, 34, 376.

25 P. S. Monks, C. Granier, S. Fuzzi, A. Stohl, M. L. Williams, H. Akimoto, M. Amann, A. Baklanov, U. Baltensperger, I. Bey, N. Blake, R. S. Blake, K. Carslaw, O. R. Cooper, F. Dentener, D. Fowler, E. Fragkou, G. J. Frost, S. Generoso, P. Ginoux, V. Grewe, A. Guenther, H. C. Hansson, S. Henne, J. Hjorth, A. Hofzumahaus, H. Huntrieser, I. S. A. Isaksen, M. E. Jenkin, J. Kaiser, M. Kanakidou, Z. Klimont, M. Kulmala, P. Laj, M. G. Lawrence, J. D. Lee, C. Liousse, M. Maione, G. McFiggans, A. Metzger, A. Mieville, N. Moussiopoulos, J. J. Orlando, C. D. O'Dowd, P. I. Palmer, D. D. Parrish, A. Petzold, U. Platt, U. Poeschl, A. S. H. Prevot, C. E. Reeves, S. Reimann, Y. Rudich, K. Sellegri, R. Steinbrecher, D. Simpson, H. ten Brink, J. Theloke, G. R. van der Werf, R. Vautard, V. Vestreng, C. Vlachokostas and R. von Glasow, Atmos. Environ., $2009, \mathbf{4 3}, 5268$.

26 P. Laj, J. Klausen, M. Bilde, C. Plass-Duelmer, G. Pappalardo, C. Clerbaux, U. Baltensperger, J. Hjorth, D. Simpson, S. Reimann, P. F. Coheur, A. Richter, M. De Maziere, Y. Rudich, G. McFiggans, K. Torseth, A. Wiedensohler, S. Morin, M. Schulz, J. D. Allan, J. L. Attie, I. Barnes, W. Birmili, J. P. Cammas, J. Dommen, H. P. Dorn, D. Fowler, S. Fuzzi, M. Glasius, C. Granier, M. Hermann, I. S. A. Isaksen, S. Kinne, I. Koren, F. Madonna, M. Maione, A. Massling, O. Moehler, L. Mona, P. S. Monks, D. Mueller, T. Mueller, J. Orphal, V. H. Peuch, F. Stratmann, D. Tanre, G. Tyndall, A. A. Riziq, M. Van Roozendael, P. Villani, B. Wehner, H. Wex and A. A. Zardini, Atmos. Environ., 2009, 43, 5351.

27 Free radicals in the troposphere: Their measurement, interpretation of field data and future directions, ed. D. E. Heard, ACCENT Leeds Expert Meeting, ACCENT Secretariat, 2006.

28 Analytical Techniques for Atmospheric Measurement, ed. D. E. Heard, Blackwell Publishing, 2006.

29 K. C. Clemitshaw, Crit. Rev. Environ. Sci. Technol., 2004, 34, 1.

30 H. Fuchs, B. Bohn, A. Hofzumahaus, F. Holland, K. Lu, S. Nehr, F. Rohrer and A. Wahner, Atmos. Meas. Tech., 2011, 4, 1209. 
31 J. Mao, X. Ren, W. Brune, D. M. Van Duin, R. C. Cohen, J. H. Park, A. Goldstein, F. Paulot, M. R. Beaver, J. D. Crounse, P. O. Wennberg, J. P. DiGangi, S. B. Henry, F. N. Keutsch, C. Park, G. W. Schade, G. M. Wolfe and J. A. Thornton, Atmos. Chem. Phys., 2012, 12, 6715.

32 M. E. Jenkin, S. M. Saunders and M. J. Pilling, Atmos. Environ., 1997, 31, 81 .

33 M. E. Jenkin, S. M. Saunders, V. Wagner and M. J. Pilling, Atmos. Chem. Phys., 2003, 3, 181.

34 S. M. Saunders, M. E. Jenkin, R. G. Derwent and M. J. Pilling, Atmos. Chem. Phys., 2003, 3, 161.

35 C. Bloss, V. Wagner, M. E. Jenkin, R. Volkamer, W. J. Bloss, J. D. Lee, D. E. Heard, K. Wirtz, M. Martin-Reviejo, G. Rea, J. C. Wenger and M. J. Pilling, Atmos. Chem. Phys., 2005, 5, 641.

36 W. Stockwell, R. F. Kirchner, M. Kuhn and S. Seefeld, J. Geophys. Res., [Atmos.], 1997, 102, 25847.

37 M. Michou, D. Saint-Martin, H. Teyssedre, A. Alias, F. Karcher, D. Olivie, A. Voldoire, B. Josse, V. H. Peuch, H. Clark, J. N. Lee and F. Cheroux, Geoscientific Model Development, 2011, 4, 873.

38 K. M. Emmerson and M. J. Evans, Atmos. Chem. Phys., 2009, 9, 1831.

39 N. Carslaw, D. J. Creasey, D. E. Heard, P. J. Jacobs, J. D. Lee, A. C. Lewis, J. B. McQuaid and M. J. Pilling, J. Geophys. Res., $2002, \mathbf{1 0 7}, 5$.

40 Y. Kanaya, Y. Sadanaga, J. Matsumoto, U. K. Sharma, J. Hirokawa, Y. Kajii and H. Akimoto, J. Geophys. Res., [Atmos.], 2000, 105, 24205.

41 Y. Kanaya, Y. Sadanaga, K. Nakamura and H. Akimoto, J. Geophys. Res., [Atmos.], 2001, 106, 24197.

42 A. S. Mahajan, J. M. C. Plane, H. Oetjen, L. Mendes, R. W. Saunders, A. Saiz-Lopez, C. E. Jones, L. J. Carpenter and G. McFiggans, Atmos. Chem. Phys., 2010, 10, 4611.

43 K. A. Read, A. S. Mahajan, L. J. Carpenter, M. J. Evans, B. V. E. Faria, D. E. Heard, J. R. Hopkins, J. D. Lee, S. J. Moller, A. C. Lewis, L. Mendes, J. B. McQuaid, H. Oetjen, A. Saiz-Lopez, M. J. Pilling and J. M. C. Plane, Nature, 2008, 453, 1232.

44 K. L. Furneaux, L. K. Whalley, D. E. Heard, H. M. Atkinson, W. J. Bloss, M. J. Flynn, M. W. Gallagher, T. Ingham, L. Kramer, J. D. Lee, R. Leigh, G. B. McFiggans, A. S. Mahajan, P. S. Monks, H. Oetjen, J. M. C. Plane and J. D. Whitehead, Atmos. Chem. Phys., 2010, 10, 3645.

45 R. Commane, K. Seitz, C. S. E. Bale, W. J. Bloss, J. Buxmann, T. Ingham, U. Platt, D. Poehler and D. E. Heard, Atmos. Chem. Phys., 2011, 11, 6721.

46 F. Taketani, Y. Kanaya and H. Akimoto, J. Phys. Chem. A, 2008, $112,2370$.

47 F. Taketani, Y. Kanaya and H. Akimoto, Atmos. Environ., 2009, 43, 1660.

48 J. R. Olson, J. H. Crawford, G. Chen, W. H. Brune, I. C. Faloona, D. Tan, H. Harder and M. Martinez, J. Geophys. Res., 2006, 111, D10301.

49 M. Hanke, J. Uecker, T. Reiner and F. Arnold, Int. J. Mass Spectrom., 2002, 213, 91.

50 G. D. Edwards, C. Cantrell, S. Stephens, B. Hill, O. Goyea, R. Shetter, R. L. Mauldin, E. Kosciuch, D. Tanner and F. Eisele, Anal. Chem. (Washington, DC, U. S.), 2003, 75, 5317.

51 G. H. Mount, J. Geophys. Res., [Atmos.], 1992, 97, 2427.

52 F. J. Comes, W. Armerding, M. Spiekermann, J. Walter and C. Ruger, Ber. Bunsen-Ges., 1993, 97, 1156.

53 F. J. Comes, W. Armerding, M. Spiekermann, J. Walter and C. Ruger, Atmos. Environ., 1995, 29, 169.

54 H. P. Dorn, U. Brandenburger, T. Brauers and H. Hausmann, J. Atmos. Sci., 1995, 52, 3373.

55 H. P. Dorn, U. Brandenburger, T. Brauers, M. Hausmann and D. H. Ehhalt, Geophys. Res. Lett., 1996, 23, 2537.

56 D. Perner, U. Platt, M. Trainer, G. Hubler, J. Drummond, W. Junkermann, J. Rudolph, B. Schubert, A. Volz, D. H. Ehhalt, K. J. Rumpel and G. Helas, J. Atmos. Chem., 1987, 5, 185.

57 D. Perner, Fresenius' Z. Anal. Chem., 1989, 333, 699.

58 G. Hubler, D. Perner, U. Platt, A. Tonnissen and D. H. Ehhalt, J. Geophys. Res., [Atmos.], 1984, 89, 1309.

59 E. Schlosser, T. Brauers, H.-P. Dorn, H. Fuchs, A. Hofzumahaus, F. Holland and A. Wahner, J. Atmos. Chem., 2007, 56, 187.
60 E. Schlosser, T. Brauers, H.-P. Dorn, H. Fuchs, R. H'aseler, A. Hofzumahaus, F. Holland, A. Wahner, Y. Kanay, Y. Kajii, S. Miyamoto, S. Nishida, K. Watanabe, A. Yoshino, D. Kubistin, M. Martinez, M. Rudolf, H. Harder, H. Berresheim, T. Elste, C. Plass-Dülmer, G. Stange and U. Schurath, Atmos. Chem. Phys., 2009, 9, 7923.

61 D. Mihelcic, D. H. Ehhalt, J. Klomfass, G. F. Kulessa, U. Schmidt and M. Trainer, Ber. Bunsen-Ges., 1978, 82, 16.

62 D. Mihelcic, D. Klemp, P. Musgen, H. W. Patz and A. Volzthomas, J. Atmos. Chem., 1993, 16, 313.

63 D. Mihelcic, F. Holland, A. Hofzumahaus, L. Hoppe, S. Konrad, P. Musgen, H. W. Patz, H. J. Schafer, T. Schmitz, A. VolzThomas, K. Bachmann, S. Schlomski, U. Platt, A. Geyer, B. Alicke and G. K. Moortgat, J. Geophys. Res., [Atmos.], 2003, 108, 8254.

64 H. Fuchs, T. Brauers, H. P. Dorn, H. Harder, R. Häseler, A. Hofzumahaus, F. Holland, Y. Kanaya, Y. Kajii, D. Kubistin, S. Lou, M. Martinez, K. Miyamoto, S. Nishida, M. Rudolf, E. Schlosser, A. Wahner, A. Yoshino and U. Schurath, Atmos. Chem. Phys., 2010, 10, 12233.

65 D. E. Heard, Annu. Rev. Phys. Chem., 2006, 57, 191-216.

66 M. Siese, K. H. Becker, K. J. Brockmann, H. Geiger, A. Hofzumahaus, F. Holland, D. Mihelcic and K. Wirtz, Environ. Sci. Technol., 2001, 35, 4660.

67 W. J. Bloss, J. D. Lee, C. Bloss, D. E. Heard, M. J. Pilling, K. Wirtz, M. Martin-Reviejo and M. Siese, Atmos. Chem. Phys., 2004, 4, 571

68 D. J. Creasey, P. A. Halford-Maw, D. E. Heard, M. J. Pilling and B. J. Whitaker, J. Chem. Soc., Faraday Trans., 1997, 93, 2907.

69 R. Commane, C. F. A. Floquet, T. Ingham, D. Stone, M. J. Evans and D. E. Heard, Atmos. Chem. Phys., 2010, 10, 8783 .

70 L. K. Whalley, K. L. Furneaux, A. Goddard, J. D. Lee, A. Mahajan, H. Oetjen, K. A. Read, N. Kaaden, L. J. Carpenter, A. C. Lewis, J. M. C. Plane, E. S. Saltzman, A. Wiedensohler and D. E. Heard, Atmos. Chem. Phys., 2010, 10, 1555.

71 D. Tan, I. Faloona, J. B. Simpas, W. Brune, J. Olson, J. Crawford, M. Avery, G. Sachse, S. Vay, S. Sandholm, H. W. Guan, T. Vaughn, J. Mastromarino, B. Heikes, J. Snow, J. Podolske and H. Singh, J. Geophys. Res., [Atmos.], 2001, 106, 32667.

72 I. C. Faloona, D. Tan, R. L. Lesher, N. L. Hazen, C. L. Frame, J. B. Simpas, H. Harder, M. Martinez, P. di Carlo, X. Ren and W. H. Brune, J. Atmos. Chem., 2004, 47, 139.

73 S. Lou, F. Holland, F. Rohrer, K. Lu, B. Bohn, T. Brauers, C. C. Chang, H. Fuchs, R. Haeseler, K. Kita, Y. Kondo, X. Li, M. Shao, L. Zeng, A. Wahner, Y. Zhang, W. Wang and A. Hofzumahaus, Atmos. Chem. Phys., 2010, 10, 11243.

74 A. Hofzumahaus, F. Rohrer, K. Lu, B. Bohn, T. Brauers, C. C. Chang, H. Fuchs, F. Holland, K. Kita, Y. Kondo, X. Li, S. Lou, M. Shao, L. Zeng, A. Wahner and Y. Zhang, Science, 2009, 324, 1702.

75 F. Holland, M. Hessling and A. Hofzumahaus, J. Atmos. Sci., $1995,52,3393$.

76 M. Martinez, H. Harder, D. Kubistin, M. Rudolf, H. Bozem, G. Eerdekens, H. Fischer, T. Klupfel, C. Gurk, R. Konigstedt, U. Parchatka, C. L. Schiller, A. Stickler, J. Williams and J. Lelieveld, Atmos. Chem. Phys., 2010, 10, 3759.

77 S. Dusanter, D. Vimal and P. S. Stevens, Atmos. Chem. Phys., 2008, 8, 321 .

78 S. Dusanter, D. Vimal, P. S. Stevens, R. Volkamer and L. T. Molina, Atmos. Chem. Phys., 2009, 9, 1665.

79 Y. Kanaya, Y. Sadanaga, J. Hirokawa, Y. Kajii and H. Akimoto, J. Atmos. Chem., 2001, 38, 73.

80 Y. Kanaya and H. Akimoto, Chem. Rec., 2002, 2, 199.

81 Y. Kanaya, R. Cao, H. Akimoto, M. Fukuda, Y. Komazaki, Y. Yokouchi, M. Koike, H. Tanimoto, N. Takegawa and Y. Kondo, J. Geophys. Res., [Atmos.], 2007, 112.

82 Y. Sadanaga, A. Yoshino, K. Watanabe, A. Yoshioka, Y. Wakazono, Y. Kanaya and Y. Kajii, Rev. Sci. Instrum., 2004, 75, 2648

83 Y. Sadanaga, A. Yoshino, K. Shungo and K. Yoshizumi, Environ. Sci. Technol., 2005, 39, 8847.

84 D. Amedro, K. Miyazaki, A. Parker, C. Schoernaecker and C. Fittschen, J. Environ. Sci.(Beijing, China), 2012, 24, 78. 
85 M. S. Alam, M. Camredon, A. R. Rickard, T. Carr, K. P. Wyche, K. E. Hornsby, P. S. Monks and W. J. Bloss, Phys. Chem. Chem. Phys., 2011, 12, 11002.

86 D. R. Glowacki, A. Goddard, K. Hemavibool, T. L. Malkin, R. Commane, F. Anderson, W. J. Bloss, D. E. Heard, T. Ingham, M. J. Pilling and P. W. Seakins, Atmos. Chem. Phys., 2007, 7, 5371-5390.

87 T. L. Malkin, A. Goddard, D. E. Heard and P. W. Seakins, Atmos. Chem. Phys., 2010, 10, 1441.

88 R. Dlugi, M. Berger, M. Zelger, A. Hofzumahaus, M. Siese, F. Holland, A. Wisthaler, W. Grabmer, A. Hansel, R. Koppmann, G. Kramm, M. Mollmann-Coers and A. Knaps, Atmos. Chem. Phys., 2010, 10, 6215.

89 H. Fuchs, F. Holland and A. Hofzumahaus, Rev. Sci. Instrum., 2008, 79, 084104.

90 M. Hanke, J. Uecker, T. Reiner and F. Arnold, Int. J. Mass Spectrom., 2002, 213, 91.

91 H. Fuchs, T. Brauers, R. Häseler, F. Holland, D. Mihelcic, P. Müsgen, F. Rohrer, R. Wegener and A. Hofzumahaus, Atmos. Meas. Tech., 2009, 2, 55.

92 J. Liao, L. G. Huey, D. J. Tanner, N. Brough, S. Brooks, J. E. Dibb, J. Stutz, J. L. Thomas, B. Lefer, C. Haman and K. Gorham, Atmos. Chem. Phys., 2011, 11, 8577.

93 S. J. Sjostedt, L. G. Huey, D. J. Tanner, J. Peischl, G. Chen, J. E. Dibb, B. Lefer, M. A. Hutterli, A. J. Beyersdorf, N. J. Blake, D. R. Blake, D. Sueper, T. Ryerson, J. Burkhart and A. Stohl, Atmos. Environ., 2007, 41, 5122.

94 H. Berresheim, T. Elste, C. Plass-Dülmer, F. L. Eiseleb and D. J. Tannerb, Int. J. Mass Spectrom., 2000, 202, 91.

95 F. Rohrer and H. Berresheim, Nature, 2006, 442, 184.

96 F. L. Eisele and J. D. Bradshaw, Anal. Chem. (Washington, DC, U. S.), 1993, 65, A927.

97 D. J. Tanner, A. Jefferson and F. L. Eisele, J. Geophys. Res., [Atmos.], 1997, 102, 6415.

98 R. L. Mauldin, D. J. Tanner and F. L. Eisele, J. Geophys. Res., [Atmos.], 1998, 103, 3361.

99 A. Kukui, G. Ancellet and G. Le Bras, J. Atmos. Chem., 2008, 61, 133.

100 J. H. Mather and W. H. Brune, Geophys. Res. Lett., 1990, $17,1283$.

101 U. Aschmutat, M. Hessling, F. Holland and A. Hofzumahaus, Phys.-Chem. Behav. Atmos. Pollut., [Proc. Eur. Symp.], 1994, 811.

102 H. Fuchs, B. Bohn, A. Hofzumahaus, F. Holland, K. D. Lu, S. Nehr, F. Rohrer and A. Wahner, Atmos. Meas. Tech., 2011, 4, 1255.

103 A. Hofzumahaus, U. Aschmutat, U. Brandenburger, T. Brauers, H. P. Dorn, M. Hausmann, M. Hessling, F. Holland, C. PlassDulmer and D. H. Ehhalt, J. Atmos. Chem., 1998, 31, 227.

104 C. Y. Chan, T. M. Hard, A. A. Mehrabzadeh, L. A. George and R. J. O'Brien, J. Geophys. Res., 1990, 95, 18569.

105 T. M. Hard, L. A. George and R. J. O’Brien, J. Atmos. Sci., 1995, 52, 3354.

106 W. J. Bloss, J. D. Lee, C. Bloss, D. E. Heard, M. J. Pilling, K. Wirtz, M. Martin-Reviejo and M. Siese, Atmos. Chem. Phys., 2004, 4, 571 .

107 F. L. Eisele, R. L. Mauldin, D. J. Tanner, C. Cantrell, E. Kosciuch, J. B. Nowak, B. Brune, I. Faloona, D. Tan, D. D. Davis, L. Wang and G. Chen, J. Geophys. Res., [Atmos.], 2001, 106, 32683.

108 E. Schlosser, T. Brauers, H. P. Dorn, H. Fuchs, R. Häseler, A. Hofzumahaus, F. Holland, A. Wahner, Y. Kanaya, Y. Kajii, K. Miyamoto, S. Nishida, K. Watanabe, A. Yoshino, D. Kubistin, M. Martinez, M. Rudolf, H. Harder, H. Berresheim, T. Elste, C. Plass-Dülmer, G. Stange and U. Schurath, Atmos. Chem. Phys., 2009, 9, 7923.

109 X. Ren, G. D. Edwards, C. Cantrell, R. L. Lesher, A. R. Metcalf, T. Shirley and W. H. Brune, J. Geophys. Res., 2003, 108, 4605.

110 X. Ren, H. Harder, M. Martinez, I. Faloona, D. Tan, R. Lesher, P. Di Carlo, J. B. Simpas and W. H. Brune, J. Atmos. Chem., 2004, 47, 169 .

111 D. E. Heard, L. K. Whalley, M. A. Blitz and P. W. Seakins, Abstract 11I-04, The sensitivity of laser-induced fluorescence instruments at low pressure to $\mathrm{RO}_{2}$ radicals and the use of this detection method to determine the yield of $\mathrm{HO}_{2}$ during $\mathrm{OH}$-initiated isoprene oxidation, Proceedings Fall Meeting AGU, 2011.
112 K. Lu, F. Rohrer, F. Holland, H. Fuchs, B. Bohn, T. Brauers, C. C. Chang, R. Haeseler, M. Hu, K. Kita, Y. Kondo, X. Li, S. Lou, S. Nehr, M. Shao, L. Zeng, A. Wahner, Y. Zhang and A. Hofzumahaus, Atmos. Chem. Phys., 2012, 12, 1541.

113 H. Fuchs, H.-P. Dorn, M. Bachner, B. Bohn, T. Brauers, S. Gomm, A. Hofzumahaus, F. Holland, S. Nehr, F. Rohrer, R. Tillmann and A. Wahner, Atmos. Meas. Tech., 2012, 5, 2077.

114 D. J. Tanner and F. L. Eisele, J. Geophys. Res., 1995, 100, 2883.

115 F. L. Eisele and D. J. Tanner, J. Geophys. Res., [Atmos.], 1991, 96, 9295.

116 O. Welz, J. D. Savee, D. L. Osborn, S. S. Vasu, C. J. Percival, D. E. Shallcross and C. A. Taatjes, Science, 2012, 335, 204.

117 S. A. Penkett, J. M. C. Plane, F. J. Comes, K. C. Clemitshaw and H. Coe, J. Atmos. Chem., 1999, 33, 107.

118 O. Forberich, T. Pfeiffer, M. Spiekermann, J. Walter, F. J. Comes, R. Grigonis, K. C. Clemitshaw and R. A. Burgess, J. Atmos. Chem., 1999, 33, 155.

119 J. L. Grenfell, N. H. Savage, R. M. Harrison, S. A. Penkett, O. Forberich, F. J. Comes, K. C. Clemitshaw, R. A. Burgess, L. M. Cardenas, B. Davison and G. G. McFadyen, J. Atmos. Chem., 1999, 33, 183.

120 K. C. Clemitshaw, L. J. Carpenter, S. A. Penkett and M. E. Jenkin, J. Geophys. Res., [Atmos.], 1997, 102, 25405.

121 T. Brauers, M. Hausmann, A. Bister, A. Kraus and H. P. Dorn, J. Geophys. Res., [Atmos.], 2001, 106, 7399.

122 D. J. Creasey, Development and implementation of the FAGE technique for measurement of $\mathrm{OH}$ and $\mathrm{HO}_{2}$ in the troposphere, University of Leeds, Leeds, 1998.

123 D. J. Creasey, D. E. Heard and J. D. Lee, J. Geophys. Res., [Atmos.], 2002, 107, 4091.

124 N. Carslaw, D. J. Creasey, D. E. Heard, A. C. Lewis, J. B. McQuaid, M. J. Pilling, P. S. Monks, B. J. Bandy and S. A. Penkett, J. Geophys. Res., [Atmos.], 1999, 104, 30241.

125 N. Carslaw, P. J. Jacobs and M. J. Pilling, J. Geophys. Res., 1999, 104(D23), 30257.

126 N. Carslaw, D. J. Creasey, D. E. Heard, P. J. Jacobs, J. D. Lee, A. C. Lewis, J. B. McQuaid, M. J. Pilling, S. Bauguitte, S. A. Penkett, P. S. Monks and G. Salisbury, J. Geophys. Res., [Atmos.], 2002, 107, 4190.

127 F. D. Yin, D. Grosjean and J. H. Seinfeld, J. Atmos. Chem., 1990, 11, 309.

128 F. D. Yin, D. Grosjean, R. C. Flagan and J. H. Seinfeld, J. Atmos. Chem., 1990, 11, 365.

129 H. Berresheim, T. Elste, H. G. Tremmel, A. G. Allen, H. C. Hansson, K. Rosman, M. Dal Maso, J. M. Makela, M. Kulmala and C. D. O'Dowd, J. Geophys. Res., [Atmos.], 2002, 107, 8100.

130 G. Salisbury, A. R. Rickard, P. S. Monks, B. J. Allan, S. Bauguitte, S. A. Penkett, N. Carslaw, A. C. Lewis, D. J. Creasey, D. E. Heard, P. J. Jacobs and J. D. Lee, J. Geophys. Res., [Atmos.], 2001, 106, 12669.

131 G. Salisbury, P. S. Monks, S. Bauguitte, B. J. Bandy and S. A. Penkett, J. Atmos. Chem., 2002, 41, 163.

132 D. J. Creasey, G. E. Evans, D. E. Heard and J. D. Lee, J. Geophys. Res., 2003, 108, 4475.

133 R. Sommariva, A.-L. Haggerstone, L. J. Carpenter, N. Carslaw, D. J. Creasey, D. E. Heard, J. D. Lee, A. C. Lewis, M. J. Pilling and J. Zador, Atmos. Chem. Phys., 2004, 4, 839.

134 B. J. Allan, G. McFiggans and J. M. C. Plane, J. Geophys. Res., 2000, 105, 14363.

135 A. L. Haggerstone, L. J. Carpenter, N. Carslaw and G. McFiggans, J. Geophys. Res., 2005, 110.

136 H. Berresheim, C. Plass-Dulmer, T. Elste, N. Mihalopoulos and F. Rohrer, Atmos. Chem. Phys., 2003, 3, 639.

137 M. Vrekoussis, M. Kanakidou, N. Mihalopoulos, P. J. C. A. Lelieveld, D. P. H. Berresheim and E. Baboukas, Atmos. Chem. Phys., 2004, 4, 169.

138 Y. Kanaya, J. Matsumoto, S. Kato and H. Akimoto, J. Geophys. Res., [Atmos.], 2001, 106, 24209.

139 Y. Kanaya, J. Matsumoto and H. Akimoto, J. Geophys. Res., [Atmos.], 2002, 107, 4368.

140 Y. Kanaya, K. Nakamura, S. Kato, J. Matsumoto, H. Tanimoto and H. Akimoto, Atmos. Environ., 2002, 36, 4929.

141 B. Qi, Y. Kanaya, A. Takami, S. Hatakeyama, S. Kato, Y. Sadanaga, H. Tanimoto and Y. Kajii, J. Geophys. Res., [Atmos.], 2007, 112. 
142 C. C. Kircher and S. P. Sander, J. Phys. Chem., 1984, 88, 2082.

143 D. Stone and D. M. Rowley, Phys. Chem. Chem. Phys., 2005, 7, 2156.

144 N. Kanno, K. Tonokura, A. Tezaki and M. Koshi, J. Phys. Chem. A, 2005, 109, 3153.

145 B. Alicke, K. Hebestreit, J. Stutz and U. Platt, Nature, 1999, 397, 572.

146 J. Stutz, K. Hebestreit, B. Alicke and U. Platt, J. Atmos. Chem., 1999, 34, 65.

147 R. M. Harrison, J. P. Shi and J. L. Grenfell, Atmos. Environ., 1998, 32, 2769.

148 J. Thornton and J. P. D. Abbatt, J. Geophys. Res., [Atmos.], $2005,110$.

149 J. A. Thornton, L. Jaeglé and V. F. McNeill, J. Geophys. Res., 2008, 113, D05303.

150 H. L. Macintyre and M. J. Evans, Atmos. Chem. Phys., 2011, 11, 10965.

151 R. Wada, J. M. Beames and A. J. Orr-Ewing, J. Atmos. Chem., 2007, 58, 69.

152 D. E. Heard, K. Read, J. Methven, S. Al-Haider, W. J. Bloss, G. P. Johnson, M. J. Pilling, P. W. Seakins, S. C. Smith, R. Sommariva, J. C. Stanton, T. J. Still, B. Brooks, G. De Leeuw, A. V. Jackson and J. B. McQuaid, et al., Atmos. Chem. Phys., 2006, 6, 2241.

153 R. Sommariva, M. J. Pilling, W. J. Bloss, D. E. Heard, J. D. Lee, Z. L. Fleming, P. S. Monks, J. M. C. Plane, A. Saiz-Lopez, S. M. Ball, M. Bitter, R. L. Jones, N. Brough, S. A. Penkett, J. R. Hopkins, A. C. Lewis and K. A. Read, Atmos. Chem. Phys., 2007, 7, 587.

154 A. Saiz-Lopez, J. A. Shillito, H. Coe and J. M. C. Plane, Atmos. Chem. Phys., 2006, 6, 1513.

155 M. Bitter, S. M. Ball, I. M. Povey and R. L. Jones, Atmos. Chem. Phys., 2005, 5, 2547.

156 J. D. Lee, G. McFiggans, J. D. Allan, A. R. Baker, S. M. Ball, A. K. Benton, L. J. Carpenter, R. Commane, B. D. Finley, M. Evans, E. Fuentes, K. Furneaux, A. Goddard, N. Good, J. F. Hamilton, D. E. Heard, H. Herrmann, A. Hollingsworth, J. R. Hopkins, T. Ingham, M. Irwin, C. E. Jones, R. L. Jones, W. C. Keene, M. J. Lawler, S. Lehmann, A. C. Lewis, M. S. Long, A. Mahajan, J. Methven, S. J. Moller, K. Mueller, T. Mueller, N. Niedermeier, S. O'Doherty, H. Oetjen, J. M. C. Plane, A. A. P. Pszenny, K. A. Read, A. Saiz-Lopez, E. S. Saltzman, R. Sander, R. von Glasow, L. Whalley, A. Wiedensohler and D. Young, Atmos. Chem. Phys., 2010, 10, 1031.

157 L. J. Carpenter, Z. L. Fleming, K. A. Read, J. D. Lee, S. J. Moller, J. R. Hopkins, R. M. Purvis, A. C. Lewis, K. Mueller, B. Heinold, H. Herrmann, K. W. Fomba, D. van Pinxteren, C. Mueller, I. Tegen, A. Wiedensohler, T. Mueller, N. Niedermeier, E. P. Achterberg, M. D. Patey, E. A. Kozlova, M. Heimann, D. E. Heard, J. M. C. Plane, A. Mahajan, H. Oetjen, T. Ingham, D. Stone, L. K. Whalley, M. J. Evans, M. J. Pilling, R. J. Leigh, P. S. Monks, A. Karunaharan, S. Vaughan, S. R. Arnold, J. Tschritter, D. Poehler, U. Friess, R. Holla, L. M. Mendes, H. Lopez, B. Faria, A. J. Manning and D. W. R. Wallace, J. Atmos. Chem., 2011, 67, 87.

158 V. Sinha, J. Williams, J. M. Diesch, F. Drewnick, M. Martinez, H. Harder, E. Regelin, D. Kubistin, H. Bozem, Z. HosaynaliBeygi, H. Fischer, M. D. Andres-Hernandez, D. Kartal, J. A. Adame and J. Lelieveld, Atmos. Chem. Phys., 2012, 12, 4979.

159 B. J. H. v. Stratum, J. V.-G. d. Arellano, H. G. Ouwersloot, K. v. d. Dries, T. W. v. Laar, M. Martinez, J. Lelieveld, J.-M. Diesch, F. Drewnick, H. Fischer, Z. H. Beygi, H. Harder, E. Regelin, V. Sinha, J. A. Adame, M. Sorgel, R. Sander, H. Bozem, W. Song, J. Williams and N. Yassaa, Atmos. Chem. Phys., 2012, 12, 6519 .

160 W. H. Brune, D. Tan, I. F. Faloona, L. Jaegle, D. J. Jacob, B. G. Heikes, J. Snow, Y. Kondo, R. Shetter, G. W. Sachse, B. Anderson, G. L. Gregory, S. Vay, H. B. Singh, D. D. Davis, J. H. Crawford and D. R. Blake, Geophys. Res. Lett., 1999, 26, 3077.

161 L. Jaegle, D. Jacob, W. H. Brune, D. Tan, I. C. Faloona, A. J. Weinheimer, B. A. Ridley, T. L. Campos and G. W. Sachse, Geophys. Res. Lett., 1998, 25, 1709.

162 I. Faloona, D. Tan, W. H. Brune, L. Jaegle, D. J. Jacob, Y. Kondo, M. Koike, R. Chatfield, R. Pueschel, G. Ferry,
G. Sachse, S. Vay, B. Anderson, J. Hannon and H. Fuelberg, J. Geophys. Res., [Atmos.], 2000, 105, 3771.

163 L. Jaegle, D. J. Jacob, W. H. Brune and P. O. Wennberg, Atmos. Environ., 2001, 25, 469.

164 J. Crawford, D. Davis, J. Olson, G. Chen, S. Liu, G. Gregory, J. Barrick, G. Sachse, S. Sandholm, B. Heikes, H. Singh and D. Blake, J. Geophys. Res., [Atmos.], 1999, 104, 16255.

165 C. Mari, C. Saut, D. J. Jacob, F. Ravetta, B. Anderson, M. A. Avery, D. R. Blake, W. H. Brune, I. Faloona, G. L. Gregory, B. G. Heikes, G. W. Sachse, S. T. Sandholm, H. B. Singh, R. W. Talbot, D. Tan and S. Vay, J. Geophys. Res. [Atmos.], 2003, 108, 8229.

166 M. Blitz, D. E. Heard, M. J. Pilling, S. R. Arnold and M. P. Chipperfield, Geophys. Res. Lett., 2004, 31, L06111.

167 S. R. Arnold, M. P. Chipperfield, M. A. Blitz, D. E. Heard and M. J. Pilling, Geophys. Res. Lett., 2004, 31, L07110.

168 S. R. Arnold, M. P. Chipperfield and M. A. Blitz, J. Geophys. Res., [Atmos.], 2005, 110, D22305.

169 F. Ravetta, D. J. Jacob, W. H. Brune, B. G. Heikes, B. E. Anderson, D. R. Blake, G. L. Gregory, G. W. Sachse, S. T. Sandholm, R. E. Shetter, H. B. Singh and R. W. Talbot, J. Geophys. Res., [Atmos.], 2001, 106, 32709.

170 Y. H. Wang, S. C. Liu, P. H. Wine, D. D. Davis, S. T. Sandholm, E. L. Atlas, M. A. Avery, D. R. Blake, N. J. Blake, W. H. Brune, B. G. Heikes, G. W. Sachse, R. E. Shetter, H. B. Singh, R. W. Talbot and D. Tan, J. Geophys. Res., [Atmos.], 2001, 106, 32733.

171 R. L. Mauldin, F. L. Eisele, C. A. Cantrell, E. Kosciuch, B. A. Ridley, B. Lefer, D. J. Tanner, J. B. Nowak, G. Chen, L. Wang and D. Davis, J. Geophys. Res., [Atmos.], 2001, 106, 32657.

172 D. Davis, G. Grodzinsky, G. Chen, J. Crawford, F. Eisele, L. Mauldin, D. Tanner, C. Cantrell, W. Brune, D. Tan, I. Faloona, B. Ridley, D. Montzka, J. Walega, F. Grahek, S. Sandholm, G. Sachse, S. Vay, B. Anderson, M. Avery, B. Heikes, J. Snow, D. O'Sullivan, R. Shetter, B. Lefer, D. Blake, N. Blake, M. Carroll and Y. Wang, J. Geophys. Res., [Atmos.], 2001, 106, 32691.

173 G. Chen, D. Davis, J. Crawford, B. Heikes, D. O'Sullivan, M. Lee, F. Eisele, L. Mauldin, D. Tanner, J. Collins, J. Barrick, B. Anderson, D. Blake, J. Bradshaw, S. Sandholm, M. Carroll, G. Albercook and A. Clarke, J. Atmos. Chem., 2001, 38, 317.

174 J. R. Olson, J. H. Crawford, D. D. Davis, G. Chen, M. A. Avery, J. D. W. Barrick, G. W. Sachse, S. A. Vay, S. T. Sandholm, D. Tan, W. H. Brune, I. C. Faloona, B. G. Heikes, R. E. Shetter, B. L. Lefer, H. B. Singh, R. W. Talbot and D. R. Blake, J. Geophys. Res., [Atmos.], 2001, 106, 32749.

175 F. Eisele, L. Mauldin, C. Cantrell, M. Zondlo, E. Apel, A. Fried, J. Walega, R. Shetter, B. Lefer, F. Flocke, A. Weinheimer, M. Avery, S. Vay, G. Sachse, J. Podolske, G. Diskin, J. D. Barrick, H. B. Singh, W. Brune, H. Harder, M. Martinez, A. Bandy, D. Thornton, B. Heikes, Y. Kondo, D. Riemer, S. Sandholm, D. Tan, R. Talbot and J. Dibb, J. Geophys. Res., 2003, 108, 8791 .

176 R. L. Mauldin, C. A. Cantrell, M. Zondlo, E. Kosciuch, F. L. Eisele, G. Chen, D. Davis, R. Weber, J. Crawford, D. Blake, A. Bandy and D. Thornton, J. Geophys. Res., 2003, 108, 8796.

177 C. A. Cantrell, G. D. Edwards, S. Stephens, R. L. Mauldin, M. A. Zondlo, E. Kosciuch, F. L. Eisele, R. E. Shetter, B. L. Lefer, S. Hall, F. Flocke, A. Weinheimer, A. Fried, E. Apel, Y. Kondo, D. R. Blake, N. J. Blake, I. J. Simpson, A. R. Bandy, D. C. Thornton, B. G. Heikes, H. B. Singh, W. H. Brune, H. Harder, M. Martinez, D. J. Jacob, M. A. Avery, J. F. Barrick, G. W. Sachse, J. R. Olson, J. H. Crawford and A. D. Clarke, J. Geophys. Res., 2003, 108, 8797.

178 J. R. Olson, J. H. Crawford, G. Chen, A. Fried, M. J. Evans, C. E. Jordan, S. T. Sandholm, D. D. Davis, B. E. Anderson, M. A. Avery, J. D. Barrick, D. R. Blake, W. H. Brune, F. L. Eisele, F. Flocke, H. Harder, D. J. Jacob, Y. Kondo, B. L. Lefer, M. Martinez, R. L. Mauldin, G. W. Sachse, R. E. Shetter, H. B. Singh, R. W. Talbot and D. Tan, J. Geophys. Res., 2004, 109, S101.

179 N. Carslaw, D. J. Creasey, D. Harrison, D. E. Heard, M. C. Hunter, P. J. Jacobs, M. E. Jenkin, J. D. Lee, 
A. C. Lewis, M. J. Pilling, S. M. Saunders and P. W. Seakins, Atmos. Environ., 2001, 35, 4725.

180 D. Tan, I. Faloona, J. B. Simpas, W. Brune, P. B. Shepson, T. L. Couch, A. L. Sumner, M. A. Carroll, T. Thornberry, E. Apel, D. Riemer and W. Stockwell, J. Geophys. Res., [Atmos.], 2001, 106, 24407.

181 M. Zhang, H. Akimoto and I. Uno, J. Atmos. Chem., 2006, 54, 233.

182 X. Ren, J. R. Olson, J. Crawford, W. H. Brune, J. Mao, R. B. Long, Z. Chen, G. Chen, M. A. Avery, G. W. Sachse, J. D. Barrick, G. S. Diskin, G. Huey, A. Fried, R. C. Cohen, B. Heikes, P. O. Wennberg, H. B. Singh, D. Blake and R. Shetter, J. Geophys. Res., [Atmos.], 2008, 113, D05310.

183 H. B. Singh, W. H. Brune, J. H. Crawford, F. Flocke and D. J. Jacob, Atmos. Chem. Phys., 2009, 9, 2301.

184 J. Mao, X. Ren, W. H. Brune, J. R. Olson, J. H. Crawford, A. Fried, L. G. Huey, R. C. Cohen, B. Heikes, H. B. Singh, D. R. Blake, G. W. Sachse, G. S. Diskin, S. R. Hall and R. E. Shetter, Atmos. Chem. Phys., 2009, 9, 163.

185 A. Guenther, C. N. Hewitt, D. Erickson, R. Fall, C. G. a Graedel, P. Harley, L. Klinger, M. Lerdau, W. A. M. a. Pierce, B. Scholes, R. Steinbrecher, R. Tallamraju and J. T. P. Zimmerman, J. Geophys. Res., 1995, 100, 8873.

186 F. L. Eisele, G. H. Mount, F. C. Fehsenfeld, J. Harder, E. Marovich, D. D. Parrish, J. Roberts and M. Trainer, J. Geophys. Res., [Atmos.], 1994, 99, 18605.

187 G. H. Mount and E. J. Williams, J. Geophys. Res., [Atmos.], 1997, 102, 6171

188 S. A. McKeen, G. Mount, F. Eisele, E. Williams, J. Harder, P. Goldan, W. Kuster, S. C. Liu, K. Baumann, D. Tanner, A. Fried, S. Sewell, C. Cantrell and R. Shetter, J. Geophys. Res., [Atmos.], 1997, 102, 6467.

189 M. Trainer, E.-Y. Hsie, S. A. McKeen, R. Tallamraju, D. D. Parrish, F. C. Fehsenfeld and S. C. Liu, J. Geophys. Res., [Atmos.], 1987, 92, 11879.

190 C. A. Cantrell, R. E. Shetter, J. G. Calvert, F. L. Eisele, E. Williams, K. Baumann, W. H. Brune, P. S. Stevens and J. H. Mather, J. Geophys. Res., [Atmos.], 1997, 102, 6369.

191 A. Fried, S. McKeen, S. Sewell, J. Harder, B. Henry, P. Goldan, W. Kuster, E. Williams, K. Baumann, R. Shetter and C. Cantrell, J. Geophys. Res., 1997, 102, 6283.

192 N. Carslaw, D. J. Creasey, D. Harrison, D. E. Heard, M. C. Hunter, P. J. Jacobs, M. E. Jenkin, J. D. Lee, A. C. Lewis, M. J. Pilling, S. M. Saunders and P. W. Seakins, Atmos. Environ., 2001, 35, 4725.

193 J. Lelieveld, T. M. Butler, J. N. Crowley, T. J. Dillon, H. Fischer, L. Ganzeveld, H. Harder, M. G. Lawrence, M. Martinez, D. Taraborrelli and J. Williams, Nature, 2008, 452, 737.

194 T. M. Butler, D. Taraborrelli, C. B. H. Fischer, H. Harder, M. Martinez, J. Williams, M. G. Lawrence and J. Lelieveld, Atmos. Chem. Phys., 2008, 8, 4529.

195 T. A. M. Pugh, A. R. MacKenzie, C. N. Hewitt, B. Langford, P. M. Edwards, K. L. Furneaux, D. E. Heard, J. R. Hopkins, C. E. Jones, A. Karunaharan, J. Lee, G. Mills, P. Misztal, S. Moller, P. S. Monks and L. K. Whalley, Atmos. Chem. Phys., 2010, 10, 279.

196 D. Kubistin, H. Harder, M. Martinez, M. Rudolf, R. Sander, H. Bozem, G. Eerdekens, H. Fischer, C. Gurk, T. Klupfel, R. Konigstedt, U. Parchatka, C. L. Schiller, A. Stickler, D. Taraborrelli, J. Williams and J. Lelieveld, Atmos. Chem. Phys., 2010, 10,9705.

197 D. Stone, M. J. Evans, P. M. Edwards, R. Commane, T. Ingham, A. R. Rickard, D. M. Brookes, J. Hopkins, R. J. Leigh, A. C. Lewis, P. S. Monks, D. Oram, C. E. Reeves, D. Stewart and D. E. Heard, Atmos. Chem. Phys., 2011, 11, 6749.

198 L. K. Whalley, P. M. Edwards, K. L. Furneaux, A. Goddard, T. Ingham, M. J. Evans, D. Stone, J. R. Hopkins, C. E. Jones, A. Karunaharan, J. D. Lee, A. C. Lewis, P. S. Monks, S. Moller and D. E. Heard, Atmos. Chem. Phys., 2011, 11, 7223.

199 D. J. Creasey, D. E. Heard and J. D. Lee, Atmos. Environ., 2001, 35, 4713.

200 D. Stone, M. J. Evans, R. Commane, T. Ingham, C. F. A. Floquet, J. B. McQuaid, D. M. Brookes, P. S. Monks, R. Purvis, J. F. Hamilton, J. Hopkins, J. Lee, A. C. Lewis, D. Stewart, J. G. Murphy, G. Mills, D. Oram, C. E. Reeves and D. E. Heard, Atmos. Chem. Phys., 2010, 10, 9415.
201 I. Faloona, D. Tan, W. Brune, J. Hurst, D. Barket, T. L. Couch, P. Shepson, E. Apel, D. Riemer, T. Thornberry, M. A. Carroll, S. Sillman, G. J. Keeler, J. Sagady, D. Hooper and K. Paterson, J. Geophys. Res., [Atmos.], 2001, 106, 24315.

202 X. R. Ren, W. H. Brune, A. Oliger, A. R. Metcalf, J. B. Simpas, T. Shirley, J. J. Schwab, C. H. Bai, U. Roychowdhury, Y. Q. Li, C. X. Cai, K. L. Demerjian, Y. He, X. L. Zhou, H. L. Gao and J. Hou, J. Geophys. Res., [Atmos.], 2006, 111.

203 Y. Kanaya, A. Hofzumahaus, H.-P. Dorn, T. Brauers, H. Fuchs, F. Holland, F. Rohrer, B. Bohn, R. Tillmann, R. Wegener, A. Wahner, Y. Kajii, K. Miyamoto, S. Nishida, K. Watanabe, A. Yoshino, D. Kubistin, M. Martinez, M. Rudolf, H. Harder, H. Berresheim, T. Elste, C. Plass-Dulmer, G. Stange, J. Kleffmann, Y. Elshorbany and U. Schurath, Atmos. Chem. Phys., 2011, 11, 28851.

204 E. Schlosser, T. Brauers, H. P. Dorn, H. Fuchs, R. Haseler, A. Hofzumahaus, F. Holland, A. Wahner, Y. Kanaya, Y. Kajii, K. Miyamoto, S. Nishida, K. Watanabe, A. Yoshino, D. Kubistin, M. Martinez, M. Rudolf, H. Harder, H. Berresheim, T. Elste, C. Plass-Dulmer, G. Stange and U. Schurath, Atmos. Chem. Phys., 2009, 9, 7923.

205 J. Lelieveld, W. Peters, F. Dentener and M. C. Krol, J. Geophys. Res., [Atmos.], 2002, 107.

206 J. Lelieveld, F. Dentener, W. Peters and M. C. Krol, Atmos. Chem. Phys., 2004, 4, 2337.

207 I. Bey, B. Aumont and G. Toupance, J. Geophys. Res., 2001, 106, 9991.

208 A. Guenther, T. Karl, P. Harley, C. Wiedinmyer, P. I. Palmer and C. Geron, Atmos. Chem. Phys., 2006, 6, 3181.

209 C. N. Hewitt, J. D. Lee, A. R. MacKenzie, M. P. Barkley, N. Carslaw, G. D. Carver, N. A. Chappell, H. Coe, C. Collier, R. Commane, F. Davies, B. Davison, P. Di Carlo, C. F. Di Marco, J. R. Dorsey, P. M. Edwards, M. J. Evans, D. Fowler, K. L. Furneaux, M. Gallagher, A. Guenther, D. E. Heard, C. Helfter, J. Hopkins, T. Ingham, M. Irwin, C. Jones, A. Karunaharan, B. Langford, A. C. Lewis, S. F. Lim, S. M. MacDonald, A. S. Mahajan, S. Malpass, G. McFiggans, G. Mills, P. Misztal, S. Moller, P. S. Monks, E. Nemitz, V. Nicolas-Perea, H. Oetjen, D. E. Oram, P. I. Palmer, G. J. Phillips, R. Pike, J. M. C. Plane, T. Pugh, J. A. Pyle, C. E. Reeves, N. H. Robinson, D. Stewart, D. Stone, L. K. Whalley and X. Yin, Atmos. Chem. Phys., 2010, 10, 169.

210 D. E. Heard, L. K. Whalley, M. A. Blitz and P. W. Seakins, Fall Meeting, AGU, San Francisco, California, 2011.

211 T. J. Dillon and J. N. Crowley, Atmos. Chem. Phys., 2008, 8, 4877.

212 A. S. Hasson, G. S. Tyndall and J. J. Orlando, J. Phys. Chem. A, 2004, 108, 5979.

213 J. P. Le Crane, M. T. Rayez, J. C. Rayez and E. Villenave, Phys. Chem. Chem. Phys., 2006, 8, 2163.

214 M. E. Jenkin, M. D. Hurley and T. J. Wallington, Phys. Chem. Chem. Phys., 2007, 9, 3149.

215 M. E. Jenkin, M. D. Hurley and T. J. Wallington, Phys. Chem. Chem. Phys., 2008, 10, 4274.

216 M. E. Jenkin, M. A. Hurley and T. J. Wallington, J. Phys. Chem. A, 2010, 114, 408.

217 F. Paulot, J. D. Crounse, H. G. Kjaergaard, A. Kurten, J. M. St Clair, J. H. Seinfeld and P. O. Wennberg, Science, 2009, 325, 730 .

218 G. Da Silva, C. Graham and Z.-F. Wang, Environ. Sci. Technol., 2010, 44, 250.

219 J. Peeters, T. L. Nguyen and L. Vereecken, Phys. Chem. Chem. Phys., 2009, 11, 5935.

220 J. Peeters and J.-F. Muller, Phys. Chem. Chem. Phys., 2010, 12, 14227.

221 T. L. Nguyen, L. Vereecken and J. Peeters, ChemPhysChem, 2010, 11, 3996

222 G. M. Wolfe, J. D. Crounse, J. D. Parrish, J. M. St. Clair, M. R. Beaver, F. Paulot, T. P. Yoon, P. O. Wennberg and F. N. Keutsch, Phys. Chem. Chem. Phys., 2012, 14, 7276.

223 T. Stavrakou, J. Peeters and J. F. Muller, Atmos. Chem. Phys., 2010, 10, 9863.

224 A. T. Archibald, M. C. Cooke, S. R. Utembe, D. E. Shallcross, R. G. Derwent and M. E. Jenkin, Atmos. Chem. Phys., 2010, 10, 8097.

225 G. M. Wolfe, J. A. Thornton, N. C. Bouvier-Brown, A. H. Goldstein, J. H. Park, M. McKay, D. M. Matross, 
J. Mao, W. H. Brune, B. W. LaFranchi, E. C. Browne, K. E. Min, P. J. Wooldridge, R. C. Cohen, J. D. Crounse, I. C. Faloona, J. B. Gilman, W. C. Kuster, J. A. de Gouw, A. Huisman and F. N. Keutsch, Atmos. Chem. Phys., 2011, 11, 1269.

226 D. Taraborrelli, M. G. Lawrence, J. N. Crowley, T. J. Dillon, S. Gromov, C. B. M. Groß, L. Vereecken and J. Lelieveld, Nat. Geosci., 2012, 5, 190.

227 J. D. Crounse, F. Paulot, H. G. Kjaergaard and P. O. Wennberg, Phys. Chem. Chem. Phys., 2011, 13, 13607.

228 T. Karl, A. Guenther, A. Turnipseed, G. Tyndall, P. Artaxo and S. Martin, Atmos. Chem. Phys., 2009, 9, 7753.

229 T. A. M. Pugh, A. R. MacKenzie, B. Langford, E. Nemitz, P. K. Misztal and C. N. Hewitt, Atmos. Chem. Phys., 2011, 11, 4121.

230 A. J. Huisman, J. R. Hottle, M. M. Galloway, J. P. DiGangi, K. L. Coens, W. Choi, I. C. Faloona, J. B. Gilman, W. C. Kuster, J. de Gouw, N. C. Bouvier-Brown, A. H. Goldstein, B. W. LaFranchi, R. C. Cohen, G. M. Wolfe, J. A. Thornton, K. S. Docherty, D. K. Farmer, M. J. Cubison, J. L. Jimenez, J. Mao, W. H. Brune and F. N. Keutsch, Atmos. Chem. Phys., $2011,11,8883$.

231 B. W. LaFranchi, G. M. Wolfe, J. A. Thornton, E. C. Browne, K.-E. Min, P. J. Wooldridge, M. McKay, A. H. Goldstein, J. B. Gilman, D. Welsh-Bon, W. C. Kuster, J. A. deGouw, J. Mao, Z. Chen, X. Ren, W. H. Brune and R. C. Cohen, Abstracts of Papers of the American Chemical Society, 2009, 237, 289.

232 J. Williams, J. Crowley, H. Fischer, H. Harder, M. Martinez, T. Petaja, J. Rinne, J. Back, M. Boy, M. D. Maso, J. Hakala, M. Kajos, P. Keronen, P. Rantala, J. Aalto, H. Aaltonen, J. Paatero, T. Vesala, H. Hakola, J. Levula, T. Pohja, F. Herrmann, J. Auld, E. Mesarchaki, W. Song, N. Yassaa, A. Nolscher, A. M. Johnson, T. Custer, V. Sinha, J. Thieser, N. Pouvesle, D. Taraborrelli, M. J. Tang, H. Bozem, Z. Hosaynali-Beygi, R. Axinte, R. Oswald, A. Novelli, D. Kubistin, K. Hens, U. Javed, K. Trawny, C. Breitenberger, P. J. Hidalgo, C. J. Ebben, F. M. Geiger, A. L. Corrigan, L. M. Russell, H. G. Ouwersloot, J. V.-G. d. Arellano, L. Ganzeveld, A. Vogel, M. Beck, A. Bayerle, C. J. Kampf, M. Bertelmann, F. Kollner, T. Hoffmann, J. Valverde, D. Gonzalez, M.-L. Riekkola, M. Kulmala and J. Lelieveld, Atmos. Chem. Phys., 2011, 11, 10599.

233 S. M. MacDonald, H. Oetjen, A. S. Mahajan, L. K. Whalley, P. M. Edwards, D. E. Heard, C. E. Jones and J. M. C. Plane, Atmos. Chem. Phys., 2012, 12, 5903.

234 UN, State of World Population Reports 2011, United Nations.

235 M. Martinez, H. Harder, T. A. Kovacs, J. B. Simpas, J. Bassis, R. Lesher, W. H. Brune, G. J. Frost, E. J. Williams, C. A. Stroud, B. T. Jobson, J. M. Roberts, S. R. Hall, R. E. Shetter, B. Wert, A. Fried, B. Alicke, J. Stutz, V. L. Young, A. B. White and R. J. Zamora, J. Geophys. Res., 2003, 108, 4617.

236 R. M. Harrison, J. Yin, R. M. Tilling, X. Cai, P. W. Seakins, J. R. Hopkins, D. L. Lansley, A. C. Lewis, M. C. Hunter, D. E. Heard, L. J. Carpenter, D. J. Creasey, J. D. Lee, M. J. Pilling, N. Carslaw, K. M. Emmerson, A. Redington, R. G. Derwent, D. Ryall, G. Mills and S. A. Penkett, Sci. Total Environ., 2006, 360, 5.

237 D. E. Heard, L. J. Carpenter, D. J. Creasey, J. R. Hopkins, J. D. Lee, A. C. Lewis, M. J. Pilling, P. W. Seakins, N. Carslaw and K. M. Emmerson, Geophys. Res. Lett., 2004, 31, L18112.

238 K. M. Emmerson, N. Carslaw, L. J. Carpenter, D. E. Heard, J. D. Lee and M. J. Pilling, J. Atmos. Chem., 2005, 52, 143.

239 K. M. Emmerson, N. Carslaw and M. J. Pilling, J. Atmos. Chem., 2005, 52, 165.

240 Y. Sadanaga, A. Yoshino, S. Kato, A. Yoshioka, K. Watanabe, Y. Miyakawa, I. Hayashi, M. Ichikawa, J. Matsumoto, A. Nishiyama, N. Akiyama, Y. Kanaya and J. Kajii, Geophys. Res. Lett., 2004, 31.

241 X. Ren, H. Harder, M. Martinez, R. Lesher, A. Oliger, T. Shirley, J. Adams, J. B. Simpas and W. H. Brune, Atmos. Environ., 2003, $37,3627$.

242 X. Ren, H. Harder, M. Martinez, R. Lesher, A. Oliger, J. B. Simpas, W. H. Brune, J. J. Schwab, K. L. Demerjian, Y. He, X. Zhou and H. Gao, Atmos. Environ., 2003, 37, 3639.

243 X. Ren, W. H. Brune, J. Mao, M. J. Mitchell, R. Lesher, J. B. Simpas, A. R. Metcalf, J. J. Schwab, C. Cai, Y. Li,
K. L. Demerjian, H. D. Felton, G. Boynton, A. Adams, J. Perry, Y. He, X. Zhou and J. Hou, Atmos. Environ., 2006, 40, S525.

244 C. Cai, C. Hogrefe, P. Katsafados, G. Kallos, M. Beauharnois, J. J. Schwab, X. Ren, W. H. Brune, X. Zhou, Y. He and K. L. Demerjian, Atmos. Environ., 2008, 42, 8585.

245 J. R. Hopkins, A. C. Lewis and P. W. Seakins, Atmos. Environ., 2005, 39, 535.

246 J. D. Lee, A. C. Lewis, P. S. Monks, M. Jacob, J. F. Hamilton, J. R. Hopkins, N. M. Watson, J. E. Saxton, C. Ennis, L. J. Carpenter, N. Carslaw, Z. L. Fleming, A. Bandy, D. E. Oram, S. A. Penkett, J. Slemr, E. G. Norton, A. R. Rickard, L. K. Whalley, D. E. Heard, W. J. Bloss, T. Gravestock, S. C. Smith, J. Stanton, M. J. Pilling and M. E. Jenkin, Atmos. Environ., 2006, 40, 7598-7613.

247 K. M. Emmerson, N. Carslaw, D. C. Carslaw, J. D. Lee, G. McFiggans, W. J. Bloss, T. Gravestock, D. E. Heard, J. Hopkins, T. Ingham, M. J. Pilling, S. C. Smith, M. Jacob and P. S. Monks, Atmos. Chem. Phys., 2007, 7, 167-181.

248 K. M. Emmerson and N. Carslaw, Atmos. Environ., 2009, 43, 3220

249 T. R. Shirley, W. H. Brune, X. Ren, J. Mao, R. Lesher, B. Cardenas, R. Volkamer, L. T. Molina, M. J. Molina, B. Lamb, E. Velasco, T. Jobson and M. Alexander, Atmos. Chem. Phys., 2006, 6, 2753.

250 L. A. George, T. M. Hard and R. J. O'Brien, J. Geophys. Res., [Atmos.], 1999, 104, 11643.

251 S. Dusanter, D. Vimal, P. S. Stevens, R. Volkamer, L. T. Molina, A. Baker, S. Meinardi, D. Blake, P. Sheehy, A. Merten, R. Zhang, J. Zheng, E. C. Fortner, W. Junkermann, M. Dubey, T. Rahn, B. Eichinger, P. Lewandowski, J. Prueger and H. Holder, Atmos. Chem. Phys., 2009, 9, 6655.

252 L. K. Emmons, E. C. Apel, J. F. Lamarque, P. G. Hess, M. Avery, D. Blake, W. Brune, T. Campos, J. Crawford, P. F. DeCarlo, S. Hall, B. Heikes, J. Holloway, J. L. Jimenez, D. J. Knapp, G. Kok, M. Mena-Carrasco, J. Olson, D. O'Sullivan, G. Sachse, J. Walega, P. Weibring, A. Weinheimer and C. Wiedinmyer, Atmos. Chem. Phys., 2010, 10, 6195 .

253 L. T. Molina, S. Madronich, J. S. Gaffney, E. Apel, B. de Foy, J. Fast, R. Ferrare, S. Herndon, J. L. Jimenez, B. Lamb, A. R. Osornio-Vargas, P. Russell, J. J. Schauer, P. S. Stevens, R. Volkamer and M. Zavala, Atmos. Chem. Phys., 2010, 10, 8697.

254 B. Adhikary, G. R. Carmichael, S. Kulkarni, C. Wei, Y. Tang, A. D'Allura, M. Mena-Carrasco, D. G. Streets, Q. Zhang, R. B. Pierce, J. A. Al-Saadi, L. K. Emmons, G. G. Pfister, M. A. Avery, J. D. Barrick, D. R. Blake, W. H. Brune, R. C. Cohen, J. E. Dibb, A. Fried, B. G. Heikes, L. G. Huey, D. W. O'Sullivan, G. W. Sachse, R. E. Shetter, H. B. Singh, T. L. Campos, C. A. Cantrell, F. M. Flocke, E. J. Dunlea, J. L. Jimenez, A. J. Weinheimer, J. D. Crounse, P. O. Wennberg, J. J. Schauer, E. A. Stone, D. A. Jaffe and D. R. Reidmiller, Atmos. Chem. Phys., 2010, 10, 2091.

255 P. M. Sheehy, R. Volkamer, L. T. Molina and M. J. Molina, Atmos. Chem. Phys., 2010, 10, 6993.

256 R. Volkamer, P. Sheehy, L. T. Molina and M. J. Molina, Atmos. Chem. Phys., 2010, 10, 6969.

257 G. Li, W. Lei, M. Zavala, R. Volkamer, S. Dusanter, P. Stevens and L. T. Molina, Atmos. Chem. Phys., 2010, 10, 6551.

258 J. Mao, X. Ren, S. Chen, W. H. Brune, Z. Chen, M. Martinez, H. Harder, B. Lefer, B. Rappengluck, J. Flynn and M. Leuchner, Atmos. Environ., 2010, 44, 4107.

259 S. Chen, X. Ren, J. Mao, Z. Chen, W. H. Brune, B. Lefer, B. Rappenglueck, J. Flynn, J. Olson and J. H. Crawford, Atmos. Environ., 2010, 44, 4116.

260 A. Hofzumahaus, U. Aschmutat, M. Hessling, F. Holland and D. H. Ehhalt, Geophys. Res. Lett., 1996, 23, 2541.

261 A. Hofzumahaus, T. Brauers, U. Aschmutat, U. Brandenburger, H. P. Dorn, M. Hausmann, M. Hessling, F. Holland, C. PlassDulmer, M. Sedlacek, M. Weber and D. H. Ehhalt, Geophys. Res. Lett., 1997, 24, 3039.

262 B. Plass-Dulmer and J. Rudolph, J. Atmos. Chem., 1998, 31, 5.

263 U. Platt, B. Alicke, R. Dubois, A. Geyer, A. H. a. Holland, M. Martinez, D. Mihelcic, T. Klupfel, B. L. W. Patz, D. Perner, F. Rohrer, J. Schafer and J. Stutz, J. Atmos. Chem., 2002, 42, 359. 
264 A. Volz-Thomas, H. W. Pätz, N. Houben, S. Konrad, D. Mihelcic, T. Klüpfel and D. Perner, J. Geophys. Res., [Atmos.], 2003, 108, 8248.

265 F. Holland, A. Hofzumahaus, R. Schafer, A. Kraus and H. W. Patz, J. Geophys. Res., 2003, 108, 8246.

266 S. Konrad, T. Schmitz, H. J. Buers, N. Houben, K. Mannschreck, D. Mihelcic, P. Musgen, H. W. Patz, F. Holland, A. Hofzumahaus, H. J. Schafer, S. Schroder, A. Volz-Thomas, K. Bachmann, S. Schlomski, G. Moortgat and D. Grossmann, J. Geophys. Res., [Atmos.], 2003, 108.

267 B. Alicke, A. Geyer, A. Hofzumahaus, F. Holland, S. Konrad, H. W. Patz, J. Schafer, J. Stutz, A. Volz-Thomas and U. Platt, J. Geophys. Res., 2003, 108, 8247.

268 A. Geyer, K. Bachmann, A. Hofzumahaus, F. Holland, S. Konrad, T. Klupfel, H. W. Patz, D. Perner, D. Mihelcic, H. J. Schafer, A. Volz-Thomas and U. Platt, J. Geophys. Res., [Atmos.], 2003, 108, 8249.

269 S. Sillman, M. A. Carroll, T. Thornberry, B. K. Lamb, H. Westberg, W. H. Brune, I. Faloona, D. Tan, P. B. Shepson, A. L. Sumner, D. R. Hastie, C. M. Mihele, E. C. Apel, D. D. Riemer and R. G. Zika, J. Geophys. Res., 2002, 107, 4043.

270 S. Vaughan, C. E. Canosa-Mas, C. Pfrang, D. E. Shallcross, L. Watson and R. P. Wayne, Phys. Chem. Chem. Phys., 2006, 8, 3749 .

271 X. R. Ren, W. H. Brune, C. A. Cantrell, G. D. Edwards, T. Shirley, A. R. Metcalf and R. L. Lesher, J. Atmos. Chem., 2005, 52, 231.

272 W. Birmili, H. Berresheim, C. Plass-Dulmer, T. Elste, S. Gilge, A. Wiedensohler and U. Uhrner, Atmos. Chem. Phys., 2003, 3,361 .

273 G. M. Handisides, C. Plass-Dulmer, S. Gilge, H. Bingemer and H. Berresheim, Atmos. Chem. Phys., 2003, 3, 1565.

274 K. Acker, D. Moller, W. Wieprecht, F. X. Meixner, B. Bohn, S. Gilge, C. Plass-Dulmer and H. Berresheim, Geophys. Res. Lett., 2006, 33 .

275 Y. Kanaya, A. Hofzumahaus, H.-P. Dorn, T. Brauers, H. Fuchs, F. Holland, F. Rohrer, B. Bohn, R. Tillmann, R. Wegener, A. Wahner, Y. Kajii, K. Miyamoto, S. Nishida, K. Watanabe, A. Yoshino, D. Kubistin, M. Martinez, M. Rudolf, H. Harder, H. Berresheim, T. Elste, C. Plass-Dulmer, G. Strange, J. Kleffmann, Y. Elshorbany and U. Schurath, Atmos. Chem. Phys., 2012, 12, 2567.

276 Y. F. Elshorbany, J. Kleffmann, A. Hofzumahaus, R. Kurtenbach, P. Wiesen, T. Brauers, B. Bohn, H.-P. Dorn, H. Fuchs, F. Holland, F. Rohrer, R. Tillmann, R. Wegener, A. Wahner, Y. Kanaya, A. Yoshino, S. Nishida, Y. Kajii, M. Martinez, D. Kubistin, H. Harder, J. Lelieveld, T. Elste, C. Plass-Dulmer, G. Stange, H. Berresheim and U. Schurath, J. Geophys. Res., [Atmos.], 2012, 117.

277 F. Paulot, J. D. Crounse, H. G. Kjaergaard, A. Kurten, J. M. St. Clair, J. H. Seinfeld and P. O. Wennberg, Science, 2009, 325, 730 .

278 A. Jefferson, D. J. Tanner, F. L. Eisele, D. D. Davis, G. Chen, J. Crawford, J. W. Huey, A. L. Torres and H. Berresheim, J. Geophys. Res., [Atmos.], 1998, 103, 1647.

279 R. L. Mauldin, F. L. Eisele, D. J. Tanner, E. Kosciuch, R. Shetter, B. Lefer, S. R. Hall, J. B. Nowak, M. Buhr, G. Chen, P. Wang and D. Davis, Geophys. Res. Lett., 2001, 28, 3629 .

280 R. E. Honrath, M. C. Peterson, M. P. Dziobak, J. E. Dibb, M. A. Arsenault and S. A. Green, Geophys. Res. Lett., 2000, 27, 2237.

281 A. M. Grannas, A. E. Jones, J. Dibb, M. Ammann, C. Anastasio, H. J. Beine, M. Bergin, J. Bottenheim, C. S. Boxe, G. Carver, G. Chen, J. H. Crawford, F. Dominé, M. M. Frey, M. I. Guzmán, D. E. Heard, D. Helmig, M. R. Hoffmann, R. E. Honrath, L. G. Huey, M. Hutterli, H. W. Jacobi, P. Klán, B. Lefer, J. McConnell, J. Plane, R. Sander, J. Savarino, P. B. Shepson, W. R. Simpson, J. R. Sodeau, R. von Glasow, R. Weller, E. W. Wolff and T. Zhu, Atmos. Chem. Phys., 2007, 7, 4329.

282 G. Chen, D. Davis, J. Crawford, J. B. Nowak, F. Eisele, R. L. Mauldin, D. Tanner, M. Buhr, R. Shetter, B. Lefer, R. Arimoto, A. Hogan and D. Blake, Geophys. Res. Lett., 2001, 28, 3633.

283 A. L. Sumner and P. B. Shepson, Nature, 1999, 298, 230.
284 J. McConnell, R. C. Bales, R. W. Stewart, A. M. Thompson, M. R. Albert and R. Ramos, J. Geophys. Res., [Atmos.], 1997, 103, 10561

285 R. E. Honrath, Y. Lu, M. C. Peterson, J. E. Dibb, M. A. Arsenault, N. J. Cullen and K. Steffen, Atmos. Environ., 2002, 36, 2629.

286 R. Mauldin, E. Kosciuch, F. Eisele, G. Huey, D. Tanner, S. Sjostedt, D. Blake, G. Chen, J. Crawford and D. Davis, Atmos. Environ., 2010, 44, 572.

287 G. Chen, D. Davis, J. Crawford, L. M. Hutterli, L. G. Huey, D. Slusher, L. Mauldin, F. Eisele, D. Tanner, J. Dibb, M. Buhr, J. McConnell, B. Lefer, R. Shetter, D. Blake, C. H. Song, K. Lombardi and J. Arnoldy, Atmos. Environ., 2004, 38, 5451.

288 J. E. Dibb, L. G. Huey, D. L. Slusher and D. J. Tanner, Atmos. Environ., 2004, 38, 5399.

289 W. Liao, A. T. Case, J. Mastromarino, D. Tan and J. E. Dibb, Geophys. Res. Lett., 2006, 33, L09810.

290 J. Yang, R. E. Honrath, M. C. Peterson, J. E. Dibb, A. L. Sumner, P. B. Shepson, M. Frey, H. W. Jacobi, A. Swanson and N. Blake, Atmos. Environ., 2002, 36, 2523.

291 C. A. Cantrell, G. D. Edwards, S. Stephens, L. Mauldin, E. Kosciuch, M. Zondlo and F. Eisele, J. Geophys. Res., [Atmos.], 2003, 108.

292 G. Chen, L. G. Huey, J. H. Crawford, J. R. Olson, M. A. Hutterli, S. Sjostedt, D. Tanner, J. Dibb, B. Lefer, N. Blake, D. Davis and A. Stohl, Atmos. Environ., 2007, 41, 7806.

293 A. Swanson, N. Blake, D. Blake, F. S. Rowland and J. Dibb, Atmos. Environ., 2002, 36, 2671.

294 M. J. Evans, D. J. Jacob, E. Atlas, C. A. Cantrell, F. Eisele, F. Flocke, A. Fried, R. L. Mauldin, B. A. Ridley, B. Wert, R. Talbot, D. Blake, B. Heikes, J. Snow, J. G. Walega, A. J. Weinheimer and J. Dibb, J. Geophys. Res., [Atmos.], 2003, 108.

295 W. J. Bloss, J. D. Lee, D. E. Heard, R. A. Salmon, S. J. B. Bauguitte, H. K. Roscoe and A. E. Jones, Atmos. Chem. Phys., $2007,7,4171$.

296 A. Saiz-Lopez, A. S. Mahajan, R. A. Salmon, S. J. B. Bauguitte, A. E. Jones, H. K. Roscoe and J. M. C. Plane, Science, 2007, 317, 348.

297 R. L. Mauldin, E. Kosciuch, B. Henry, F. L. Eisele, R. Shetter, B. Lefer, G. Chen, D. Davis, G. Huey and D. Tanner, Atmos. Environ., 2004, 38, 5423.

298 W. J. Bloss, M. Camredon, J. D. Lee, D. E. Heard, J. M. C. Plane, A. Saiz-Lopez, S. J. B. Bauguitte, R. A. Salmon and A. E. Jones, Atmos. Chem. Phys., 2010, 10, 10187.

299 J. Mao, D. J. Jacob, M. J. Evans, J. R. Olson, X. Ren, W. H. Brune, J. M. St. Clair, J. D. Crounse, K. M. Spencer, M. R. Beaver, P. O. Wennberg, M. J. Cubison, J. L. Jimenez, A. Fried, P. Weibring, J. G. Walega, S. R. Hall, A. J. Weinheimer, R. C. Cohen, G. Chen, J. H. Crawford, C. McNaughton, A. D. Clarke, L. Jaegle, J. A. Fisher, R. M. Yantosca, P. Le Sager and C. Carouge, Atmos. Chem. Phys., 2010, 10, 5823.

300 E. Scheuer, R. Talbot, J. Dibb, G. K. Seid, L. DeBell and B. Lefer, J. Geophys. Res., [Atmos.], 2003, 108, 8370.

301 I. J. George, P. S. Matthews, B. Brooks, A. Goddard, L. K. Whalley and M. T. Baeza-Romero, Fall Meeting, AGU, San Francisco, California, 2011.

302 C. E. Kolb, D. R. Worsnop, M. S. Zahniser, P. Davidovits, L. F. Keyser, M.-T. Leu, M. J. Molina, D. R. Hanson and A. R. Ravishankara, in 'Laboratory studies of atmospheric heterogeneous chemistry', ed. J. Baker, 1995.

303 F. Taketani, Y. Kanaya and H. Akimoto, J. Phys. Chem. Lett., 2010, 1, 1701-1704.

304 J. R. Olson, J. H. Crawford, W. Brune, J. Mao, X. Ren, A. Fried, B. Anderson, E. Apel, M. Beaver, D. Blake, G. Chen, J. Crounse, J. Dibb, G. Diskin, S. R. Hall, L. G. Huey, D. Knapp, D. Richter, D. Riemer, J. St. Clair, K. Ullmann, J. Walega, P. Weibring, A. Weinheimer, P. Wennberg and A. Wisthaler, Atmos. Chem. Phys., 2012, 12, 9377.

305 P. M. Edwards, M. J. Evans, R. Commane, T. Ingham, D. Stone, A. S. Mahajan, H. Oetjen, J. Dorsey, J. R. Hopkins, J. D. Lee, S. Moller, R. Leigh, J. M. C. Plane, L. J. Carpenter and D. E. Heard, J. Geophys. Res., [Atmos.], 2011, 116, D016390.

306 J. A. Thornton, J. P. Kercher, T. P. Riedel, N. L. Wagner, J. Cozic, J. S. Holloway, W. P. Dubé, G. M. Wolfe, 
P. K. Quinn, A. M. Middlebrook, B. Alexander and S. S. Brown, Nature, 2010, 464, 271.

307 J. Matthews, A. Sinha and J. S. Francisco, Proc. Natl. Acad. Sci. U. S. A., 2005, 102, 7449.

308 S. Li, J. Matthews and A. Sinha, Science, 2008, 319, 1657.

309 J. N. Crowley and S. A. Carl, J. Phys. Chem. A, 1997, 101, 4178.

310 S. Carr, D. E. Heard and M. A. Blitz, Science, 2009, 324, 336.

311 D. Cariolle, M. J. Evans, M. P. Chipperfield, N. Butkovskaya, A. Kukui and G. L. Bras, Atmos. Chem. Phys., 2008, 8, 4061.

312 N. I. Butkovskaya, A. Kukui, N. Pouvesle and G. L. Bras, J. Phys. Chem. A, 2005, 109, 6509.

313 N. Butkovskaya, A. Kukui and G. L. Bras, J. Phys. Chem. A, 2007, 111, 9047.

314 N. Butkovskaya, M.-T. Rayez, J.-C. Rayez, A. Kukui and G. L. Bras, J. Phys. Chem. A, 2009, 113, 11327.

315 C. Murray, E. L. Derro, T. D. Sechler and M. I. Lester, J. Phys. Chem. A, 2007, 111, 4727.

316 S. D. L. Picard, M. Tizniti, A. Canosa, I. R. Sims and I. W. M. Smith, Science, 2010, 328, 1258.

317 N. Kanno, K. Tonokura and M. Koshi, J. Geophys. Res., [Atmos.], 2006, 111, D20312.

318 M. Djehiche, A. Tomas, C. Fittshcen and P. Coddeville, Z. Physiol. Chem., 2011, 225, 983.

319 N. Carslaw, N. Bell, A. C. Lewis, J. B. McQuaid, M. J. Pilling and P. J. Jacobs, Atmos. Environ., 2000, 34, 2827.

320 Z. Hosaynali Beygi, H. Fischer, H. D. Harder, M. Martinez, R. Sander, J. Williams, D. M. Brookes, P. S. Monks and J. Lelieveld, Atmos. Chem. Phys., 2011, 11, 8497.

321 W. H. Brune, I. C. Faloona, D. Tan, A. J. Weinheimer, T. Campos, B. A. Ridley, S. A. Vay, J. E. Collins, G. W. Sachse, L. Jaegle and D. J. Jacob, Geophys. Res. Lett., 1998, 25, 1701.

322 L. Jaegle, D. J. Jacob, W. H. Brune, I. Faloona, D. Tan, B. G. Heikes, Y. Kondo, G. W. Sachse, B. Anderson, G. L. Gregory, H. B. Singh, R. Pueschel, G. Ferry, D. R Blake and R. E. Shetter, J. Geophys. Res., [Atmos.], 2000, 105, 3877 .

323 J. Crawford, J. Olson, D. Davis, G. Chen, J. Barrick, R. Shetter, B. Lefer, C. Jordan, B. Anderson, A. Clarke, G. Sachse, D. Blake, H. Singh, S. Sandolm, D. Tan, Y. Kondo, M. Avery, F. Flocke, F. Eisele, L. Mauldin, M. Zondlo, W. Brune, H. Harder,
M. Martinez, R. Talbot, A. Bandy and D. Thornton, J. Geophys. Res., 2003, 108, 8818.

324 G. H. Mount and F. L. Eisele, Science, 1992, 256, 1187.

325 P. S. Stevens, J. H. Mather, W. H. Brune, F. Eisele, D. Tanner, A. Jefferson, C. Cantrell, R. Shetter, S. Sewall, A. Fried, B. Henry, E. Williams, K. Baumann, P. Goldan and W. Kuster, J. Geophys. Res., [Atmos.], 1997, 102, 6379.

326 A. T. Archibald, J. G. Levine, N. L. Abraham, M. C. Cooke, P. M. Edwards, D. E. Heard, M. E. Jenkin, A. Karunaharan, R. C. Pike, P. S. Monks, D. E. Shallcross, P. J. Telford, L. K. Whalley and J. A. Pyle, Geophys. Res. Lett., 2011, 38.

327 J. A. Thornton, P. J. Wooldridge, R. C. Cohen, M. Martinez, H. Harder, W. H. Brune, E. J. Williams, J. M. Roberts, F. C. Fehsenfeld, S. R. Hall, R. E. Shetter, B. P. Wert and A. Fried, J. Geophys. Res., [Atmos.], 2002, 107, 4146.

328 Y. Kanaya, M. Fukuda, H. Akimoto, N. Takegawa, Y. Komazaki, Y. Yokouchi, M. Koike and Y. Kondo, J. Geophys. Res., 2008, 113.

329 F. Holland, U. Aschmutat, M. Hessling, A. Hofzumahaus and D. H. Ehhalt, J. Atmos. Chem., 1998, 31, 205.

330 E. J. Lanzendorf, T. F. Hanisco, N. M. Donahue and P. O. Wennberg, Geophys. Res. Lett., 1997, 24, 3037.

331 U. Brandenburger, T. Brauers, H. P. Dorn, M. Hausmann and D. H. Ehhalt, J. Atmos. Chem., 1998, 31, 181.

332 A. Volz-Thomas, H. W. Patz, N. Houben, S. Konrad, D. Mihelcic, T. Klupfel and D. Perner, J. Geophys. Res., [Atmos.], 2003, 108.

333 A. Volz-Thomas, H. Geiss, A. Hofzumahaus and K.-H. Becker, J. Geophys. Res., 2003, 108, 8252.

334 W. Birmili, H. Berresheim, C. Plass-Dulmer, T. Elste, S. Gilge, A. Wiedensohler and U. Uhrner, Atmos. Chem. Phys., 2003, 2, 361.

335 S. C. Smith, Atmospheric Measurements of $\mathrm{OH}$ and $\mathrm{HO}_{2}$ using the FAGE technique: Instrument development and data analysis, University of Leeds, 2007.

336 K. L. Furneaux, PhD thesis, University of Leeds, 2009.

337 R. L. Mauldin, C. A. Cantrell, M. A. Zondlo, E. Kosciuch, B. A. Ridley, R. Weber and F. E. Eisele, J. Geophys. Res., [Atmos.], 2003, 108.

338 L. K. Whalley, I. J. George, D. Stone and D. E. Heard, Abstract A43D-0174, The impact of clouds on radical concentrations: Observations of $\mathrm{OH}$ and $\mathrm{HO}_{2}$ during HCCT-2010, Proceedings Fall Meeting AGU, 2011. 